PNNL-11451

UC-2030

\title{
Efficient Separations and Processing Crosscutting Program: Develop and Test Sorbents
}

Fiscal Year 1996 Annual Progress Report

October 1, 1995 - September 30, 1996

G. N. Brown, Principal Investigator

Major Contributors:

J. E. Amonette

T. M. Kafka ${ }^{(a)}$

S. F. Yates ${ }^{(b)}$

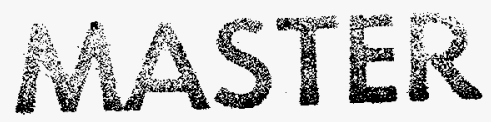

January 1997

\section{J3)}

Prepared for

the U.S. Department of Energy

under Contract DE-AC06-76RLO 1830

Pacific Northwest Laboratory

Richland, Washington 99352
(a) 3M Company
(b) AlliedSignal 


\section{DISCLAIMER}

This report was prepared as an account of work sponsored by an agency of the United States Government. Neither the United States Government nor any agency thereof, nor any of their employees, make any warranty, express or implied, or assumes any legal liability or responsibility for the accuracy, completeness, or usefulness of any information, apparatus, product, or process disclosed, or represents that its use would not infringe privately owned rights. Reference herein to any specific commercial product, process, or service by trade name, trademark, manufacturer, or otherwise does not necessarily constitute or imply its endorsement, recommendation, or favoring by the United States Government or any agency thereof. The views and opinions of authors expressed herein do not necessar. ily state or reflect those of the United States Government or any agency thereof. 


\section{DISCLAMMER}

Portions of this document may be illegible in electronic image products. Images are produced from the best available original document. 


\section{Executive Summary}

Pacific Northwest National Laboratory (PNNL), ${ }^{(\mathrm{a})}$ in conjunction with two teams of contractors (3M/IBC Advanced Technologies and AlliedSignal, Inc./Texas A\&M University), conducted this study for the Efficient Separations and Processing Crosscutting Program (ESP) under the Office of Science and Technology, U.S. Department of Energy (DOE). The work was completed under the Technical Task Plan Number RL3-6-C3-42, Test Sorbents; Industrial Contracts.

Pretreatment of nuclear process wastes for the ion exchange removal of $\mathrm{Cs}, \mathrm{Sr}, \mathrm{Tc}$, transuranic (TRU), and other radionuclides has been proposed previously as one method of minimizing the amount of high-level radioactive waste (HLW) at the Hanford Site. This project is designed to test the capacity, selectivity, and stability of selected sequestering agents and substrates in representative physical, chemical, and radiation environments with emphasis on materials with potential nuclear waste management applications that would result in major cost reductions and environmental benefits.

The following programmatic highlights were completed during FY 1996:

- Three formal PNNL documents were issued during the reporting period. The first report describes the uptake of various radionuclide and nonradionuclide species from actual Hanford 101-AW Double Shell Slurry. Feed (DSSF) tank waste by seven experimental and commercial ion exchange materials. The second report describes the chemical and radiolytic stability of the engineered SuperLig@644/ WWL material in several realistic process flowsheet solutions. The final report describes the largescale filtration/cartridge removal of Sr from groundwater at the 100 Area N-Springs using the Process Absorber.Development Unit (PADU).

- A small pilot-scale skid system was designed and constructed by $3 \mathrm{M}$ personnel for testing and demonstrating cartridge-based radionuclide removal. The PADU consists of a system pump, prefiltration, pressure gauges, pressure sensors for emergency cut-off, and three cartridge vessels in series, each capable of holding six Sr-selective cartridges. The unit is electronically controlled to load two vessels at a time and is capable of sequencing through several cycles. The system was demonstrated at the Hanford 100 Area N-Springs and N-Basin, and is currently located at the Savannah River Technical Center R-Basin where a third demonstration is planned, and preparations are being finalized.

- Seven ion exchange materials (CS-100, R-F, SuperLigß 644, IE-910, IE-911, TIE-96 and NaTi) were evaluated for the pretreatment of actual and simulated Hanford DSSF tank waste. Cs and $\mathrm{Sr}$ $\mathrm{K}_{\mathrm{d}}$ 's, column distribution ratios $\left(\lambda=\mathrm{K}_{\mathrm{d}} \times \rho_{\mathrm{b}}\right)$, and decontamination factors (DF) are compared as a function of contact duration, solution composition, supernate: exchanger phase ratio, and multiple sequential contacts. The actual DSSF waste was a volume composite from tanks $101-\mathrm{AW}(70 \%)$,

(a) PNNL is operated for the U.S. Department of Energy by Battelle. 
106-AP (20\%), and 102-AP (10\%). The actual waste tests were conducted at $4.96 \pm 0.19 \mathrm{M} \mathrm{Na}$ and $23^{\circ} \mathrm{C}$ with $\mathrm{Na} / \mathrm{Cs}$ mole ratios that ranged from 100 to 500,000 . The simulant composition was formulated based on previous analytical characterization of the actual waste, and tests were conducted at dilutions ranging from 7 to $0.2 \mathrm{M} \mathrm{Na}$, over a wide range of Na/Cs mole ratios $(50$ to 500,000$)$.

- Three technical papers were presented at the ESP 1996 Annual Technical Exchange Meeting held in Gaithersburg, Maryland, January 16-18, 1996.

- In conjunction with personnel from Bechtel Hanford, Inc. (BHI) and CH2M Hill Hanford, Inc. an onsite technology demonstration by PNNL, 3M, and AlliedSignal, Inc. was completed on January 25, 1996 at the Hanford 100-N Area N-Springs. A side-stream from the N-Springs Pump and Treat Facility influent was pumped through the PADU, containing a series of prefilters and Sr-selective web cartridges, at 3.5 gallons per minute (gpm). The process is designed to remove $\mathrm{Sr}$, initially at low levels (ca. $1000 \mathrm{pCi} / \mathrm{L}$ ), to below the proposed drinking water standard of $40 \mathrm{pCi} / \mathrm{L}$. Based on laboratory evaluations at PNNL and $3 \mathrm{M}$, the test was completed in 3 hours during which time operations personnel obtained analytical samples and recorded system parameters (flow rate and cartridge pressures) every 15 minutes. Small-scale disk or cartridge laboratory experiments with either simulated or actual groundwater accurately predicted the volume of solution required to reach to $0.5 \mathrm{C} / \mathrm{C}_{0}$ (approximately 1000 bed volumes [CV]).

- In March 1996, a second PADU test in conjunction with BHI, PNNL, 3M, and AlliedSignal, Inc. demonstrated the $3 \mathrm{M}$ web technology for radioactive $\mathrm{Cs}$ and $\mathrm{Sr}$ decontamination of the 105-N-Reactor Basin. Basin water was processed through the PADU at $1 \mathrm{gpm}$ for Cs removal and 2 gpm for Sr removal. During the demonstration, two separate tests were conducted: a Sr removal test using two 7-inch $\mathrm{NaTi}$ cartridges in each of three vessels, and a Cs removal test using a single 7-inch Tc cobalt hexacyanoferrate (CoHex) cartridge in each of three vessels. Each cartridge contained about 100 grams of active adsorbent particle entrapped in a proprietary (WWL) membrane. During the first sequence, more than 380 gallons ( 7200 absorber bed volumes) of water was passed through the first $\mathrm{Cs}$ absorber cartridge with no detectable breakthrough observed. As expected from the earlier $\mathrm{N}$-Springs and laboratory testing, strontium breakthrough $\left(0.5 \mathrm{C} / \mathrm{C}_{0}\right)$ was achieved after processing only $900 \mathrm{CV}$.

- It was demonstrated that a WWL membrane, loaded with SuperLig®644 may be formed into a cartridge and repeatedly used to remove Cs from simulated NCAW waste and, after elution, to deliver it in a more concentrated form. This may be done at 70 bed volumes per hour.

- $3 \mathrm{M}$ and AlliedSignal, Inc. continued to work closely together to further develop the powdered NaTi technology for web fabrication and testing.

- AlliedSignal, Inc.'s inorganic ion exchange powders have been used extensively by Savannah River and 3M. AlliedSignal, Inc. NaTi has been produced in three distinct particle sizes for industrial and national laboratory customers. 
- Personnel at the Westinghouse Savannah River Company completed an extensive study of the AlliedSignal, Inc. NaTi in comparison to Savannah River amorphous monosodium titanate. The AlliedSignal material has met each processing criteria.

- In conjunction with Operations Technical Support personnel at the West Valley Nuclear Services (WVNS) Company, Inc., West Valley, New York, a third onsite technology demonstration by PNNL, $3 \mathrm{M}$, and AlliedSignal, Inc. was initiated on January 11, 1996. A side-stream from the 02 Low Level Waste Treatment Facility (02 LLTF) ion exchange effluent was pumped through a series of prefilters and radionuclide selective web membranes at $0.3 \mathrm{gpm}$. The process is designed to remove $\mathrm{Tc}$, uranium, Cs, Sr, and column particulate fines. Every 4 hours, plant operations personnel obtained analytical samples and recorded system parameters (flow rate and cartridge pressures). Based on laboratory testing at $3 \mathrm{M}$ and WVNS, the strong anion exchange material (SLP) exhibited several times the Tc capacity of the previous carbon/Aliquot 336 material.

- The radiolytic stability of the SuperLig@644/WWL membrane appears to be sufficient for typical radioactive $\mathrm{Cs}$ ion exchange pretreatment activities. Essentially no decrease in Cs selectivity or loading $\left(\mathrm{K}_{\mathrm{d}}\right)$ was observed during ${ }^{60} \mathrm{Co}$ gamma irradiation of the material in either distilled water or $0.5 \mathrm{M} \mathrm{HNO}_{3}$ up to $1.0 \mathrm{E}+09 \mathrm{Rad}$. The $\mathrm{Cs} \mathrm{K}_{\mathrm{d}}$ decreased by a factor of two after exposure to $2.0 \mathrm{E}+09 \mathrm{Rad}$ in water or acid.

- Essentially no decrease in $\mathrm{Cs}_{\mathrm{K}} \mathrm{K}_{d}$ was observed during the irradiation of the SuperLig®644/WWL membrane in $5 \mathrm{M} \mathrm{NCAW}$ or ambient air up to $1.0 \mathrm{E}+08 \mathrm{Rad}$. However, under these same conditions, the observed $\mathrm{Cs} \mathrm{K}_{d}$ values decreased more than an order of magnitude between $1.0 \mathrm{E}+08$ and $2.0 \mathrm{E}+09 \mathrm{Rad}$. These high irradiation dose results portray an extreme situation and should not be considered representative of typical process conditions.

- Chemical stability of the SuperLig $(644 / W W L$ membrane under caustic conditions is significantly lower than in ambient air, neutral, or acidic conditions. Even at low irradiation doses (e.g., 0 to $1.0 \mathrm{E}+07 \mathrm{Rad}$ ), $\mathrm{Cs} \mathrm{K}_{\mathrm{d}} \mathrm{s}$ of approximately $80 \mathrm{~mL} \mathrm{~g}^{-1}$ were observed for the NCAW irradiated. membrane. At these lower irradiation doses, $\mathrm{Cs} \mathrm{K}_{\mathrm{d}} \mathrm{s}$ of approximately $300 \mathrm{~mL} \mathrm{~g}^{-1}$ were measured in other matrices. These results suggest that the material is less stable in caustic solution, irrespective of the radiation exposure.

- A small-column Cs ion exchange removal demonstration was completed using actual tank waste from Hanford tank 241-SY-101. The waste had been allocated to an organic destruction and analysis program that required $\mathrm{Cs}$ removal to reduce radiation exposure. Approximately $700 \mathrm{~mL}$ of diluted supernate was passed through a 1-cm-diameter $10-\mathrm{mL}$ column of an inorganic zeolite (IE-96) at $6 \mathrm{CV} / \mathrm{hr}$. Analytical samples were collected every hour for chemical and radiochemical analysis. A partial Cs breakthrough curve was generated, and the $0.5 \mathrm{C} / \mathrm{C}_{0}$ point was estimated to be $60 \mathrm{CV}$, as was expected from previous simulant data. The Cs-deficient effluent was returned to the organic destruction program. Although the zeolite IE- 96 currently is not considered as a baseline material 
for removing $\mathrm{Cs}$ from Hanford tank waste, the decontamination process required an inorganic material that would not remove Sr. In addition, the experiment was completed as a comparison to a FY95 test using the previous baseline organic resin (CS-100).

- Several new inorganic ion exchangers useful for groundwater remediation and possibly for tank wastes have been synthesized and characterized. Using hydrothermal techniques, zirconium and tin silicates have been synthesized using different sources of silica (silicic acid, $\mathrm{Na}$ trisilicate, $\mathrm{Na}_{2} \mathrm{Si}_{3} \mathrm{O}_{7}$, and $\mathrm{Na}$ metasilicate, $\mathrm{Na}_{2} \mathrm{SiO}_{3}$ ). Analysis of the data shows that the highest affinity for $\mathrm{Cs}$ among the novel framework and layered zirconium and tin silicates was exhibited by hydrated zirconium and tin trisilicates (ZS55,TN7). It was found earlier that both these exchangers (as well as hydrous titanium trisilicate) practically do not adsorb di- and trivalent metal cations $(\mathrm{Ca}, \mathrm{Mg}, \mathrm{Sr}, \mathrm{Co}, \mathrm{Ni}, \mathrm{Cr}, \mathrm{Fe}$, etc.) due to the peculiarities of their channel structure (charge exclusion mechanism of sorption). Taking this into consideration, it is possible to expect their extremely efficient performance for selective Cs recovery from water and wastes with a high content of $\mathrm{Ca}$ and $\mathrm{Mg}$ (groundwaters, sea water, etc.). Several other materials (framework tin silicates TN2, TN3, TN5 and layered zirconium silicates SZ47, SZ58) show moderate affinity for Cs. None of the tested exchangers (both in hydrogen and salt forms) show any affinity for $\mathrm{Sr}$.

- Sr batch distribution tests with the AlliedSignal, Inc. bound NaTi exchanger were encouraging, with $\mathrm{K}_{\mathrm{d}} \mathrm{s}$ on the order of $400,000 \mathrm{~mL} \mathrm{~g}^{-1}$. 


\section{Acknowledgments}

Pacific Northwest National Laboratory (PNNL) is collaborating with universities, national laboratories, and industry to develop and test new materials for the pretreatment of nuclear wastes stored at the Hanford Site. The experimental work described in this report would not have been possible without the encouragement and resources provided by Kurt D. Gerdes, Office of Environmental Restoration and Waste Management's Office of Technology Development of the U.S. Department of Energy (DOE) and the Efficient Separations and Processing Crosscutting Program (ESP).

The authors would like to acknowledge the contributions to this effort of W. F. Bonner and W. L. Kuhn at PNNL for programmatic support; G. E. Johnson and M. R. Telander at PNNL for ${ }^{60} \mathrm{Co}$ irradiation of various materials; P. K. Berry, K. J. Carson, J. R. DesChane, and R. J. Elovich at PNNL for ion exchange material evaluations; D. Boggs, K. Carlson, T. Fredrickson, T. Kafka, D. C. Seely, I. Shaw-Epperson, N. Stern, L. R. White, and E. Wisted at 3M (St. Paul, MN) for the development of the web technology and design and construction of the Process Absorber Development Unit (PADU); R. L. Bruening, R. H. Decker, S. R. Izatt, G. Maas, and B. Tarbet at IBC Advanced Technologies (American Fork, UT) for the development and production of the SuperLig $\otimes 644$ ligand technology; S. F. Yates, R. Sedath, and I. C. Gangl-DeFilippi for developments in the engineering of inorganic ion exchangers; and Professor Abraham Clearield and V. Bortuyn at Texas A\&M University for the development of new and emerging inorganic ion exchange materials. Technical demonstrations were completed by K. A. Brewer and T. A. Todd at Idaho National Engineering Laboratory, M. Thompson at Westinghouse Savannah River Company, and E. Dingmore at West Valley Nuclear Services. This work was performed by researchers at PNNL under the Technical Task Plan (TTP) RL3-6-C3-42. PNNL is operated for DOE by Battelle under Contract DE-AC06-76RLO 1830. 



\section{Contents}

Executive Summary $\ldots \ldots \ldots \ldots \ldots \ldots \ldots \ldots \ldots \ldots \ldots \ldots \ldots \ldots \ldots \ldots \ldots \ldots \ldots \ldots$

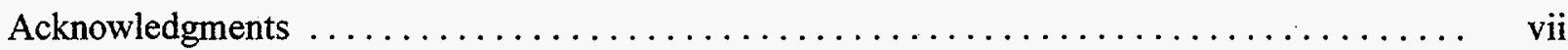

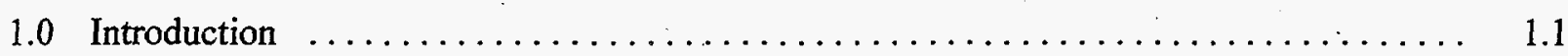

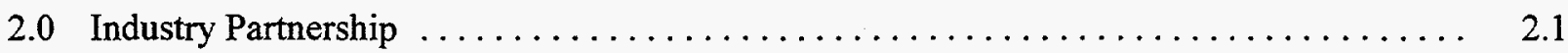

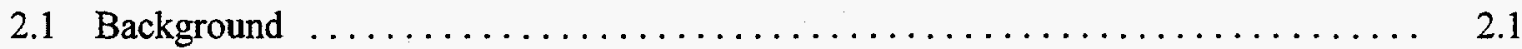

2.2 Team Formation and Operation $\ldots \ldots \ldots \ldots \ldots \ldots \ldots \ldots \ldots \ldots \ldots \ldots \ldots \ldots \ldots \ldots \ldots \ldots$

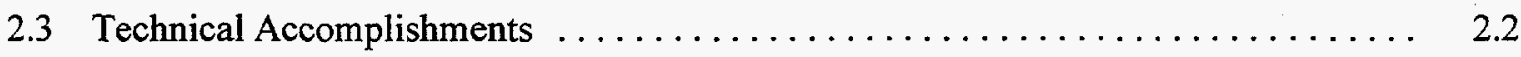

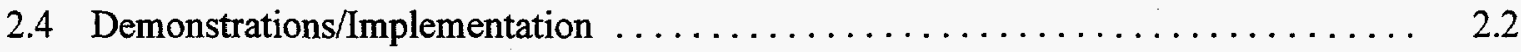

2.4.1 Hanford High Level Tank Waste $\ldots \ldots \ldots \ldots \ldots \ldots \ldots \ldots \ldots \ldots .2 .2$

2.4.2 West Valley Demonstration Project Effluent $\ldots \ldots \ldots \ldots \ldots \ldots \ldots \ldots .2 .2$

2.4.3 Hanford 100 Area N-Springs Groundwater $\ldots \ldots \ldots \ldots \ldots \ldots \ldots \ldots \ldots$

2.4.4 Hanford 100 Area N-Basin Water . . . . . . . . . . . . . . . 2.3

2.4.5 INEL Test Area North Technical Support Facility-05 Injection Well . . . . 2.3

2.4.6 Hanford High-Level Waste $\ldots \ldots \ldots \ldots \ldots \ldots \ldots \ldots \ldots \ldots \ldots \ldots \ldots \ldots \ldots \ldots \ldots \ldots .4 .4$

2.4.7 ORNL Melton Valley Waste $\ldots \ldots \ldots \ldots \ldots \ldots \ldots \ldots \ldots \ldots \ldots \ldots \ldots \ldots \ldots \ldots \ldots$

2.4.8 Radiation and Chemical Stability of SuperLig®644/WWL Membrane . . . . . 2.4

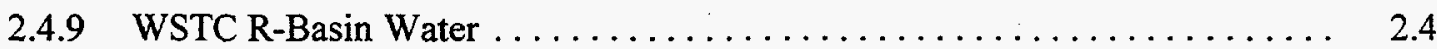

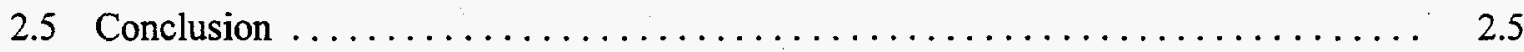

3.0 Technical Coordination and Materials Testing $\ldots \ldots \ldots \ldots \ldots \ldots \ldots \ldots \ldots \ldots \ldots \ldots \ldots$

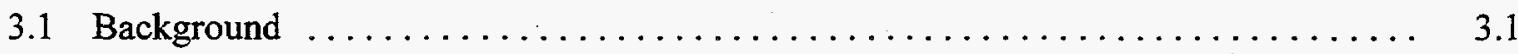

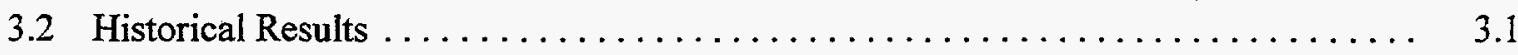

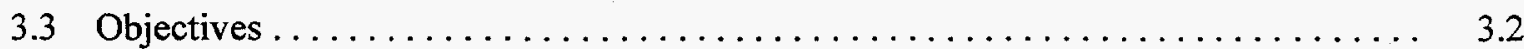


3.4 Batch Distribution $\ldots \ldots \ldots \ldots \ldots \ldots \ldots \ldots \ldots \ldots \ldots \ldots \ldots \ldots \ldots \ldots \ldots \ldots \ldots \ldots \ldots \ldots \ldots .2$

3.5 Chemical and Radiation Stability Testing $\ldots \ldots \ldots \ldots \ldots \ldots \ldots \ldots \ldots \ldots \ldots \ldots \ldots$

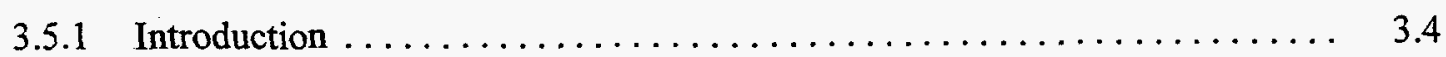

3.5.2 Ion Exchange Material Selection $\ldots \ldots \ldots \ldots \ldots \ldots \ldots \ldots \ldots \ldots \ldots \ldots$

3.5.3 Simulant Solution Selection $\ldots \ldots \ldots \ldots \ldots \ldots \ldots \ldots \ldots \ldots \ldots \ldots \ldots \ldots$

3.5.4 Experimental Sample Irradiation $\ldots \ldots \ldots \ldots \ldots \ldots \ldots \ldots \ldots \ldots \ldots \ldots \ldots$

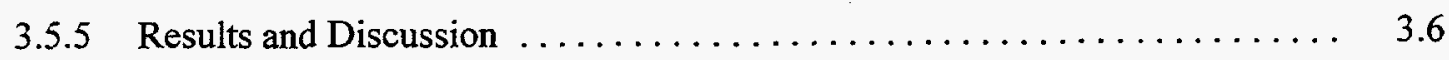

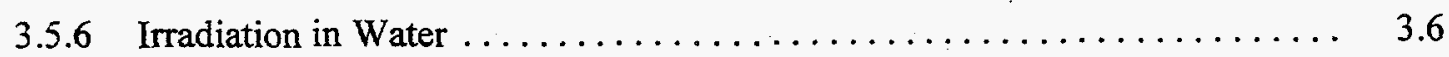

3.5.7 Irradiation in $0.5 \underline{\mathrm{M}} \mathrm{HNO}_{3} \ldots \ldots \ldots \ldots \ldots \ldots \ldots \ldots \ldots \ldots \ldots \ldots \ldots \ldots$

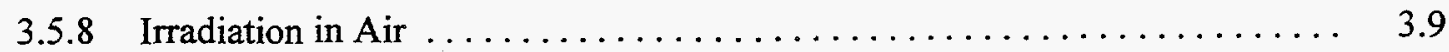

3.5.9 Irradiation in NCAW $\ldots \ldots \ldots \ldots \ldots \ldots \ldots \ldots \ldots \ldots \ldots \ldots \ldots \ldots \ldots \ldots \ldots .10$

3.5.10 Cs Batch Distribution as a Function of Irradiation Dose $\ldots \ldots \ldots \ldots \ldots \ldots .11$

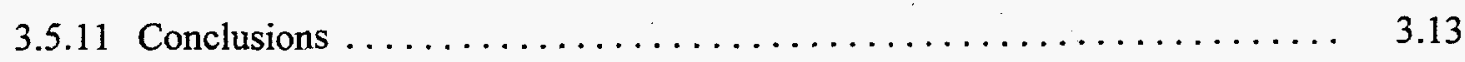

3.6 Strontium Removal From N-Springs Groundwater $\ldots \ldots \ldots \ldots \ldots \ldots \ldots \ldots \ldots \ldots$

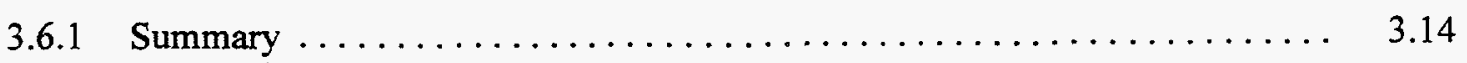

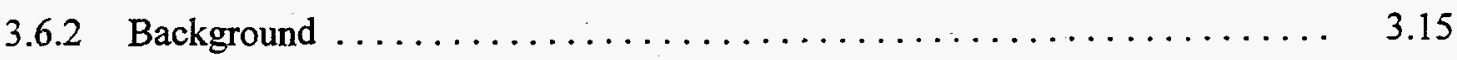

3.6.3 Experimental Approach $\ldots \ldots \ldots \ldots \ldots \ldots \ldots \ldots \ldots \ldots \ldots \ldots \ldots \ldots \ldots \ldots \ldots \ldots$

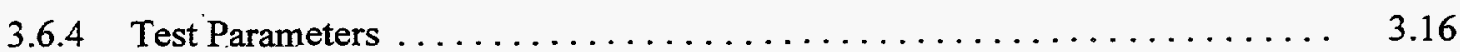

3.6.5 Preliminary Disk Tests $\ldots \ldots \ldots \ldots \ldots \ldots \ldots \ldots \ldots \ldots \ldots \ldots \ldots \ldots \ldots \ldots \ldots \ldots \ldots .18$

3.6.6 Preliminary Cartridge Tests $\ldots \ldots \ldots \ldots \ldots \ldots \ldots \ldots \ldots \ldots \ldots \ldots \ldots \ldots$

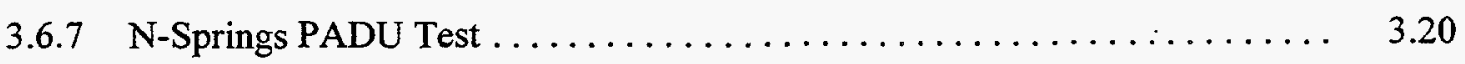

3.6.8 Sr Loading Comparison $\ldots \ldots \ldots \ldots \ldots \ldots \ldots \ldots \ldots \ldots \ldots \ldots \ldots \ldots \ldots \ldots \ldots \ldots \ldots \ldots .22$

3.6.9 Interferant Loading $\ldots \ldots \ldots \ldots \ldots \ldots \ldots \ldots \ldots \ldots \ldots \ldots \ldots \ldots \ldots \ldots \ldots \ldots \ldots$

3.6.10 PADU Demonstration $\ldots \ldots \ldots \ldots \ldots \ldots \ldots \ldots \ldots \ldots \ldots \ldots \ldots \ldots \ldots \ldots \ldots \ldots \ldots \ldots .24$ 
3.6.11 Ion Exchange Loading Capacity $\ldots \ldots \ldots \ldots \ldots \ldots \ldots \ldots \ldots \ldots \ldots \ldots \ldots \ldots$

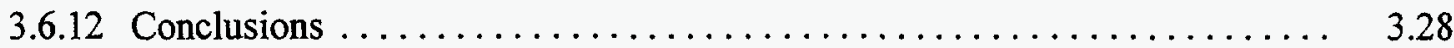

3.7 105-N-Reactor Basin Water Decontamination Using Ion Exchange $\ldots \ldots \ldots \ldots \ldots$

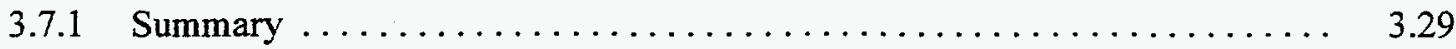

3.7.2 105-N-Reactor Basin Background $\ldots \ldots \ldots \ldots \ldots \ldots \ldots \ldots \ldots \ldots \ldots \ldots \ldots$

3.7.3 Decontamination Requirements $\ldots \ldots \ldots \ldots \ldots \ldots \ldots \ldots \ldots \ldots \ldots . . . \ldots \ldots$

3.7.4 Experimental Approach $\ldots \ldots \ldots \ldots \ldots \ldots \ldots \ldots \ldots \ldots \ldots \ldots \ldots \ldots \ldots \ldots . .30$

3.7.5 Material and Solution Selection $\ldots \ldots \ldots \ldots \ldots \ldots \ldots \ldots \ldots \ldots \ldots \ldots \ldots \ldots \ldots$

3.8 Cs Decontamination of Hanford Tank 241-SY-101 Waste $\ldots \ldots \ldots \ldots \ldots \ldots \ldots .31$

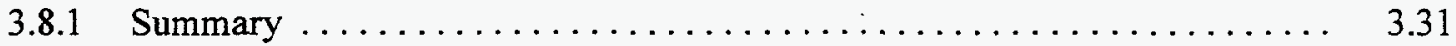

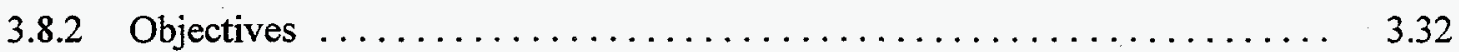

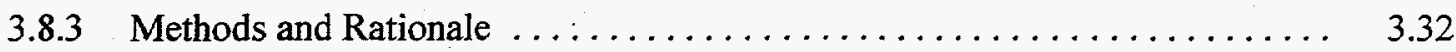

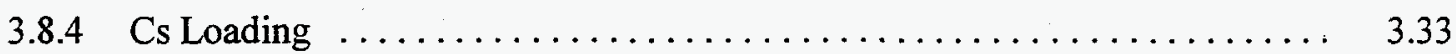

3.8.5 Interferant Loading $\ldots \ldots \ldots \ldots \ldots \ldots \ldots \ldots \ldots \ldots \ldots \ldots \ldots \ldots \ldots \ldots \ldots \ldots \ldots \ldots$

3.8.6 Ion Exchange Loading Capacity $\ldots \ldots \ldots \ldots \ldots \ldots \ldots \ldots \ldots \ldots \ldots \ldots \ldots \ldots \ldots \ldots$

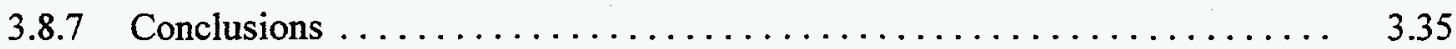

4.0 Testing and Development of Novel Inorganic $\ldots \ldots \ldots \ldots \ldots \ldots \ldots \ldots \ldots \ldots \ldots \ldots \ldots$

4.1 Surfactant-Modified Anion [Tc(VII), Cr(VI)] Exchangers in Simulated $\ldots \ldots \ldots \ldots \quad 4.1$

4.1.1 Surfactant-Modified Zirconium Oxide $\ldots \ldots \ldots \ldots \ldots \ldots \ldots \ldots \ldots \ldots .4 .1$

4.1.2 Other Surfactant-Modified Materials $\ldots \ldots \ldots \ldots \ldots \ldots \ldots \ldots \ldots \ldots$

4.2 Na-Titanate Cation (Sr) Exchangers in Alkaline HLW Simulant $\ldots \ldots \ldots \ldots \ldots \ldots \quad 4.6$

4.3 Tunnel-Structure Manganese-Oxide Cation $(\mathrm{Ba}, \mathrm{Ra})$ Exchangers $\ldots \ldots \ldots \ldots \ldots .4 .7$

$5.0 \quad 3 \mathrm{M}$ Selective Separation Technologies for $\mathrm{Cs}$, $\mathrm{Sr}$, and $\mathrm{Tc} \ldots \ldots \ldots \ldots \ldots \ldots \ldots \ldots \ldots$

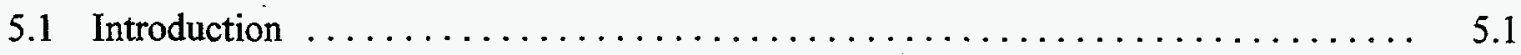


5.2 Summary Highlights $\ldots \ldots \ldots \ldots \ldots \ldots \ldots \ldots \ldots \ldots \ldots \ldots \ldots \ldots \ldots \ldots \ldots \ldots \ldots \ldots$

5.3 Technology Demonstrations $\ldots \ldots \ldots \ldots \ldots \ldots \ldots \ldots \ldots \ldots \ldots \ldots \ldots \ldots \ldots \ldots \ldots \ldots \ldots \ldots \ldots$

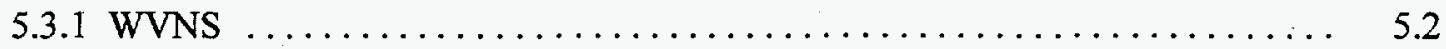

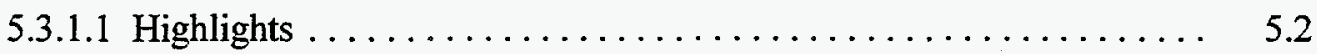

5.3 .1 .2 West Valley I $\ldots \ldots \ldots \ldots \ldots \ldots \ldots \ldots \ldots \ldots \ldots \ldots \ldots \ldots \ldots \ldots \ldots$

5.3 .1 .3 West Valley II $\ldots \ldots \ldots \ldots \ldots \ldots \ldots \ldots \ldots \ldots \ldots \ldots .3$

5.3.1.4 West Valley III $\ldots \ldots \ldots \ldots \ldots \ldots \ldots \ldots \ldots \ldots \ldots \ldots \ldots \ldots .7$

$5.3 .2 \quad$ Idaho Falls TAN $\ldots \ldots \ldots \ldots \ldots \ldots \ldots \ldots \ldots \ldots \ldots \ldots \ldots \ldots \ldots \ldots \ldots \ldots$

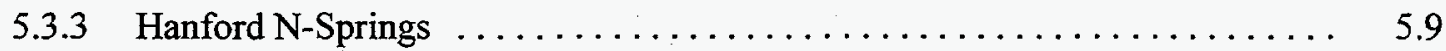

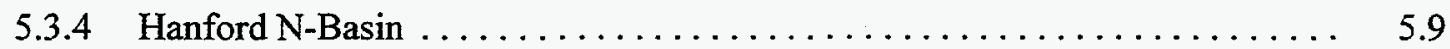

5.4 Materials and Equipment Development $\ldots \ldots \ldots \ldots \ldots \ldots \ldots \ldots \ldots \ldots \ldots \ldots \ldots \ldots \ldots \ldots$

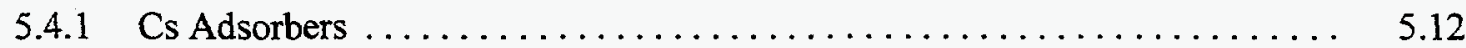

5.4.1.1 SuperLig ${ }^{\circledR} 644$ Production $\ldots \ldots \ldots \ldots \ldots \ldots \ldots \ldots \ldots \ldots \ldots \ldots \ldots \ldots \ldots \ldots \ldots$

5.4.1.2 Potassium Cobalthexacyanoferrate $(\mathrm{CoHex}) \ldots \ldots \ldots \ldots \ldots \ldots . .14$

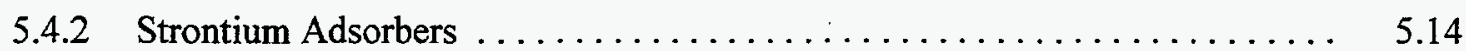

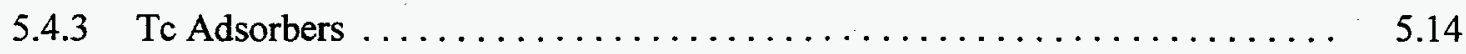

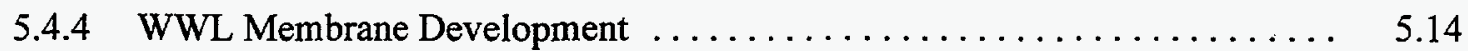

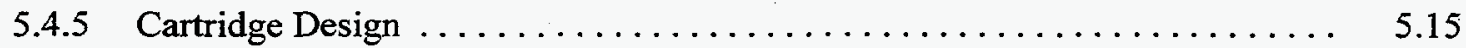

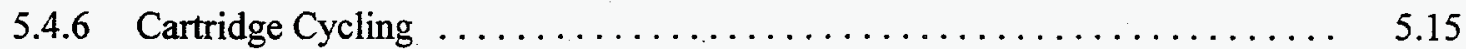

5.4.7 Mobile Process Adsorber Development Unit (PADU) . . . . . . . . 5.16

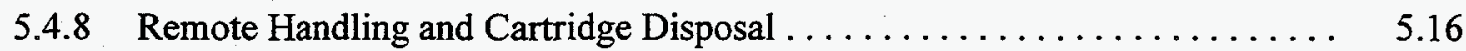

5.5 Cross Program Interactions $\ldots \ldots \ldots \ldots \ldots \ldots \ldots \ldots \ldots \ldots \ldots \ldots \ldots \ldots \ldots \ldots \ldots \ldots \ldots \ldots$

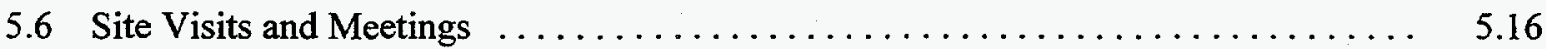

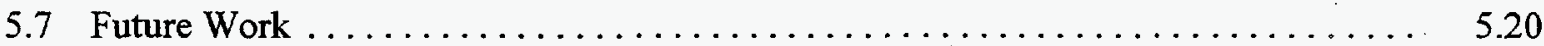


6.0 Novel Inorganic Ion Exchangers

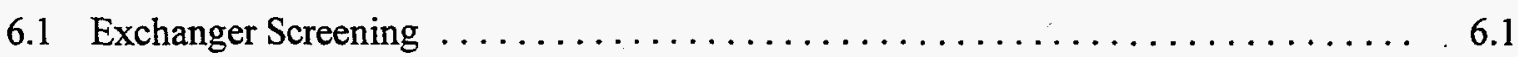

6.1.1 Group 4B Trisilicates: A New Family of Ion Exchangers $\ldots \ldots \ldots \ldots \ldots \ldots .1$

6.1 .2 Sodium Micas $\ldots \ldots \ldots \ldots \ldots \ldots \ldots \ldots \ldots \ldots \ldots \ldots \ldots \ldots \ldots \ldots \ldots \ldots \ldots .2$

6.1 .3 Pharmacosiderites $\ldots \ldots \ldots \ldots \ldots \ldots \ldots \ldots \ldots \ldots \ldots \ldots \ldots \ldots \ldots \ldots \ldots$

6.2 Sodium Titanate Development and Outside Testing $\ldots \ldots \ldots \ldots \ldots \ldots \ldots \ldots .6 .5$

6.2 .1 Testing at Savannah River $\ldots \ldots \ldots \ldots \ldots \ldots \ldots \ldots \ldots \ldots \ldots \ldots \ldots$

6.2 .2 Testing by $3 \mathrm{M}$ at INEL and Other Sites $\ldots \ldots \ldots \ldots \ldots \ldots \ldots \ldots \ldots \ldots$

6.3 Preparation and Testing of Pellet Form Sodium Titanate $\ldots \ldots \ldots \ldots \ldots \ldots \ldots .6$

7.0 Conclusions and Recommendations $\ldots \ldots \ldots \ldots \ldots \ldots \ldots \ldots \ldots \ldots \ldots \ldots \ldots \ldots \ldots \ldots \ldots \ldots .1$

8.0 References $\quad \ldots \ldots \ldots \ldots \ldots \ldots \ldots \ldots \ldots \ldots \ldots \ldots \ldots \ldots \ldots \ldots \ldots \ldots \ldots \ldots \ldots \ldots \ldots .1$

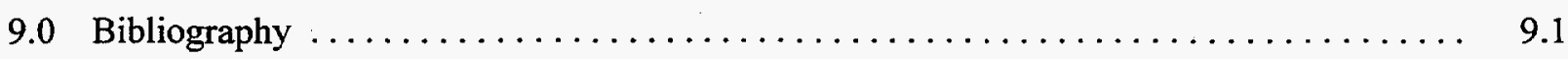




\section{Figures}

3.1. Cs Batch Distribution Ratio as a Function of $\mathrm{Na} / \mathrm{Cs}$ Ratio for Samples of the

SuperLig ${ }^{844 / W W L ~ W e b ~ I r r a d i a t e d ~ i n ~ D i s t i l l e d ~ W a t e r ~}$

3.2. Cs Batch Distribution Ratio as a Function of $\mathrm{Na} / \mathrm{Cs}$ Ratio for Samples of the SuperLig ${ }^{\circledR} 644 / \mathrm{WWL}$ Web Irradiated in $0.5 \mathrm{M} \mathrm{HNO}_{3} \ldots \ldots \ldots \ldots \ldots \ldots \ldots \ldots \ldots$

3.3. Cs Batch Distribution Ratio as a Function of $\mathrm{Na} / \mathrm{Cs}$ Ratio for Samples of the SuperLig ${ }^{\circledR 4} 4 /$ WWL Web Irradiated in Air .

3.4. Cs Batch Distribution Ratio as a Function of $\mathrm{Na} / \mathrm{Cs}$ Ratio for Samples of the SuperLig ${ }^{\circledR} 644 /$ WWL Web Irradiated in NCAW

3.5. Cs Batch Distribution Ratio as a Function of Irradiation Dose at a Na/Cs Ratio of 1.0E+05 for Samples of the SuperLig ${ }^{\circledR} 644 / W W L$ Web Irradiated in Various Solutions

3.6. Schematic Diagram of the Laboratory Disk Filtration Apparatus $\ldots \ldots \ldots \ldots \ldots \ldots$

3.7. Schematic Diagram of the $3 \mathrm{M}$ Cartridge

3.8. Schematic Diagram of the 3M Process Absorber Development Unit (PADU)

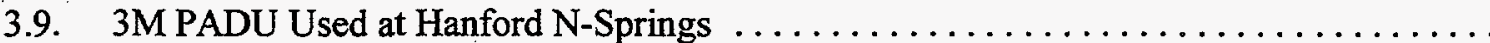

3.10. Comparison of Sr Breakthrough Curves for NaTi Disks and Cartridges in Simulated and Actual Groundwater from Hanford N-Springs

3.11. $\mathrm{Ca}, \mathrm{Mg}$, and $\mathrm{Sr}$ Breakthrough Curves for a Laboratory-Scale $\mathrm{NaTi}$ Cartridge in Simulated Groundwater from Hanford N-Springs

3.12. $\mathrm{Ca}, \mathrm{Mg}$, and $\mathrm{Sr}$ Breakthrough Curves for a NaTi Cartridge in Actual Groundwater During the Third Sequence of Hanford N-Springs PADU Demonstration ............

3.13. Sr Breakthrough Curves During PADU Sequencing at Hanford N-Springs $\ldots \ldots \ldots \ldots$

3.14. Cs Breakthrough Curves During Loading of IE-96 with Actual 101-SY Tank Waste ....

4.1. Power X-Ray Diffraction Patterns (Co-K $\alpha$ ) Obtained for Untreated $\mathrm{ZrO}_{2}$ (bottom) and Aliquat ${ }^{336-T r e a t e d ~} \mathrm{ZrO}_{2}$ (top) Ion-Exchange Materials

4.2. Thermal-Gravimetric Analysis (TGA) and Differential-Thermal Analysis (DTA) Data for Untreated $\mathrm{ZrO}_{2}$ Ion-Exchange Material 
4.3. Thermal-Gravimetric Analysis (TGA) and Differential-Thermal Analysis (DTA) Data for Aliquat ${ }^{\circledR}$-Treated $\mathrm{ZrO}_{2}$ Ion-Exchange Material $\ldots \ldots \ldots \ldots \ldots \ldots \ldots \ldots \ldots$

4.4. Relative Amounts of $\mathrm{TcO}_{4}^{-1}$ and $\mathrm{Cr}$ (VI) Retained by Aliquat ${ }^{-1336-T r e a t e d ~} \mathrm{ZrO}_{2}$ and Untreated $\mathrm{ZrO}_{2}$ After 48 Hours in a Simulated Groundwater at $\mathrm{pH} 7$

4.5. Distribution Coefficients at Different Solid: Solution Ratios for $\mathrm{TcO}_{4}{ }^{-1}$ Retention by Aliquat ${ }^{\circledR 3}$ 36-Treated $\mathrm{ZrO}_{2}$ and Reillex ${ }^{\mathrm{TM}}$ Ion-Exchange Materials in Simulated Groundwater

4.6. Amounts of $\mathrm{TcO}_{4}^{-1}$ Sorbed by Aliquat ${ }^{\circledR 3} 36-$ Treated $\mathrm{ZrO}_{2}$ at Different Final Solution Concentrations

4.7. Langmuir Isotherm Plot of $\mathrm{TcO}_{4}{ }^{-1}$ Sorption by Aliquat ${ }^{\otimes 36-T r e a t e d ~} \mathrm{ZrO}_{2} \ldots \ldots \ldots$

4.8. Amounts of $\mathrm{TcO}_{4}^{-1}$ Sorbed by Reillex ${ }^{\mathrm{TM}} \mathrm{HPQ}$ Anion-Exchange Resin at Different

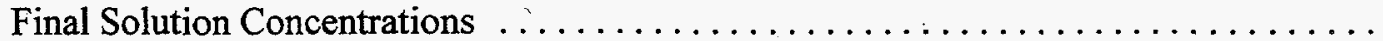

4.9. Langmuir Two-Surface Isotherm Plot of $\mathrm{TcO}_{4}^{-1}$ Sorption by Reillex ${ }^{\mathrm{TM}} \mathrm{HPQ}$

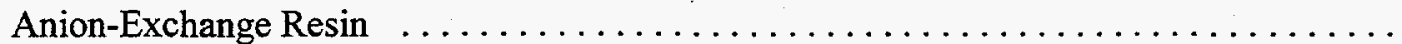

4.10 Cumulative Fractions of $\mathrm{Cr}$ (VI) Sorbed to Aliquat ${ }^{1336-T r e a t e d ~} \mathrm{ZrO}_{2}$ that were Desorbed by Sequential Treatments with Water (RT), $0.01 \underline{\mathrm{M} \mathrm{Na}} \mathrm{HPO}_{4}(\mathrm{pH} 7, \mathrm{RT})$, Ethanol $\left(60^{\circ} \mathrm{C}\right)$, and $6 \underline{\mathrm{M} \mathrm{HNO}} \mathrm{HN}_{3}\left(60^{\circ} \mathrm{C}\right)$ and, in Separate Experiments, by Treatments at RT and Near-Boiling Temperatures with Three Alkaline Extractants . . . . . . . . .

4.11. Cumulative Fractions of $\mathrm{TcO}_{4}^{-1}$ Sorbed to Aliquat ${ }^{\circledR 3}$ 36-Treated $\mathrm{ZrO}_{2}$ that were Desorbed by Sequential Treatments with Water (RT) and $0.01 \mathrm{M} \mathrm{Na} \mathrm{HPO}_{4}(\mathrm{pH} 7, \mathrm{RT})$, and, in Separate Experiments, by Treatments at RT and Near-Boiling Temperatures with Three Alkaline Extractants . . . . . . . . . . . . . . . . . . . . . . . . .

4.12. Cumulative Fractions of $\mathrm{TcO}_{4}^{-1}$ Sorbed to Reillex ${ }^{\mathrm{TM}} \mathrm{HPQ}$ Anion-Exchange Resin that were Desorbed by Treatments at RT and Near-Boiling Temperatures with Three Alkaline Extractants

4.13. Changes in Distribution Coefficients with Time for $\mathrm{TcO}_{4}^{-1}$ Retention by

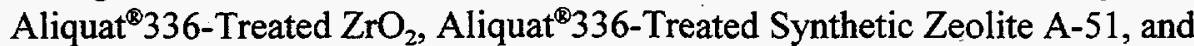
HDTMA-Treated Clinoptilolite Zeolite

4.14. Changes in Distribution Coefficients with Time for $\mathrm{Rb}^{+}, \mathrm{Ba}^{2+}$, and $\mathrm{Ca}^{2+}$ Retention

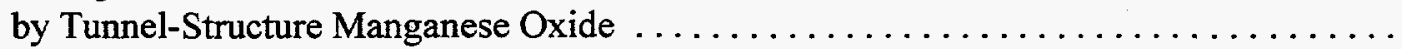

4.15. Changes in Equilibrium Concentrations of $\mathrm{BaSO}_{4}$ in $0.2 \mathrm{M}$ DTPA at $90^{\circ} \mathrm{C}$ as a

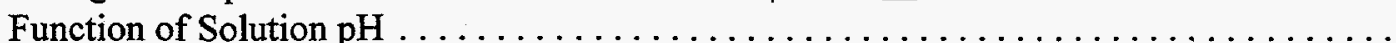


5.1. Schematic Diagram of the Cartridge System for West Valley $1 \ldots \ldots \ldots \ldots \ldots \ldots$

5.2 Schematic Diagram of the Separation and Prefiltration System for West Valley ...... 5.5

5.3 Tc Removal During the Second West Valley Demonstration $\ldots \ldots \ldots \ldots \ldots \ldots \ldots$

5.4 Tc Concentrations During the Third West Valley Demonstration $\ldots \ldots \ldots \ldots \ldots \ldots \ldots$

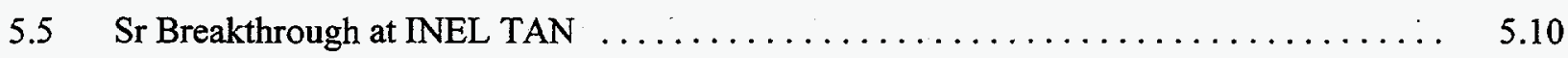

5.6 Process Adsorber Development Unit (PADU) $\ldots \ldots \ldots \ldots \ldots \ldots \ldots \ldots \ldots \ldots \ldots \ldots \ldots$

5.7 Performance of Cartridges in Parallel Compared with Performance of a

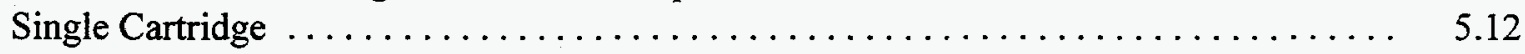

5.8 Sr Breakthrough Data at Hanford N-Basin, Sequence $1 \ldots \ldots \ldots \ldots \ldots \ldots \ldots \ldots$

5.9 Sr Breakthrough Data at Hanford N-Basin, Sequence $2 \ldots \ldots \ldots \ldots \ldots \ldots \ldots$

5.10 Mobile Process Adsorber Development Unit . . . . . . . . . . . . . . 5.17

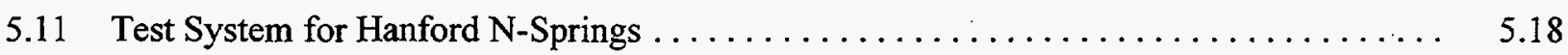

5.12 PADU Shakedown; Capture of Perrhenate Ion by Carbon/EMPORE ${ }^{\mathrm{TM}} \ldots \ldots \ldots \ldots$

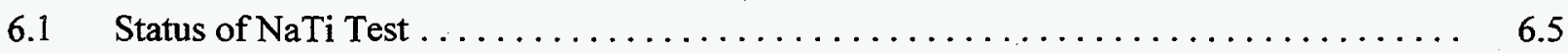

6.2 Performance of NaTi Using INEL Groundwater $\ldots \ldots \ldots \ldots \ldots \ldots \ldots \ldots \ldots \ldots .7$ 


\section{Tables}

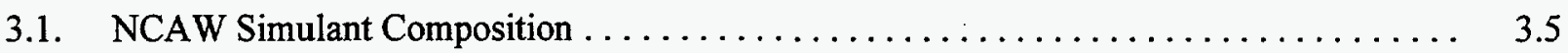

3.2. Comparison of Experimental Test Conditions for the $\mathrm{N}$-Springs PADU Demonstration, the PNNL Laboratory Disk Test, and the $3 \mathrm{M}$ Laboratory Cartridge Test ........ 3.16

3.3. Analytical Results for the Composition of 3M Simulant and Actual N-Springs Water ... 3.17

3.4. Alkaline Metal Loading of the PADU NaTi/WWL Web with Actual N-Springs Water . $\quad 3.27$

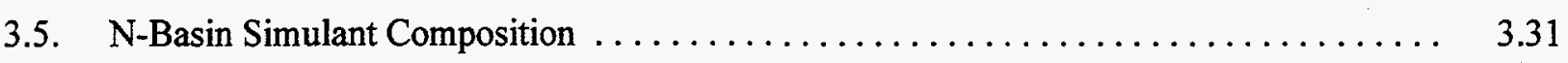

3.6. Elemental Composition of Column Effluent During Loading of IONSIV ${ }^{\mathrm{TM}}$ IE-96 with Hanford Tank $241-\mathrm{SY}-101$ Waste $\ldots \ldots \ldots \ldots \ldots \ldots \ldots \ldots \ldots \ldots \ldots \ldots \ldots \ldots \ldots \ldots \ldots$

4.1. Results of Sr Selectivity Tests on $\mathrm{Na}$ Titanate Materials Before and After Pre-Treatment of Simulant to Remove Trace Levels of $\mathrm{Ca}$, $\mathrm{Sr}$, and $\mathrm{Ba} \ldots \ldots \ldots \ldots .7$

5.1 Concentrations of Select Constituents in the Feed Water Used in this Study ....... 5.11

6.1 Distribution Coefficient Values for Cs Adsorption from Model Solutions, Containing

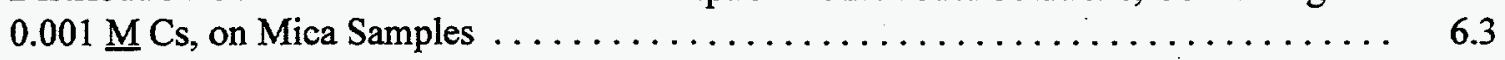

$6.2 \mathrm{~K}_{\mathrm{d}}$ and Equilibrium $\mathrm{pH}$ Values for $\mathrm{KTiSiGe}_{0.5} \ldots \ldots \ldots \ldots \ldots \ldots \ldots \ldots \ldots \ldots \ldots \ldots \ldots$

6.3 $\mathrm{K}_{\mathrm{d}}$ and Equilibrium $\mathrm{pH}$ Values for K-Exchanged Form of Ti Germanate $\ldots \ldots \ldots \ldots .4$

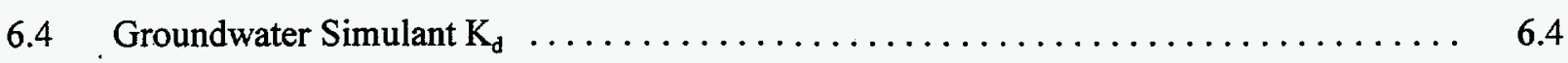

6.5 Recent Results of $\mathrm{NaTi}$ Testing at Savannah River $\ldots \ldots \ldots \ldots \ldots \ldots \ldots \ldots \ldots \ldots$

$6.6 \quad$ NaTi Pellet Physical Properties $\ldots \ldots \ldots \ldots \ldots \ldots \ldots \ldots \ldots \ldots \ldots \ldots \ldots \ldots \ldots \ldots$ 


\subsection{Introduction}

The purpose of this work is to develop high-capacity, selective solid extractants for the recovery of Cs, $\mathrm{Sr}, \mathrm{Tc}$, and other radionuclides from nuclear wastes. To achieve this goal, Pacific Northwest National Laboratory (PNNL) has adopted a broad-based approach for the identification and testing of candidates as solid-based sequestering agents as well as the development and application of existing materials. A solicitation of interest and capabilities was issued in FY 1992 through the Commerce Business Daily to identify candidate industry/university teams to collaborate with PNNL in the proposed studies. Two contracts were awarded in 1992: to AlliedSignal, Inc., (AlliedSignal) with a subcontract to Professor Abraham Clearfield at Texas A\&M University (TAMU) on July 1, 1992; and to 3M Company (3M), with a subcontract with IBC Advanced Technologies, Inc. (IBC) on November 5, 1992.

This project is designed to develop and test the capacity, selectivity, and stability of selected sequestering agents and substrates in representative physical, chemical, and radiation environments. Emphasis has been placed on producing and demonstrating ion exchangers with potential applications in nuclear waste management that would result in major cost reductions and environmental benefits. Although contributions from this task should be useful in addressing a variety of problems in the DOE complex, specific Cs, Sr, and Tc decontamination applications at the Hanford Site were initially targeted.

Significant progress was made in FY 1994, including 1) completion of the first successful hotcell demonstration of 3M/IBC technology in August 1994 at the Idaho National Engineering Laboratory (NNEL) using WM-185 radioactive acid feed, 2) production of the SuperLig@644 sequesterant for removing $\mathrm{Cs}$ from $\mathrm{pH}>14$ waste to the exclusion of $\mathrm{K}$, and 3) discovery of a new method for preparing bound $\mathrm{NaTi}$, which preserves the high $\mathrm{Sr} \mathrm{K}_{\mathrm{d}} \mathrm{s}$ of the original powder and allows the preparation of the engineered form titanate. The binder works at low weight percent, has acceptable mechanical strength, and is resistant to attack by alkali. This represents a major breakthrough in the development of inorganic ion exchangers for use in column operation under high alkaline waste conditions.

In FY 1995, an extensive technical effort was required to scale up the materials and processes necessary to demonstrate the IBC particle, $3 \mathrm{M}$ web, and AlliedSignal binder technologies. Kilogram quantities of various SuperLigß materials were produced and tested by IBC. Kilogram quantities of powdered and bound forms of NaTi were produced by AlliedSignal. Significant advances in the web/ particle technology were demonstrated including the production of webs containing $\mathrm{NaTi}$, titanium dioxide, titanium phosphate, activated carbon, Reillex®HPQ, an anion exchanger, resorcinolformaldehyde, and $\mathrm{K}$ cobalt hexacyanoferrate (CoHex). Researchers at TAMU continued to investigate several new classes of inorganic ion exchangers including zirconates, micas, titanium silicates, pharmacosiderites, and titanium phosphates. Researchers at PNNL continued to evaluate these and other commercial materials for chemical and radiation stability and for the removal of various radionuclides from actual and simulated Hanford process nuclear wastes.

The FY 1996 goals were to build on the successes of FY 1995 and to obtain additional scientific and engineering information required to 1) implement ligand-particle web technology, 2) evaluate inorganic 
ion exchangers for $\mathrm{Cs}$, $\mathrm{Sr}$, and $\mathrm{Tc}$ removal, and 3) implement these technologies using actual process wastes. Successful demonstrations were completed by personnel at PNNL's Shielded Analytical Laboratory and High Level Radiochemical Facility, Hanford 100 Area N-Springs and N-Basin, INEL Test Area North (TAN) Ground Water Treatment Facility, West Valley Nuclear Services, Inc. (WVNS) 02 Low Level Water Treatment Facility, and Oak Ridge National Laboratory (ORNL). 


\subsection{Industry Partnership}

Technology for selective removal of contaminants from DOE high-level waste (HLW) and waste water is being developed and successfully deployed by the PNNL industry/national laboratory partnership. This partnership can be a model for effectively and efficiently bringing industry and national laboratory staff together to solve DOE waste remediation needs. Interfacing with industry in this manner provides

- application of industrial technology to DOE needs

- transfer of knowledge of DOE needs from national laboratories to industry

- management of technology development/adaptation by experts in the field

- entrepreneurial spirit of industry focused on DOE needs.

\subsection{Background}

It has been determined that remediation of the DOE waste legacy will be performed by industry under the direction of DOE. Technology developed for this purpose must, therefore, include industry at the earliest possible time. A team composed of PNNL scientists and industry representatives has been highly successful in converting industrial expertise into solutions for DOE waste needs. Below is a description of this emerging collaborative relationship.

\subsection{Team Formation and Operation}

Responding to needs identified at several DOE sites, in 1992 PNNL contracted with industrial partners to assist in development/deployment of technologies for removal of contaminants from DOE wastes. 3M/IBC and AlliedSignal/TAMU were the successful bidder teams selected. These teams provided an appropriate mix of sorbents development expertise coupled with the ability to engineer the sorbent into a form capable of being deployed in a cartridge for ease in waste cleanup operations.

Under the direction of experts in the sorbents field who were also well acquainted with needs for separations technology at DOE sites, a membrane-based sorbent system and other inorganic and organic ion exchange materials were developed that are directly applicable to DOE needs. A team was organized and is now functioning that, through careful application of industry expertise and knowledge of DOE needs, constraints, etc. has developed sorbents with uniquely applicable properties. Development of the organic resins, inorganic exchangers, and membrane systems in the industrial/university laboratories was followed by testing against competing products, often with actual radioactive wastes at PNNL, which has provided an efficient development path.

Under contractor tutelage, the industrial partners have quickly learned the DOE needs, constraints, policies and business methods. The 3M/1BC and AlliedSignal/TAMU staffs have become knowledgeable 
about DOE needs through DOE and contractor personnel at several sites. The subcontracts have been worded to encourage aggressive interface with DOE sites. In turn, the sites all responded by indicating waste streams they wanted addressed. There has been a major difference in attitude when the industrial/university partners present our case rather than having PNNL, a competing lab, promote the technology.

\subsection{Technical Accomplishments}

Sorbents have been developed and tested that are uniquely applicable to DOE needs for both groundwater and HLW applications. The ion exchange sorbents have been incorporated into a web structure that provides selective ion removal without the disadvantages of a large ion exchange column system. The web can be placed in a cartridge and either disposed when loaded or the captured contaminants can be eluted and the web reused. Organic and inorganic ion exchange materials are being tested at selected sites.

\subsection{Demonstrations/Implementation}

The radionuclide removal technologies described in this report were conceived and initially tested under small-scale laboratory conditions. The most promising materials and processes are being implemented in site-specific demonstrations in order to illustrate the viability of these methods under actual process conditions. As a result, a number of site demonstrations have been completed as a team effort between PNNL, the industrial subcontractors, other DOE national laboratories, and universities.

\subsubsection{Hanford High Level Tank Waste}

Seven ion exchange materials (CS-100, R-F, SuperLig® 644, IE-910, IE-911, TIE-96 and NaTi) were evaluated for the pretreatment of actual and simulated Hanford Double Shell Slurry Feed (DSSF) tank waste. Cs and $\mathrm{Sr} \mathrm{K}_{\mathrm{d}} \mathrm{s}$, column distribution ratios $\left(\lambda=\mathrm{K}_{\mathrm{d}} \times \mathrm{r}_{\mathrm{b}}\right)$, and decontamination factors (DF) are compared as a function of contact duration, solution composition, supernate:exchanger phase ratio, and multiple sequential contacts. The actual DSSF waste was a volume composite from tanks $101-\mathrm{AW}(70 \%)$, 106-AP $(20 \%)$, and 102-AP (10\%). The actual waste tests were conducted at $4.96 \pm 0.19 \mathrm{M} \mathrm{Na}$ and $23^{\circ} \mathrm{C}$ with $\mathrm{Na} / \mathrm{Cs}$ mole ratios that ranged from 100 to 500,000 . The simulant composition was formulated based on previous analytical characterization of the actual waste, and tests were conducted at dilutions ranging from 7 to $0.2 \mathrm{M} \mathrm{Na}$ over a wide range of $\mathrm{Na} / \mathrm{Cs}$ mole ratios (50 to 500,000) (Brown et al. 1996a).

\subsubsection{West Valley Demonstration Project Effluent}

A small-scale demonstration of ${ }^{99} \mathrm{Tc},{ }^{137} \mathrm{Cs}$, and ${ }^{90} \mathrm{Sr}$ removal from plant effluent was conducted at WVNS. During this test, a $0.3 \mathrm{gpm}$ side-stream of plant effluent flowed through a skid-mounted unit containing snap-in $3 \mathrm{M}$ cartridges, each containing $0.09 \mathrm{~m}^{2}$ of active surface. Equipment installation/ setup, operations, sampling, and primary sample analysis was provided by onsite EM-30 operating staff. During the test, approximately 3200 gallons of water was processed in 192 hours. Cs was removed to 
below the analytical detection limit for the duration of the test. Initially, Tc was removed by more than a factor of 100 , which decreased to a factor of 10 after 24 hours. Sr removal was not demonstrated.

\subsubsection{Hanford 100 Area N-Springs Groundwater}

In conjunction with personnel from Bechtel Hanford, Inc. (BHI) and CH2M Hill Hanford, Inc., an onsite technology demonstration by PNNL, 3M, and AlliedSignal was completed on January 25, 1996 at the Hanford 100-N Area N-Springs. A side-stream from the N-Springs Pump and Treat Facility influent was pumped through the PADU containing a series of prefilters and $\mathrm{Sr}$-selective web cartridges at $3.5 \mathrm{gpm}$. The process is designed to remove $\mathrm{Sr}$, initially at low levels (ca. $1000 \mathrm{pCi} / \mathrm{L}$ ), to below the proposed drinking water standard of $40 \mathrm{pCi} / \mathrm{L}$. Based on laboratory evaluations at $\mathrm{PNNL}$ and $3 \mathrm{M}$, the test was completed in 3 hours during which time operations personnel obtained analytical samples and recorded system parameters (flow rate and cartridge pressures) every 15 minutes. Small-scale disk or cartridge laboratory experiments with either simulated or actual groundwater accurately predicted approximately 1000 exchanger bed volumes required to reach to $0.5 \mathrm{C} / \mathrm{C}_{0}$ (Brown et al. 1996b).

\subsubsection{Hanford 100 Area N-Basin Water}

In March 1996, a second PADU test in conjunction with BHI, PNNL, 3M, and AlliedSignal demonstrated the $3 \mathrm{M}$ web technology for radioactive $\mathrm{Cs}$ and $\mathrm{Sr}$ decontamination of the 105-N-Reactor Basin. Basin water was processed through the PADU at $1 \mathrm{gpm}$ for Cs removal and $2 \mathrm{gpm}$ for Sr removal. During the demonstration, two separate tests were conducted: a Sr removal test using two 7-inch NaTi cartridges in each of three vessels and a Cs removal test using a single 7-inch $\mathrm{K}$ cobalt hexacyanoferrate (CoHex) cartridge in each of three vessels. Each cartridge contained about 100 grams of active adsorbent particle entrapped in a proprietary (WWL) membrane. During the first sequence, more than 380 gallons (7200 absorber bed volumes) of water was passed through the first Cs absorber cartridge with no detectable breakthrough observed. As expected from the earlier N-Springs and laboratory testing, $0.5 \mathrm{C} / \mathrm{C}_{0}$ was achieved after processing only $900 \mathrm{CV}$.

\subsubsection{INEL Test Area North Technical Support Facility-05 Injection Well}

Groundwater remediation efforts are in progress at the Technical Support Facility-05 injection well (TSF-05) at TAN located at INEL. Efforts are focused primarily on the Groundwater Treatment Facility (GWTF) near the TSF-05 injection well at TAN, which was installed in 1994 to pump and treat the injection well water. The presence of ${ }^{137} \mathrm{Cs}$, combined with higher than expected concentrations of suspended particles, significantly hampered remediation operations. Twelve hundred gallons of water that had been processed using the existing system at TAN but that still contained $33 \mathrm{pCi} / \mathrm{L}$ of ${ }^{90} \mathrm{Sr}$ and $256 \mathrm{pCi} / \mathrm{L}$ of ${ }^{137} \mathrm{Cs}$ were placed in drums and shipped to the Idaho Chemical Processing Plant where INEL personnel, under the direction of PNNL and 3M, continuously operated a cartridge-based radionuclide removal system at 16 gallons per hour. Complete removal of the $\mathrm{Sr}$ and $\mathrm{Cs}$ was achieved, and the prefiltration system was shown to be effective (Herbst et al. 1995). 


\subsubsection{Hanford High-Level Waste}

A small-column Cs ion exchange removal demonstration was completed using actual tank waste from Hanford tank 241-SY-101. The waste had been allocated to an organic destruction and analysis program that required Cs removal in order to reduce radiation exposure. Approximately $700 \mathrm{~mL}$ of diluted supernate was passed through a 1-cm-diameter, 10-mL column of an inorganic zeolite (IE-96) at 6 column volumes per hour $(\mathrm{CV} / \mathrm{hr})$. Analytical samples were collected every hour for chemical and radiochemical analysis. A partial Cs breakthrough curve was generated, and the $0.5 \mathrm{C} / \mathrm{C}_{0}$ point was estimated to be $60 \mathrm{CV}$, as was expected from previous simulant data. The Cs- deficient effluent was returned to the organic destruction program. Although the zeolite IE- 96 currently is not considered as a baseline material for removing Cs from Hanford tank waste, the decontamination process required an inorganic material that would not remove Sr. In addition, the experiment was completed as a comparison to a FY95 test using the previous baseline organic resin (CS-100).

\subsubsection{ORNL Melton Valley Waste}

ORNL personnel completed testing of the SuperLigß644 ion exchanger in the 20-40 mesh ion exchange column form and in the $3 \mathrm{M}$ web form using actual alkaline Melton Valley waste. $3 \mathrm{M}$ and IBC prepared the ion exchange and web materials to be tested and instructed ORNL personnel on material preparation and operating procedures but were not present during the actual experiments to avoid any conflict of interest. The results of this testing have been reported previously (Lee et al. 1996).

\subsubsection{Radiation and Chemical Stability of SuperLig®644/WWL Membrane}

PNNL investigated the chemical and radiolytic stability of IBC's newly synthesized SuperLigß644 sequestering agent that has been engineered by $3 \mathrm{M}$ into a proprietary web-like matrix. Material stability was evaluated by irradiating the material to a total dose of $2.0 \mathrm{E}+09 \mathrm{Rad}$ at $1.6 \mathrm{E}+06 \mathrm{Rad} \mathrm{hr}^{-1}$ in realistic process flow sheet solutions (e.g., either a simulated Neutralized Current Acid Waste (NCAW) supernatant liquid, $0.5 \underline{\mathrm{M} \mathrm{HNO}}$, distilled water, or ambient air). The samples were analyzed for ion exchange selectivity and capacity by $\mathrm{Cs}$ batch distribution $\left(\mathrm{K}_{\mathrm{d}}\right)$ experiments in a simulated NCAW solution containing variable concentrations of $\mathrm{Cs}$ and $5.0 \mathrm{M} \mathrm{Na}$. Before the ion exchange $\mathrm{K}_{\mathrm{d}}$ contact, the initial $\mathrm{Na}$-to-Cs molar ratio $\left(\mathrm{Na} / \mathrm{Cs}\right.$ ) ranged from 500 to 500,000 . These $\mathrm{K}_{d}$ data were used to determine the relative stability of the material tested (Brown et al. 1996c).

\subsubsection{WSTC R-Basin Water}

The PADU has been transported to the WSTC R-Basin for another experiment designed to demonstrate the separation of radioactive $\mathrm{Cs}$ from polychlorinated biphenyls (PCBs). Modification of the PADU and experimental planning is in progress. Testing will be completed by WSTC personnel. 


\subsection{Conclusion}

The "Partnership Model" has been used effectively and efficiently in bringing industry and national laboratory staff together to solve DOE waste remediation needs. Interfacing a national laboratory such as INEL, ORNL, or PNNL with industry in this manner provides a link in solving DOE needs. Learning time is shortened, management of new technology development is strengthened, and new products are deployed by experts in the field. Such partnering also infuses industry's entrepreneurial spirit on DOE needs with an industry requirement to enter the market with a profitable and successful product.

The following report sections briefly describe the work performed by researchers from PNNL, $3 \mathrm{M}$, AlliedSignal, and TAMU. 



\title{
3.0 Technical Coordination and Materials Testing
}

\author{
G. N. Brown, P. K. Berry, K. J. Carson, J. R. DesChane, and R. J. Elovich
}

A wide variety of ion exchange materials are being evaluated at PNNL under the Technical Coordination and Materials Testing subtask for radionuclide uptake using simulated and actual process, groundwater, and high level tank wastes. Materials are tested in ion exchange column, filter disk, and small-scale batch distribution formats. In addition, chemical and radiation stability testing of selected materials has been and will continue to be completed as deemed necessary by project personnel. Samples of particle webs (3M), Na titanates (AlliedSignal), silicates, titanates, zirconates, and micas (TAMU), SuperLig® (IBC), and crystalline silicotitanates (Sandia National Laboratory and UOP Corporation) are tested side-by-side with other commercially available organic resorcinol-formaldehyde (R-F) and phenolformaldehyde resins for radionuclide uptake in a variety of solutions (e.g., composition, ionic strength, $\mathrm{pH}$, temperature, etc.). Concerns for organic resin, binder, and web radiation and chemical stability are addressed by ${ }^{60} \mathrm{Co}$ sample irradiation under various solution conditions.

\subsection{Background}

The contents of Hanford's 177 underground storage tanks include a mixture of sludge, salt cake, and alkaline supernatant liquid. The insoluble sludge fraction of the waste consists of metal oxides and hydroxides and contains the bulk of the ${ }^{90} \mathrm{Sr}$ and many of the TRUs. The salt cake, generated by extensive evaporation of aqueous solution, consists primarily of dried Na salts. The supernate consists of concentrated aqueous solutions of $\mathrm{Na}$ nitrate/nitrite salts with smaller quantities of hydroxide, aluminum, $\mathrm{K}$, carbonate, sulfate, and phosphate. The bulk of the water-soluble radionuclides such as ${ }^{137} \mathrm{Cs}$ are likely contained in the supernatant solution, interstitial liquid, and salt cake fractions.

Although the pretreatment and disposal strategy is still being defined, one of the first steps in most pretreatment scenarios will be a solids/liquid separation of the pumpable waste liquor, followed by ion exchange removal of $\mathrm{Cs}$ from the resulting supernatant liquid. Next, a salt cake dissolution and sludge wash step will be initiated followed by another solids/liquid separation. Most of the Cs is expected to be in the aqueous liquids from these processes, and it is these solutions that are the focus of the Cs ion exchange removal process. This process is being designed with the goal of removing enough $\mathrm{Cs}$ so that the resulting low-level waste (LLW) will meet the Nuclear Regulatory Commission's (NRC's) 10 CFR 61 Class A Limit for ${ }^{137} \mathrm{Cs}\left(1 \mathrm{Ci} \mathrm{m}^{-3}\right)$. However, a greater $\mathrm{Cs}$ decontamination and the removal of ${ }^{90} \mathrm{Sr},{ }^{99} \mathrm{Tc}$, and TRUs from the alkaline supernate may be required in order to meet the NRC incidental waste or other designation.

\subsection{Historical Results}

The technology for Cs decontamination of high-level alkaline wastes and sludge wash waters has been investigated at PNNL (Bray 1989a; Bray 1989b; Bray et al. 1990a; Bray et al. 1992; Bray et al. 1993a; Bray et al. 1993b; Brown et al. 1995c; Kurath et al. 1994), at the Westinghouse Savannah River Company (Bibler et al. 1989; Bibler 1991; Bibler 1994; Bray et al. 1990a), and at WVNS (Bray et al. 1984; 
Kurath et al. 1989; Bray and Hara 1991). Previous work (Bray et al. 1984; Brown et al. 1995b; Brown et al. 1995c) focused on applications to treat high-level alkaline tank wastes but many of the technologies can also be applied in process and groundwater remediation (Herbst et al. 1995).

Many ion exchange materials have demonstrated the ability to remove Cs from various simulated solutions (Marsh et al. 1994a; Marsh et al. 1994b; Marsh et al. 1994c; Marsh et al. 1995). Brown et al. (1995b) investigated the column ion exchange removal of radioactive Cs from actual and simulated Hanford tank 101-SY and 103-SY waste using CS-100. In addition, several inorganic and organic materials have been evaluated for $\mathrm{Cs}$ and $\mathrm{Sr}$ selectivity using small-scale batch distribution experiments with actual and simulated 101-AW tank waste (Brown et al. 1996a).

The chemical and radiolytic stability of several organic ion exchange resins (e.g., SuperLigß644, R-F, and CS-100) has been evaluated in simulated alkaline waste solutions using ${ }^{60} \mathrm{Co}$ gamma radiation (Bibler and Crawford 1994; Brown et al. 1995a; Bryan et al. 1993; Carlson et al. 1995; Hubler et al. 1995).

\subsection{Objectives}

Experimental studies are being conducted by PNNL under the Efficient Separations and Processing Crosscutting Program (ESP) Technical Task Plan Number RL3-6-C3-42, Test Sorbents; Industrial Contracts. The overall project objectives are to 1) develop and evaluate newly-conceived novel materials for the recovery of $\mathrm{Cs}, \mathrm{Sr}$, and $\mathrm{Tc}$ from alkaline wastes, 2) determine the loading and elution efficiency of these processes, 3) determine the physical life cycle (including radiation and chemical stability) of these materials, and 4) determine if basic ion exchange data can be applied to a broad range of tank wastes.

The goal is to provide the technology to produce a LLW effluent with radioactivity suitable for treatment in the LLW glass vitrification facility. Ultimately, each process must be evaluated for removal efficiency, process chemical consumption and recycle, chemical and radiation stability of materials, compatibility with other process streams, secondary waste generation, process and maintenance costs, final material disposal, and impact upon the volume and quality of the HLW.

\subsection{Batch Distribution}

The batch distribution coefficient $\left(\mathrm{K}_{\mathrm{d}}=[\mathrm{Cs}]_{\text {solid }} \div[\mathrm{Cs}]_{\text {liquid }}\right)$ is an equilibrium measure of the overall ability of the solid phase ion exchange material to remove an ion from solution under the particular experimental conditions that exist during the contact. In most batch $\mathrm{K}_{\mathrm{d}}$ tests, a known quantity of ion exchange material is placed in contact with a known volume of solution containing the particular ions of interest. The material is allowed to contact the solution for sufficient time to achieve equilibrium at a constant temperature, after which the solid ion exchange material and liquid supernate are separated and analyzed. In this report, the batch $K_{d}$ 's were achieved by contacting between 0.010 and $0.50 \mathrm{~g}$ of the web or ion exchange material with between 10 and $1000 \mathrm{~mL}$ of supernate liquid. The exact phase ratio (volume of solution divided by mass of solid) depends upon the material loading under the particular chosen experimental conditions (e.g., material capacity, solution composition, temperature, etc.). 
The equation for determination of the $\mathrm{K}_{\mathrm{d}}$ can be simplified by determining the concentration of the analyte before and after contact and calculating the quantity of analyte on the ion exchanger by difference (Equation 3.1).

$$
\mathrm{K}_{\mathrm{d}}=\frac{\left(\mathrm{C}_{\mathrm{i}}-\mathrm{C}_{\mathrm{f}}\right)}{\mathrm{C}_{\mathrm{f}}} * \frac{\mathrm{V}}{\mathrm{M} * \mathrm{~F}}
$$

Where $\mathrm{C}_{\mathrm{i}}$ is the initial amount or activity of the ion of interest in the feed solution before contact, $\mathrm{C}_{\mathrm{f}}$ is the amount or activity after contact, $\mathrm{V}$ is the solution volume, $\mathrm{M}$ is the exchanger mass and $\mathrm{F}$ is the mass of dry ion exchanger divided by the mass of wet ion exchanger ( $F$-factor). $\mathrm{K}_{\mathrm{d}}$ (normal units are $\mathrm{mL} \mathrm{g}^{-1}$ ) represents the theoretical volume of solution $(\mathrm{mL}$ ) that can be processed per mass of exchanger (dry weight basis) under equilibrium conditions. Lambda, the theoretical number of bed volumes of solution that can be processed per volume of exchanger, is obtained by multiplying $K_{d}$ by the exchanger bed density, $\rho_{b}$ ( $\mathrm{g}$ of resin per $\mathrm{mL}$ of resin) as shown in Equation 3.2.

$$
\lambda=\mathrm{K}_{\mathbf{d}} * \rho_{\mathrm{b}}
$$

Lambda provides a method of comparing ion exchange performance of a wide variety of materials on a volume basis (e.g., in an ion exchange column). Brown et al. (1995c) reported that this method is biased against low bed density materials (e.g., SuperLigß644 $\rho_{\mathrm{b}}=0.22 \mathrm{~g} \mathrm{~mL}^{-1} ; \mathrm{R}-\mathrm{F} \rho_{\mathrm{b}}=0.45 \mathrm{~g} \mathrm{~mL}^{-1}$ ).

The experimental equipment required to complete the batch $\mathrm{K}_{\mathrm{d}}$ determinations includes an analytical balance, a constant temperature water bath, an oven for F-Factor determinations, a variable speed shaker table, $20-\mathrm{mL}$ to $1000-\mathrm{mL}$ vials, $0.2-\mu \mathrm{m}$ syringe filters, the appropriate ion exchangers, and simulant or actual waste solutions.

\subsection{Chemical and Radiation Stability Testing}

The purpose of this section is to describe the chemical and radiolytic stability of the newly synthesized SuperLig $\otimes 644$ sequestering agent (IBC) which has been engineered into a proprietary web-like matrix abbreviated SL644/WWL (3M). Material stability was evaluated by irradiating the material to a total dose of $2.0 \mathrm{E}+09 \mathrm{Rad}$ at $1.6 \mathrm{E}+06 \mathrm{Rad} \mathrm{hr}^{-1}$ in realistic process flow sheet solutions (e.g., either a simulated $\mathrm{NCAW}$ supernatant liquid, $0.5 \mathrm{M} \mathrm{HNO}_{3}$, distilled water, or ambient air). The samples were analyzed for ion exchange selectivity and capacity by $\mathrm{Cs}$ batch distribution $\left(\mathrm{K}_{\mathrm{d}}\right)$ experiments in a simulated NCAW solution containing variable concentrations of $C s$ and $5.0 \mathrm{M} \mathrm{Na}$. Before the ion exchange $\mathrm{K}_{\mathrm{d}}$ contact, the initial Na-to-Cs molar ratio $\left(\mathrm{Na} / \mathrm{Cs}\right.$ ) ranged from 500 to 500,000 . These $\mathrm{K}_{d}$ data were used to determine the relative stability of the material tested. 


\subsubsection{Introduction}

Previous experimental work completed before Fiscal Year 1996 for Cs recovery included the evaluation of several ion exchange materials (e.g., SuperLig®644, R-F, and CS-100) in simulated and actual waste matrices using bench-scale column loading and elution tests, small-scale batch distribution contacts, and chemical and radiolytic stability experiments. Brown et al. (1995a) exposed three organic ion exchange resins (SuperLig $\left(644, \mathrm{R}-\mathrm{F}\right.$, and CS-100) to either ${ }^{60} \mathrm{Co}$ gamma radiation or oxygen in simulated alkaline waste solutions in order to evaluate each material's relative radiolytic and oxidative stability. Radiolytic stability was deduced by periodic gas generation and Cs batch $\mathrm{K}_{\mathrm{d}}$ analysis of each material. Stability toward oxidation was inferred by $\mathrm{O}_{2}$ uptake measurements, nuclear magnetic resonance, and Cs batch $\mathrm{K}_{d}$ analysis of the exposed materials.

The focus of the current experimentation is to further investigate the chemical and radiolytic stability of engineered SuperLig $\ll 44$ entrapped in a web-like polymer matrix and to compare these results to those obtained previously (Brown et al. 1995a) for the ion exchange resin in the absence of the WWL web matrix. Because of the limited availability of actual radioactive waste, simulated solutions have been used for the current stability testing.

\subsubsection{Ion Exchange Material Selection}

The removal of radioactive Cs by column ion exchange is considered to be the baseline pretreatment process for cleanup of a majority of the waste currently stored at Hanford. In addition to SuperLigß644, several materials are capable of removing Cs from highly alkaline solutions including organic ion exchange resins (CS-100 and R-F), inorganic zeolites (IE-95, IE-96, TIE-96), and other materials (Crystalline Silico-Titanates). The SuperLig®644 polymer resin is the latest version of the covalently bound SuperLig@ macrocycle family of sequestering ligands from IBC and has been shown to be highly selective for $\mathrm{Cs}$ even in the presence of excess $\mathrm{Na}$ or K (Brown et al. 1995c). The SuperLigß644 polymer has recently become available engineered in a web-like matrix produced by $3 \mathrm{M}$. In the current study, this SuperLigß644/WWL web material was evaluated for chemical and radiation stability under a variety of solution conditions.

\subsubsection{Simulant Solution Selection}

The NCAW simulant described in Table 3.1 was chosen for the current ion exchanger irradiation/ stability experiments. This composition is considered to represent much of the Hanford tank wastes. It has been shown previously that this composition replicates the chemical environment of actual NCAW tank wastes for radiation and chemical stability experiments (Brown et al. 1995a; Bryan et al. 1993; Carlson et al. 1995). Numerous $C s$ batch $K_{d}$ and column loading tests have been completed using this formulation (Bray et al. 1992; Kurath et al. 1994; Brown et al. 1995c). Cs was absent from the NCAW simulant during material irradiation but was present during the batch $\mathrm{K}_{d}$ determinations at an initial concentration that varied from $1.0 \mathrm{E}-02$ to $1.0 \mathrm{E}-05 \underline{\mathrm{M}}$ as $\mathrm{CsNO}_{3}$. 
Table 3.1. NCAW Simulant Composition

\begin{tabular}{|c|c|}
\hline Species & Molarity, $\underline{\mathrm{M}}$ \\
\hline $\mathrm{Na}$ & 5.00 \\
\hline $\mathrm{K}$ & 0.12 \\
\hline $\mathrm{Rb}$ & $5.00 \mathrm{E}-05$ \\
\hline $\mathrm{Cs}$ & Variable \\
\hline $\mathrm{Al}$ & 0.43 \\
\hline $\mathrm{SO}_{4}$ & 0.15 \\
\hline $\mathrm{OH}(\mathrm{Total})$ & 3.40 \\
\hline $\mathrm{OH}_{(\mathrm{Free})}$ & 1.68 \\
\hline $\mathrm{CO}_{3}$ & 0.23 \\
\hline $\mathrm{NO}_{2}$ & 0.43 \\
\hline $\mathrm{NO}_{3}$ & 1.67 \\
\hline $\mathrm{F}$ & 0.089 \\
\hline $\mathrm{PO}_{4}$ & 0.025 \\
\hline
\end{tabular}

\subsubsection{Experimental Sample Irradiation}

To evaluate the chemical and radiation stability of the SuperLigß644/WWL sorbent, samples were contained in glass scintillation vials and were exposed to high-dose ${ }^{60} \mathrm{Co}$ gamma radiation. The sealed system was convenient for exposing the resin to either an NCAW simulant, $0.5 \underline{\mathrm{M}} \mathrm{HNO}_{3}$, distilled water, or ambient air during the radiolysis process. A single piece of the sorbent web weighing approximately $0.6 \mathrm{~g}$ was triple rinsed and placed into $15 \mathrm{~mL}$ of the appropriate irradiation solution. No attempt was made to evacuate or purge the entrained oxygen or air from the sample containers. Following irradiation, the samples were rinsed with copious amounts of distilled water and air-dried for a minimum of 48 hours.

Small subsample $(0.07 \mathrm{~g})$ portions of the sorbent at each irradiation dose were evaluated for Cs uptake using the ${ }^{137} \mathrm{Cs}$ batch distribution coefficient $\mathrm{K}_{d}$ (see Section 3.4). The remainder of the irradiated sample for each solution was dried at $105^{\circ} \mathrm{C}$ for 24 hours and the fraction (F-Factor) of easily removed water was calculated. The samples were contacted with fresh NCAW simulant containing an variable initial Cs concentration (Na/Cs from 500 to 500,000$)$. The obtained distribution coefficients are used as an indicator of the material Cs loading and an approximation of the radiation damage to the resin material. The materials were exposed to a total radiation dose of approximately $2.0 \mathrm{E}+09 \mathrm{Rad}$ at $1.6 \mathrm{E}+06 \mathrm{Rad} \mathrm{hr}^{-1}$ over the course of several weeks. 
The Gamma Irradiation Facility is operated by PNNL and contains 37 stainless steel irradiation tubes positioned in a 7-ft.-diameter by $13-\mathrm{ft}-8 \mathrm{in}$.-deep stainless steel tank. Two arrays of ${ }^{60} \mathrm{Co}$ with a combined inventory of $32 \mathrm{KCi}$ are located near the bottom of the tank. For radiation shielding purposes, the tank is completely filled with water, and a 3.5-ft.-high concrete wall surrounds the top of the tank. The irradiation tubes, which are sealed on the bottom, vary in length and diameter from $16 \mathrm{ft}$. to $18 \mathrm{ft}$. and from $1.8 \mathrm{in}$. to $6 \mathrm{in}$., respectively. The irradiation flux of the tubes ranges from approximately $2.0 \mathrm{E}+06 \mathrm{Rad} \mathrm{hr}^{-1}$ to $2.0 \mathrm{E}+02 \mathrm{Rad} \mathrm{hr}^{-1}$. The uniform flux region varies from $\sim 6 \mathrm{in}$. for the tubes closest to the sources to greater than 12 in. for the tubes farthest away from the sources. All flux measurements of the tubes are traceable to the National Institute for Standards and Technology.

All materials and test systems were lowered into the irradiation tubes manually and were left in the tubes for the specific amount of time $(6.25 \mathrm{E}-01,6.25 \mathrm{E}+00,6.25 \mathrm{E}+01,6.25 \mathrm{E}+02,1.25 \mathrm{E}+03$ hour $)$ to achieve the required exposure $(1.0 \mathrm{E}+06,1.0 \mathrm{E}+07,1.0 \mathrm{E}+08,1.0 \mathrm{E}+09,2.0 \mathrm{E}+09 \mathrm{Rad})$. There is no activation associated with the gamma irradiation so the materials were transported to other facilities for $\mathrm{Cs}$ batch $\mathrm{K}_{\mathrm{d}}$ evaluation (see Section 2.3) after removal from the tubes. The temperature of the test was approximately $15^{\circ} \mathrm{C}$ to $20^{\circ} \mathrm{C}$ based on the recorded ambient temperatures in the gamma facility.

\subsubsection{Results and Discussion}

A new class of sequestering agents (SuperLig(B) has been developed by IBC that can selectively remove various radionuclides ( $\mathrm{Cs}$, $\mathrm{Sr}$, etc.) from high ionic-strength alkaline solutions based on molecular recognition technology. Previous tests have demonstrated that one of these materials in resin form (SuperLig $\otimes 644$ ) is capable of removing Cs from simulated Hanford tank waste even in the presence of excess $\mathrm{Na}$ and $\mathrm{K}$ (Brown et al. 1995c). To assess more accurately the potential use of this technology for the pretreatment of nuclear process wastes, the oxidative and radiolytic stability of SuperLig@644 was tested and compared to that of two current baseline materials (Brown et al. 1995a).

More recently, a novel form of the SuperLig $@ 644$ material has been developed in a collaboration between IBC and $3 \mathrm{M}$. In this material, the organic resin is ground to a fine uniform particle size and entrapped into a web-like fibrous matrix designated WWL. Because of the unique nature of this novel material, the chemical and radiolytic stability has been questioned. The potential exists for a reduction in stability due to the increased surface area-to-mass ratio of the smaller particles. However, the potential also exists for an overall increase in stability due to a greater stability of the inert fibrous matrix. For these reasons, the SuperLig $® 644 / \mathrm{WWL}$ material was exposed to ${ }^{60} \mathrm{Co}$ gamma radiation in a variety of solutions over the course of several weeks. The irradiated samples were analyzed for Cs selectivity in a simulated NCAW solution by batch distribution $\left(\mathrm{K}_{\mathrm{d}}\right)$ analysis.

\subsubsection{Irradiation in Water}

Cs batch distribution $\left(\mathrm{K}_{\mathrm{d}}\right)$ results as a function of equilibrium $\mathrm{Na} / \mathrm{Cs}$ ratio are displayed in Figure 3.1 for samples of the SuperLig $\otimes 644 / W W L$ membrane irradiated in distilled water. Each data curve represents a known irradiation dose from zero to $2.0 \mathrm{E}+09 \mathrm{Rad}$. It is evident from the data that irradiation in water to $1.0 \mathrm{E}+09 \mathrm{Rad}$ does not appreciably change the $\mathrm{Cs}_{\mathrm{d}}$ results. Even after irradiation to 2.0E+09 Rad, the Cs $\mathrm{K}_{\mathrm{d}}$ decreased by less than a factor of two. 


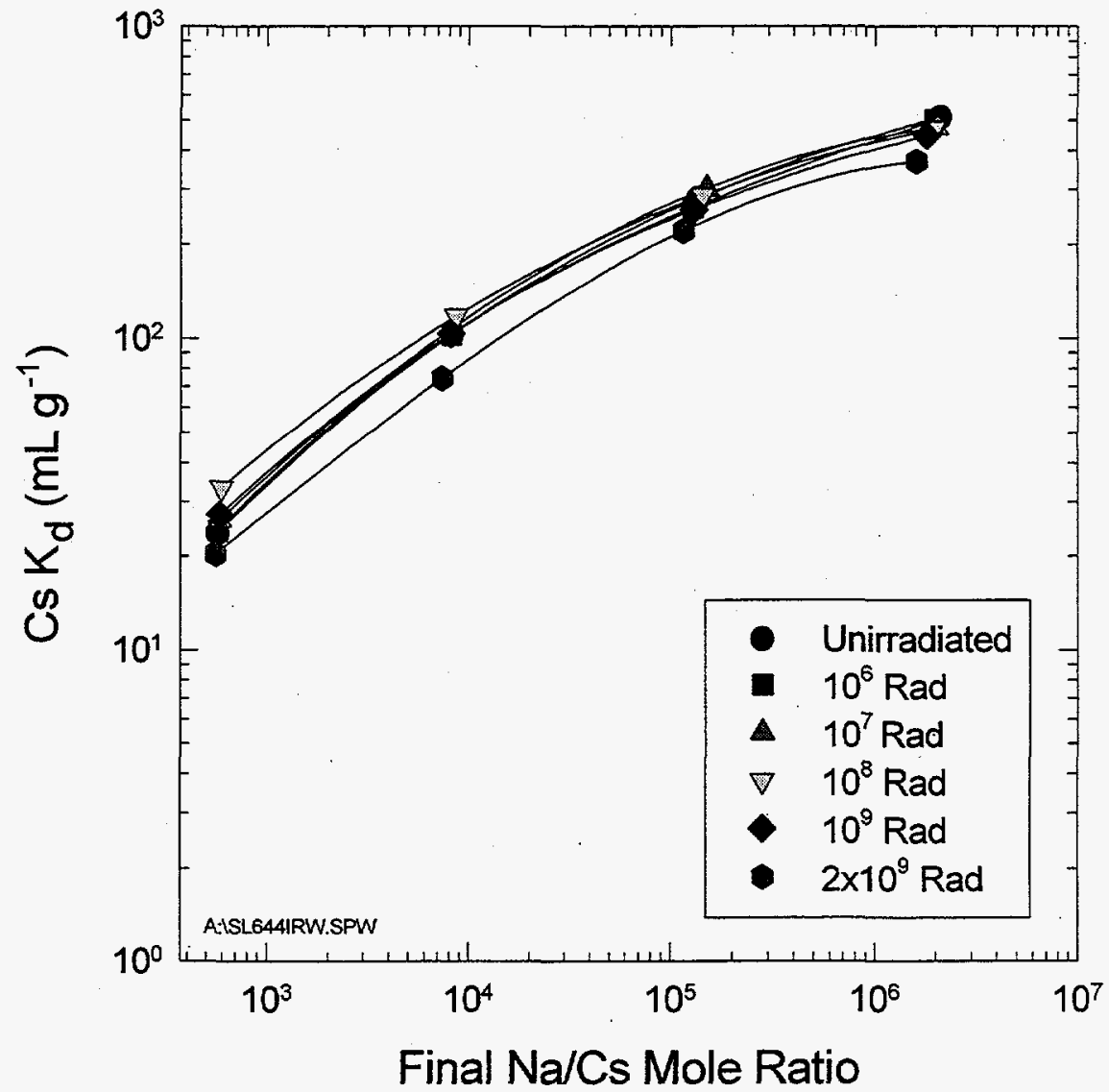

Figure 3.1. Cs Batch Distribution Ratio as a Function of $\mathrm{Na} / \mathrm{Cs}$ Ratio for Samples of the SuperLigß644/WWL Web Irradiated in Distilled Water

The $\mathrm{K}_{\mathrm{d}}$ data are presented as a function of the equilibrium $\mathrm{Na} / \mathrm{Cs}$ ratio (i.e., the $\mathrm{Na} / \mathrm{Cs}$ ratio remaining after material and solution contact) so that the reader can easily extrapolate back to the original composition of the NCAW feed solution. Data displayed in this manner allow evaluation of material loading and extrapolation to column ion exchange performance. The samples were evaluated for Cs uptake in a series of standard NCAW simulants with variable Cs content ( 500 to $500,000 \mathrm{Na} / \mathrm{Cs}$ ) as described previously (Bibler et al. 1989; Bibler 1994; Bray et al. 1990; Bray et al. 1993; Brown et al. 1996; Kurath et al. 1994).

At a final $\mathrm{Na} / \mathrm{Cs}$ ratio of $5.0 \mathrm{E}+04$ (e.g., the composition of the standard NCAW solution used previously by Brown et al. (1995c)), the Cs $\mathrm{K}_{\mathrm{d}}$ was determined to be approximately $220 \mathrm{~mL} \mathrm{~g}^{-1}$ for the unirradiated samples. The value decreased slightly to $170 \mathrm{~mL} \mathrm{~g}^{-1}$ after irradiation to $2.0 \mathrm{E}+09 \mathrm{Rad}$. Multiplying this value by the estimated SuperLigß644/WWL bed density $\left(\rho_{\mathrm{b}}=0.347 \mathrm{~g} \mathrm{~mL}^{-1}\right)$ yields a lambda $(\lambda)$ value of nearly $80 \mathrm{CV}$. When the fractional amount of SuperLigß644 loaded into the WWL membrane is taken into account, this value compares favorably to the $110 \mathrm{CV}$ value reported earlier for 
unirradiated SuperLig $\otimes 44$ resin (Brown et al. 1995c). The percentage of active particle in the WWL membrane is known to vary between $60 \%$ and $95 \%$, depending on production conditions.

\subsubsection{Irradiation in $\mathbf{0 . 5} \mathrm{M}_{\mathrm{HNO}}$}

The Cs $\mathrm{K}_{\mathrm{d}}$ results for the irradiation of the SuperLig(B644/WWL membrane in dilute nitric acid $\left(0.5 \mathrm{M} \mathrm{HNO}_{3}\right)$ are displayed in Figure 3.2. The results are analogous, and nearly identical to those displayed in Figure 3.1 for irradiation in distilled water. This is not surprising since the SuperLig@644/ WWL material is obtained from the supplier in the acid form. The manufacturer suggests that if the material is to be stored for an extended period of time the acid form is preferred. The equilibrium $\mathrm{pH}$ was not measured during the experiment but it is likely that the distilled water became slightly acidic after contact. At 2.0E+09 Rad, the samples irradiated in either water or acid exhibited a moderate weight loss $(6 \%)$, which was only slightly greater than the $2 \%$ weight loss observed for the lower irradiation doses.

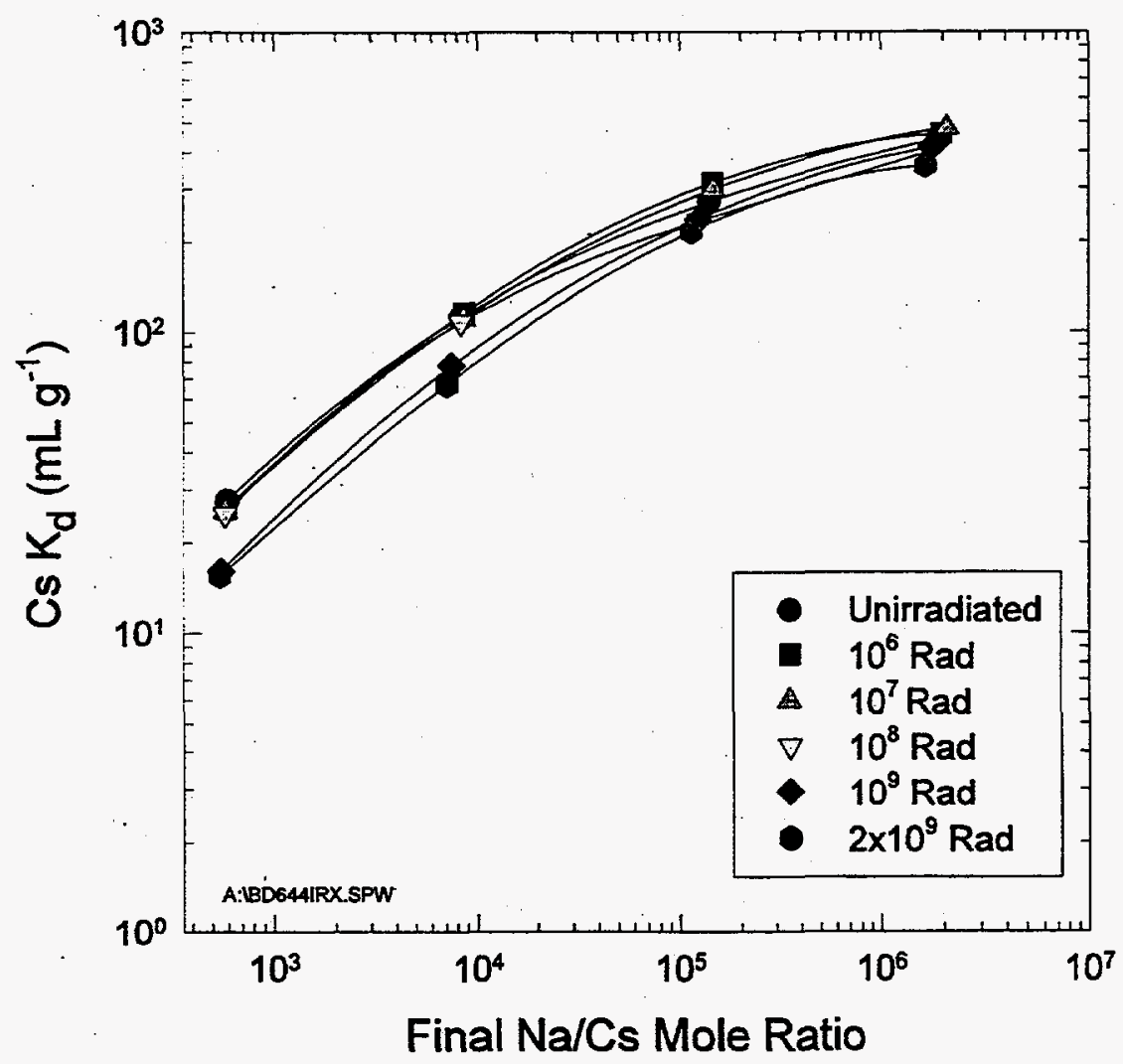

Figure 3.2. Cs Batch Distribution Ratio as a Function of $\mathrm{Na} / \mathrm{Cs}$ Ratio for Samples of the SuperLig®644/WWL Web Irradiated in $0.5 \mathrm{M} \mathrm{HNO}_{3}$ 


\subsubsection{Irradiation in Air}

The Cs $\mathrm{K}_{\mathrm{d}}$ results for the irradiation of the SuperLigß644/WWL membrane in ambient air are displayed in Figure 3.3. The results are analogous but more extreme than those described for the irradiation in dilute nitric acid or distilled water. After irradiation, the $\mathrm{Cs}_{\mathrm{d}}$ results at a $\mathrm{Na} / \mathrm{Cs}$ ratio of $1.0 \mathrm{E}+05$ drop significantly from approximately $300 \mathrm{~mL} \mathrm{~g}^{-1}$ at $1.0 \mathrm{E}+07 \mathrm{Rad}$ to less than $30 \mathrm{~mL} \mathrm{~g}^{-1}$ at 2.0E+09 Rad. Evidently, exposure of the material to either dilute acid or distilled water solution during the irradiation process may protect the resin from chemical degradation. Several protection mechanisms can be postulated including free radical transfer from the resin to a water molecule or a reduction in oxygen availability in solution versus in air. The air-irradiated sample actually displayed a minor weight gain $(0.8 \%$ and $2.1 \%)$ at $1.0 \mathrm{E}+09$ and $2.0 \mathrm{E}+09 \mathrm{Rad}$, respectively.

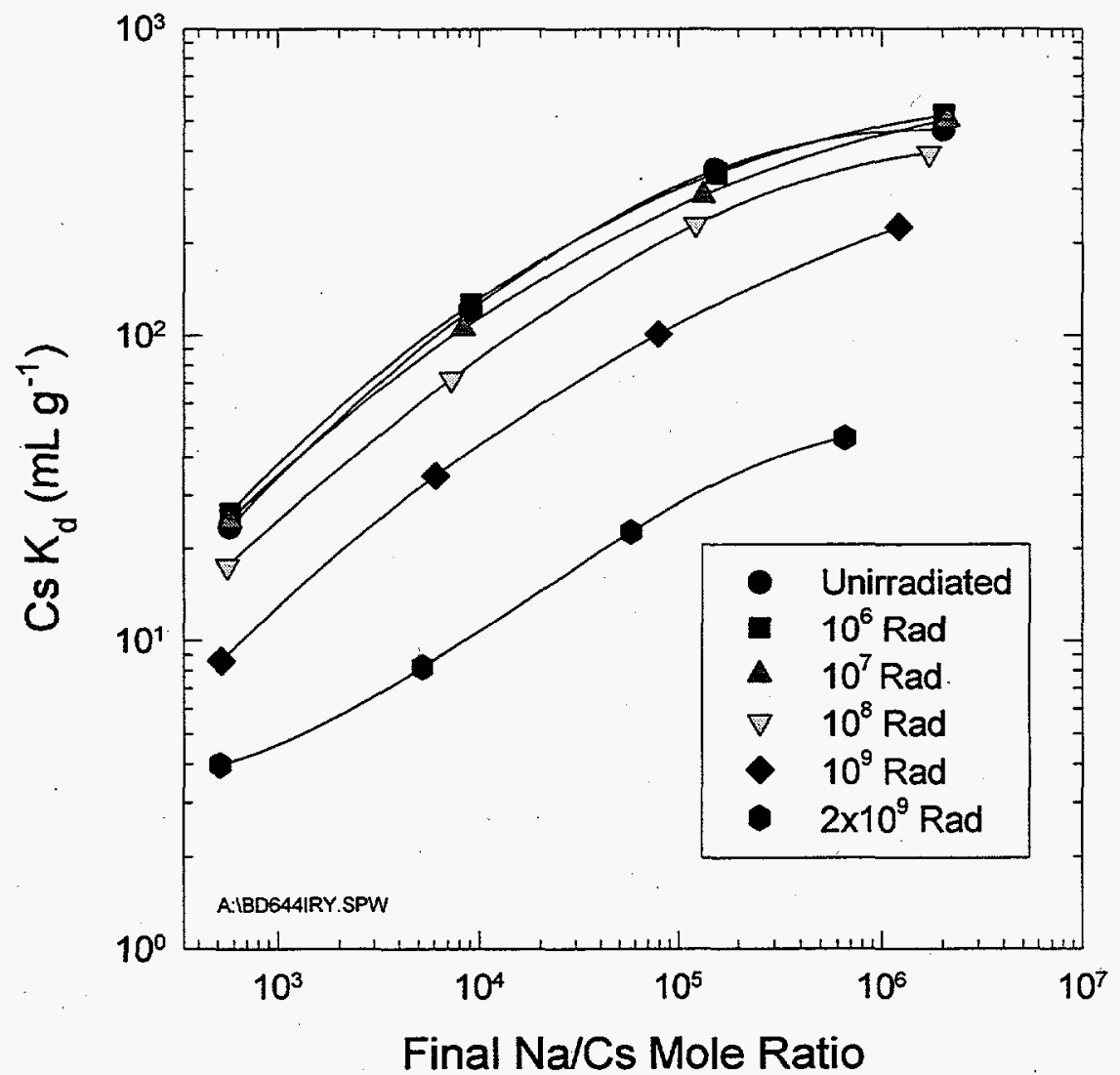

Figure 3.3. Cs Batch Distribution Ratio as a Function of $\mathrm{Na} / \mathrm{Cs}$ Ratio for Samples of the SuperLig®644/WWL Web Irradiated in Air 


\subsubsection{Irradiation in NCAW}

The Cs $\mathrm{K}_{\mathrm{d}}$ results for the irradiation of the SuperLig( $844 / \mathrm{WWL}$ membrane in simulated NCAW solutions are displayed in Figure 3.4. The results are analogous and surprisingly similar to those described for the irradiation in ambient air. However, after irradiation, the $\mathrm{Cs} \mathrm{K}_{\mathrm{d}}$ results drop significantly from approximately $70 \mathrm{~mL} \mathrm{~g}^{-1}$ at $1.0 \mathrm{E}+07 \mathrm{Rad}$ to less than $1 \mathrm{~mL} \mathrm{~g}^{-1}$ at $2.0 \mathrm{E}+09 \mathrm{Rad}$. Also evident is the significant reduction in Cs $\mathrm{K}_{\mathrm{d}}$ for the unirradiated material stored in NCAW when compared to storage and irradiation in either distilled water, dilute nitric acid, or ambient air. Evidently, the material is less stable toward radiation in the NCAW than in air or other solutions.

A comparison of these result to those described previously (Brown et al. 1995a) for a pure SuperLigß644 resin irradiated at 1.0E+09 Rad is also displayed in Figure 3.4. The previous $\mathrm{K}_{\mathrm{d}}$ results are significantly higher than the current results. For example, in the current experiment, a $\mathrm{Cs} \mathrm{K}_{\mathrm{d}}$ value of $14 \mathrm{~mL} \mathrm{~g}^{-1}$ (measured in NCAW at $1.0 \mathrm{E}+05 \mathrm{Na} / \mathrm{Cs}$ ) was determined for the SuperLig $\otimes 644 / \mathrm{WWL}$ membrane irradiated in an NCAW solution to $1.0 \mathrm{E}+09 \mathrm{Rad}$. Using the same irradiation solution, the SuperLigß644 polymeric resin yielded a $\mathrm{K}_{\mathrm{d}}$ value of $110 \mathrm{~mL} \mathrm{~g}^{-1}$ (Brown et al. 1995a).

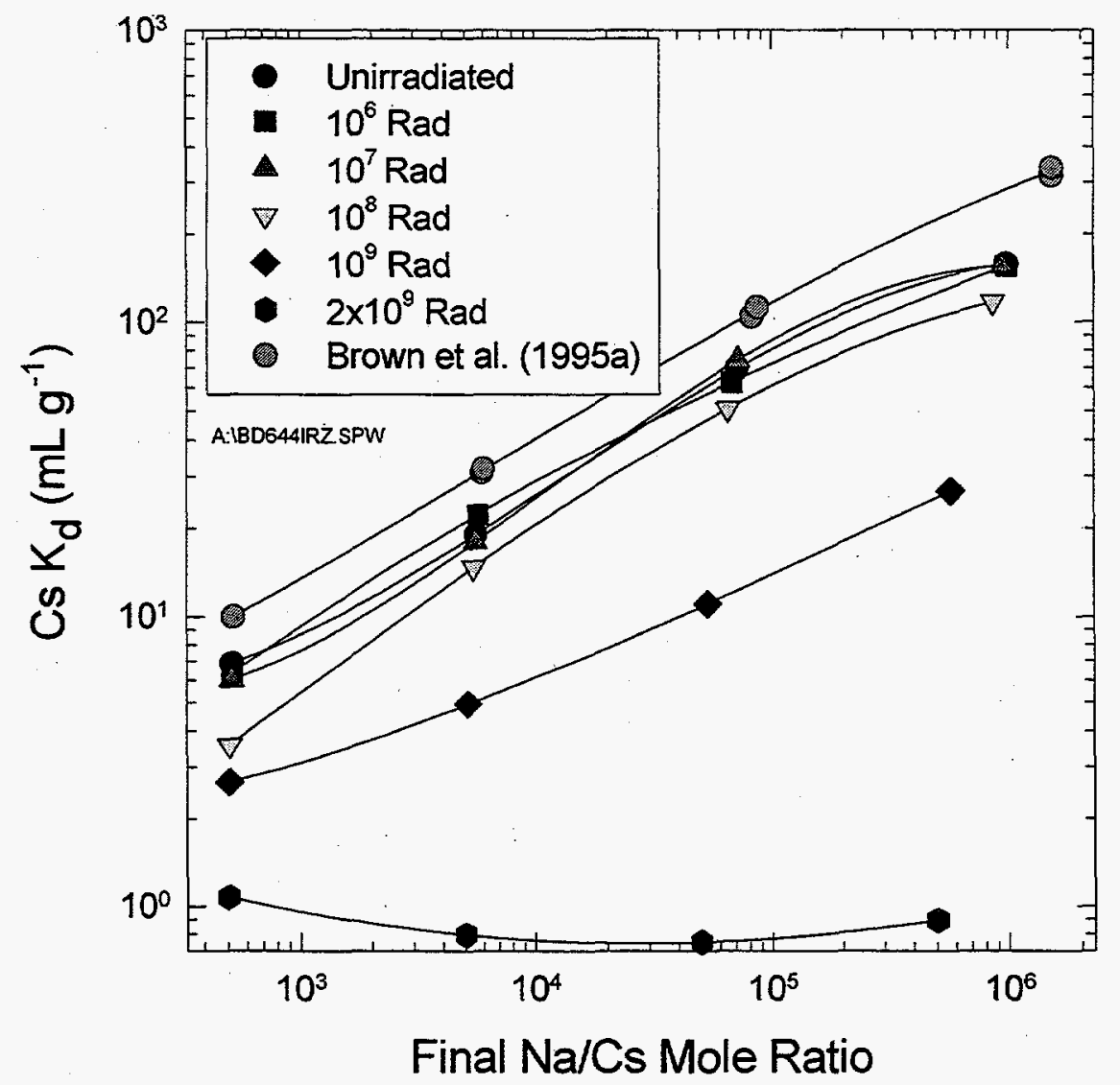

Figure 3.4. Cs Batch Distribution Ratio as a Function of Na/Cs Ratio for Samples of the SuperLig®644/WWL Web Irradiated in NCAW 
The reason for the lower $C s K_{d}$ results could be related to a number of important differences between the two experiments. First, in the current tests, no attempt was made to exclude oxygen or entrained air from the samples. In the previous gas generation experiments (Brown et al. 1995a), the samples were explicitly purged with ultra high-purity argon so that the generation of various gases could be determined accurately. Second, the SuperLig $₫ 644$ material is known to swell in caustic solutions and this may enhance diffusion-limited degradation mechanisms as compared to the unswelled sorbent (e.g., irradiated in air, water, or acid). Third, the SuperLig $\$ 644 / W W L$ membrane contained smaller active particles (>400 mesh) than the polymeric resin ( 20 to 50 mesh), which might also explain the differences. Also, the current membrane samples were irradiated at a higher volume-to-mass phase ratio $(V / M=30)$ than the resin samples $(V / M=6)$ reported by Brown et al. (1995a). Finally, a significant post-irradiation weight increase (50\%) from approximately $0.5 \mathrm{~g}$ to $0.75 \mathrm{~g}$ was observed for these samples, which was only partially compensated by the F-Factor ( 0.88$)$ correction. Evidently, the sorbent picked up one or more of the components from the NCAW that could not be easily rinsed out of the web. In this case, the actual sorbent mass would be lower than expected and a reduced $\mathrm{Cs}_{\mathrm{d}}$ would be calculated.

Previous column loading experiments in NCAW at 5.0E+04 Na/Cs (Brown et al. 1995c) have indicated a loading of between 80 and $90 \mathrm{CV}$ for the unirradiated SuperLig®644 resin. In the current experiment (Figure 3.4), it was estimated that only $21 \mathrm{CV}$ could be processed $\left(\lambda=\rho_{b} \times \mathrm{K}_{d}=0.347 * 60\right)$ for the SuperLig@644 membrane. Samples that were not exposed to NCAW demonstrated a greater performance $\left(\lambda=\rho_{b} \times K_{d}=0.347 * 300=104\right)$. It is likely that this difference is due to the additional 8-week exposure to the NCAW solution before the batch $\mathrm{K}_{d}$ experiment.

\subsubsection{Cs Batch Distribution as a Function of Irradiation Dose}

Cs batch $K_{d}$ results for samples of the SuperLig $® 644 / W W L$ membrane are displayed in Figure 3.5 as a function of irradiation dose. The data are displayed at a constant equilibrium $\mathrm{Na} / \mathrm{Cs}$ ratio of $1.0 \mathrm{E}+05$ (5.0E-05 $\mathrm{M} \mathrm{Cs}$ ). The chosen $\mathrm{Na} / \mathrm{Cs}$ ratio was entirely arbitrary but represents an approximate estimate of the Cs concentration expected in many of the Hanford waste tanks. The samples were irradiated with an external ${ }^{60} \mathrm{Co}$ source at $1.6 \mathrm{E}+06 \mathrm{Rad} \mathrm{hr}^{-1}$ in a variety of aqueous solutions. The maximum dose was 2.0E+09 Rad, which required nearly 8 weeks of exposure.

From the data, it is evident that the $\mathrm{K}_{\mathrm{d}}$ values are nearly constant for all solution conditions at exposures below 1.0E+08 Rad. A slight reduction in $\mathrm{K}_{d}$ is noted for the samples irradiated up to $2.0 \mathrm{E}+09$ Rad in distilled water and dilute nitric acid. However, this degradation appears to be minor when compared to the results for the material irradiated in air or NCAW. In these cases, a significant reduction in the measured $\mathrm{K}_{d}$ value occurred at exposures greater than $1.0 \mathrm{E}+08 \mathrm{Rad}$. For the air-irradiated sample, $\mathrm{K}_{\mathrm{d}}$ decreased more than an order of magnitude, from approximately 300 to less than $30 \mathrm{~mL} \mathrm{~g}^{-1}$. For the NCAW-irradiated sample, a reduction from $80 \mathrm{~mL} \mathrm{~g}^{-1}$ to less than $1 \mathrm{~mL} \mathrm{~g}^{-1}$ was observed. Degradation at these extreme conditions is not unexpected and has been observed previously for the SuperLig®644 and other organic resins (Brown et al. 1995a).

However, the reduction is minor considering that most organic materials display extreme degradation at these high exposures. The SuperLigß644/WWL web retained its physical form over the entire exposure range and was only slightly brittle at the highest doses (over 1.0E+09 Rad). These doses are based on 


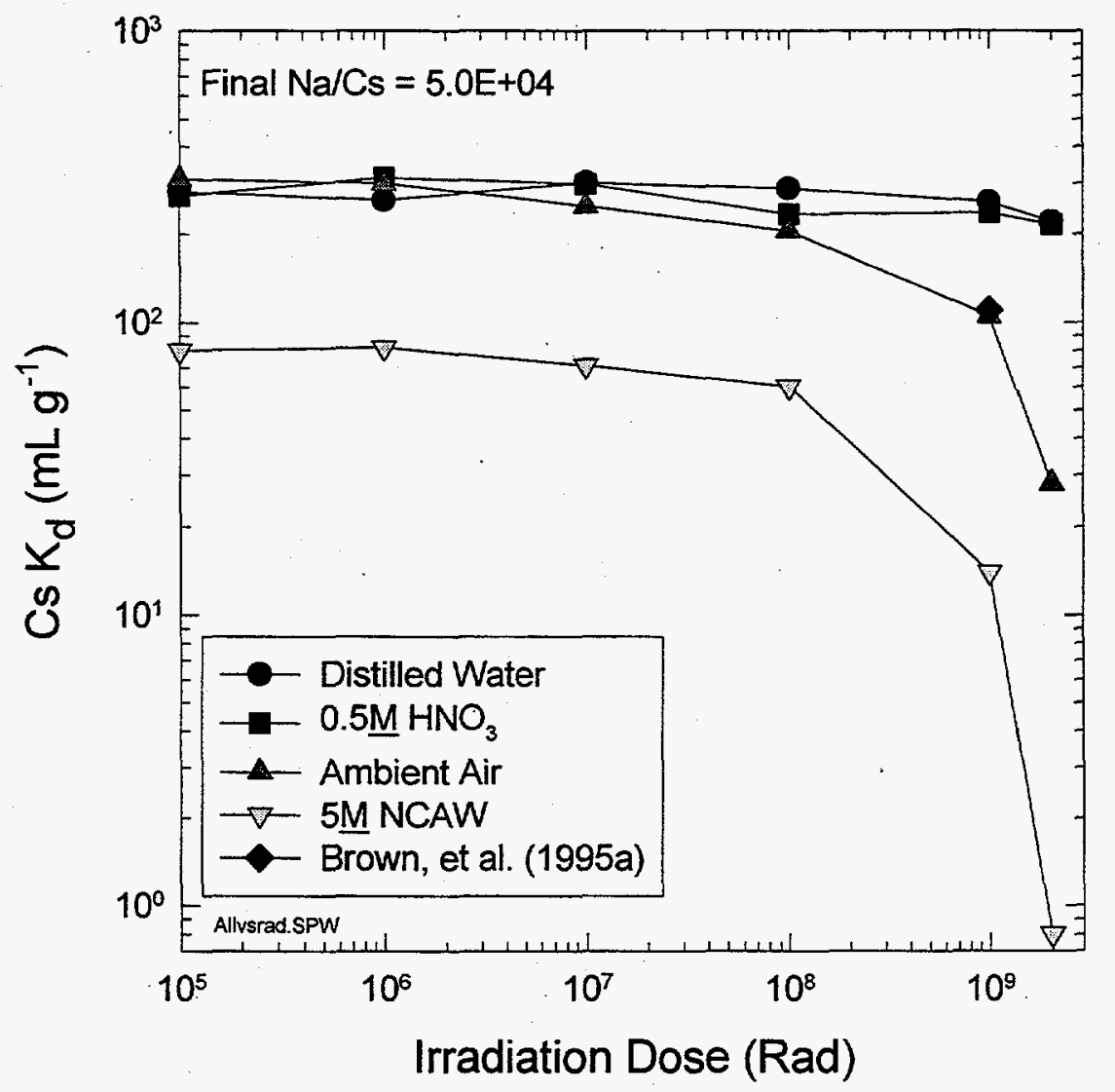

Figure 3.5. Cs Batch Distribution Ratio as a Function of Irradiation Dose at a Na/Cs Ratio of $1.0 \mathrm{E}+05$ for Samples of the SuperLigß644/WWL Web Irradiated in Various Solutions

irradiation with an external ${ }^{60} \mathrm{Co}$ source and may or may not accurately predict resin exposure during actual waste processing. However, Penwell et al. (1994) estimated that a maximum radiation field of $2.7 \mathrm{E}+05$ $\mathrm{Rad} \mathrm{hr}^{-1}$ would exist at the surface of an NCAW-loaded resorcinol-formaldehyde (R-F) ion exchange column. The NCAW solution is expected to contain the highest Cs concentration and therefore exhibit the highest radiation field. Assuming a loading cycle of 50 hours (e.g., full loading at $300 \mathrm{CV}$ and a process flowrate of $6 \mathrm{CV} \mathrm{hr}^{-1}$ ) and a total of 10 loading cycles before resin disposal, a conservative maximum for material exposure would be $1.4 \mathrm{E}+08 \mathrm{Rad}$. The time-averaged radiation dose would be approximately one-half this value since the resin is only fully loaded at the end of the cycle. Therefore, it is estimated that from 1 to 2 months of continuous operation would be required to reach the $1.0 \mathrm{E}+08 \mathrm{Rad}$ dose.

One interesting observation is that the NCAW-irradiated material consistently yields lower $\mathrm{K}_{\mathrm{d}}$ values than materials irradiated in other solutions. Even the unirradiated sample that was exposed to the NCAW simulant exhibited a much lower value $\left(80 \mathrm{~mL} \mathrm{~g}^{-1}\right)$ compared to the other solutions $\left(300 \mathrm{~mL} \mathrm{~g}^{-1}\right)$. This effect is attributed to the reduced chemical stability of the SuperLig@644 material in caustic solutions (Brown et al. 1995a). During the radiation testing, all samples were exposed to the respective solutions for 
the entire 8-week duration of the experiment. The samples were prepared before the start of the irradiation process and were irradiated in reverse order so that all of the materials would be removed simultaneously at the end of the test. Therefore, the SuperLig $(644 /$ WWL webs were exposed to the NCAW, distilled water, dilute nitric acid, and air for the entire 8-week irradiation period irrespective of the dose received. This method allows the separation of chemical degradation (solution exposure) from radiolytic degradation as well as nonsolution degradation (air exposure).

If the NCAW-irradiated samples had been freshly prepared such that the resin was only exposed to the NCAW solution during irradiation, one might observe degradation of the resin based on chemical and radiation damage and would not be able to separate the two effects. With these conditions, the chemical degradation of the SuperLig $\otimes 644 / W W L$ is clearly differentiated from the radiolytic stability. If the nonirradiated samples had been placed into the NCAW solution just before determination of the Cs $\mathrm{K}_{\mathrm{d}}$, one would expect that the $\mathrm{K}_{\mathrm{d}}$ data would be much closer to that measured for irradiation in ambient air (e.g., constant 250 to $300 \mathrm{~mL} \mathrm{~g}^{-1}$ between zero and $1.0 \mathrm{E}+08 \mathrm{Rad}$ ). No evaluation of resin storage methods (e.g., storage under nitrogen or other inert cover gas) was attempted.

Unfortunately, the data suggest that prolonged storage in a caustic solution will enhance chemical degradation of the resin. Due to safety considerations and the concern of organic-nitrate oxidation reactions, cation exchange resins are often converted to the $\mathrm{Na}$ form with $\mathrm{Na}$ hydroxide for storage. Historically, runaway organic-nitrate oxidation reactions have caused significant damage to ion exchange systems. For this reason, following elution with nitric acid it is recommended that the organic resin be converted to the $\mathrm{Na}$ form as quickly as possible.

\subsubsection{Conclusions}

The data are self-consistent and indicate the relative stability of the SuperLig®644/WWL membrane under a variety of chemical and radiolytic conditions. The material was irradiated in ambient air, distilled water, dilute nitric acid, and highly caustic tank waste simulant (NCAW). Following exposure from 0 to $2.0 \mathrm{E}+09 \mathrm{Rad}$, the material was evaluated for Cs uptake in a series of $5 \mathrm{M} \mathrm{Na}$ NCAW simulants with variable $\mathrm{Cs}$ concentrations. The following was concluded:

- Essentially no decrease in Cs selectivity or capacity $\left(\mathrm{K}_{d}\right)$ was observed during the irradiation of the SuperLig $® 644 / W W L$ membrane in distilled water or $0.5 \mathrm{M} \mathrm{HNO}_{3}$ up to a ${ }^{60}$ cobalt gamma irradiation total dose of 2.0E+09 Rad. The stability of the SuperLigß644/WWL membrane, as measured by the Cs $\mathrm{K}_{d}$ on a mass equivalence basis, is essentially equivalent to that of the SuperLig $\otimes 644$ resin in the absence of the WWL membrane.

- Essentially no decrease in Cs selectivity or capacity $\left(\mathrm{K}_{\mathrm{d}}\right)$ was observed during the irradiation of the SuperLig $844 / W W L$ membrane in 5 M NCAW or ambient air up to $1.0 \mathrm{E}+08 \mathrm{Rad}$.

- Following irradiation of the SuperLig $(644 / W W L$ membrane in either 5M NCAW or ambient air, the observed Cs $\mathrm{K}_{d}$ values decreased more than an order of magnitude between $1.0 \mathrm{E}+08$ and $2.0 \mathrm{E}+09$ $\mathrm{Rad}$. These high irradiation dose results portray upper bounding limits and should not be considered representative of typical ion exchange process conditions. 
- The Cs $\mathrm{K}_{\mathrm{d}}$ results for the SuperLigß644/WWL membrane irradiated in 5M NCAW were significantly lower than those results obtained in other solutions $\left(0.5 \mathrm{M} \mathrm{HNO}\right.$, distilled water, or ambient air). $\mathrm{K}_{\mathrm{d}} \mathrm{s}$ of approximately $80 \mathrm{~mL} \mathrm{~g}^{-1}$ were observed for the NCAW irradiated membrane and about $300 \mathrm{~mL} \mathrm{~g}^{-1}$ for irradiation in the other matrices. These results suggest that the material is less stable in the caustic NCAW solution than in the other matrices irrespective of the radiation exposure.

\subsection{Strontium Removal From N-Springs Groundwater}

\subsubsection{Summary}

PNNL, in conjunction with $3 \mathrm{M}$, AlliedSignal, $\mathrm{BHI}$, and $\mathrm{CH} 2 \mathrm{M}$ Hill conducted this study to assess the performance of the 3M PADU and the AlliedSignal Na titanate ( $\mathrm{NaTi}$ ) material for removing Sr from simulated and actual groundwater from the Hanford N-Springs Pump and Treat Demonstration Facility. The objective of these experiments was to determine the Sr-loading breakthrough profiles of actual and simulated groundwaters by ion exchange using a proprietary $3 \mathrm{M}$ engineered material (termed $\mathrm{NaTi} / \mathrm{WWL}$ ) in either disk or cartridge forms. Specific experimental objectives included 1) demonstrating the PADU as a viable cartridge test unit, 2) generating complete $\mathrm{Sr}, \mathrm{Ca}$, and $\mathrm{Mg}$ breakthrough curves for the cartridge and disk tests, 3) demonstrating Sr decontamination to meet drinking water standards, and 4) verifying simulant performance.

Experiments were completed using actual and simulated N-Springs groundwater and either 7-in. cartridges (100-g NaTi/WWL, 0.043-gallon bed volume (BV) each) or 2.5-cm disks (0.59-g NaTi/ WWL, $0.98-\mathrm{mL} \mathrm{BV}$ ) of NaTi/WWL web. Simulants were developed based on available analytical data. The laboratory disk studies were completed using the following process steps: 1) web preparation in caustic, 2) loading at neutral $\mathrm{pH}, 3$ ) elution with $\left.0.5 \mathrm{M} \mathrm{HNO}_{3}, 4\right)$ water wash, 5) caustic regeneration, and 6) water rinse. Laboratory and field cartridge studies were undertaken in the loading mode (steps 1 and 2) only. The following results were obtained in this study:

- BHI personnel successfully operated the 3M PADU at the N-Springs Pump and Treat Facility. Although minor system difficulties were encountered, the effectiveness of the NaTi/WWL membrane in removing $\mathrm{Sr}$ from Hanford groundwater was demonstrated.

- Laboratory testing of small-scale disks and process-scale cartridges using simulated and actual groundwater effectively predicted the field performance of the PADU. Approximately $1000 \mathrm{BV}$ of solution could be processed before reaching a $\mathrm{Sr} C / \mathrm{C}_{0}$ of 0.5 . The data suggest that accurate scale up of process performance data from laboratory disk tests to full-scale cartridge systems is likely. Complete loading breakthrough curves were generated for $\mathrm{Ba}, \mathrm{Ca}, \mathrm{Mg}$, and $\mathrm{Sr}$.

- The disk loading (mmole Sr per gram or milliliter of resin) of the NaTi/WWL was calculated to be 2.61E-03 mmol g $\mathrm{m}^{-1}\left(1.57 \mathrm{E}-03 \mathrm{mmol} \mathrm{mL}^{-1}\right)$ for the actual N-Springs water. Elution was accomplished with $0.5 \mathrm{M} \mathrm{HNO}_{3}$ at $7.5 \mathrm{BV} / \mathrm{min}$ and required $80 \mathrm{BV}$ to reach $0.1 \mathrm{Sr} \mathrm{C} / \mathrm{C}_{0}$. 
- During the field demonstration, the PADU cartridge loading $\left(\mathrm{mmol} \mathrm{g}^{-1}\right)$ was determined to be 2.84E-04, 8.68E-01, 7.58E-02, and 2.60E-03, for $\mathrm{Ba}, \mathrm{Ca}, \mathrm{Mg}$, and $\mathrm{Sr}$, respectively. In addition, $1.78 \mathrm{E}+00 \mathrm{mmol} \mathrm{Na} \mathrm{g}^{-1}$ was released during loading, effectively confirming the mass balance.

The Sr breakthrough curves described in this report were nearly identical irrespective of solution (simulated and actual groundwater), geometry of the ion exchange material (disks or cartridges), or material volume (single or multiple cartridges), and indicate an ability to mimic Sr ion exchange with the intelligent formulation of nonradioactive simulant solutions.

\subsubsection{Background}

Hanford's 100-N Area N-Springs water (from wells 199-N-106A, 199-N-14, and 199-N-75) is known to be contaminated with traces of radioactive ${ }^{90} \mathrm{Sr}$ and ${ }^{3} \mathrm{H}$. Other radionuclides and organic and inorganic species have been detected but generally exist at levels below federal drinking-water standards (Dirkes 1990; Hartman and Lindsey 1993). ${ }^{90} \mathrm{Sr}$ levels vary between 1000 and $2000 \mathrm{pCi} \mathrm{L}^{-1}$, depending upon the water table level. Tritium concentrations are normally about $60,000 \mathrm{pCi} \mathrm{L}^{-1}$. In addition, the groundwater contains high concentrations of nonradioactive $\mathrm{Sr}(0.13 \mathrm{ppm}), \mathrm{Ca}(30 \mathrm{ppm})$, and $\mathrm{Mg}(5 \mathrm{ppm})$, and their presence frustrates efforts to remediate the ${ }^{90} \mathrm{Sr}$ using ion exchange technologies. The major anionic component of the groundwater is carbonate.

The N-Springs Pump and Treat Demonstration Facility is currently processing groundwater from the $100-\mathrm{N}$ Area wells at $50 \mathrm{gpm}$ using conventional ion exchange technology. The present system consists of four columns, each capable of holding $65 \mathrm{ft}^{3}$ of a natural zeolite, clinoptilotite. Normally, three columns are connected in series, with the fourth held off-line for disposal and installation of the spent exchanger. The system is typically operated continuously at $50 \mathrm{gpm}$ for 2 weeks and then the lead column is removed from service. The column previously held in reserve is then placed in service at the end or trailing position, and solution processing is continued. Sr is removed by the ion exchanger to levels below federal drinking water standards of $40 \mathrm{pCi} \mathrm{L}^{-1}$. However, the process generates a large amount of solid radioactive waste. $\mathrm{BHI}$ operators and engineers are searching for methods to improve the process and reduce the amount of secondary waste.

\subsubsection{Experimental Approach}

The removal of $\mathrm{Sr}$ from actual and simulated groundwater using an engineered form of $\mathrm{Na}$ nonatitanate was investigated in three separate tests. In the first test, a small-scale laboratory disk loading experiment was completed at PNNL using actual N-Springs water containing approximately $1100 \mathrm{pCi} / \mathrm{L}$ ${ }^{90} \mathrm{Sr}$ that had been collected from well 199-N-106A on 11/1/95, 11:10 a.m. In the second test, a single cartridge loading experiment was completed at $3 \mathrm{M}$ using a simulated groundwater composition designed to mimic the N-Springs groundwater. The final test was completed at the N-Springs Pump and Treat Demonstration Facility on January 25, 1996, using the 3M PADU, a skid-mounted cartridge-based system operated by BHI personnel. 


\subsubsection{Test Parameters}

Table 3.2 compares the experimental parameters used in each of the three tests, and Table 3.3 compares the actual and simulated groundwater chemical compositions. Inductively coupled plasma (ICP) analysis of the nonradioactive $\mathrm{Sr}$ was used as an analytical method for the $3 \mathrm{M}$ simulant and N-Springs PADU cartridge tests. In addition, to confirm the ICP results for $\mathrm{Sr},{ }^{90} \mathrm{Sr}$ beta analysis was completed on selected samples obtained from the N-Springs PADU demonstration. For the PNNL disk test, radioactive

Table 3.2. Comparison of Experimental Test Conditions for the N-Springs PADU Demonstration, the PNNL Laboratory Disk Test, and the 3M Laboratory Cartridge Test

\begin{tabular}{|c|c|c|c|}
\hline Parameter & $\begin{array}{c}\text { PNNL Laboratory } \\
\text { Disk Test }\end{array}$ & $\begin{array}{l}3 \mathrm{M} \text { Laboratory } \\
\text { Cartridge Test } \\
\end{array}$ & $\begin{array}{c}\text { Actual Test } \\
\mathrm{N} \text {-Springs } \\
\end{array}$ \\
\hline Analytical Method & $\mathrm{GEA}^{85} \mathrm{Sr}$ & ICP & ICP and ${ }^{90} \mathrm{Sr}$ \\
\hline Sorbent Material & $\mathrm{NaTi}$ & $\mathrm{NaTi}$ & $\mathrm{NaTi}$ \\
\hline Sorbent Mass (g) & 0.593 & 100 & 300 \\
\hline Sorbent BV (gal, mL) & $0.982 \mathrm{~mL}$ & 0.043 gal & $0.129 \mathrm{gal}$ \\
\hline Sorbent Area $\left(\mathrm{cm}^{2}\right)$ & 4.91 & 680 & 2040 \\
\hline Number of Pleats & 0 & 13 & 39 \\
\hline Pleat Height $(\mathrm{cm})$ & 0 & 1.59 & 1.59 \\
\hline Pleat Length $(\mathrm{cm})$ & 0 & 16.5 & 16.5 \\
\hline Sorbent $(\%)$ & 0.72 & 0.72 & 0.72 \\
\hline Sorbent Particle $(\mu \mathrm{m})$ & 12.4 & 12.4 & 12.4 \\
\hline Sorbent Thickness $(\mathrm{cm})$ & 0.20 & 0.24 & 0.24 \\
\hline Solution Flow Rate $\left(\mathrm{mL} \mathrm{min}^{-1}\right)$ & 6.24 & 2870 & 13,700 \\
\hline Solution Flow Rate (BV $\mathrm{min}^{-1}$ ) & 6.35 & 17.7 & 28.1 \\
\hline Solution Flow Rate $\left(\mathrm{cm} \mathrm{min}^{-1}\right)$ & 1.27 & 4.21 & 6.72 \\
\hline Sorbent Lot \# & $92095-2$ & $\mathrm{NA}^{(a)}$ & NA \\
\hline Flow Rate (gpm) & 0.00165 & $0.6-0.76$ & 3.62 \\
\hline Flow $\left(\mathrm{mL} \min ^{-1} \mathrm{~g}^{-1}\right)$ & 10.5 & 28.7 & 45.7 \\
\hline
\end{tabular}


Table 3.3. Analytical Results for the Composition of 3M Simulant and Actual N-Springs Water

\begin{tabular}{|c|c|c|c|}
\hline \multirow{2}{*}{ Species } & \multicolumn{3}{|c|}{ Species Concentration $(\underline{\mathrm{M}})$} \\
\hline & PNNL Lab Test ${ }^{(a)}$ & 3M Simulant & $\mathrm{N}$-Springs Test ${ }^{(b)}$ \\
\hline $\mathrm{Ba}$ & $1.15 \mathrm{E}-07$ & $0.00 \mathrm{E}+00$ & $(1.12 \pm 0.03) \mathrm{E}-07 \mathrm{n}=18$ \\
\hline $\mathrm{Ca}^{\sim}$ & 7.39E-04 & $7.24 \mathrm{E}-04$ & $(7.28 \pm 0.07) E-04 n=19$ \\
\hline $\mathrm{K}$ & $5.29 \mathrm{E}-05$ & $5.12 \mathrm{E}-05$ & $(5.35 \pm N A) E-05 n=1$ \\
\hline $\mathrm{Mg}$ & $2.20 \mathrm{E}-04$ & $2.06 \mathrm{E}-04$ & $(2.16 \pm 0.02) E-04 n=19$ \\
\hline $\mathrm{Na}$ & $1.64 \mathrm{E}-04$ & $1.74 \mathrm{E}-04$ & $(2.61 \pm 0.13) E-04 n=19$ \\
\hline $\mathrm{P}$ & $3.45 \mathrm{E}-06$ & $0.00 \mathrm{E}+00$ & $(3.39 \pm 0.18) E-06 n=5$ \\
\hline $\mathrm{S}$ & $2.30 \mathrm{E}-04$ & $2.29 \mathrm{E}-04$ & $N A^{(c)}$ \\
\hline $\mathrm{Si}$ & 3.33E-04 & $0.00 \mathrm{E}+00$ & $(3.21 \pm 0.05) \mathrm{E}-04 \mathrm{n}=19$ \\
\hline $\mathrm{Sr}$ & $1.49 \mathrm{E}-06$ & $1.71 \mathrm{E}-06$ & $(1.49 \pm 0.02) E-06 n=19$ \\
\hline${ }^{90} \mathrm{Sr}$ & $1.10 \mathrm{pCi} \mathrm{mL}^{-1}$ & $0.00 \mathrm{E}+00$ & $(1.35 \pm 0.10) \mathrm{pCi} \mathrm{mL}^{-1} \mathrm{n}=3$ \\
\hline $\mathrm{Ca} / \mathrm{Sr}$ Ratio & $4.98 \mathrm{E}+02$ & $4.23 E+02$ & $(4.88 \pm 0.08) E+02 n=19$ \\
\hline \multicolumn{4}{|c|}{$\begin{array}{l}\text { (a) Sample collected from the N-Springs Well } 199-\mathrm{N}-106 \mathrm{~A} \text { by A. G. Rizzo of IT Hanford on } \\
11 / 1 / 95 \text { at } 11: 10 \text { a.m. } \\
\text { (b) Sample collected from the N-Spring Pump and Treat Facility by D. L. Bowers of BHI on } \\
11 / 25 / 96 \text { at 10:30 a.m. } \\
\text { (c) Not analyzed. }\end{array}$} \\
\hline
\end{tabular}

\footnotetext{
${ }^{85} \mathrm{Sr}$ tracer was added to the water and measured by gamma energy analysis (GEA). All material calculations were based on the mass of the entire NaTi/WWL web and did not account for the percentage of active particle in the web.

In general, the purpose of the laboratory tests was to estimate the Sr loading characteristics of the adsorbent material before conducting the actual N-Springs PADU demonstration. Therefore, an accurate comparison of the solution flow rate was not critical. However, the difference in flow rates between the three tests must be emphasized. The PNNL disk test was completed at $6.35 \mathrm{BV} / \mathrm{min}$, whereas the flow rates for the cartridge tests were much higher. The PADU was run at $28.1 \mathrm{BV} / \mathrm{min}$, while the $3 \mathrm{M}$ cartridge test was run at constant pressure (10 psig), and the flow rate varied from 17.7 to $14.0 \mathrm{BV} / \mathrm{min}$. The effect of flow rate on ion exchange breakthrough curves is well known (Kurath et al. 1994) and may affect the results presented in this report.
} 


\subsubsection{Preliminary Disk Tests}

The ion exchange material used in the preliminary PNNL laboratory tests consisted of a fine-powdered Na nonatitanate (NaTi) (AlliedSignal, Des Plaines, IL) entrapped in a proprietary web matrix developed by 3M (St. Paul, MN). The material (3M Lot \#92095-2) was cut into a 2.5-cm-diameter disk (0.2-cm-thick) with a leather punch and placed into a Millipore in-line disk filter holder, as shown in Figure 3.6. The ion exchange web was used in the form received from the manufacturer and was not chemically pretreated. The feed solution (N-Springs water from well 199-N-106A) was passed upwards through the web at $6.24 \mathrm{~mL} \mathrm{~min}^{-1}(6.35 \mathrm{BV} / \mathrm{min})$ and at ambient temperature $\left(25^{\circ} \mathrm{C}\right)$. The system pressure was measured upstream of the web, and the effluent downstream was discharged to either a sample or waste container at atmospheric pressure. After loading, the $\mathrm{Sr}$ was removed from the material by eluting with $0.5 \mathrm{M} \mathrm{HNO} \mathrm{HI}_{3}$ at $6.08 \mathrm{~mL} \mathrm{~min}^{-1}(6.19 \mathrm{BV} / \mathrm{min})$ and ambient temperature $\left(25^{\circ} \mathrm{C}\right)$. Following elution and in preparation for a second loading cycle, the web was flushed with distilled water, $50-\mathrm{mL} 2 \mathrm{M} \mathrm{NaOH}$, and a second distilled water rinse until the effluent reached $\mathrm{pH} 8$. The system was then left overnight, and the second load/elute cycle was initiated the following morning. All data described in this report are from the second cycle. Elution and/or repeated cycling of the disk was not necessary for the current systems evaluation and for determining loading predictions at the Hanford N-Springs, but was completed for future reference in case elution is necessary for additional applications of this technology.

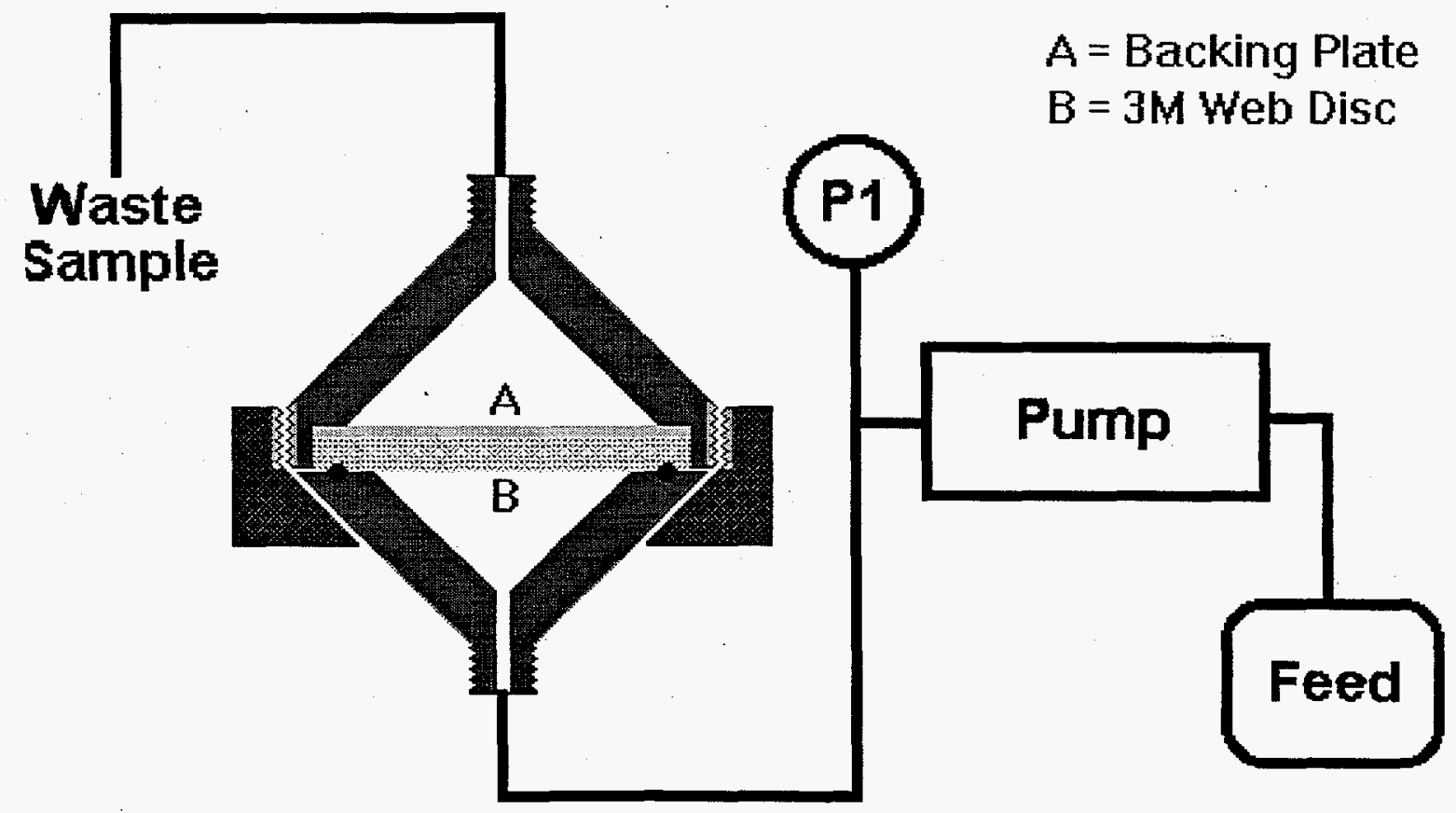

Figure 3.6. Schematic Diagram of the Laboratory Disk Filtration Apparatus 


\subsubsection{Preliminary Cartridge Tests}

The preliminary cartridge test was done to evaluate the $\mathrm{Sr}$ loading required to produce a full breakthrough curve for a 18-cm length NaTi cartridge before using the PADU skid unit to process N-Springs water. $3 \mathrm{M}$ personnel tested a single NaTi cartridge for the Sr loading characteristics before the entire lot of cartridges was delivered for the $\mathrm{N}$-Springs PADU field demonstration. The NaTi material was converted to the $\mathrm{Na}$ form by pretreating the intact cartridge with a flowing solution containing $0.1 \mathrm{M} \mathrm{NaOH}$ and

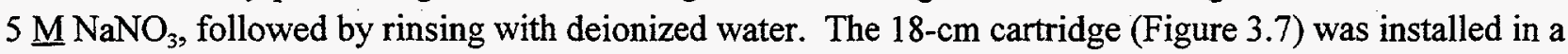
commercial filtration housing, and a simulated groundwater designed to mimic the actual N-Springs water was passed through the system at constant pressure and at a flow rate that varied from 0.76 to $0.60 \mathrm{gpm}$. Table 3.3 provides the exact composition of the groundwater simulant. The direction of solution flow was inward (radially) through the web material and out the top of the cartridge in the axial direction as shown in Figure 3.7. The flow rate varied between 17.7 and $14.0 \mathrm{BV} / \mathrm{min}$.

Throughout the test, a constant pressure drop of approximately 10 to 12 psig was maintained across the cartridge material. Temperature control during cartridge loading was not attempted but ambient temperature was $25^{\circ} \mathrm{C}$. Table 3.2 lists additional experimental conditions. Elution and/or repeated cycling of the cartridge during the field demonstration was not planned and therefore was not necessary for evaluating the overall system.

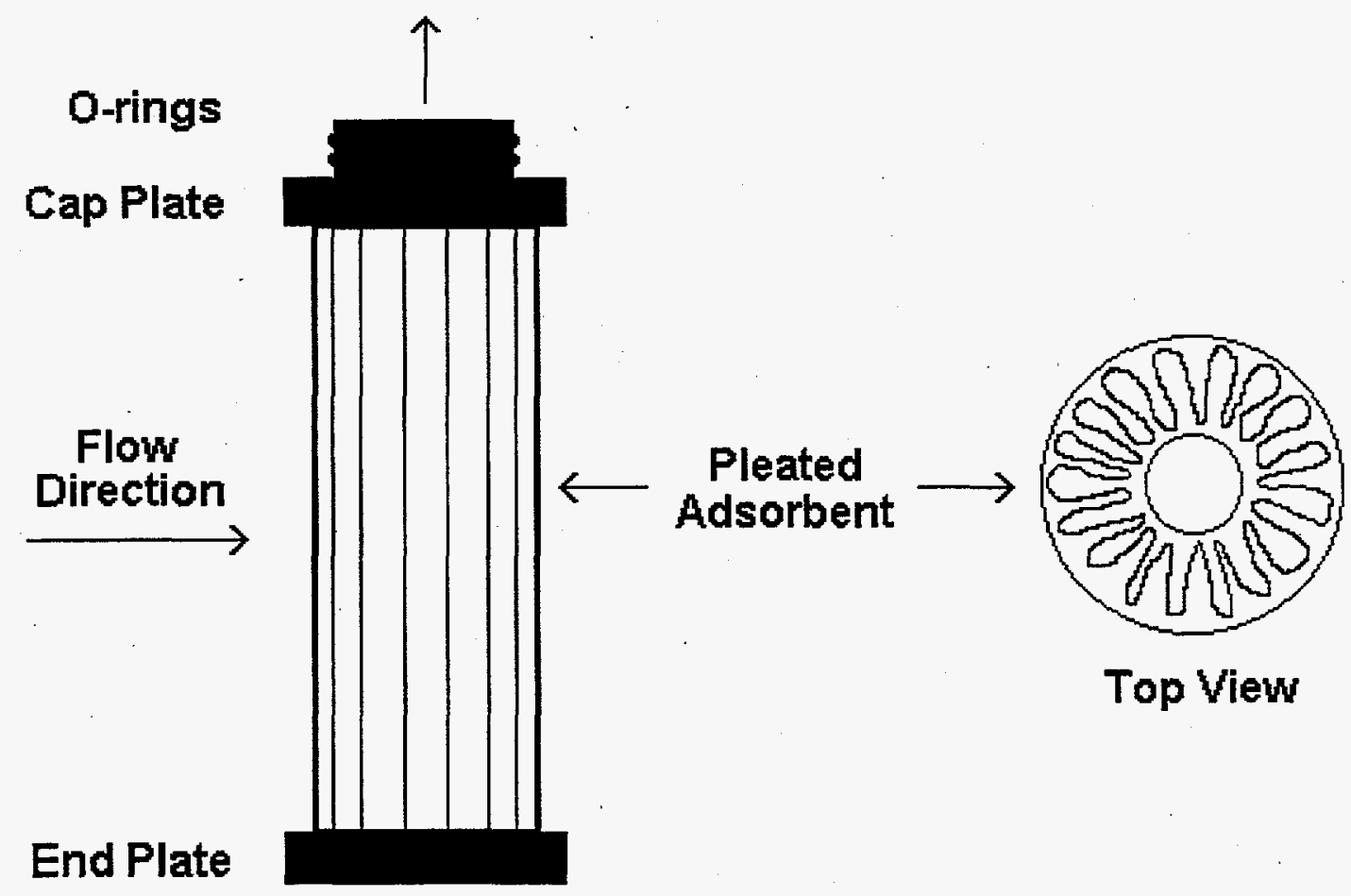

\section{Side View}

Figure 3.7. Schematic Diagram of the $3 \mathrm{M}$ Cartridge 


\subsubsection{N-Springs PADU Test}

The PADU is a skid-mounted, cartridge-based system designed to demonstrate the removal of various radionuclides from contaminated groundwater or other low-level process streams. The self-contained system is approximately $4 \times 5 \times 4$ feet and consists of three vessels, each of which contain multiple cartridges in parallel. Figure 3.8 shows a schematic diagram of the PADU system. Figure 3.9 is a photograph of the unit in operation at the N-Springs Pump and Treat Demonstration Facility.

The PADU cartridge size and number can vary, but for this demonstration, three $18-\mathrm{cm}$ cartridges per vessel were used. Two-stage pre-filtration capability (in the current experiment, $2-\mu \mathrm{m}[3 \mathrm{M}]$ and $0.1-\mu \mathrm{m}$ [Pall] commercial filters), pressure indicators, electronic valves, and all associated piping are included with the system. In addition, the unit is electronically controlled and can shut down automatically if overpressure conditions occur.

During normal operations, solution flows through two vessels in series, with the third vessel held offline in reserve. The system automatically switches the sequence of vessels based on a pre-programmed cycle time. In the first sequence, the first or leading vessel (\#1) is completely loaded with the radionuclide of interest, while the second or trailing vessel (\#2) polishes the remaining radionuclide from the system effluent. In the second sequence, flow is electronically switched so vessel $\# 2$ becomes the leading vessel and vessel \#3 is placed in service as the trailing or polishing vessel. At this point, vessel \#1 is taken
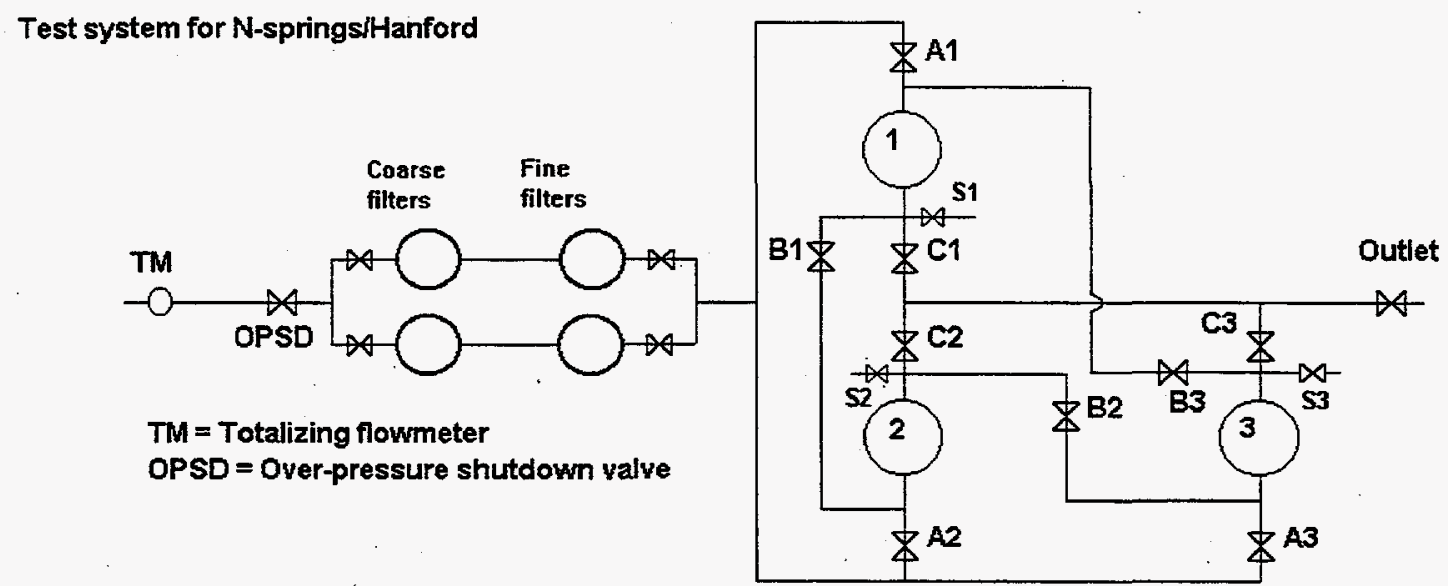

Valve sequencing for 3-cartridge absorber

$O$ denotes valve open, $C$ denotes valve closed.

A, B, \& C valves are electrically actuated $S$ valyes are manual and are for sampling

\begin{tabular}{|c|c|c|c|c|c|c|c|c|c|}
\hline \multirow{2}{*}{$\begin{array}{l}\text { Sequence } \\
\text { ID }\end{array}$} & \multicolumn{8}{|c|}{ Valve ID } & \\
\hline & $\overline{\mathrm{A1}}$ & T81 & CI & A2 & TE2 & $\mathrm{C}_{2}$ & A3 & E3 & TC3 \\
\hline $1: 1$ to 2.3 idle & 0 & 0 & C & C & C & $\mathrm{o}$ & C & C & c \\
\hline 2.2 to 3.1 idle & E & $\mathrm{C}$ & $\mathrm{C}$ & 0 & D & C & C & C & 0 \\
\hline 3,3 to 1,2 idle & E & C & to & C & c & C & 0 & 0 & $\vec{C}$ \\
\hline
\end{tabular}

CARTSYS7.BMP

Figure 3.8. Schematic Diagram of the 3M Process Absorber Development Unit (PADU) 


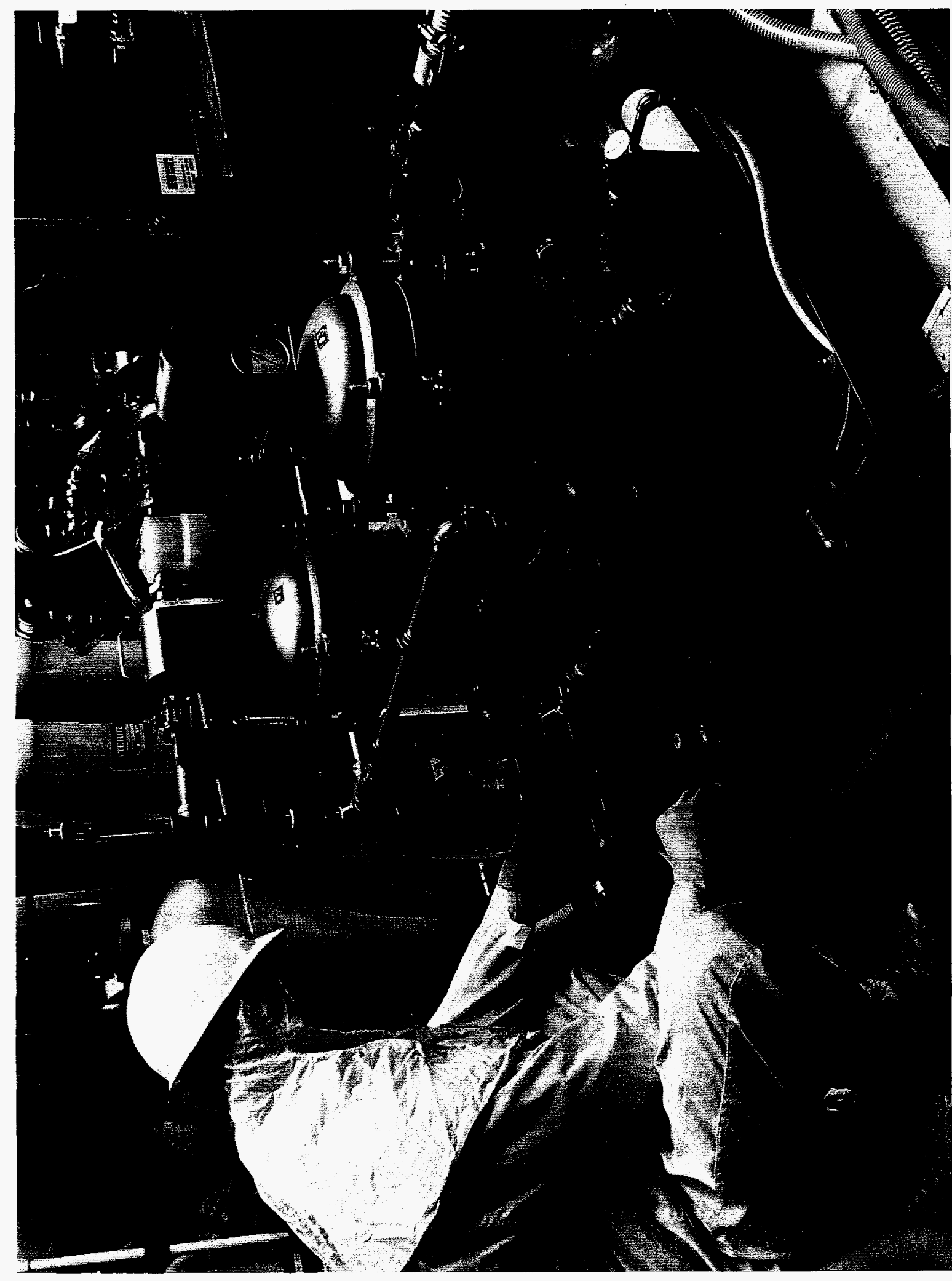

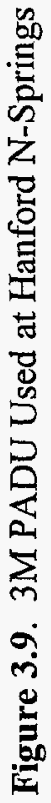


off-line and the loaded cartridges are manually removed for disposal. It is important to note that the system is designed as a demonstration unit for low-activity solutions and requires contact maintenance (e.g., cartridge removal by hand). The use of this system for highly radioactive solutions was not intended and is not recommended.

The PADU system was operated at ambient temperature and used a side-stream from the N-Springs Pump and Treat Demonstration Facility. Because the demonstration took place in January and involved water from the 199-N-106A well, the water temperature was substantially lower than it was in the previously described laboratory tests (see Sections 2.3 and 2.4). The system flow rate was approximately 3.6 gpm or $28.1 \mathrm{BV} / \mathrm{min}$., which was much faster than in the previous laboratory tests (see Table 3.2). The effect of temperature and flow rate on ion exchange breakthrough curves has been investigated previously (Kurath et al. 1994) and may affect the results presented in this report. In general, earlier breakthrough is observed at higher flow rates and later breakthrough is observed at lower temperature.

\subsubsection{Sr Loading Comparison}

Figure 3.10 shows results for the removal of $\mathrm{Sr}$ from simulated and actual $\mathrm{N}$-Springs water. The normalized $\mathrm{Sr}$ concentration $\left(\mathrm{Sr} \mathrm{C} / \mathrm{C}_{0}\right.$ ) is plotted against the BVs of solution passed through the NaTi web. For visual clarity, the data are plotted in the log-probability format. The typical sigmoidal or S-shaped loading breakthrough curve will appear linear when displayed in this manner (Buckingham 1967). The data are displayed in this format to facilitate comparison between the small-scale disk tests, the larger-scale cartridge tests, and the variety of analytical methods used to measure $\mathrm{Sr}$ concentration. For reference, Table 3.3 displays the initial concentration (approximately $1.5 \mathrm{E}-06 \mathrm{M} \mathrm{Sr}$ ) of $\mathrm{Sr}$ in the various feed solutions.

As shown in Figure 3.10, the $0.5 \mathrm{C} / \mathrm{C}_{0}$ breakthrough point corresponds to approximately 900,1000 , and $1000 \mathrm{BV}$ of solution passed through the NaTi web for the PNNL disk test, the $3 \mathrm{M}$ cartridge simulant test, and the PADU N-Springs demonstration, respectively. The $0.5 \mathrm{C} / \mathrm{C}_{0}$ point can be used as an estimate of the theoretical quantity of analyte that can be processed to fully load an ion exchanger. The assumption is valid if the wave shape of the loading curve is symmetric on either side of the $0.5 \mathrm{C} / \mathrm{C}_{0}$ point. At this point, one can assume that the quantity of radionuclide that has exited the column (e.g., broken through) is equivalent to the quantity that could still be loaded if the experiment were continued to $1.0 \mathrm{C} / \mathrm{C}_{0}$. Alternatively, one can integrate the amount of $\mathrm{Sr}$ exiting the column from the analytical data and back calculate the Sr loading.

From the data in Figure 3.10, it appears that an accurate estimate of the PADU operations was obtained using either a small-scale disk, single cartridge, or a groundwater simulant with the appropriate chemical composition. Interestingly, the results were not affected by the higher $\mathrm{Sr}$ concentration of the $3 \mathrm{M}$ simulant $(1.71 \mathrm{E}-06 \mathrm{M})$ as compared to the actual N-Springs water $(1.49 \mathrm{E}-06 \underline{\mathrm{M}})$. It is likely that the Ca concentration, which is nearly 500 times higher than the $\mathrm{Sr}$ concentration, is controlling the volume of solution that can be processed. 


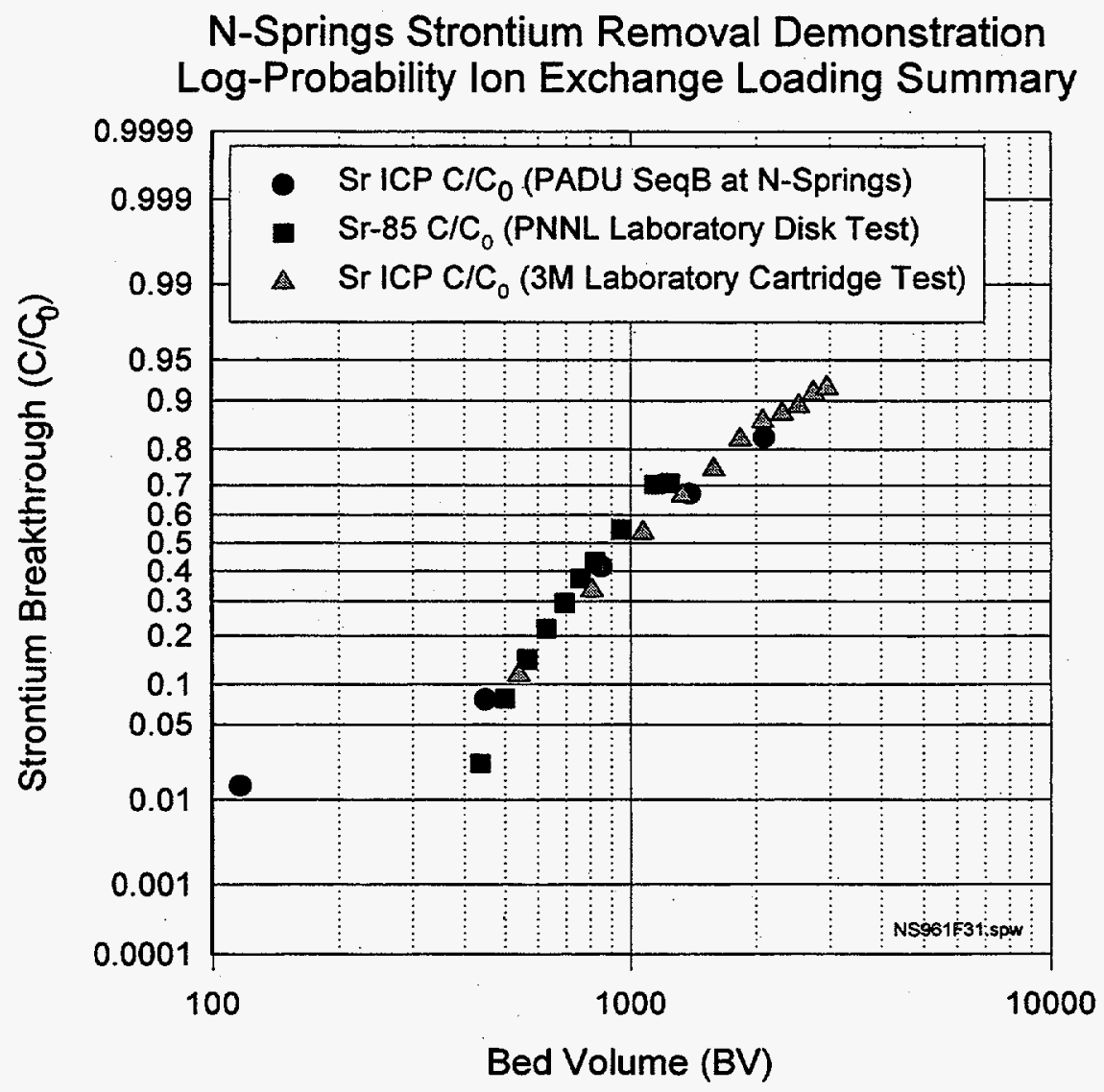

Figure 3.10. Comparison of Sr Breakthrough Curves for NaTi Disks and Cartridges in Simulated and Actual Groundwater from Hanford N-Springs

\subsubsection{Interferant Loading}

Figure 3.11 shows the $3 \mathrm{M}$ cartridge results for the removal of $\mathrm{Ca}, \mathrm{Mg}$, and $\mathrm{Sr}$ from the simulated $\mathrm{N}$-Springs solution. $\mathrm{Mg}$ is initially loaded on the NaTi material for the first $500 \mathrm{BV}$ but is displaced later in the loading sequence. The $\mathrm{Mg}$ concentration exceeds the input value between 500 and $1500 \mathrm{BV}$, indicating that the $\mathrm{Mg}$ is being eluted from the cartridge by another more strongly bound ion (e.g., $\mathrm{Ca}$ and/or $\mathrm{Sr}$ ). $\mathrm{Ca}$, however, is not displaced and is loaded on the NaTi in a manner similar to Sr. This same alkaline earth breakthrough behavior was noted previously (Herbst et al. 1995) for the NaTi material loaded with groundwater from the TAN at INEL. Since the concentration of $\mathrm{Ca}$ is approximately 500 times greater than that of $\mathrm{Sr}$, the $\mathrm{NaTi}$ becomes saturated with $\mathrm{Ca}$. Therefore, the majority of the material's capacity is filled with $\mathrm{Ca}$. Sr breakthrough is eventually observed even though the material exhibits a high selectivity for $\mathrm{Sr}$ over $\mathrm{Ca}$. It is interesting to note that the cartridge effluent $\mathrm{Sr}$ concentration does not completely return to the influent or feed value over the course of the experiment, suggesting that either Sr continues to load onto the $\mathrm{NaTi}$ material and additional solution could be processed given additional time, or the influent sample analysis $\left(\mathrm{C}_{0}\right)$ may be in error. 
$\mathrm{Ca}, \mathrm{Mg}$, Sr lon Exchange Loading Summary

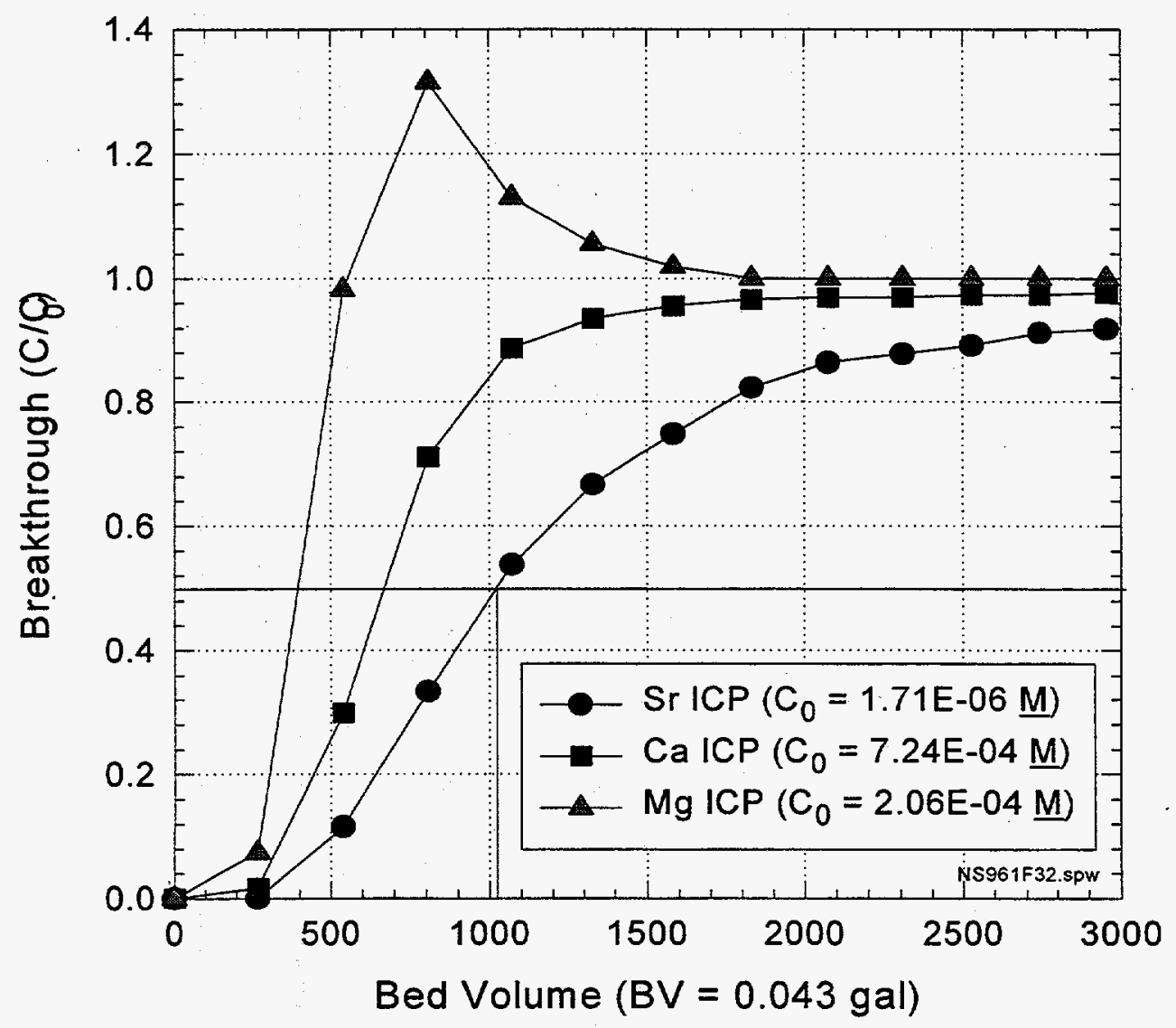

Figure 3.11. $\mathrm{Ca}, \mathrm{Mg}$, and $\mathrm{Sr}$ Breakthrough Curves for a Laboratory-Scale $\mathrm{NaTi}$ Cartridge in Simulated Groundwater from Hanford N-Springs

\subsubsection{PADU Demonstration}

Figures 3.3 and 3.4 show the results for the PADU demonstration. The PADU was evaluated through three load sequences, each containing two vessels in series and one cartridge change-out. Unfortunately, an ongoing operational failure prevented the system from loading two vessels in series. One or more of the cartridges in vessel $\# 2$ detached during system pressurization before the experiment began. Because of this problem, the cartridges never properly loaded and allowed unprocessed water to pass through the vessel throughout the entire test. When the unit electronically switched to the second sequence, this vessel became the lead vessel. At this point, solution passed untreated to the trailing vessel, forcing a premature loading of those cartridges. In effect, at no point during the experiment were there two fully functional vessels in series. 
The PADU system was designed to hold $25-\mathrm{cm}$ cartridges, not the $18-\mathrm{cm}$ cartridges. Because of the time constraints placed on the demonstration, $3 \mathrm{M}$ could not produce the larger cartridges on such short notice. In addition, a spacer capable of holding the smaller cartridges in place was thought to be unnecessary and potentially difficult to work with under radiological conditions. For these reasons, the system was delivered without the necessary spacers. During the preliminary system pressurization and functional testing, a large back pressure developed that evidently dislodged the cartridges from their position within the second vessel. The pressure drop across each vessel indicated a problem might exist, but the specific problem and its source could not be confirmed until the test had been completed.

The results displayed in Figure 3.12 depict the loading of $\mathrm{Ca}, \mathrm{Mg}$, and $\mathrm{Sr}$ on the three parallel cartridges contained in the trailing vessel (\#1) during the third PADU sequence. Sr removal data were collected using Sr ICP and ${ }^{90} \mathrm{Sr}$ beta counting. Note that the two $\mathrm{Sr}$ analyses are nearly identical, with the ${ }^{90} \mathrm{Sr}$ beta counting results only slightly below those of the $\mathrm{Sr}$ ICP. One possible reason for this difference could be a less than $100 \%$ collection efficiency during the ${ }^{90} \mathrm{Sr}$ analytical separation method. Note that the Sr breakthrough results displayed in Figure 3.12 are slightly better (i.e., shifted to higher volume) than those shown in Figure 3.10 because of a slightly reduced $\mathrm{Sr}$ concentration. $(1.0 \mathrm{vs} .1 .3 \mathrm{pCi} / \mathrm{mL})$ reaching the trailing vessel.

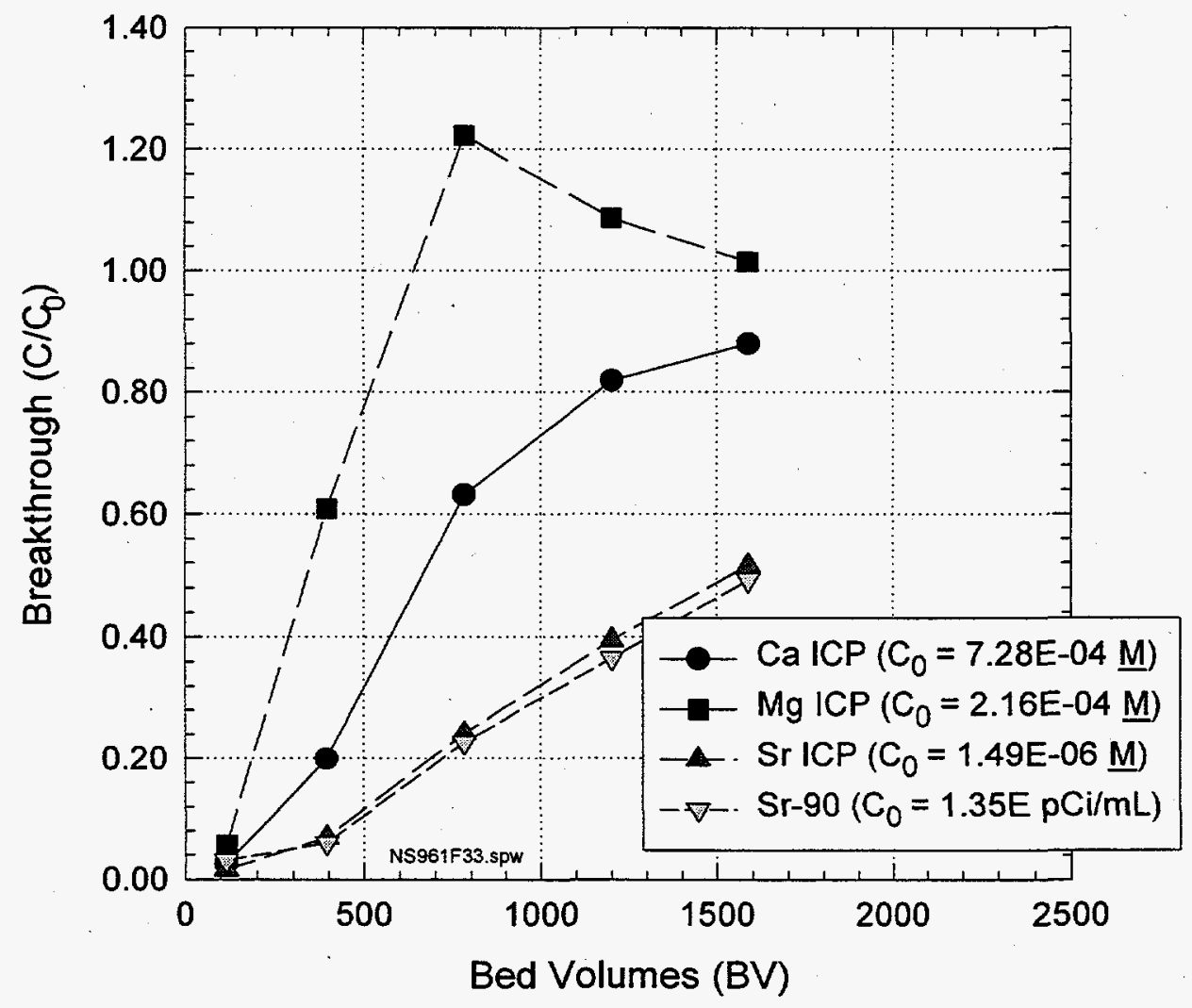

Figure 3.12. $\mathrm{Ca}, \mathrm{Mg}$, and $\mathrm{Sr}$ Breakthrough Curves for a NaTi Cartridge in Actual Groundwater During the Third Sequence of Hanford N-Springs PADU Demonstration 
The effect of the dislodged cartridge is evident in Figure 3.13. During the first sequence, the effluent from both vessel \#1 and \#2 show identical breakthrough, suggesting that the second vessel is ineffective. During the second sequence, vessel \#2 passes untreated water (constant $\mathrm{C} / \mathrm{C}_{0}=1$ ) to the third vessel, which loads to nearly $0.7 \mathrm{C} / \mathrm{C}_{0}$. At this point, the unit switched to the third sequence, and the effluent of vessel \#3 increased to nearly $0.9 \mathrm{C} / \mathrm{C}_{0}$. A slightly delayed breakthrough curve is observed for vessel \#1 since that vessel is in the trailing position and is subjected to a slightly reduced $\mathrm{Sr}$ concentration.

\subsubsection{Ion Exchange Loading Capacity}

The total cation loading of the NaTi/WWL web material was evaluated by determining the influent and effluent $\mathrm{Ba}, \mathrm{Ca}, \mathrm{Mg}$, and $\mathrm{Sr}$ concentrations as a function of time and volume over the course of the PADU field demonstration at the Hanford N-Springs. The elemental loadings are displayed in Table 3.4 as

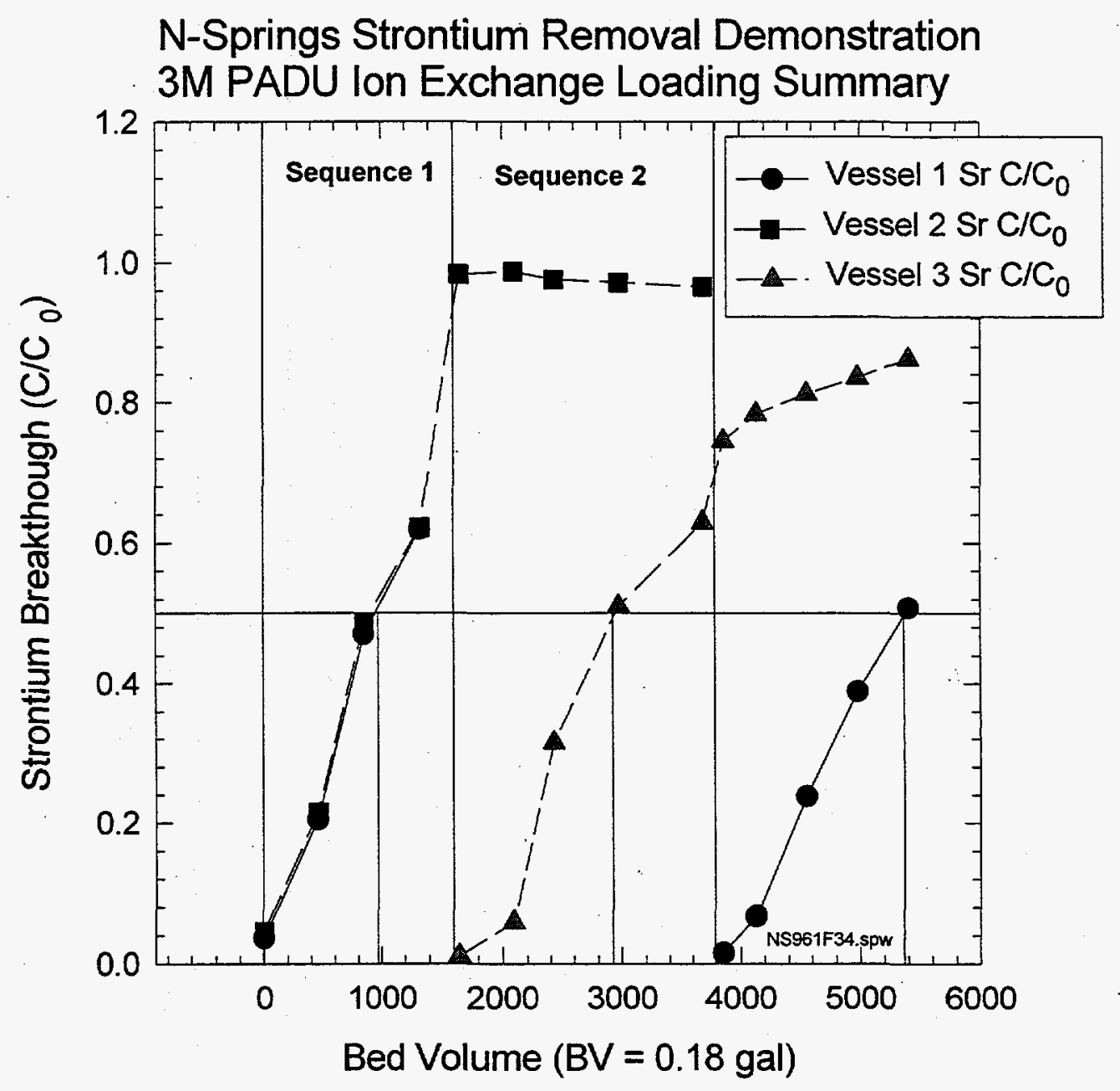

Figure 3.13. Sr Breakthrough Curves During PADU Sequencing at Hanford N-Springs 
Table 3.4. Alkaline Metal Loading of the PADU NaTi/WWL Web with Actual N-Springs Water

\begin{tabular}{|c|c|c|c||}
\hline \multirow{2}{*}{ Species } & \multicolumn{3}{|c|}{ Elemental Loading of NaTi/WWL Web } \\
\cline { 2 - 4 } & $\mathrm{mmol} / \mathrm{g}$ & $\mathrm{mmol} / \mathrm{mL}$ & Capacity (\%) \\
\hline \hline $\mathrm{Ba}$ & $2.84 \mathrm{E}-04$ & $1.75 \mathrm{E}-04$ & $0.03 \%$ \\
\hline $\mathrm{Ca}$ & $8.68 \mathrm{E}-01$ & $5.34 \mathrm{E}-01$ & $91.66 \%$ \\
\hline $\mathrm{Mg}$ & $7.58 \mathrm{E}-02$ & $4.67 \mathrm{E}-02$ & $8.01 \%$ \\
\hline $\mathrm{Sr}$ & $2.60 \mathrm{E}-03$ & $1.75 \mathrm{E}-03$ & $0.30 \%$ \\
\hline Total (mmol) & $9.47 \mathrm{E}-01$ & $5.83 \mathrm{E}-01$ & $100.00 \%$ \\
\hline Total (meq) & $1.89 \mathrm{E}+00$ & $1.17 \mathrm{E}+00$ & $100.00 \%$ \\
\hline $\mathrm{Na}$ & $-1.78 \mathrm{E}+00$ & $-1.10 \mathrm{E}+00$ & $-94.25 \%$ \\
\hline Balance (meq) & $1.09 \mathrm{E}-01$ & $6.70 \mathrm{E}-02$ & $-11.51 \%$ \\
\hline
\end{tabular}

a function of NaTi/WWL web mass $(\mathrm{mmol} / \mathrm{g})$ and volume $(\mathrm{mmol} / \mathrm{mL})$. From these data, it is clear that the majority of the $\mathrm{NaTi} / W W L$ web capacity $(9.47 \mathrm{E}-01 \mathrm{mmol} / \mathrm{g}$ ) is loaded with $\mathrm{Ca}(8.68 \mathrm{E}-01 \mathrm{mmol} / \mathrm{g})$ under the conditions of the test. Based on an assumed total capacity of $9.47 \mathrm{E}-01 \mathrm{mmol} / \mathrm{g}$, only $0.30 \%$ of the material's capacity is loaded with $\mathrm{Sr}$. $\mathrm{Ba}, \mathrm{Ca}$, and $\mathrm{Mg}$ occupy $0.03 \%, 91.66 \%$, and $8.01 \%$ of the total, respectively.

The capacity and loading data described above assume that the NaTi/WWL material removes only the detected alkaline earth metals (i.e., $\mathrm{Ba}, \mathrm{Ca}, \mathrm{Mg}$, and $\mathrm{Sr}$ ) from the $\mathrm{N}$-Springs water. No other metals loading was measured using the ICP analytical data because the data were below the detection limit. However, the Na ICP data displayed in Table 3.4 provide an additional check on the NaTi/WWL capacity. To preserve the ionic charge balance, for each divalent (e.g., $\mathrm{Ca}^{2+}$ ) cation loaded, two monovalent (in this case, $\mathrm{Na}^{+}$) cations must be expelled from the material. During the PADU demonstration, $1.78 \mathrm{E}+00 \mathrm{mmol}$ $\mathrm{Na}$ was released per gram of $\mathrm{NaTi} / \mathrm{WWL}$. In comparison, a total of $9.47 \mathrm{E}-01 \mathrm{mmol}(1.89 \mathrm{E}+00 \mathrm{meq})$ of divalent cations were loaded. These data provide a secondary check and indicate that the majority of the ion exchange has been taken into account. However, it is important to note that these data are reported on the basis of the entire NaTi/WWL web mass or volume and not the mass or volume of the NaTi material alone.

Using the data from Table 3.4 and the equilibrium concentration of $\mathrm{Ba}, \mathrm{Ca}, \mathrm{Mg}$, and $\mathrm{Sr}$ in the actual $\mathrm{N}$-Springs water (Table 3.3) the ion exchange selectivity coefficient $\left(\mathrm{K}_{\mathrm{c}}\right)$ can be calculated from the following equation 


$$
K_{c}=\frac{C_{B}^{v_{A}} \times C_{S A}^{v_{B}}}{C_{A}^{v_{B}} \times C_{S B}^{v_{A}}}
$$

where $C_{A}$ and $C_{B}$ are the equilibrium concentrations of ions $A$ and $B$ in solution, $C_{S A}$ and $C_{S B}$ are the equilibrium concentrations of ions $A$ and $B$ on the ion exchange material, and $V_{A}$ and $V_{B}$ are the ion valancies of each ion, respectively. $K_{c}$ is a measure of the preference of an ion exchange material for one ionic species (A) over another (B) and takes into account the concentrations of each ion in solution. In the actual N-Springs water, the calculated selectivity of $\mathrm{Sr}$ over $\mathrm{Ba}, \mathrm{Ca}$, and $\mathrm{Mg}$ is $0.569,2.57$, and 29.7, respectively.

\subsubsection{Conclusions}

Sr removal from simulated and actual N-Springs well water was demonstrated using an AlliedSignal $\mathrm{NaTi}$ material engineered into a web adsorbent cartridge developed by $3 \mathrm{M}$. Laboratory tests were completed using a $2.5-\mathrm{cm}$ disk and a $18-\mathrm{cm}$ cartridge. The laboratory tests effectively predicted the loading breakthrough curve expected for the multiple cartridge/multiple vessel PADU. In every test, approximately $1000 \mathrm{BV}$ of solution was passed through the $\mathrm{NaTi}$ material before reaching $0.5 \mathrm{C} / \mathrm{C}_{0}$. This was the case irrespective of solution (simulated or actual), material geometry (disks or cartridges), or material volume (single or multiple cartridges). The $\mathrm{NaTi}$ material was shown to remove $\mathrm{Ba}, \mathrm{Ca}, \mathrm{Mg}$, and $\mathrm{Sr}$ from the N-Springs groundwater matrix. Based on these experiments, the following observations and conclusions are made:

- The 3M PADU was operated successfully by BHI personnel at the N-Springs Pump and Treat Demonstration Facility. Although minor system difficulties were encountered, the effectiveness of the $\mathrm{NaTi}$ WWL membrane for removing Sr from Hanford groundwater was demonstrated.

- Laboratory testing of small-scale disks and process-scale cartrìdges using simulated and actual groundwater effectively predicted the field performance of the PADU. Approximately $1000 \mathrm{BVs}$ of solution could be processed before reaching a $\mathrm{Sr} C / \mathrm{C}_{0}$ of 0.5 . These data suggest that accurate scale-up of process performance data from laboratory disk tests to full-scale cartridge systems is likely. Complete loading breakthrough curves were generated for $\mathrm{Ba}, \mathrm{Ca}, \mathrm{Mg}$, and $\mathrm{Sr}$.

- The disk loading (mmole Sr per gram or milliliter of resin) of the NaTi/WWL material was calculated to be $2.61 \mathrm{E}-03 \mathrm{mmol} / \mathrm{g}(1.57 \mathrm{E}-03 \mathrm{mmol} / \mathrm{mL})$ for the actual N-Springs water. Elution was accom-

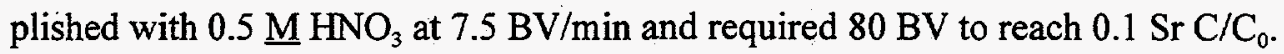

- During the field demonstration, the PADU cartridge loading $(\mathrm{mmol} / \mathrm{g})$ was determined to be $2.84 \mathrm{E}-04$, 8.68E-01, 7.58E-02, and 2.60E-03 for $\mathrm{Ba}, \mathrm{Ca}, \mathrm{Mg}$, and $\mathrm{Sr}$, respectively. In addition, $1.78 \mathrm{E}+00 \mathrm{mmol}$ $\mathrm{Na} / \mathrm{g}$ was released during loading, confirming the mass balance. 
Additional testing is needed to evaluate this material over a wider range of solution conditions and to compare its performance to other potential Sr removal candidates.

\subsection{5-N-Reactor Basin Water Decontamination Using Ion Exchange}

\subsubsection{Summary}

In collaboration with personnel from $\mathrm{BHI}$, a demonstration of the $3 \mathrm{M}$ web technology for the removal of radioactive $\mathrm{Cs}$ and $\mathrm{Sr}$ from 105-N-Reactor Basin water was completed. Water from the 105-N-Reactor Basin was processed through the $3 \mathrm{M}$ PADU at $1 \mathrm{gpm}$ for $\mathrm{Cs}$ removal and $2 \mathrm{gpm}$ for $\mathrm{Sr}$ removal. During the demonstration, two separate tests were conducted, a Sr removal test using two 7 in. Na titanate (NaTi) cartridges in each of three vessels, and a Cs removal test using a single 7-in. K cobalt hexacyanoferrate ( $\mathrm{CoHex}$ ) cartridge in each of three vessels. Each cartridge contained approximately 100 grams of active adsorbent particle entrapped in a proprietary (WWL) membrane.

Preliminary analytical data from the Environmental Analytical Laboratory indicate that Cs was removed to below the level of detection. The requested level of detection was less than $40 \mathrm{pCi} / \mathrm{mL}$, which corresponds to the federal drinking water standards for ${ }^{137} \mathrm{Cs}$. During the first sequence, more than 380 gallons ( 7200 absorber BVs) of N-Basin water was passed through the first Cs absorber cartridge with no detectable breakthrough observed. However, during the second sequence with a separate cartridge, $2 \%$ breakthrough was noted after 310 gallons ( $5900 \mathrm{BVs}$ ). The reason for the anomalous breakthrough is not known but may indicate a defective cartridge.

The Sr removal results are similar to the preliminary laboratory test results and suggest that only 900 absorber BVs can be processed before $50 \%$ breakthrough is observed. High levels of $\mathrm{Ca}$ and nonradioactive $\mathrm{Sr}$ in the 105-N-Reactor Basin are responsible for this result.

\subsubsection{5-N-Reactor Basin Background}

Hanford's 100-N Area 105-N-Reactor Basin fuel storage pool contains one million gallons of nearly pure water contaminated with trace quantities of radioactive ${ }^{137} \mathrm{Cs},{ }^{90} \mathrm{Sr},{ }^{60} \mathrm{Co}$, and minor quantities of ${ }^{154,155} \mathrm{Eu},{ }^{241} \mathrm{Am}$, and ${ }^{3} \mathrm{H}$. The basin contains about 32 curies of dissolved ${ }^{90} \mathrm{Sr}$ at a concentration of $8.4 \mathrm{Ci} / \mathrm{L}$, and 7.3 curies of dissolved ${ }^{137} \mathrm{Cs}$ at a concentration of $1.92 \mathrm{Ci} / \mathrm{L}$. ${ }^{60} \mathrm{Co}$ is present as suspended solids and can be removed by simple filtration. Except for tritium, no other dissolved radionuclides are present in concentrations exceeding $0.0053 \mathrm{Ci} / \mathrm{L}$. The basin water contains only minimal amounts of nonradioactive species (part per million levels of chloride, bromide, nitrate, and sulfate with a total conductivity of $300 \mu \mathrm{mho}$ ).

The Hanford Federal Facility Agreement and Consent Order (Tri-Party Agreement) Milestone M-16-01E-T2 has a date of September 30, 1996 requiring "Initiate pretreatment and removal of all N-Reactor fuel storage basin waters pursuant to the N-Reactor Deactivation Program Plan (WHC 1993d)." $\mathrm{N}$-Basin dewatering is on the critical path for overall deactivation of N-Reactor by March 1997. 


\subsubsection{Decontamination Requirements}

Present plans include removal of debris, hardware, algae and sediment from the basin followed by pretreatment (filtration), and then removal of $\mathrm{N}$ Basin water. Completion of water removal will be by September 30,1996. Because of the relatively high amount of radioactivity from dissolved species in the water, treatment is required before final discharge. As discussed in report BHI-00647, 105 N-Basin and Emergency Dump Basin Liquid Effluent Treatment (Dec. 1995), the recommended method of removing the water from the $\mathrm{N}$-Basin is to use pretreatment to reduce the radioactive inventory sufficiently for acceptance of the water at the Effluent Treatment Facility (ETF) in the 200 East Area. However, another treatment alternative is worth considering in case the ETF is not available to meet the schedule or additional pretreatment is needed to reduce the inventory of radioactive species to be handled at the ETF.

Demonstrating that another feasible treatment alternative is available could be of potential value for clean up of other fuel basins at Hanford. Such a demonstration could also be of use at other DOE sites and non-DOE nuclear power plants. The current process is being designed with the goal of removing Cs and Sr to below drinking water standards, which will likely require a decontamination factor of close to one million.

The goal of this experiment is to determine the $\mathrm{Cs}$ and $\mathrm{Sr}$ batch distribution coefficients for several ion exchange materials including cobalt hexacyanoferrate ( $\mathrm{CoHex}$ ) produced by $3 \mathrm{M}$, crystalline silicotitanates and TIE-96 produced by UOP, pillared biotite micas and Na nonatitanate (NaTi) produced by AlliedSignal, pharmacosiderite and phlogopite micas produced by TAMU, SuperLigß644 (SL-644) produced by IBC and to compare these results to those obtained for commercially available materials under similar conditions (e.g., R-F produced by Boulder Scientific and Amberlite IRC-718, IRC-76, Duolite C-467, and CS- 100 produced by Rohm and Haas).

\subsubsection{Experimental Approach}

The work described in this experiment involves the determination of the $\mathrm{Cs}, \mathrm{Sr}$, and Co loadings for several ion exchange materials in N-Basin water (Table 3.5). Because the chemical composition of most solutions ( $\mathrm{pH}$, concentration, constituents, etc.) can affect the amount of radionuclide removal, much of the testing was completed with an actual sample of $\mathrm{N}$-Basin water. However, to evaluate the radionuclide loading over a wide range of concentrations, several simulated solutions were tested.

\subsubsection{Material and Solution Selection}

Materials that are currently available and under consideration for the N-Basin radionuclide removal demonstration include cobalt hexacyanoferrate (CoHEX), crystalline silicotitanates (CSTs), TIE-96, pillared biotite, pharmacosiderite, and phlogopite micas, Na nonatitanate (NaTi), SuperLigß644 (SL-644), resorcinol-formaldehyde resin (R-F), Amberlite IRC-718 and IRC-76, and Duolite C-467 and CS-100. 
Table 3.5. N-Basin Simulant Composition

\begin{tabular}{|c|c|c||}
\hline \multirow{2}{*}{ Species } & \multicolumn{2}{|c|}{ Species Concentration } \\
\cline { 2 - 3 } & $\mathrm{mol} / \mathrm{L}$ & $\mathrm{mg} / \mathrm{L}$ \\
\hline $\mathrm{Al}$ & $2.892 \mathrm{E}-05$ & 0.78 \\
\hline $\mathrm{B}$ & $2.627 \mathrm{E}-03$ & 28.40 \\
\hline $\mathrm{Ba}$ & $2.270 \mathrm{E}-05$ & 3.12 \\
\hline $\mathrm{Ca}$ & $8.333 \mathrm{E}-04$ & 33.40 \\
\hline $\mathrm{Cs}$ & Variable & Variable \\
\hline $\mathrm{K}$ & $6.400 \mathrm{E}-05$ & 2.50 \\
\hline $\mathrm{Mg}$ & $2.900 \mathrm{E}-05$ & 0.70 \\
\hline $\mathrm{Na}$ & $1.619 \mathrm{E}-03$ & 37.21 \\
\hline $\mathrm{Sr}$ & $4.450 \mathrm{E}-06$ & 0.39 \\
\hline $\mathrm{H}^{+}$ & $1.200 \mathrm{E}-03$ & 1.21 \\
\hline $\mathrm{CO}_{3}$ & $1.080 \mathrm{E}-03$ & 64.81 \\
\hline $\mathrm{Cl}$ & $1.213 \mathrm{E}-03$ & 43.00 \\
\hline $\mathrm{F}$ & $6.320 \mathrm{E}-06$ & 0.12 \\
\hline $\mathrm{NO}$ & $8.900 \mathrm{E}-06$ & 0.55 \\
\hline $\mathrm{SO}_{4}$ & $1.395 \mathrm{E}-04$ & 13.40 \\
\hline
\end{tabular}

\subsection{Cs Decontamination of Hanford Tank 241-SY-101 Waste}

\subsubsection{Summary}

A small-column Cs ion exchange removal demonstration was completed using actual tank waste from Hanford tank 241-SY-101. The waste had been allocated to an organic destruction and analysis program that required $\mathrm{Cs}$ removal to reduce radiation exposure. The column testing was completed in a shielded hot cell facility at PNNL (325 Building), and the extent of the ion exchange material efficiency (radionuclide and nonradionuclide loading) was determined by periodic analysis of the column effluent. Approximately $520 \mathrm{~mL}$ of tank $241-\mathrm{SY}-101$ supernate diluted to $3.81 \pm 0.36 \underline{\mathrm{M}} \mathrm{Na}$ was passed through a 1-cm-diameter 10.8-mL column of an inorganic zeolite (IE-96) at $5.48 \mathrm{CV} / \mathrm{hr}$. Analytical samples were collected every hour and analyzed for chemical and radiochemical metal species. A partial Cs breakthrough curve was generated, and the $0.5 \mathrm{C} / \mathrm{C}_{0}$ point was estimated to be $60 \mathrm{CV}$, as was expected from 
previous simulant data. The Cs deficient effluent was returned to the organic destruction program. Although the zeolite IE-96 currently is not considered as a baseline material for removing Cs from Hanford tank waste, the decontamination process required an inorganic material that would not remove Sr. In addition, the experiment was completed as a comparison to a FY95 test using the previous baseline organic resin (CS-100).

\subsubsection{Objectives}

The primary objective of this subtask is to determine the loading of $\mathrm{Cs}, \mathrm{Sr}$, TRUs, and various nonradioactive interferant metals on a commercially available inorganic Cs exchanger (e.g., zeolite IE-96 produced by UOP) using actual alkaline supernate from Hanford tank 241-SY-101. These results will be compared to those obtained for other ion exchange materials under similar conditions.

A secondary objective of these tests is to effectively decontaminate a small volume (ca. $500 \mathrm{~mL}$ ) of actual HLW by removing ${ }^{137} \mathrm{Cs}$ so that additional experiments can be conducted outside of the hot cell facility. The solution was transferred to a radiological fume hood for a separate organic analysis/ destruction program. Removal of radioactive Cs by an inorganic ion exchange material was necessary to minimize the impact on the organic content of the waste.

\subsubsection{Methods and Rationale}

In FY 1995, using actual and simulated wastes from tanks 241-SY-101 and 241-SY-103, Brown et al. (1995) completed a Cs removal demonstration using the baseline CS-100 organic resin in a 1-cm-diameter 12-mL ion exchange column. Previous experimental work completed before FY 1995 for Cs recovery included bench-scale $(\mathrm{CV}=200 \mathrm{~mL})$ ion exchange loading and elution experiments and small-scale (15-mL sample volumes) batch distribution tests $(\mathrm{Cs} \mathrm{Kd}$ ) for numerous ion exchange materials (e.g., CS-100, R-F SuperLig) in various simulated alkaline waste matrices (NCAW, DSSF, and Complexant Concentrate). Because of the cost and limited availability of actual radioactive waste, most of the previous experiments were completed using simulated solutions for batch and column testing.

Due to the limited volume of actual HLW available for the current experiment, the size of the ion exchange column and the material had to be chosen carefully. A single 10-mL column of IE-96 was selected in order to meet the objectives of the test given the impact of organic resin degradation on the organic content of the waste and the minimal amount of waste volume available.

\subsubsection{Test Solution Selection}

The supernatant solution tested was selected based entirely on availability of the 241-SY-101 tank waste. It is important to note that the actual waste is not soluble at room temperature and must be diluted before processing in an ion exchange process. The solution contains a significant amount of aluminum, which requires that the dilution be completed with $2 \mathrm{M} \mathrm{NaOH}$ instead of pure water.

When diluted to $5 \underline{\mathrm{M}} \mathrm{Na}$, the solution compositions of the actual 241-SY-101 waste resembles the previously formulated NCAW simulant in terms of $\mathrm{Na}, \mathrm{Cs}$, and K concentration (Bray et al. 1993; Brown 
et al. 1995; Kurath et al. 1994). Based on the analysis of these researchers, it is likely that the previous Cs ion exchange results in NCAW may accurately predict the behavior of various Cs ion exchange materials in the current actual waste tests.

\subsubsection{Material Selection}

The removal of radioactive Cs by column ion exchange is considered to be the baseline pretreatment process for cleanup of a majority of the HLW currently stored at Hanford. Several materials are capable of removing Cs from highly alkaline solutions including organic ion exchange resins (CS-100 and R-F), inorganic zeolites, (IE-95, IE-96, TIE-96) and other materials (Crystalline Silico-Titanates (CSTs) and SuperLig®644). Any of these materials could have been used to meet the Cs DF requirement; however, IE-96 was chosen because the decontaminated solution was to be analyzed and tested for organic compounds and organic destruction methods. Therefore, any contact with organic ion exchange materials could have potentially contaminated the waste with resin degradation products. In addition, the IE-96 Cs loading is effectively matched to the volume of waste available.

\subsubsection{Estimation of Column Size}

The ion exchange CV must be matched to the volume of solution to be processed and can be estimated from the composition and volume of actual waste available using previous Cs batch $\mathrm{K}_{d}$ data (Brown et al. 1996; Kurath et al. 1994). As discussed in Section 3.4, the lambda value is an estimation of the number of $\mathrm{CV}$ of waste solution that can be processed to achieve a total theoretical loading (the $0.5 \mathrm{C} / \mathrm{C}_{0}$ breakthrough point).

For IE-96 at $5 \underline{\mathrm{M}} \mathrm{Na}$ and an equilibrium $\mathrm{Na} / \mathrm{Cs}$ ratio value of $1.0 \mathrm{E}+05$, the lambda value is approximately $40 \mathrm{CV}$ (Kurath et al. 1994). To exceed the $0.5 \mathrm{C} / \mathrm{C}_{0}$ point and obtain a more complete Cs breakthrough curve, approximately $25 \%$ greater volume should be used $(50 \mathrm{CV})$. Assuming that $100 \%$ of the actual waste volume will be passed through the ion exchange resin bed, one can calculate the optimum column or bed volume. Assuming $500 \mathrm{~mL}$ of waste is available, the IE-96 column bed volume should be $10 \mathrm{~mL}$ to achieve a breakthrough curve to $0.7 \cdot \mathrm{C} / \mathrm{C}_{0}$.

Based on these assumptions, the diluted waste solution was passed through a single 10.8 -mL column of IE-96 at $5.48 \mathrm{CV} / \mathrm{hr}$. The total time to load the material was estimated to be 9 hours with analytical samples taken every 60 minutes. Unfortunately, the solution was diluted more than originally anticipated, which affected the extent of Cs breakthrough that was achieved.

\subsubsection{Cs Loading}

The Cs loading breakthrough is displayed in Figure 3.14 in the log-probability format. The data are normalized to the initial Cs concentration $\left(79.1 \mathrm{KmCi} \mathrm{mL}^{-1}\right)$ of the diluted waste. The data demonstrate the poor Cs loading characteristics of the IE-96 under the conditions tested. Initial $(\sim 1 \%)$ breakthrough is observed for the first sample $(6 \mathrm{CV})$, and $10 \%$ breakthrough is noted by $20 \mathrm{CV}$. The waste solution was exhausted before a full breakthrough curve could be generated, and only $0.4 \mathrm{C} / \mathrm{C}_{0}$ was achieved. The $0.5 \mathrm{C} / \mathrm{C}_{0}$ point was estimated by extrapolation to be approximately $60 \mathrm{CV}$. 


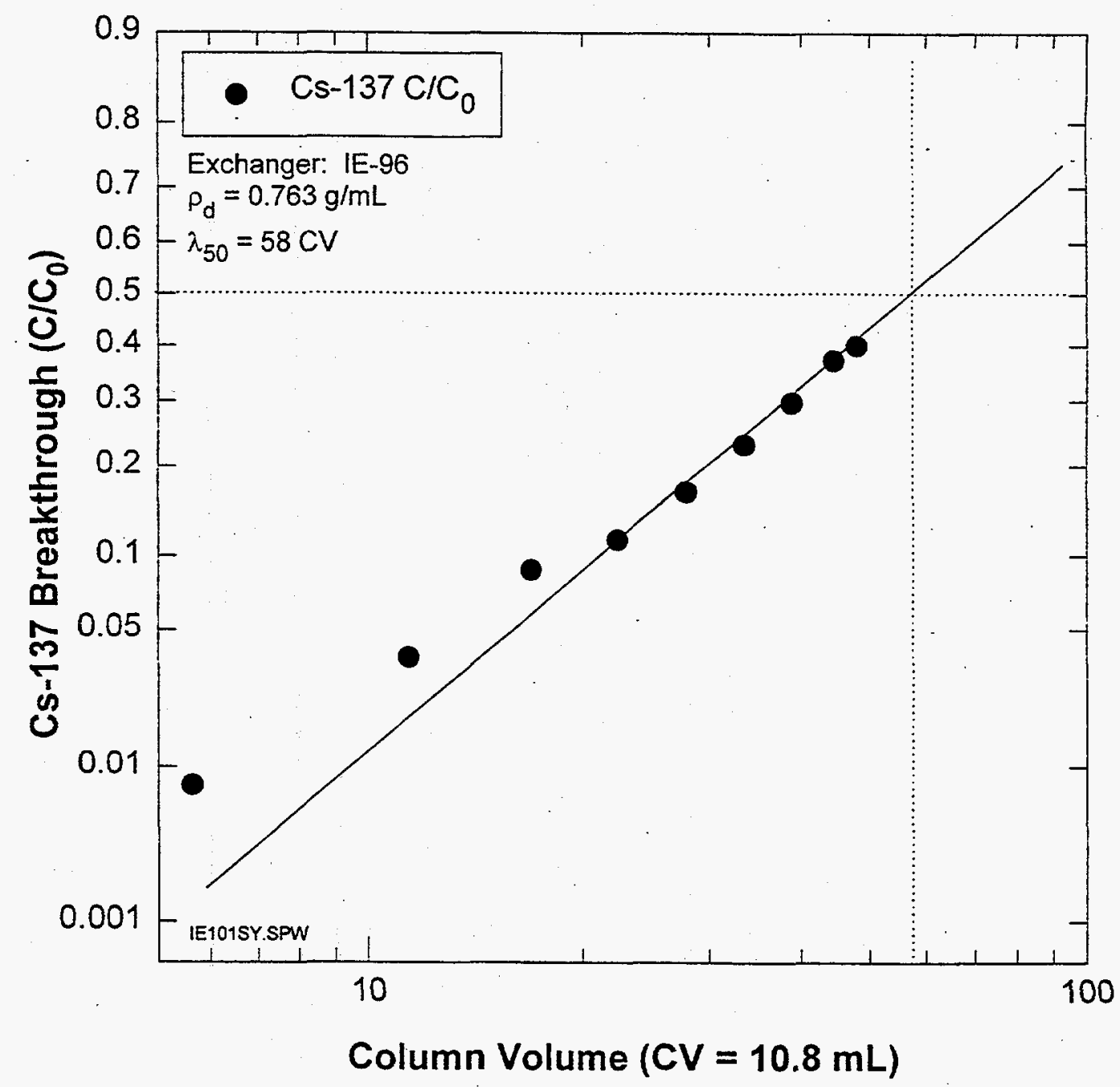

Figure 3.14. Cs Breakthrough Curves During Loading of IE-96 with Actual 101-SY Tank Waste

Generation of the incomplete breakthrough curve is a result of unexpected dilution of the waste before the ion exchange process. The analytical results received after the experiment had been completed indicate that the $\mathrm{Na}$ concentration of the diluted waste was much less than anticipated $(3.81 \pm 0.36$ instead of $5 \underline{\mathrm{M}})$. The effect of waste dilution on Cs ion exchange using NCAW simulants has been well characterized by Kurath et al. (1994) and Bray et al. (1992). Extrapolating the simulant data to $3.84 \mathrm{M} \mathrm{Na}$, the $0.5 \mathrm{C} / \mathrm{C}_{0}$ point can be estimated by extrapolation to be $60 \mathrm{CV}$, which is exactly what is found using the actual waste in the current experiment. The solution must have been accidentally diluted much more than was originally planned.

\subsubsection{Interferant Loading}

The column effluent samples were analyzed for additional radioactive and nonradioactive components other than Cs in order to evaluate the loading of other interferant species. Transuranics were determined by direct total alpha analysis. Sr was determined by two methods, ICP-AES and chemical separation 
followed by beta counting. ${ }^{99} \mathrm{Tc}$ was determined by ICP-MS and chemical separation followed by beta counting. In addition, various metallic species ( $\mathrm{Al}, \mathrm{As}, \mathrm{B}, \mathrm{Ba}, \mathrm{Ca}, \mathrm{Cd}, \mathrm{Cr}, \mathrm{Cu}, \mathrm{Fe}, \mathrm{K}, \mathrm{Li}, \mathrm{Mg}, \mathrm{Mn}, \mathrm{Mo}, \mathrm{Na}$, $\mathrm{Ni}, \mathrm{P}, \mathrm{Pb}, \mathrm{Se}, \mathrm{Si}, \mathrm{Sr}, \mathrm{Zn}$, and $\mathrm{Zr}$ ) were measured by ICP-AES.

The total alpha analysis revealed very little information due to the limited quantity of material present and the relatively high detection limits of the analytical method. The total alpha content was below the reported detection limit in all cases, varying from less than $0.02 \mathrm{KmCi} \mathrm{mL}^{-1}$ for the unprocessed feed to less than $0.09 \mathrm{nCi} \mathrm{mL}^{-1}$ for the first column effluent sample. For comparison, the NRC Class A limit for a transuranic waste is $10 \mathrm{nCi} \mathrm{mL} L^{-1}$.

The $\mathrm{Sr}$ data were somewhat scattered but indicate relatively little removal. The beta counting results suggest that between 70 and $80 \%$ of the ${ }^{90} \mathrm{Sr}$ is removed during the first several samples. Sr in the column effluent increases during the last four samples, ending at greater than $50 \%$ breakthrough $\left(0.51 \mathrm{C} / \mathrm{C}_{0}\right)$. The trend in the data indicates that $\mathrm{Sr}$ is removed by IE-96 to a certain extent. Unfortunately, the counting statistics are rather poor, with errors approaching $50 \%$. The ICP data are widely scattered and within ten times the detection limit. Although a similar trend is observed for the last four samples, the first three samples have a greater $\mathrm{Sr}$ concentration than the feed. One explanation for the conflicting results would be nonradioactive impurity Sr initially present on the IE-96 exchanger that is exchanging with the radioactive

${ }^{90} \mathrm{Sr}$ to achieve equilibrium.

Although the ICP data are very close to the detection limits in most cases, the IE-96 exchanger appears to remove trace quantities of $\mathrm{Ba}, \mathrm{Cd}, \mathrm{Cr}, \mathrm{Fe}, \mathrm{Mg}, \mathrm{Mn}$, and $\mathrm{Zr}$ from the actual 241-SY-101 tank waste. The results are tabulated in Table 3.6.

\subsubsection{Ion Exchange Loading Capacity}

As might be expected for a relatively nonselective material, the effective Cs loading of the IE-96 is relatively low under the conditions tested. The $520-\mathrm{mL}$ of diluted solution contained approximately $1.33 \mathrm{E}-02 \mathrm{mmol}$ of Cs. About $1.12 \mathrm{E}-02 \mathrm{mmol}$ of $\mathrm{Cs}$ was captured by the ion exchange material while $2.10 \mathrm{E}-03 \mathrm{mmol}$ of $\mathrm{Cs}$ exited the column. Thus, the total loading was only $1.35 \mathrm{E}-06 \mathrm{~mol}$ of Cs per gram of IE-96 exchanger.

\subsubsection{Conclusions}

The inorganic ion exchange material (IE-96) was effective at removing Cs from the actual 241-SY-101 tank waste without contaminating the solution with foreign organic material from resin degradation. $\mathrm{Sr}$ uptake, in addition to uptake of other trace elements, was also noted. Based on extrapolation of the breakthrough data, approximately $60 \mathrm{CV}$ could be processed before reaching $0.5 \mathrm{C} / \mathrm{C}_{0}$. 
Table 3.6. Elemental Composition of Column Effluent During Loading of IONSIV ${ }^{\mathrm{TM}}$ IE-96 with Hanford Tank 241-SY-101 Waste

\begin{tabular}{|c|c|c|c|c|c|c|c||}
\hline \multirow{2}{*}{$\begin{array}{c}\text { Sample } \\
\text { Number }\end{array}$} & \multicolumn{7}{|c|}{ Species Concentration $(\mu \mathrm{g} / \mathrm{mL})$} \\
\cline { 2 - 9 } & 1.2 & 1.9 & 269 & 35 & 72 & 4.8 & 4.1 \\
\hline \hline Feed & $<1.0$ & $<1.5$ & 102 & 12 & 15 & $<0.5$ & $<2.5$ \\
\hline SY-2 & $<1.0$ & $<1.5$ & 88 & 15 & 21 & $<0.5$ & $<2.5$ \\
\hline SY-3 & $<1.0$ & $<1.5$ & 99 & 64 & 20 & 0.8 & $<2.5$ \\
\hline SY-4 & $<1.0$ & $<1.5$ & 76 & 13 & 20 & $<0.5$ & $<2.5$ \\
\hline SY-5 & $<1.0$ & $<1.5$ & 77 & 13 & 19 & 0.6 & $<2.5$ \\
\hline SY-6 & $<1.0$ & $\mathrm{Cr}$ & $\mathrm{Mg}$ & $\mathrm{Zn}$ \\
\hline SY-7 & $<1.0$ & $<1.5$ & 75 & 14 & 22 & $<0.5$ & $<2.5$ \\
\hline SY-8 & $<1.0$ & $<1.5$ & 73 & 15 & 22 & $<0.5$ & $<2.5$ \\
\hline SY-9 & 1.2 & $<1.5$ & 73 & 14 & 22 & 0.5 & $<2.5$ \\
\hline SY-10 & 1.3 & $<1.5$ & 75 & 16 & 23 & 0.5 & $<2.5$ \\
\hline \hline
\end{tabular}




\title{
4.0 Testing and Development of Novel Inorganic Ion Exchangers for Groundwater
}

\author{
J. E. Amonette and X. -B. Chen, PNNL
}

This section describes 1) development and testing of several surfactant-modified anion-exchange materials for removal of $\mathrm{Tc}$ and chromate from groundwater, 2) testing of Na-titanate cation exchangers for removal of $\mathrm{Sr}$ from alkaline $\mathrm{HLW}$ simulant, and 3) development and testing of tunnel-structure manganese-oxide cation exchangers for removal of radium from groundwater.

\subsection{Surfactant-Modified Anion [Tc(VII), Cr(VI)] Exchangers in Simulated Groundwater}

Several surfactant-modified materials were developed and/or tested for the removal of aqueous anionic contaminants from groundwater. The ultimate goal of the study was to evaluate the kinetics and equilibrium sorption and desorption chemistry of these materials primarily for the removal of pertechnetate ion $\left(\mathrm{TcO}_{4}^{-}\right)$from a groundwater matrix. The materials studied include surfactant-modified samples of zirconium oxide, silicon oxide, and both natural and synthetic zeolites.

\subsubsection{Surfactant-Modified Zirconium Oxide}

\subsubsection{Introduction}

Although Tc can be produced in nature by spontaneous fission of ${ }^{238} \mathrm{U}$, its major sources stem from testing of nuclear weapons and operation of nuclear fuel-cycle facilities (Luykx 1986). These human activities, along with their related discharge of low-level radioactive wastes, have led to the release of significant amounts of $\mathrm{Tc}$, primarily as the long-lived isotope ${ }^{99} \mathrm{Tc}$, into the environment and to the contamination of surface- and groundwater systems. The behavior of ${ }^{99} \mathrm{Tc}$ in the environment is of considerable concern because of its long half-life $\left(2.15 \times 10^{5} \mathrm{yr}\right)$ and high mobility in soils and sediments. Tc is a multivalent element and can exist in aqueous solution in the oxidation states III, IV, $\mathrm{V}$, and VII. Under oxidizing conditions, $\mathrm{TcO}_{4}{ }^{-}$is the primary $\mathrm{Tc}$ species and is very mobile. A strong need exists for ion exchangers that can selectively remove $\mathrm{Tc}$ from aqueous solutions and nuclear-waste streams.

Cationic surfactants have been used widely to form ultrathin films on the surfaces of clays and other inorganic materials to enhance sorption capacity and/or selectivity of the surfaces for nonionic organic contaminants from aqueous solution (Boyd et al. 1988; Wagner et al. 1994; Brown and Burris 1996). Recently, it was reported that the sorption affinities of zeolites and zirconium oxide $\left(\mathrm{ZrO}_{2}\right)$ for inorganic oxyanions also could be greatly promoted by cationic-surfactant modification (Haggerty and Bowman 1994; Bray et al. 1995).

The cationic surfactant Aliquat $\$ 336$ is a mixture of trialkylmethylammonium [alkyl $=\mathrm{C}_{8}$ and $\mathrm{C}_{10}$, mainly $\mathrm{C}_{8}$ (i.e., caprylyl)] quaternary amines, which has been applied successfully to remove anions (e.g., 
chromate) from aqueous solution by solvent extraction (Salazar et al. 1992, Galan et al. 1994; Alonso et al. 1994). Because it is very stable in alkaline solution (Mizelli and Bart 1994), it constitutes a promising reagent for separation of pertechnetate from tank waste and contaminated groundwater. In this study, a $\mathrm{ZrO}_{2}$ powder was first treated with Aliquat $(336$. The treated powder was then tested for its behavior in separation of pertechnetate from aqueous solution. The sorption and desorption behaviors were compared to that of a strong-base polyvinylpyridine anion-exchange resin (Reillex ${ }^{\mathrm{TM}} \mathrm{HPQ}$ ), which is the best exchanger known for $\mathrm{TcO}_{4}^{-}$. Chromate $\left(\mathrm{CrO}_{4}{ }^{2-}\right)$ was investigated as a crude analog of $\mathrm{TcO}_{4}^{-}$because, in addition to being a contaminant of concern, it is nonradioactive and easily analyzed by spectrophotometric means.

\subsubsection{Experimental}

Materials. The zirconium oxide and Aliquat $@ 336$ used were obtained from the $3 \mathrm{M}$ Corporation (St. Paul, MN) and Henkel Corporation (Tucson, AZ), respectively. The Reillex ${ }^{\mathrm{TM}}$ was produced by Reilly Industries, Inc., Indianapolis, $\mathbb{N}$. The Aliquat ${ }^{\circledR 3} 36$ was in its chloride form. These and other reagent-grade chemicals used in the study were used as-received without further treatment and purification. De-ionized water was used throughout the experiments.

Preparation and Characterization of Aliquat $\$ 336-\mathrm{ZrO}_{2}$. The $\mathrm{ZrO}_{2}$ was mixed with an amount of the Aliquat (dissolved in methanol) equal to $10 \mathrm{wt} \%$ of the $\mathrm{ZrO}_{2}$. The well-mixed slurry was then airdried at room temperature. The $\mathrm{ZrO}_{2}$ mineralogy before and after the treatment was examined by X-ray diffraction (XRD), using a Philips X-ray diffractometer (APD 3520, Co-Ka X-rays) in an attempt to determine its effect on the $\mathrm{ZrO}_{2}$ crystal structure. External surface area was determined by sorption of $\mathrm{N}_{2}$ gas at different pressures using an RXM-100 apparatus (Advanced Scientific Designs Inc.) and extrapolation to full surface coverage using the BET isotherm equation. The thermal stability of the $\mathrm{ZrO}_{2}$ materials was investigated using a combined thermal analyzer (SDT 2960, TA Instruments), which generated a combination of thermogravimetric (TGA) and differential-thermal (DTA) analysis curves over a temperature range of $25^{\circ}$ to $1000^{\circ} \mathrm{C}$. Cation-exchange capacity (CEC) was determined for untreated $\mathrm{ZrO}_{2}$ using the method of Polemio and Rhoades (1977). In this determination, the concentrations of cations and anions were determined using inductively coupled plasma-atomic emission spectrometry (ICP-AES) and ion chromatography (IC), respectively.

Sorption Experiments. Batch sorption studies were conducted in triplicate in a simulated groundwater matrix ( $2 \mathrm{mM} \mathrm{NaHCO}_{3}, 4 \mathrm{mM} \mathrm{CaCl}$ ) at room temperature (RT) and $\mathrm{pH} \sim 7$. Initial concentrations of $\mathrm{TcO}_{4}{ }^{-}$and $\mathrm{Cr}(\mathrm{VI})$ were $4.5 \underline{\mathrm{nM}}$ and $20 \mu \mathrm{M}$, respectively. The Tc concentration is comparable to levels seen at the low-level-waste treatment facility of WVNS. Both treated and untreated $\mathrm{ZrO}_{2}$ were tested for their sorption capacities. In some instances, $\mathrm{H}_{2} \mathrm{O}_{2}$ was added to maintain oxidizing conditions during sorption of $\mathrm{TcO}_{4}^{-}$by the Aliquat ${ }^{\circ}-\mathrm{ZrO}_{2}$. Sorption isotherm experiments were done at six different solution:solid ratios ranging from 4000:1 to 20000:1. Earlier experiments (Bray et al. 1995) established the equilibration period of 48 hours.

Desorption Experiments. The main extractants used in this study were deionized water $(\mathrm{pH} \sim 5.7)$, phosphate $\left(0.01 \underline{\mathrm{M} \mathrm{Na}} \mathrm{HPO}_{4}, \mathrm{pH} 7\right)$, hydroxide (0.1 $\left.\underline{\mathrm{M} \mathrm{NaOH}}, \mathrm{pH} 12.9\right)$, carbonate $\left(0.1 \underline{\mathrm{M} \mathrm{Na}} \mathrm{CO}_{3}\right.$, $\mathrm{pH} 11.1)$, and a mixed carbonate-hydroxide $\left(0.28 \underline{\mathrm{M} \mathrm{Na}} \mathrm{CO}_{3} / 0.5 \mathrm{M} \mathrm{NaOH}, \mathrm{pH} 13.7\right)$ solutions. In 
addition, ethanol (EtOH) and $6 \mathrm{M} \mathrm{HNO}_{3}$ were also applied following the phosphate-desorption sequence. Batch desorption experiments were performed on the Aliquat $\left(-\mathrm{ZrO}_{2}\right.$ and the Reillex ${ }^{\mathrm{TM}}(25 \mathrm{mg})$ samples that had been equilibrated with $50 \mathrm{~mL}$ of the $4.5 \mathrm{nM}$ pertechnetate solution or with $12.5 \mathrm{~mL}$ of the $20 \mu \mathrm{M}$ chromate solution for $48 \mathrm{~h}$ at $\mathrm{pH} 7$ and RT. After the solid and supernatant were separated by centrifugation, $50 \mathrm{~mL}$ of the extractant was added to the solids reacted with $\mathrm{Tc}$ and $12.5 \mathrm{~mL}$ of the extractant was added to the solids equilibrated with $\mathrm{Cr}(\mathrm{VI})$. The desorption treatment periods were $1 \mathrm{~h}$ at $90-95^{\circ} \mathrm{C}$ and $60^{\circ} \mathrm{C}$ or $48 \mathrm{~h}$ at RT. Each extraction and blank were run in triplicate. The concentrations of soluble chromium (VI) and ${ }^{99} \mathrm{Tc}(\mathrm{VII})$ were determined by absorbance of the $\mathrm{Cr}$-diphenylcarbazide complex at $540 \mathrm{~nm}$ and by liquid-scintillation counting, respectively.

\subsubsection{Results and Discussion}

Characterization of $\mathrm{ZrO}_{2}$ Materials. The $\mathrm{XRD}$ pattern for the Aliquat $\otimes-\mathrm{ZrO}_{2}$ and the untreated $\mathrm{ZrO}_{2}$ (Figure 4.1) show no significant differences in the positions of the most intense peaks. This result suggests that the Aliquat $\circledast$ treatment has no effect on the crystal structure of the $\mathrm{ZrO}_{2}$. Comparison of the XRD data with those contained in the JCPDS files revealed that the mineralogy of the $\mathrm{ZrO}_{2}$ is similar to that of natural baddeleyite. The overall intensities are diminished by about $40 \%$ in the Aliquat $B-\mathrm{ZrO}_{2}$ pattern as a result of the attenuation of X-rays scattered by the $\mathrm{ZrO}_{2}$ and by the Aliquat $\$ 336$ ions adsorbed to the surface. The specific external-surface areas of the untreated and Aliquat $\otimes 336$-treated $\mathrm{ZrO}_{2}$ were 80 and $22 \mathrm{~m}^{2} \mathrm{~g}^{-1}$, respectively. Apparently, the Aliquat $\otimes$ treatment occluded some of the pore spaces in the $\mathrm{ZrO}_{2}$ powder and decreased the external surface area in contact with solution.

Thermal analysis (TGA and DTA) of the untreated $\mathrm{ZrO}_{2}$ (Figure 4.2) showed that the $\mathrm{ZrO}_{2}$ loses most of its water at a relatively low temperature range of $50^{\circ}-200^{\circ} \mathrm{C}$ with the maximum loss rate occurring at $100^{\circ} \mathrm{C}$. Further weight loss was observed above $200^{\circ} \mathrm{C}$, and this continued at a slow rate to $1000^{\circ} \mathrm{C}$. The resulting total weight reduction was about $3.5 \%$, of which $2 \%$ occurred between $50^{\circ}$ and $200^{\circ} \mathrm{C}$. The entire weight-loss curve was slightly endothermic, suggesting that water was loosely bound to the surface. In general, these data suggest that the untreated $\mathrm{ZrO}_{2}$ has a very high thermal stability in the temperature range studied and very few structural hydroxyls.

The TGA pattern for the Aliquat ${ }^{\circledR}-\mathrm{ZrO}_{2}$ (Figure 4.3) revealed three stages of weight loss: 1) the dehydration of the untreated $\mathrm{ZrO}_{2}$ between $50^{\circ}-200^{\circ} \mathrm{C}, 2$ ) a significant weight reduction between $200^{\circ}$ and $450^{\circ} \mathrm{C}$, and 3) the slow continuation of weight loss at temperatures above $450^{\circ} \mathrm{C}$. The weight reduction between $200^{\circ}$ and $450^{\circ} \mathrm{C}$ was an exothermic reaction, likely resulting from the combustion of the Aliquat $\left(\right.$. A comparison of the total weight loss of this sample with the untreated $\mathrm{ZrO}_{2}$ sample (Figure 4.2) shows that about $7.8 \%$ (i.e., $11.3 \%-3.5 \%$ ) of the original sample weight consisted of Aliquat (assuming complete combustion). From this, and an estimated equivalent weight of $404.17 \mathrm{~g} \mathrm{eq}^{-1}$, about 0.21 meq of Aliquat $B-336$ was adsorbed to each gram of $\mathrm{ZrO}_{2}$. As the $\mathrm{CEC}$ of the untreated $\mathrm{ZrO}_{2}$ was approximately $2.60 \mathrm{meq} \mathrm{g}^{-1}$, at most only about $8 \%$ of the exchange sites on the $\mathrm{ZrO}_{2}$ were occupied by the Aliquat $B$ ions assuming a monolayer coverage. 
Sorption Behavior. A comparison of the sorption behavior of the untreated and Aliquat $($-treated $\mathrm{ZrO}_{2}$ (Figure 4.4) shows that the Aliquat ${ }^{\circledR}$ treatment significantly increases sorption of $\mathrm{TcO}_{4}{ }^{-}$and $\mathrm{CrO}_{4}{ }^{-2}$ ions. The addition of $\mathrm{H}_{2} \mathrm{O}_{2}$ to the system to minimize reductive precipitation of $\mathrm{Tc}$ as $\mathrm{TcO}_{2}$ had no effect on the amounts of $\mathrm{TcO}_{4}^{-}$removed from solution. This result suggests that $\mathrm{Tc}$ was most likely removed in its oxidizing form, $\mathrm{TcO}_{4}^{-}$, by the Aliquat ${ }^{\circledR}-\mathrm{ZrO}_{2}$.

Sorption at different solution:solid ratios (Figure 4.5) resulted in a wide range of distribution coefficients $\left(\mathrm{K}_{-} \mathrm{s}\right)$ for the Aliquat $\left(\mathrm{B}-\mathrm{ZrO}_{2}\right.$. Values above $100,000 \mathrm{~mL} \mathrm{~g}^{-1}$ were obtained at solution:solid ratios below $5 \mathrm{~L} \mathrm{~g}^{-1}$. As the solution:solid ratio increased these values decreased, so that at a solution:solid ratio of $20 \mathrm{~L} \mathrm{~g} \mathrm{~g}^{-1}$ a K $\mathrm{K}_{\mathrm{d}}$ of about 8500 was obtained. In contrast, the $\mathrm{K}_{\mathrm{d}} \mathrm{s}$ for the Reillex ${ }^{\mathrm{TM}}$ resin were relatively constant, from a high of $60,000 \mathrm{~mL} \mathrm{~g}^{-1}$ at a solution:solid ratio of $4 \mathrm{~L} \mathrm{~g} \mathrm{~g}^{-1}$, to a plateau of about $40,000 \mathrm{~mL} \mathrm{~g}^{-1}$ at solution:solid ratios above $6 \mathrm{~L} \mathrm{~g}^{-1}$ (Figure 4.5).

The $\mathrm{TcO}_{4}^{-1}$ sorption data for the Aliquat $8-\mathrm{ZrO}_{2}$ exhibited a Langmuirian isotherm curve (Figure 4.6) and showed an excellent fit $\left(r^{2}=0.995\right)$ to the Langmuir isotherm equation (Figure 4.7), which has the following general form:

$$
\mathrm{C}_{\mathrm{FINAL}} / \mathrm{C}_{\mathrm{SORBED}}=1 / \mathrm{Kb}+\mathrm{C}_{\mathrm{FINAL}} / \mathrm{b}
$$

where $\mathrm{C}_{\mathrm{FINAL}}$ is the equilibrium concentration of Tc-99 $\left(\mathrm{nmol} \mathrm{L}^{-1}\right), \mathrm{C}_{\text {SORBED }}$ is the amount of Tc-99 sorbed on the treated $\mathrm{ZrO}_{2}$ surface ( $\mathrm{nmol} \mathrm{g}{ }^{-1}$ ), $\mathrm{K}$ is the Langmuir adsorption constant ( $\mathrm{L} \mathrm{nmol}^{-1}$ ), and $\mathrm{b}$ is the maximum amount of Tc-99 that can be sorbed by the $\mathrm{ZrO}_{2}\left(\mathrm{nmol} \mathrm{g}^{-1}\right)$. The least-square fitting yielded a value for $\mathrm{K}$ of $40.0 \mathrm{~L} \mathrm{nmol}^{-1}$ and for $\mathrm{b}$ of $34.6 \mathrm{mmol} \mathrm{g}^{-1}$.

The $\mathrm{TcO}_{4}^{-1}$ sorption data for the Reillex ${ }^{\mathrm{TM}}$ resin resulted in a direct linear relation between $\mathrm{C}_{\text {SORBED }}$ and $\mathrm{C}_{\mathrm{FINAL}}$ (Figure 4.8). A Langmuir plot (Figure 4.9) yielded a curve with two straight-line segments. This curve is a Langmuir two-surface isotherm and suggests that there are two types of Tc sorption sites on the Reillex ${ }^{\mathrm{TM}}$ resin. The different shapes of the sorption isotherms for Aliquat $\$-\mathrm{ZrO}_{2}$ and $\mathrm{Reillex}{ }^{\mathrm{TM}}$ clearly imply that the removal of $\mathrm{Tc}$ by the two sorbents followed different processes. Also, the much higher values for $b$ obtained with the Reillex ${ }^{\mathrm{TM}}$ resin show that this material has a significantly greater capacity to sorb $\mathrm{TcO}_{4}^{-}$than the Aliquat 8336 -treated $\mathrm{ZrO}_{2}$. As noted by Sposito $(1984, \mathrm{p} .122)$, however, adherence of experimental sorption data to an isotherm equation does not constitute evidence that adsorption is the actual (or single) mechanism that accounts for the removal of any sorbate from solution. In addition to the possibility of an adsorption mechanism for the removal of pertechnetate from solution, other mechanisms need to be considered. Among these alternative mechanisms is the possible reduction of pertechnetate and associated precipitation of Tc(IV) oxide by the alkylammonium organocations on the $\mathrm{ZrO}_{2}$ or by similar components of the Reillex ${ }^{\mathrm{TM}}$ resin.

Desorption Behavior. The results of the desorption experiments are summarized in Figures 4.104.12. For the desorption of $\mathrm{Cr}(\mathrm{VI})$ from the Aliquatß $\mathrm{ZrO}_{2}$ samples, approximately $50 \%$ of the $\mathrm{Cr}$ (VI) that had been removed by the solid was extracted by the sequence of water and phosphate solutions (Figure 4,10). Most of this fraction [i.e., at least $36 \%$ of the original sorbed $\mathrm{Cr}(\mathrm{VI})$ ] was merely water soluble. The remainder [ $14 \%$ of the original sorbed $\mathrm{Cr}(\mathrm{VI})]$ was removed by the first phosphate 
extraction. Subsequent extractions of the $\mathrm{Cr}(\mathrm{VI})$ samples with water or phosphate at RT, or with phosphate, EtOH, or $6 \mathrm{M} \mathrm{HNO} 3$ at $60^{\circ} \mathrm{C}$ did not lead to significant increases in $\mathrm{Cr}(\mathrm{VI})$ recovery. The alkaline solutions of hydroxide, carbonate, or their combination, each extracted more sorbed $\mathrm{Cr}(\mathrm{VI})$ $(69-85 \%)$ at RT than did the phosphate, EtOH, or $\mathrm{HNO}_{3}$ solutions. Raising the extraction temperatures to near boiling resulted in almost complete recovery of the sorbed $\mathrm{Cr}(\mathrm{VI})$ in a single step. Surprisingly,

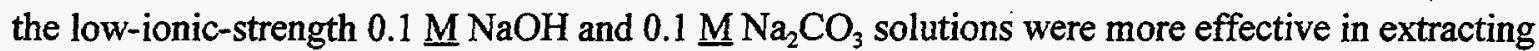

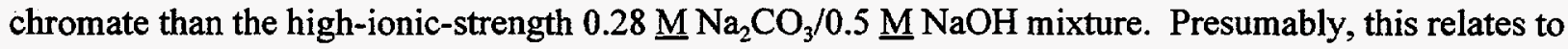
the relatively high degree of hydrophobicity of the treated $\mathrm{ZrO}_{2}$ surface, which would be more accessible to solutions of lower ionic strength.

Similar desorption patterns were observed for the recovery of the sorbed $\mathrm{TcO}_{4}{ }^{-}$from the Aliquat $8-\mathrm{ZrO}_{2}$ (Figure 4.11). Smaller fractions of the sorbed $\mathrm{TcO}_{4}{ }^{-}$could be desorbed at RT, and between 93 and $98 \%$ desorbed at near-boiling temperatures. Theoretically, complete desorption would imply that no reduction had occurred because the alkaline extractions are expected to avoid method-induced redox reactions (James et al. 1995). Therefore, these desorption results support the following hypotheses: 1) the mechanism of pertechnetate removal is by adsorption (i.e., the reduction by the surfactant on the $\mathrm{ZrO}_{2}$ surface is not a significant factor), 2) the pertechnetate is more strongly bound than the chromate, and 3) carbonate is slightly more effective than hydroxyl in desorbing pertechnetate. The last result is in contrast to that obtained for chromate and suggests that pertechnetate and chromate may be bound to different sites.

The desorption of the $\mathrm{Tc}$ that had been removed from the Reillex ${ }^{\mathrm{TM}}$ was conducted using only the alkaline $\mathrm{NaOH}$ and/or $\mathrm{Na}_{2} \mathrm{CO}_{3}$ solutions. In contrast to the Aliquat $8-\mathrm{ZrO}_{2}$ tests, only a small fraction of the Tc was recovered (Figure 4.12). This may suggest different sorption mechanism(s) for these two materials.

Possible "Sorption" Mechanisms. The mechanisms for removal of the inorganic oxyanions from solution by the Aliquat $(\mathrm{ZrO})$ or the Reillex ${ }^{\mathrm{TM}}$ resin involve either sorption (here "sorption" is defined as an easily reversible process causing the retention of the ion by the solid phase) or precipitation. Several different types of sorption sites or processes could be involved. These include 1) a combination of columbic and hydrophobic retention by partly satisfied, positively charged amine groups from the Aliquat $\left(\right.$ ions adsorbed to the $\mathrm{ZrO}_{2}, 2$ ) columbic retention by attraction of the outer-sphere oxygens of the oxyanion to protonated sites on the inorganic $\mathrm{ZrO}_{2}$ surface, and 3) site-specific ligand-exchange reactions involving inner-sphere oxygens from the oxyanion substituting for inorganic oxygens at the $\mathrm{ZrO}_{2}$ surface. Because the $\mathrm{TcO}_{4}^{-}$and $\mathrm{Cr}(\mathrm{VI})$ ions are generally quite soluble, any precipitation process would likely involve reduction to $\mathrm{Tc}(\mathrm{IV})$ or $\mathrm{Cr}(\mathrm{III})$, which are relatively insoluble.

Sorption of the oxyanions to inorganic $\mathrm{ZrO}_{2}$ sites was very limited (Figure 4.4). It is more likely, therefore, that if sorption occurs it is mainly at the Aliquat $B$ sites, as a result of columbic attraction and/or physical sorption (e.g., hydrophobic partitioning). The oxyanions might be reduced, either by the alkylamine ion or possibly by delocalized electrons in the $\mathrm{ZrO}_{2}$ matrix, and then precipitated as lesssoluble oxides. From the experimental data, it was concluded that no reduction/precipitation occurred in the removal of $\mathrm{TcO}_{4}^{-}$and $\mathrm{Cr}(\mathrm{VI})$ by the Aliquat $\left(\mathrm{ZrO}_{2}\right.$. This was because 1 ) sorption of chromate by the Aliquat $\left(\mathrm{ZrO}_{2}\right.$ yielded yellow particles, with no evidence for the blue-green particles expected if 
reduction was occurring, 2) no difference was seen in the sorption of $\mathrm{TcO}_{4}{ }^{-}$when $\mathrm{H}_{2} \mathrm{O}_{2}$ was also present to maintain oxidizing conditions, and 3) complete or near-complete recoveries of both $\mathrm{TcO}_{4}{ }^{-}$and $\mathrm{Cr}$ (VI) were obtained using the alkaline extracting solutions. The limited amounts of $\mathrm{Tc}$ recovered from the Reillex ${ }^{\mathrm{TM}}$ material, along with the Langmuir two-surface sorption behavior, suggest that the removal of the $\mathrm{TcO}_{4}^{-}$might involve a combination of adsorption and reduction by the resin.

Based on these data, it seems clear that 1) the treatment of $\mathrm{ZrO}_{2}$ with Aliquat@336 significantly enhanced the solid's capability to remove oxyanions from aqueous solution, 2) the sorption affinity of the Aliquat $8-\mathrm{ZrO}_{2}$ for $\mathrm{TcO}_{4}^{-}$could be predicted by the Langmuir isotherm, while that of the Reillex ${ }^{\mathrm{TM}}$ was best described by a Langmuir two-surface isotherm, 3) although the Reillex ${ }^{\mathrm{TM}}$ had higher sorption capacity, the Aliquat $\left(\mathrm{Z}-\mathrm{ZrO}_{2}\right.$ had higher selectivity for Tc at low solution:solid ratios, and 4) the removal of oxyanions by the Aliquat $\left(\mathrm{ZrO}_{2}\right.$ resulted mainly from sorption to the Aliquat $\$ 336$ sites with no evidence for reductive precipitation processes, whereas precipitation processes may be involved with the Reillex ${ }^{\mathrm{TM}}$ resin.

\subsubsection{Other Surfactant-Modified Materials}

Other surfactant-modified anion-exchange materials studied include an Aliquat $\circledast$-treated synthetic zeolite, Aliquat@-treated $\mathrm{SiO}_{2}$, and a natural zeolite (clinoptilolite) modified by hexadecyltrimethylammonium ion (HDTMA) and provided by Rob Bowman at New Mexico Tech. The HDTMA ion has a long 16-C chain and three methyl groups on the nitrogen. The synthetic zeolite and $\mathrm{SiO}_{2}$ were treated with Aliquat $B 336$ in the same manner as the $\mathrm{ZrO}_{2}$. Sorption experiments were performed under the same conditions described for testing of the Aliquat $\$-\mathrm{ZrO}_{2}$ samples.

The results of a kinetic batch-sorption study conduced at a solution:solid ratio of $2 \mathrm{~L} \mathrm{~g} \mathrm{~g}^{-1}$ indicated that the two surfactant-modified zeolites behaved similarly regardless of the alkylamine moiety and yielded $\mathrm{K}_{\mathrm{d}} \mathrm{s}$ of $1000-3000$ after 48 hours (Figure 4.13). Under the same conditions, the Aliquat $\otimes$-treated $\mathrm{ZrO}_{2}$ removed all the Tc even after only 2 hours. In a separate batch-sorption experiment conducted at the same solid:solution ratio, the $\mathrm{K}_{\mathrm{d}}$ for Aliquatß-treated $\mathrm{SiO}_{2}$ was $8700 \mathrm{~mL} \mathrm{~g}^{-1}$ after 48 hours (data not shown). This value was higher than that obtained for either of the surfactant-modified zeolites but at least an order of magnitude lower than the value obtained for the Aliquat $\left(\mathrm{ZrO}_{2}\right.$.

\subsection{Na-Titanate Cation (Sr) Exchangers in Alkaline HLW Simulant}

Selectivity tests were conducted to test Na-titanate materials for efficacy in the removal of $\mathrm{Sr}$ from alkaline HLW simulant. The HLW simulant used was typical of tank waste at the Savannah River Site. The materials tested included two new samples of an engineered form of Na nonatitanate provided by AlliedSignal, along with a Na nonatitanate (from AlliedSignal) and a monoNa titanate (from Boulder Scientific) reported previously. The tests were performed in triplicate using the Sr Decontamination Test Procedure, Revision 2 (Z-SPP-H-00001) provided by the Savannah River Testing Center. The results of these tests yielded very low Decontamination Factors (DFs) for both the AlliedSignal materials as well as the Boulder Scientific material (Table 4.1). 
Table 4.1. Results of Sr Selectivity Tests on Na Titanate Materials Before and After Pre-Treatment of Simulant to Remove Trace Levels of $\mathrm{Ca}, \mathrm{Sr}$, and $\mathrm{Ba}$

\begin{tabular}{||l|c|c|}
\hline \multicolumn{1}{|c|}{$\begin{array}{c}\text { Na Titanate } \\
\text { Material } \\
\text { (Sample Numbers) }\end{array}$} & Before & DF(Sr) \\
\cline { 2 - 3 } & $3.8 \pm 1.4$ & $167 \pm 6$ \\
\hline \hline $\begin{array}{l}\text { Boulder Scientific } \\
\text { (BSC-265-005 slurry) }\end{array}$ & $11.1 \pm 2.7$ & $147 \pm 10$ \\
\hline $\begin{array}{l}\text { AlliedSignal } \\
(8225-127 \text { slurry prepared at PNNL) }\end{array}$ & $2.6 \pm 0.3$ & $74 \pm 10$ \\
\hline $\begin{array}{l}\text { AlliedSignal } \\
(8212-88-1)\end{array}$ & $2.1 \pm 0.5$ & $90 \pm 15$ \\
\hline $\begin{array}{l}\text { AlliedSignal } \\
(8212-88-2)\end{array}$ & & \\
\hline
\end{tabular}

After much investigation, we determined that the low DFs resulted from the presence of nonradioactive alkaline-earth metals (i.e., $\mathrm{Ca}$, $\mathrm{Sr}$, and $\mathrm{Ba}$ ) in the simulant that nominally contained none of these elements. We found Ca levels of $2700 \mu \mathrm{g} \mathrm{L}^{-1}$, Sr levels of $100 \mu \mathrm{g} \mathrm{L}^{-1}$, and Ba levels of $90 \mu \mathrm{g} \mathrm{L}^{-1}$ in the simulant. Evidently, these "contaminants" were present in the reagents used to prepare the simulant and yielded ions that competed with the ${ }^{87} \mathrm{Sr}$ tracer for sorption sites on the Na-titanate materials. To verify the effect of the interference, a batch of simulant was pretreated by adding $5 \mathrm{~g}$ of the Boulder-Scientific titanate per $L$ of simulant, equilibrating for about 48 hours, and then separating the titanate by filtration through a $0.45-\mu \mathrm{M}$ pore-size filter membrane. Analysis of the simulant after this pretreatment showed levels of these metals to be below detection. A repeat of the Sr-selectivity test with this pretreated simulant yielded much higher DF values (Table 4.1). These results suggest that significant interference with $\mathrm{Sr}$ uptake by these materials may be caused by relatively low levels of alkaline-earth metals (most likely Ca).

\subsection{Tunnel-Structure Manganese-Oxide Cation (Ba, Ra) Exchangers}

The objectives of this exploratory effort were to 1) demonstrate the synthesis and potential selectivity of a novel tunnel-structure manganese-oxide ion-exchange material for $\mathrm{Ra}^{2+}$, and 2) further identify the optimal conditions required for rapid dissolution of $\mathrm{BaSO}_{4}$ using the process suggested in the previous year's report (Bray et al. 1995). The manganese-oxide materials are expected to have greater stability towards radiation damage than organic materials and thus may also be potentially useful as waste forms for long-term storage.

The tunnel-structure manganese oxide $\left(\alpha-\mathrm{MnO}_{2}\right)$ was synthesized following the methodology developed by Feng et al. (1994). The selectivity test of the synthetic $\alpha-\mathrm{MnO}_{2}$ for $\mathrm{Ra}$ was conducted 
using $1 \mathrm{mM} \mathrm{Ba}$ and $\mathrm{Rb}$ in a $5 \mathrm{mM} \mathrm{CaCl}$ matrix solution at $\mathrm{RT}$. Rubidium was chosen as a $\mathrm{Ra}$ analog because its ionic radius is essentially the same as that for $\mathrm{Ra}$. Because the $\mathrm{Rb}$ ion is monovalent and the $\mathrm{Ra}$ ion divalent, any demonstrated selectivity for $\mathrm{Rb}$ would be a very conservative estimate of the selectivity expected for $\mathrm{Ra}$. After 1 day, the $\mathrm{Rb}$ levels were less than $1 \%$ of their starting values, whereas those for $\mathrm{Ba}$ were about $5 \%$ of the starting values (data not shown). Equilibrium was not reached during the 4-day length of the experiment, but these results suggest that the $\mathrm{K}_{d}$ for $\mathrm{Rb}$ was about five times greater than for $\mathrm{Ba}$ (Figure 4.14) even though the charge of the $\mathrm{Ba}$ ion was twice as great as that for $\mathrm{Rb}$. Because $\mathrm{Ra}$ would have the same charge as $\mathrm{Ba}$, we believe the selectivity for $\mathrm{Ra}$ relative to that for $\mathrm{Ba}$ would be even greater, perhaps another 5 - or 10-fold.

As part of our effort to develop a Ra separation process (Bray et al. 1995), batch sorption experiments were performed to determine the optimum $\mathrm{pH}$ and temperature for dissolution of $\mathrm{BaSO}_{4}$ by DTPA solutions. The results showed a 1000 -fold increase in solubility of $\mathrm{BaSO}_{4}$ at $\mathrm{pH} 10.6$ relative to $\mathrm{pH} \sim 4$ at a temperature of $95^{\circ} \mathrm{C}$ (Figure 4.15). The rate of dissolution to reach saturation at $\mathrm{pH} 10.6$ was about 300 times faster at $95^{\circ} \mathrm{C}$ than at $\mathrm{RT}$ (data not shown). For instance, at $\mathrm{pH} 10.6$ only 18 minutes were needed at $95^{\circ} \mathrm{C}$ to reach a concentration of $2900 \mathrm{ppm} \mathrm{Ba}$ (about $40 \%$ of saturation), whereas at room temperature 4 days were needed to dissolve the same amount of $\mathrm{BaSO}_{4}$. These results show a clear preference for the use of higher temperatures and $\mathrm{pHs}$ for dissolution of $(\mathrm{Ba}, \mathrm{Ra}) \mathrm{SO}_{4}$ by DTPA solutions. 


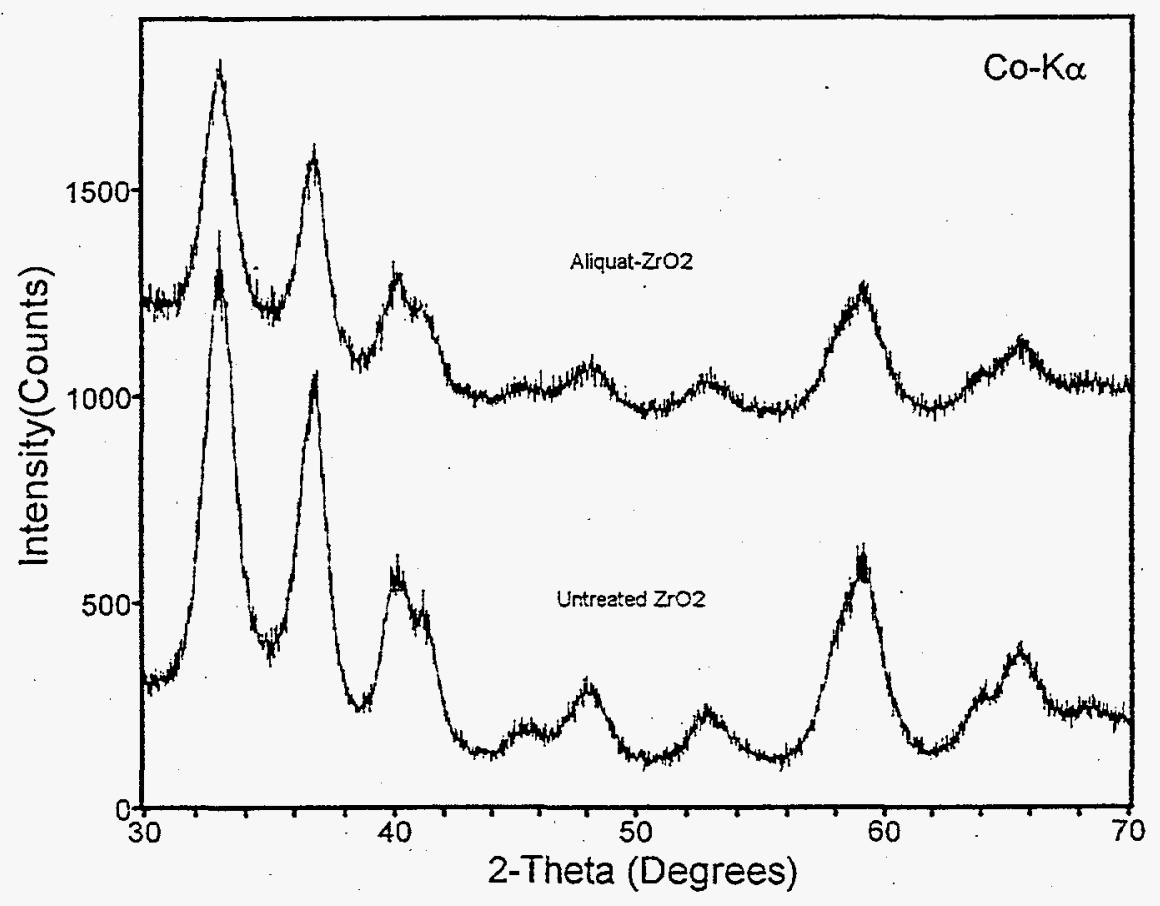

Figure 4.1. Power X-Ray Diffraction Patterns ( $\mathrm{Co}-\mathrm{K} \alpha)$ Obtained for Untreated $\mathrm{ZrO}_{2}$ (bottom) and Aliquatß336-Treated $\mathrm{ZrO}_{2}$ (top) Ion-Exchange Materials

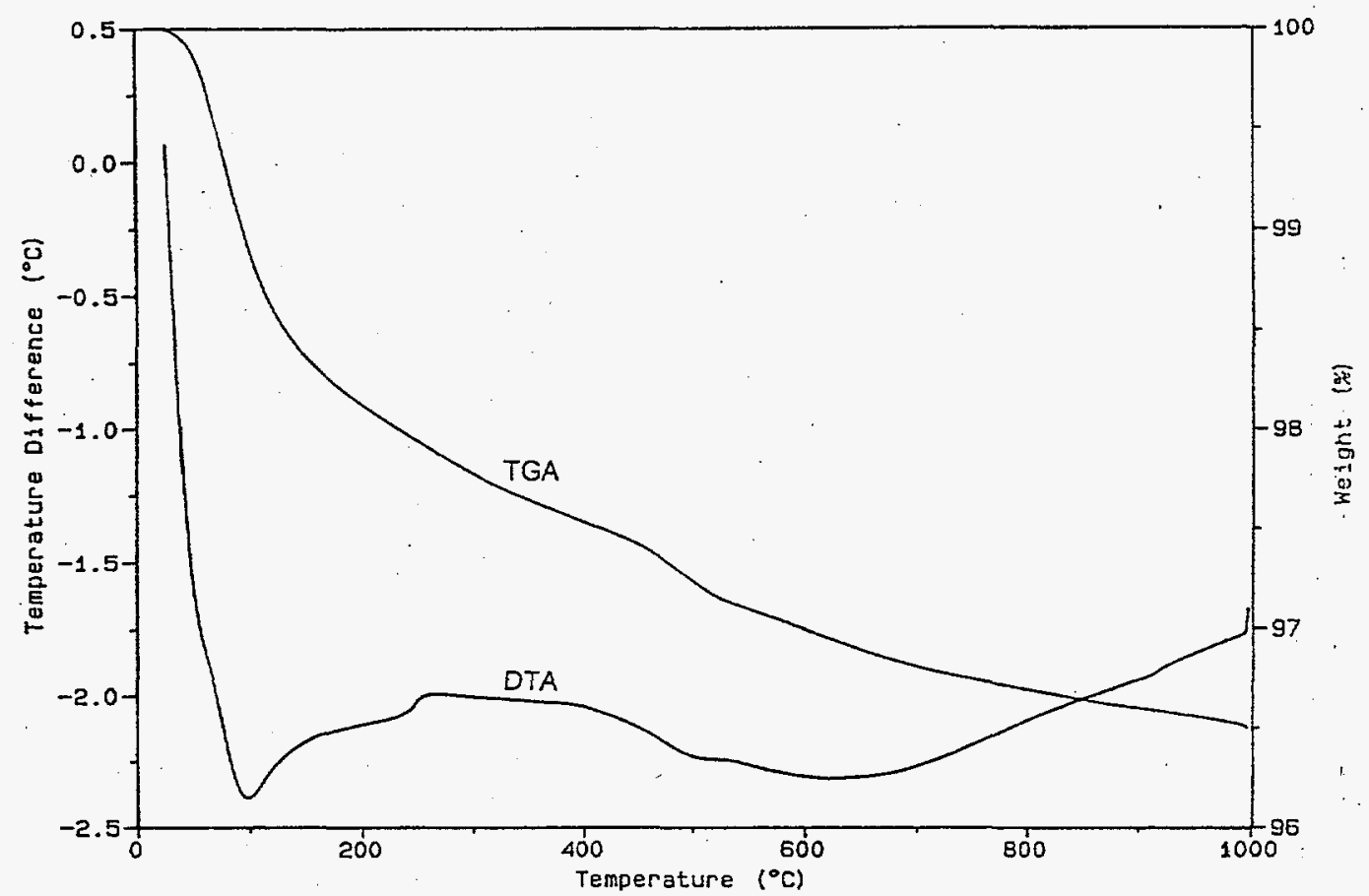

Figure 4.2. Thermal-Gravimetric Analysis (TGA) and Differential-Thermal Analysis (DTA) Data for Untreated $\mathrm{ZrO}_{2}$ Ion-Exchange Material 


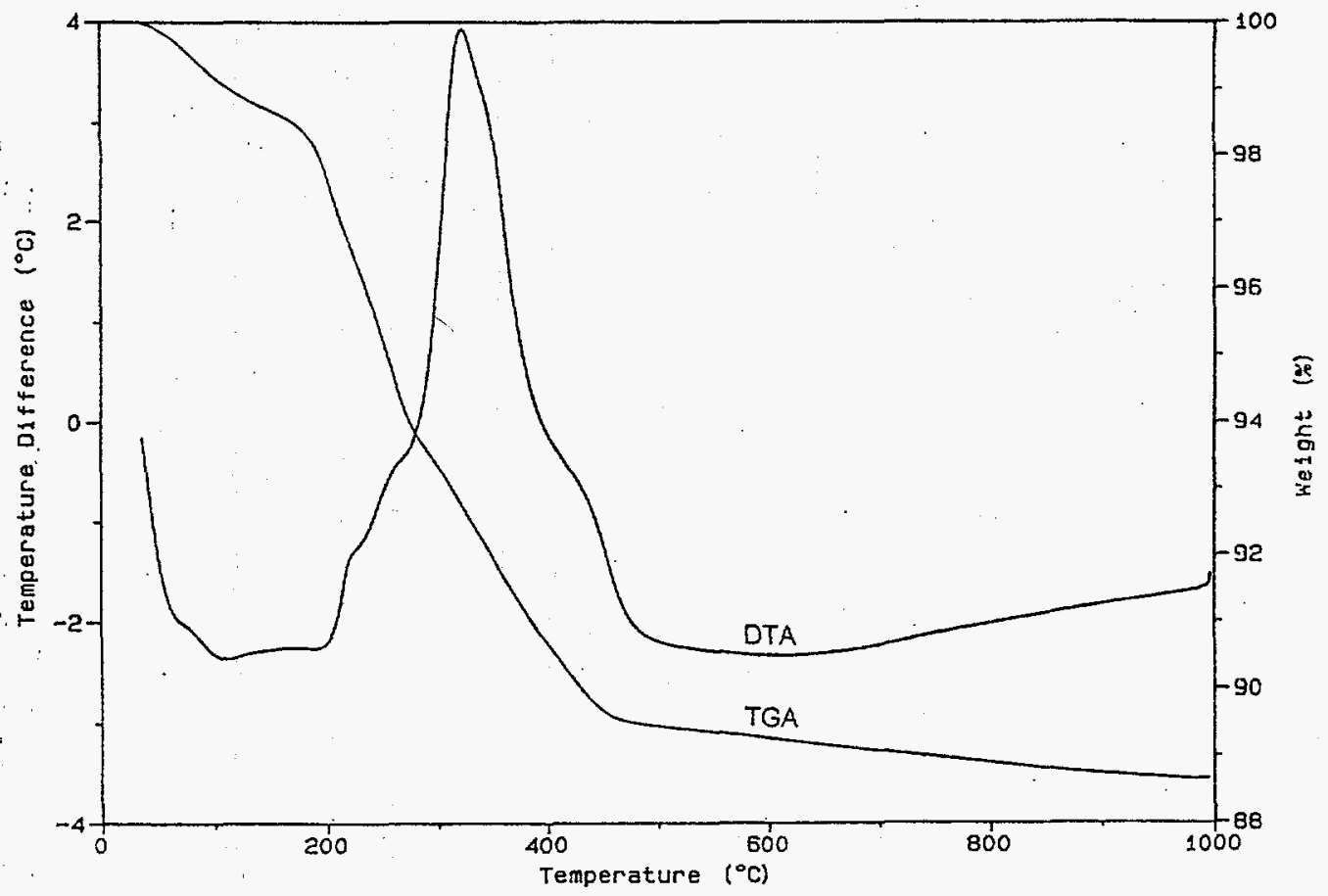

Figure 4.3. Thermal-Gravimetric Analysis (TGA) and Differential-Thermal Analysis (DTA) Data for Aliquat ${ }^{\circledR}$-Treated $\mathrm{ZrO}_{2}$ Ion-Exchange Material

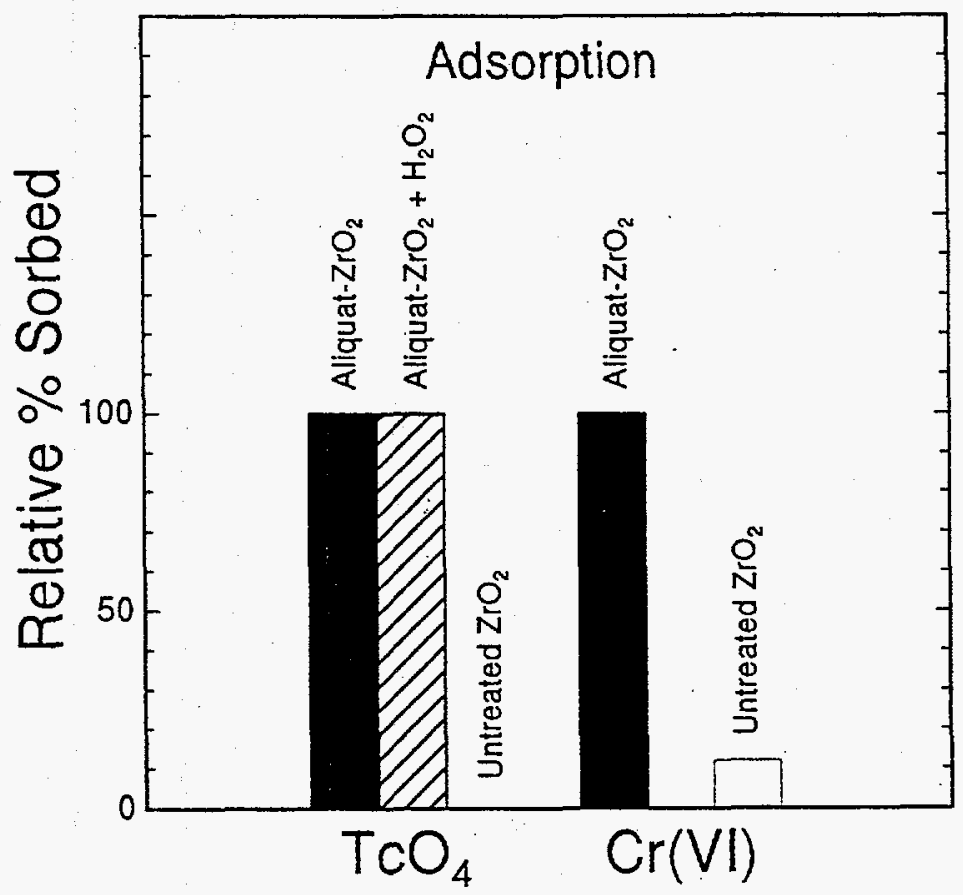

Figure 4.4. Relative Amounts of $\mathrm{TcO}_{4}{ }^{-1}$ and $\mathrm{Cr}(\mathrm{VI})$ Retained by Aliquat $\circledast 336$-Treated $\mathrm{ZrO}$ and Untreated $\mathrm{ZrO}_{2}$ After 48 Hours in a Simulated Groundwater at $\mathrm{pH} 7$. Results of a similar test for $\mathrm{TcO}_{4}^{-3}$ retention by Aliquat $\left(336-T\right.$ reated $\mathrm{ZrO}_{2}$ in the presence of $\mathrm{H}_{2} \mathrm{O}_{2}$ are also shown. 


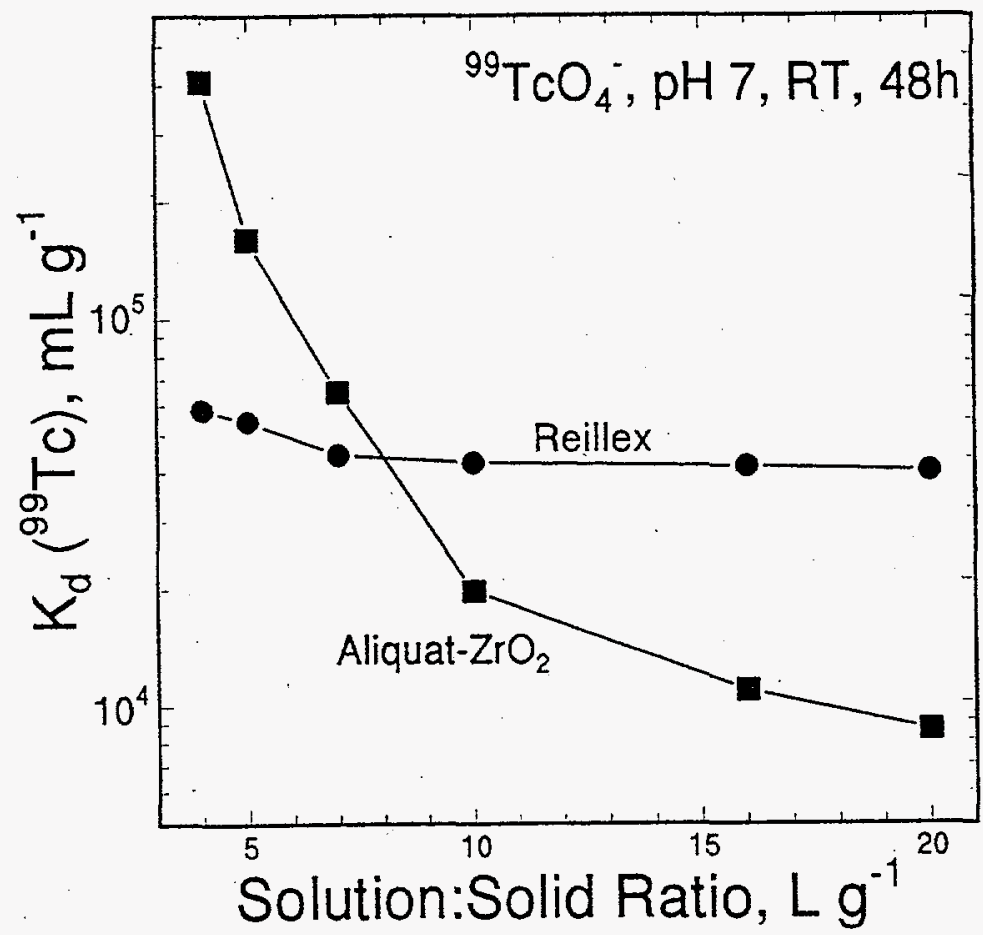

Figure 4.5. Distribution Coefficients at Different Solid:Solution Ratios for $\mathrm{TcO}_{4}^{-1}$ Retention by Aliquat $\left(336\right.$-Treated $\mathrm{ZrO}_{2}$ and Reillex ${ }^{\mathrm{TM}}$ Ion-Exchange Materials in Simulated Groundwater

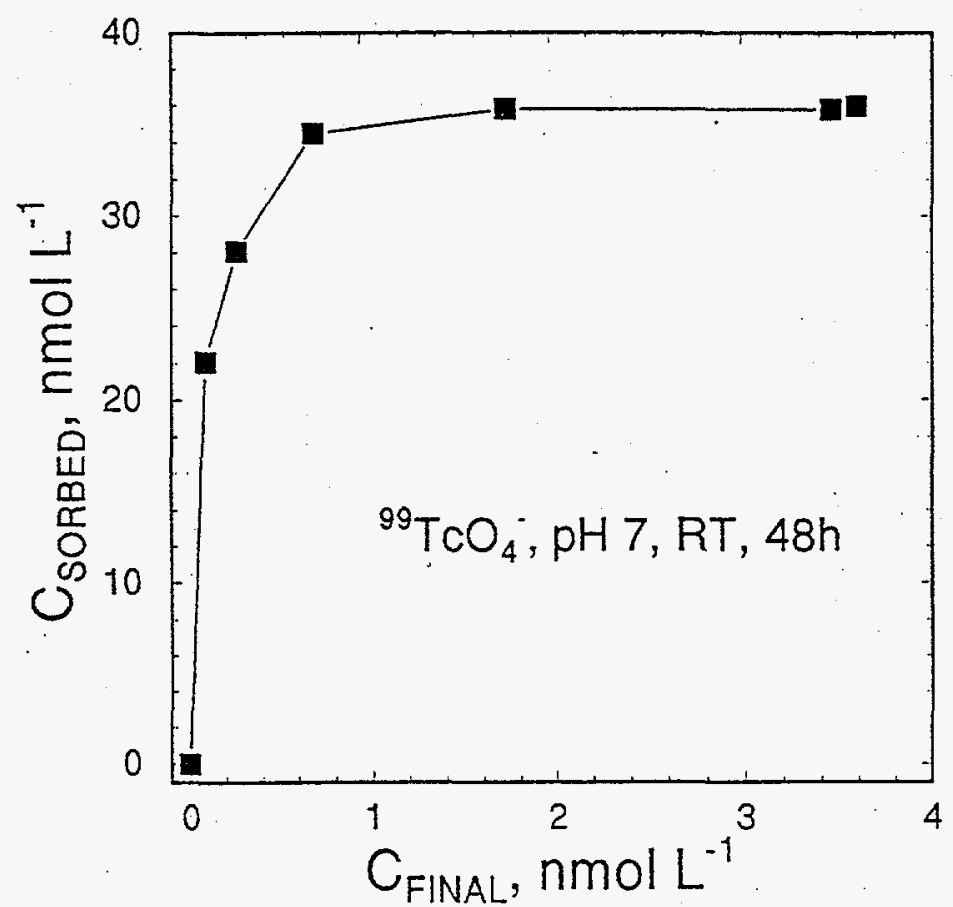

Figure 4.6. Amounts of $\mathrm{TcO}_{4}^{-1}$ Sorbed by Aliquat $\circledast 336$-Treated $\mathrm{ZrO}_{2}$ at Different Final Solution Concentrations 


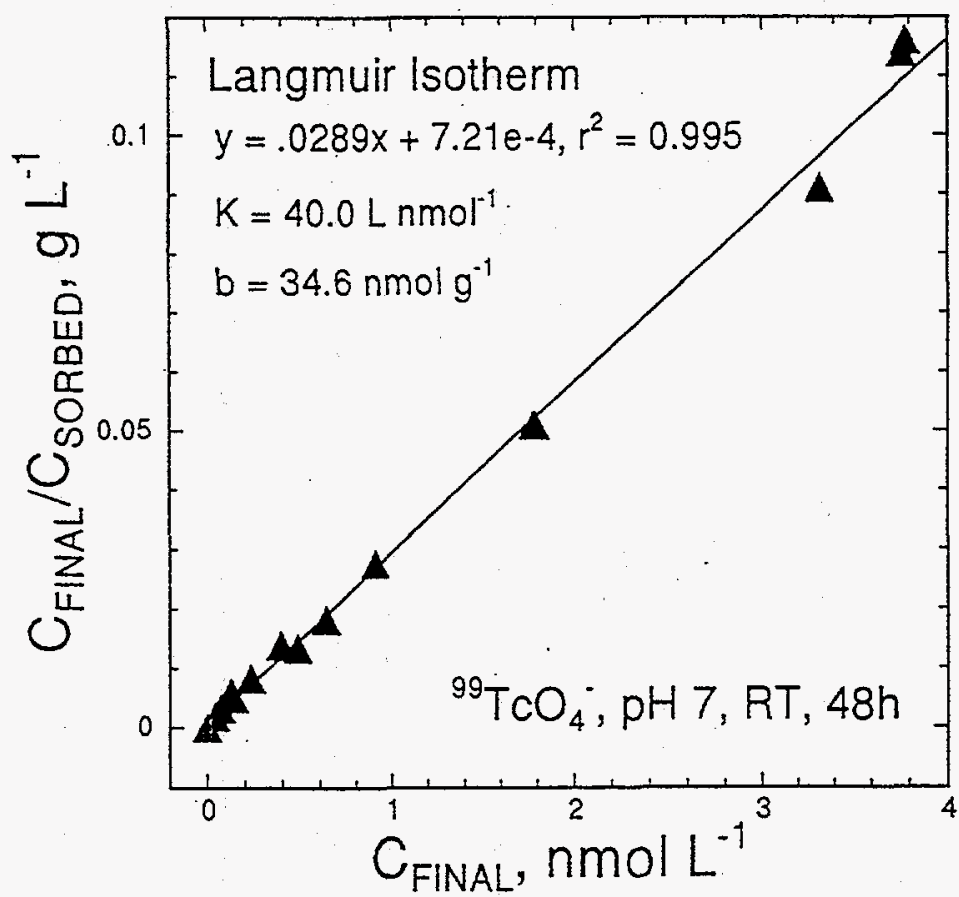

Figure 4.7. Langmuir Isotherm Plot of $\mathrm{TcO}_{4}^{-1}$ Sorption by Aliquat@336-Treated $\mathrm{ZrO}_{2}$

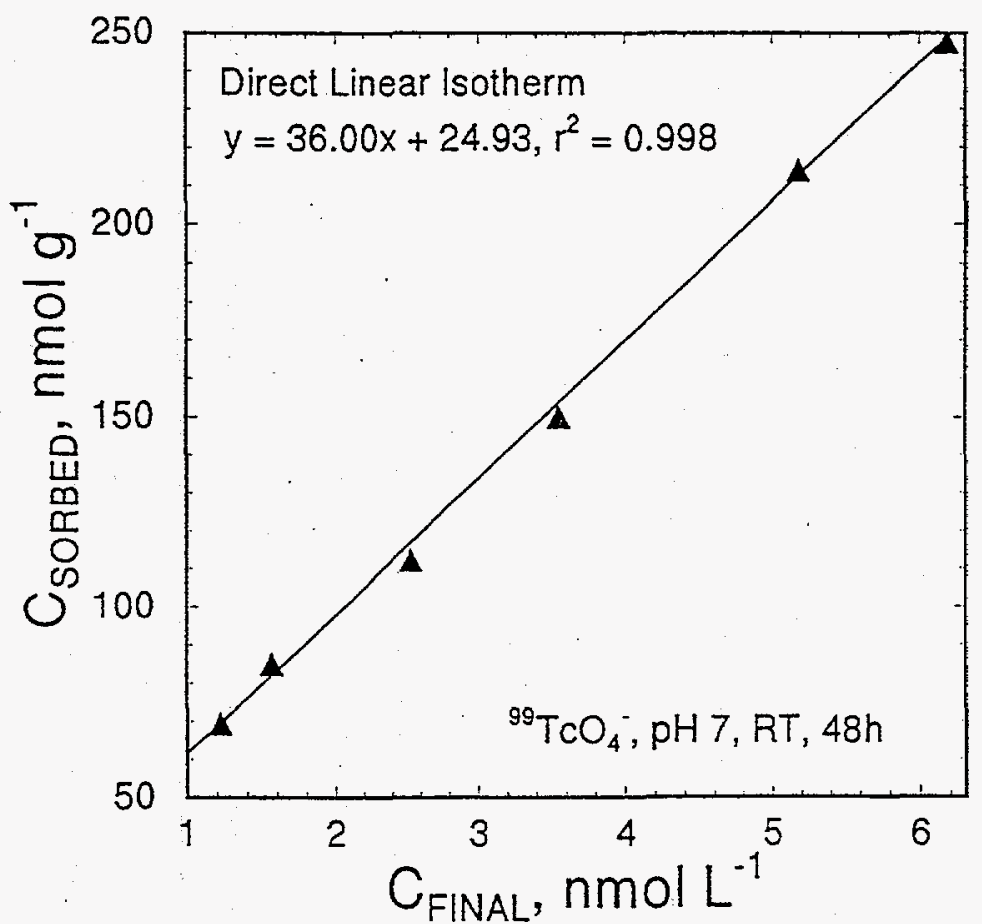

Figure 4.8. Amounts of $\mathrm{TcO}_{4}{ }^{-1}$ Sorbed by Reillex ${ }^{\mathrm{TM}} \mathrm{HPQ}$ Anion-Exchange Resin at Different Final Solution Concentrations 


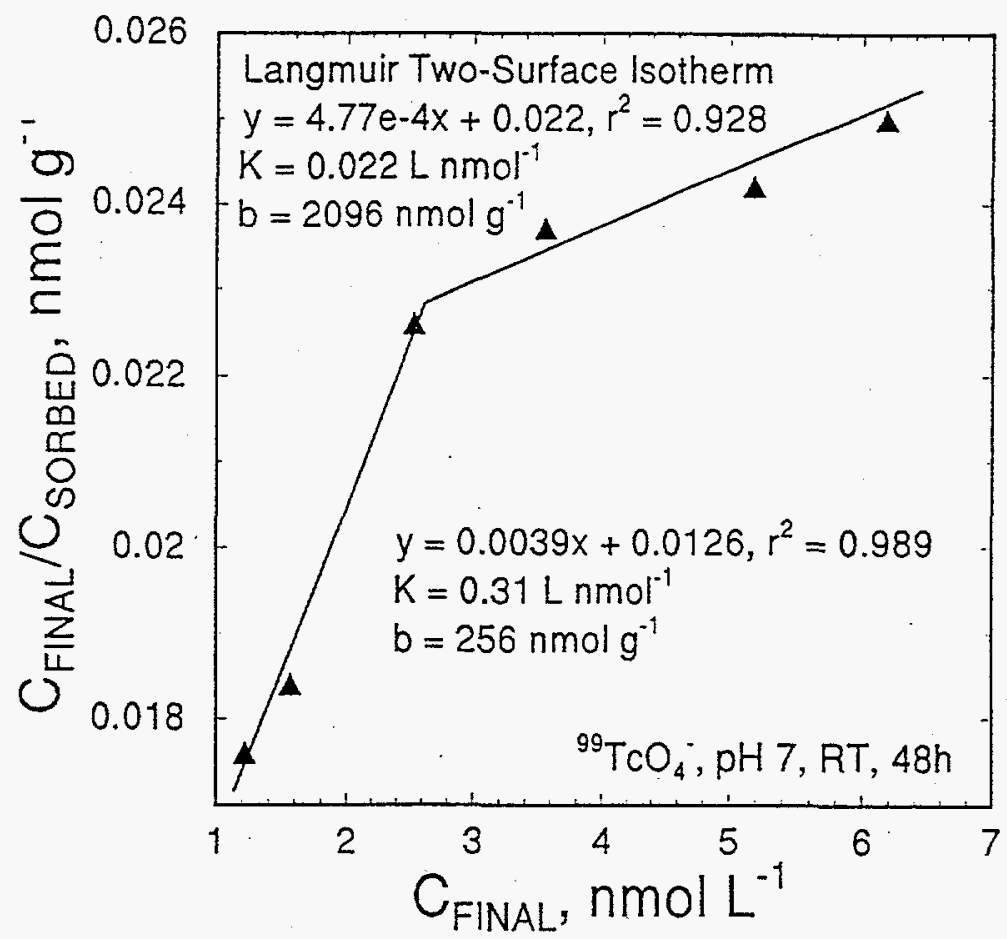

Figure 4.9. Langmuir Two-Surface Isotherm Plot of $\mathrm{TcO}_{4}{ }^{-1}$ Sorption by Reillex ${ }^{\mathrm{TM}} \mathrm{HPQ}$ Anion-Exchange Resin

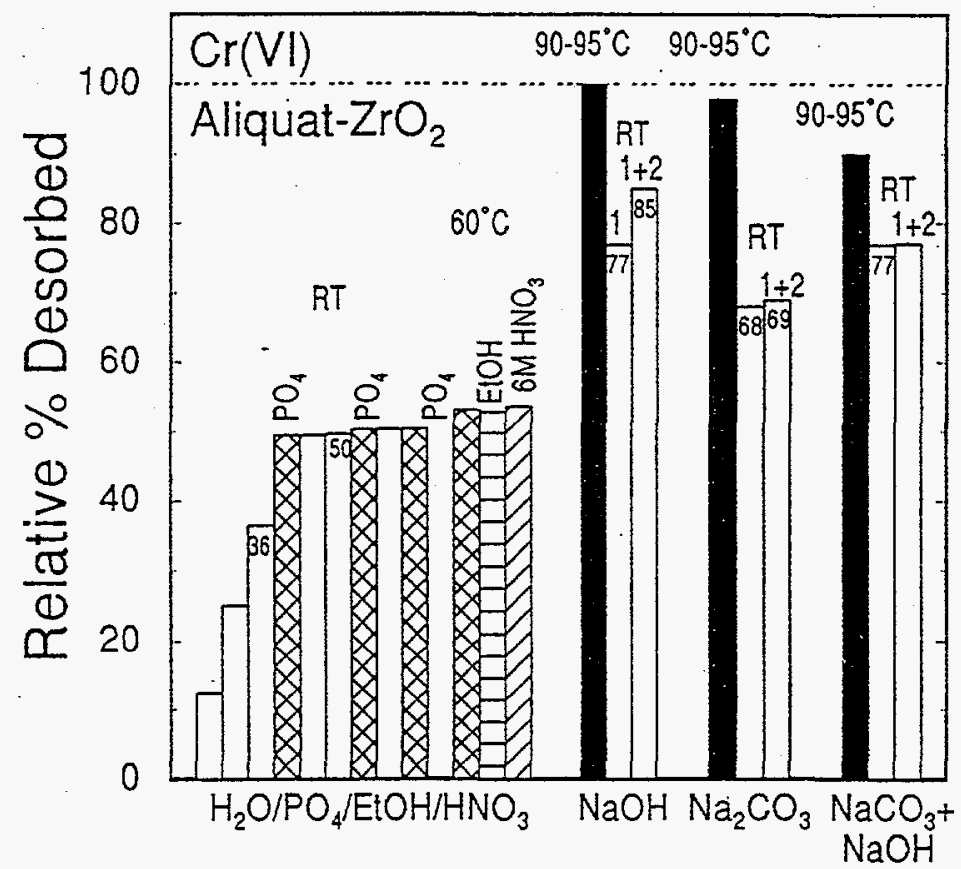

Figure 4.10. Cumulative Fractions of $\mathrm{Cr}(\mathrm{VI})$ Sorbed to Aliquat $@ 336-\mathrm{Treated} \mathrm{ZrO}_{2}$ that were Desorbed by Sequential Treatments with Water (RT), $0.01 \mathrm{M} \mathrm{Na} \mathrm{HPO}_{4}(\mathrm{pH} 7, \mathrm{RT})$, Ethanol $\left(60^{\circ} \mathrm{C}\right)$, and $6 \mathrm{M} \mathrm{HNO}{ }_{3}\left(60^{\circ} \mathrm{C}\right)$ and, in Separate Experiments, by Treatments at RT and Near-Boiling Temperatures with Three Alkaline Extractants 


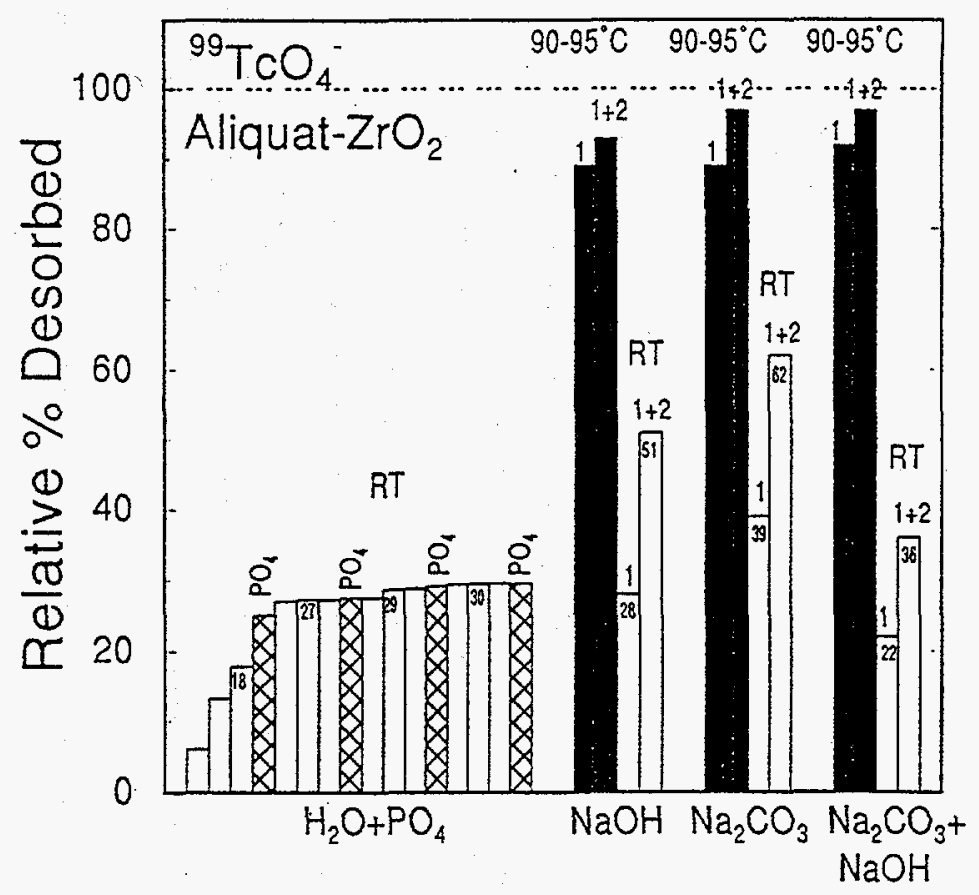

Figure 4.11. Cumulative Fractions of $\mathrm{TcO}_{4}^{-1}$ Sorbed to Aliquat $@ 336-$ Treated $\mathrm{ZrO}_{2}$ that were Desorbed by Sequential Treatments with Water (RT) and $0.01 \mathrm{M} \mathrm{Na}_{2} \mathrm{HPO}_{4}(\mathrm{pH} \mathrm{7,} \mathrm{RT),} \mathrm{and,} \mathrm{in} \mathrm{Separate}$ Experiments, by Treatments at RT and Near-Boiling Temperatures with Three Alkaline Extractants

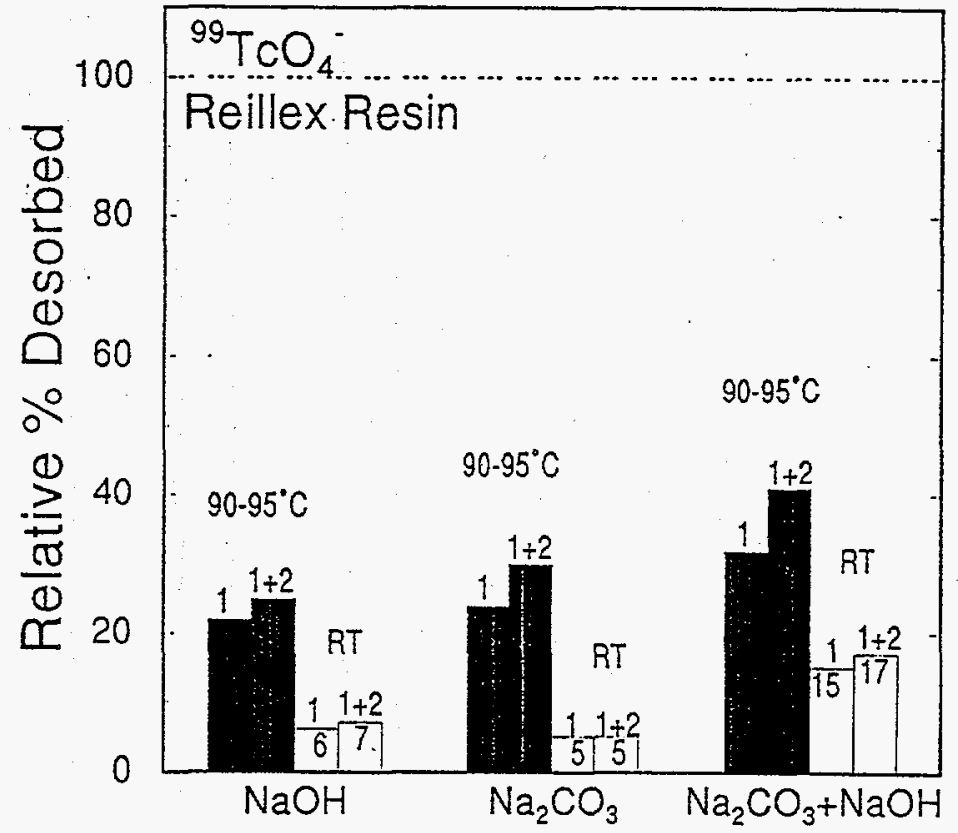

Figure 4.12. Cumulative Fractions of $\mathrm{TcO}_{4}{ }^{-1}$ Sorbed to Reillex ${ }^{\mathrm{TM}} \mathrm{HPQ}$ Anion-Exchange Resin that were Desorbed by Treatments at RT and Near-Boiling Temperatures with Three Alkaline Extractants 


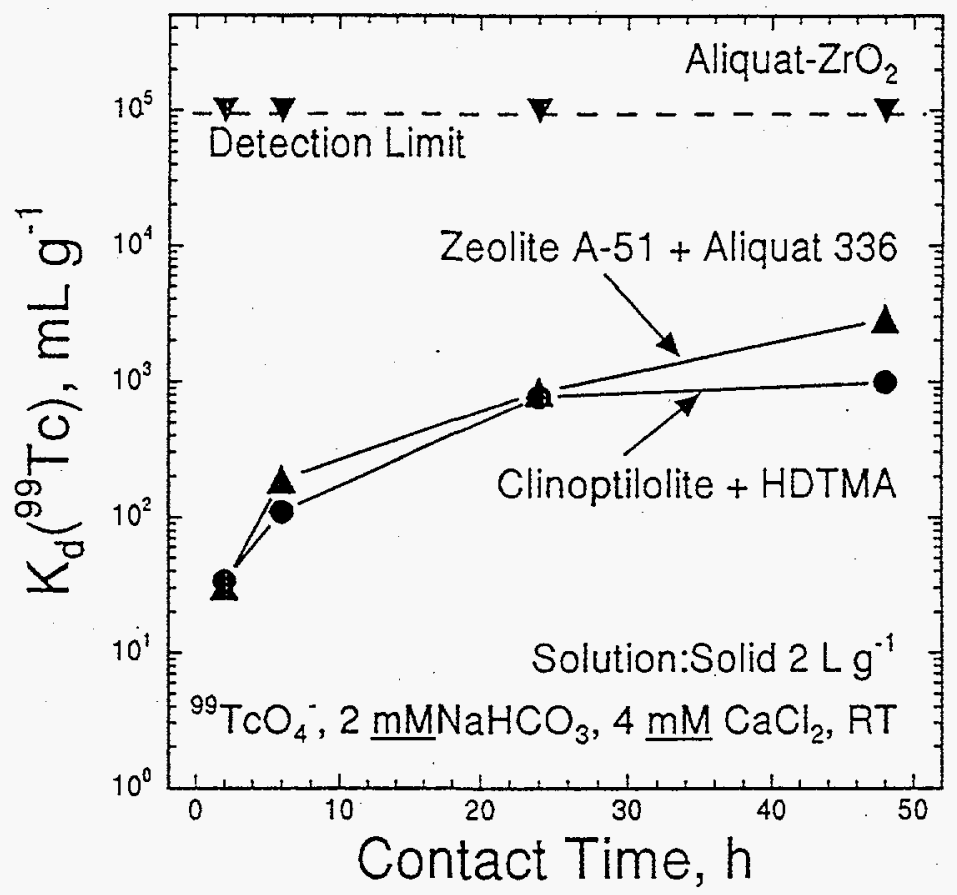

Figure 4.13. Changes in Distribution Coefficients with Time for $\mathrm{TcO}_{4}^{-1}$ Retention by Aliquat $囚 336$ Treated $\mathrm{ZrO}_{2}$, Aliquat $\$ 336$-Treated Synthetic Zeolite A-51, and HDTMA-Treated Clinoptilolite Zeolite

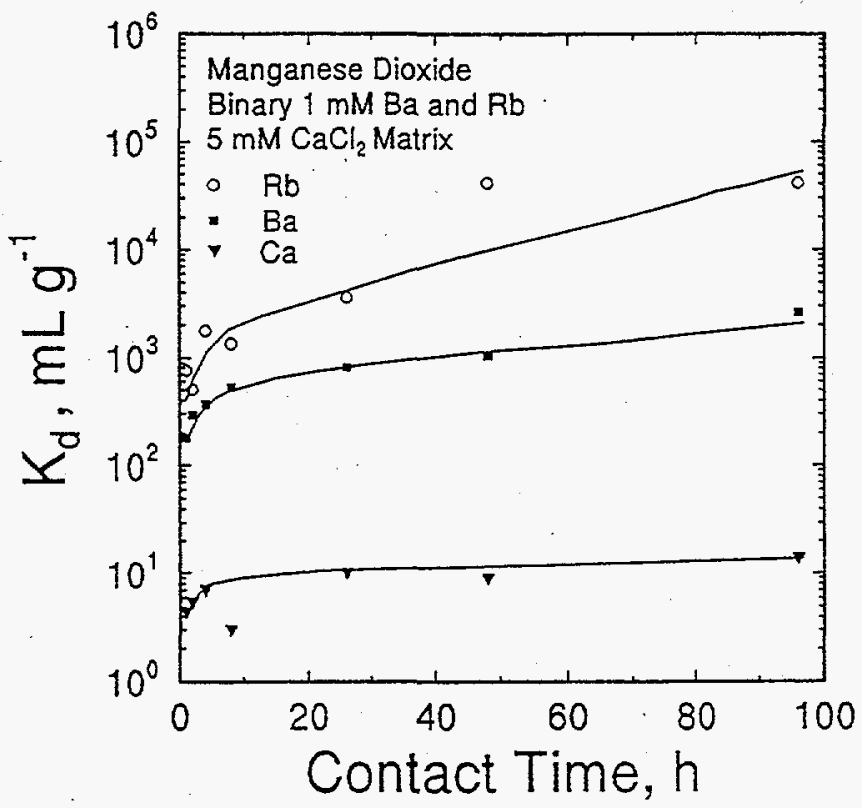

Figure 4.14. Changes in Distribution Coefficients with Time for $\mathrm{Rb}^{+}, \mathrm{Ba}^{2+}$, and $\mathrm{Ca}^{2+}$ Retention by Tunnel-Structure Manganese Oxide. $\mathrm{RB}^{+}$has the same ionic radius and serves as a conservative analog for $\mathrm{Ra}^{2+}$ 


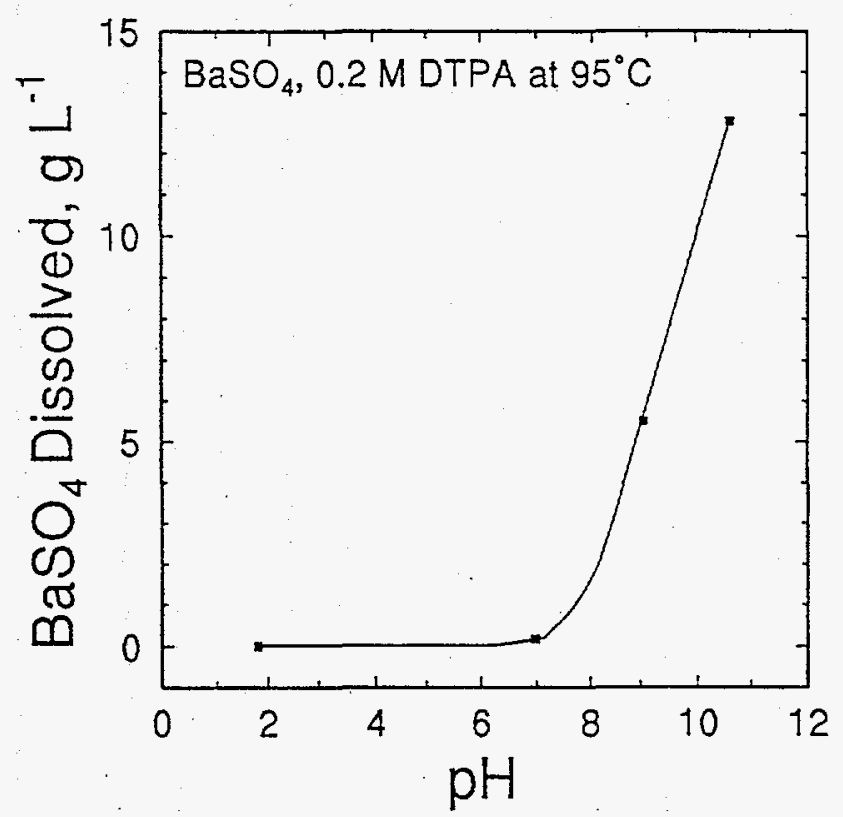

Figure 4.15. Changes in Equilibrium Concentrations of $\mathrm{BaSO}_{4}$ in $0.2 \mathrm{M}$ DTPA at $90^{\circ} \mathrm{C}$ as a Function of Solution $\mathrm{pH}$ 


\title{
5.0 3M Selective Separation Technologies for $\mathrm{Cs}$, $\mathrm{Sr}$, and $\mathrm{Tc}$
}

\author{
T. M Kafka and L. R. White, 3M Company
}

\subsection{Introduction}

DOE will rely extensively on efficient chemical separations technologies to treat radionuclidecontaining waste left behind from nuclear weapons production. One of the teams formed by DOE to address the separation of $\mathrm{Cs}, \mathrm{Sr}$, and $\mathrm{Tc}$ is $3 \mathrm{M}, \mathrm{IBC}$, and PNNL.

The waste varies in composition over extreme ranges of $\mathrm{pH}$ from acidic to basic. Bulk liquid and solid extraction processes can be used to remove the various radionuclides before vitrification or grouting but these processes have severe limitations. A new approach uses technology that has been developed to incorporate almost any sorbent particle into membranes and then fabricate these into versatile, highly efficient chemical absorbing cartridges.

The sorbent is loaded into a web or membrane that is used in a filtration-like process. Several classes of materials have been successfully incorporated into the $3 \mathrm{M}$ membranes including commercial organic ion exchange materials, inorganic adsorbents, unique zeolytic structures and sophisticated macrocyclic molecular recognition compounds. The resulting membranes are characterized by high separation efficiencies, radionuclide loading, fast flow rates and kinetics, and physical ruggedness. A radiolytically resistant material may be used as the membrane matrix. Because the membrane is very densely packed with small $(5-25 \mu \mathrm{m})$, high surface area particles, the flow rate can often be 10 to 100 times faster than standard column ion exchange processes while achieving equal extraction efficiencies. Particles of this size would result in unacceptable back pressure if used in columns. Channeling, which can be a severe limitation for columns, is absent in membranes, which is another reason high flow rates are possible. Th addition, this membrane separation technology allows the use of a number of known, high-performance, chemical adsorbing powders that previously could not be put into a useful engineered form because of their small particle size (Jones et al. 1966).

When the membrane is fabricated into a pleated cartridge large volume separations are possible. Cartridge capacity varies according to sorbent type and mass and the composition of the process stream. The equipment prototype is scalable to run at up to $50 \mathrm{gpm}$ using established technology previously developed and tested.

\subsection{Summary Highlights}

- A modular processing skid, including effective prefiltration, was developed as a part of the WVNS demonstration. A second system was assembled at INEL from the specification and used immediately without any modification or "debugging."

- The modular processing skid was used to remove Tc and Cs from more than 3,200 gallons of process water at WVNS, running at $0.3 \mathrm{gpm}$ 
- Cs and Sr were removed to below drinking water standards at the INEL TAN; 1,200 gallons were processed at $0.3 \mathrm{gpm}$. All other attempts to achieve this goal at TAN have been unsuccessful.

- A mobile PADU was designed, fabricated, and demonstrated. The small footprint (4 ft $x 5 \mathrm{ft})$ unit is capable of removing radionuclides at up to $10 \mathrm{gpm}$ and is scalable to operate at $50 \mathrm{gpm}$. Fresh adsorber cartridges are introduced to replace spent cartridges without any down time. The success of this unit suggests the potential application of the separation technology to large-scale projects. Scale-up factors are straightforward and well-understood, using an established technology and off-theshelf equipment.

- The PADU was demonstrated at the Hanford 100. Area N-Springs and N-Basin, removing $\mathrm{Sr}$ and $\mathrm{Cs}$ at a flow rates of 3.5 and $1 \mathrm{gpm}$, respectively. Separations performance was as predicted in laboratory pretrials.

- Progress was made on scaling up active particles, and new adsorbers were introduced.

- The WWL technology was scaled-up to the point where the membrane required for a large number of cartridges can be produced in a short time.

- It was demonstrated that a WWL membrane loaded with SuperLig@644 may be formed into a cartridge and used repeatedly to remove Cs from simulated NCAW waste and, after elution, deliver it in a more concentrated form. This may be done at 70 bed volumes per hour.

- A WWL/ SuperLigß644 cartridge was supplied to personnel at the ORNL for use in their evaluation of separation systems.

- Numerous visits were made to interact with DOE site personnel and to identify opportunities to apply the technology where it can provide clear advantages and thus accelerate its commercialization.

\subsection{Technology Demonstrations}

Technology demonstrations provide an effective method of testing the basic techniques that have been developed within the program, identifying and implementing necessary improvements, and operating on an increasingly large scale as a prerequisite to transferring the technology within the DOE complex and for commercialization.

\subsubsection{WVNS}

WVNS is carrying out a remediation program at a demonstration project near West Valley, New York. The liquid effluent from the site contains very small quantities of $\mathrm{Tc}$ and other regulated species. WVNS would like to remove at least $90 \%$ of the Tc from the effluent stream.

\subsubsection{Highlights}

A series of field tests was conducted using water from the Low Level Wastewater (LLW) 02 Facility at WVNS in which it was shown that: 
- Tc could be removed to the required level

- the residual $\mathrm{Cs}$ in the effluent could be removed to below detection limits

- the prefiltration system developed during the course of this first implementation of a new process scale separations technology was effective

- the need for a higher capacity Tc absorber was identified and membranes, based on a new resin, were shown to meet the DF requirement for more than 3,200 gallons, compared with 90 gallons using the previous material.

\subsubsection{West Valley I}

In February 1995, a cartridge-based test system was supplied to WVNS. Initial tests demonstrated that Tc could be removed from the process water in the LLW 02 area at WVNS using absorber cartridges containing Aliquat ${ }^{\mathrm{TM}}$ 336-treated (e.g., Darco G-60) loaded Empore ${ }^{\mathrm{TM}}$ membranes. Cumulatively, 360 gallons of water were processed at $0.1 \mathrm{gpm}$, and a DF of 10 was achieved before the system had to be shut down because of excessive pressure buildup (greater than $50 \mathrm{psi}$ ) due to plugging of the membranes.

The waste water contained $4.4 \mathrm{E}-7 \mathrm{~g} \mathrm{Tc} \mathrm{L}^{-1}$ or approximately $7.5 \mathrm{E}-6 \mu \mathrm{Ci} \mathrm{mL}{ }^{-1}$ of ${ }^{99} \mathrm{Tc}$. Initial batch distribution tests at WVNS, with samples of PNNL-prepared ion exchanger based on Aliquat ${ }^{\mathrm{TM}} 336$ and plant water, had shown that this was an effective method of removing Tc.

Figure 5.1 is a schematic diagram of the cartridge system. The 3-in.-diameter active cartridges were a nominal 4 in. high and contained approximately $1 \mathrm{ft}^{2}$ of membrane. The activated carbon-loaded Empore "post filter" cartridge was a nominal 10 in. high, ( $\left.3 \mathrm{in}^{2}\right)$, as was the silica-loaded Empore cartridge used as a prefilter.

It was shown that if a WWL membrane system were substituted for the Empore ${ }^{\mathrm{TM}}$ active membrane and an alternate system of prefilters used, the plugging (attributed to algae and zeolite fines) could be overcome (Dinsmore et al. 1996).

\subsubsection{West Valley II}

The objectives of the second demonstration (July 1995) were to 1) provide a continuously running system with no plugging of the active cartridges, 2) remove Tc from the system with a DF of 10 , and 3) polish/remove the Cs remaining in the water after it had been processed through the process ion exchange (IE-96) columns.

Figure 5.2 is a schematic of the separation and prefiltration system. Using $2-\mathrm{mm}$ and $0.1-\mathrm{mm}$ prefilters in series, together with two 4-in. cartridges containing carbon-loaded WWL membrane treated with Aliquat 336 to remove the Tc and a 4-in. cartridge containing K cobalthexacyanoferrate-loaded WWL membrane to remove the $\mathrm{Cs}$, the following results were achieved: 


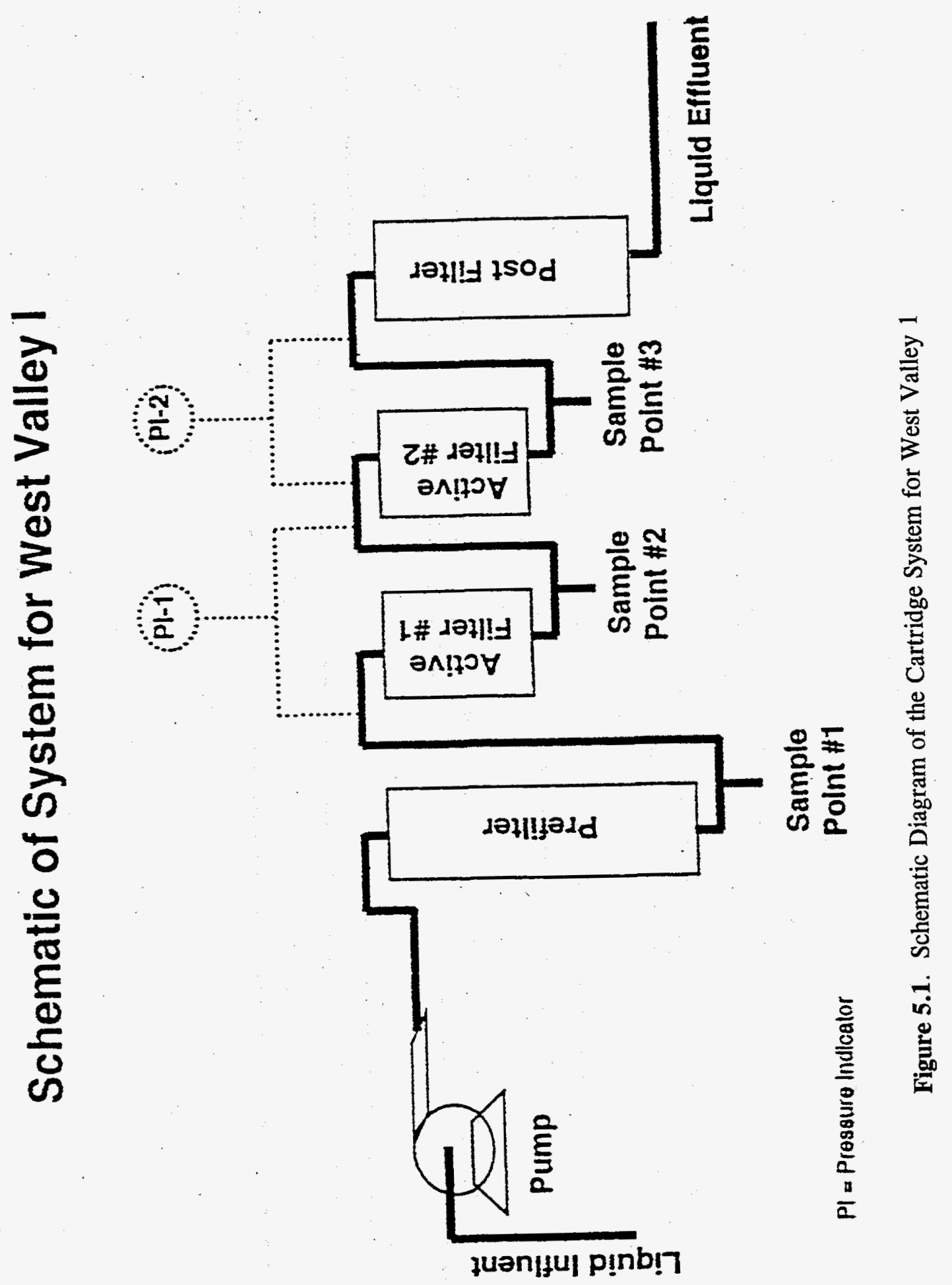




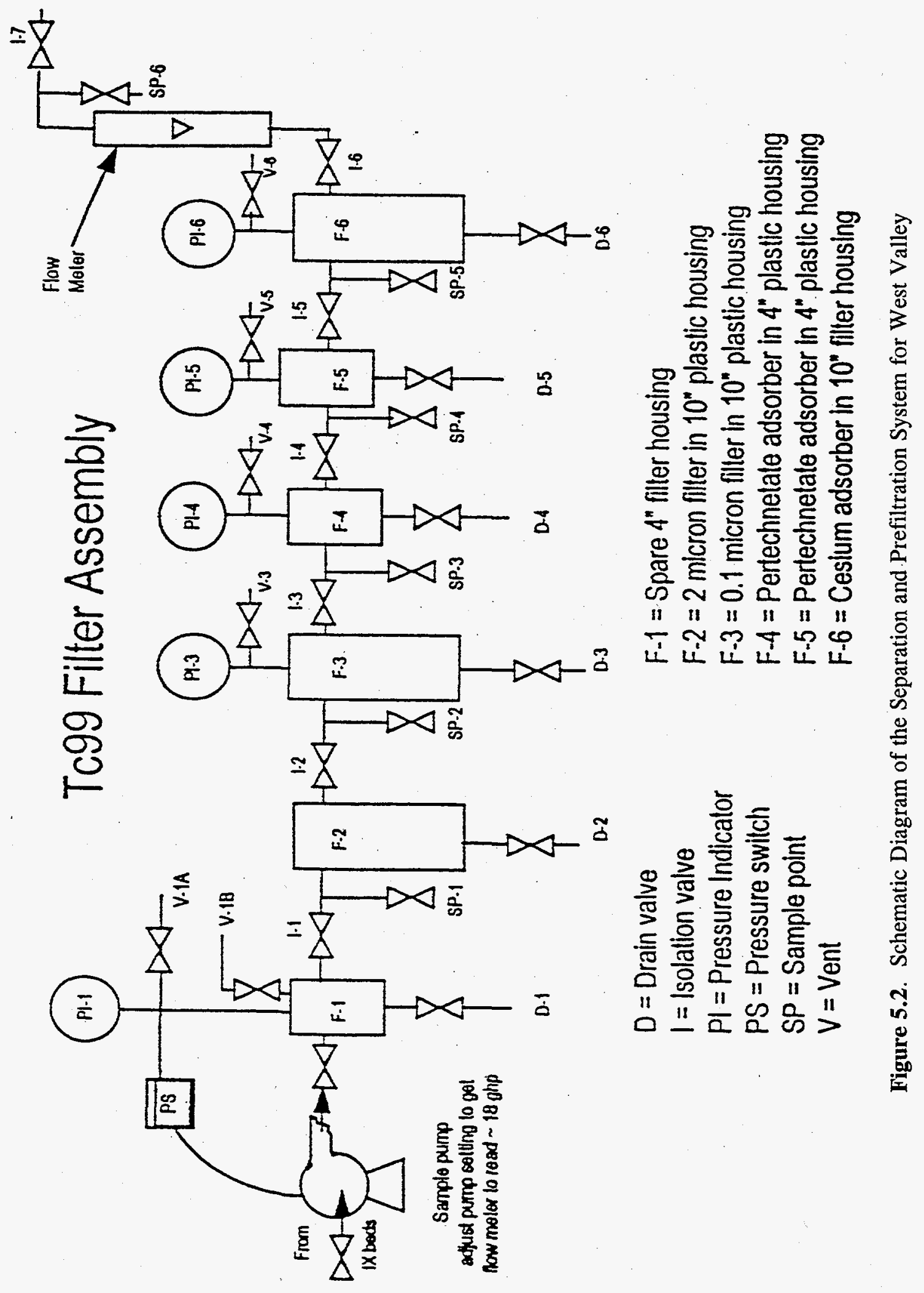


1. The system was run for 8 days at $0.1 \mathrm{gpm}$ without plugging of the active cartridges. (The $0.1-\mu \mathrm{m}$ cartridge had to be replaced every 15-20 hours.)

2. Tc was removed as required (see Figure 5.3). The first ${ }^{99} \mathrm{Tc}$ cartridge loaded to $50 \%$ breakthrough after passage of 93 gallons, and the second loaded to $50 \%$ breakthrough after 264 gallons indicating that both were functioning properly. Capacity was much lower than expected based on laboratory simulations using $\mathrm{ReO}_{4}^{-}$ion.

3. Cs was removed over a 41 -hour period, reducing the level from $1.17 \mathrm{E}-07$ to less than $4.39 \mathrm{E}-09 \mu \mathrm{Ci} \mathrm{mL}$ (detection limit). The active cartridge was then removed. On removal, the gamma count on the cartridge was reported to be 900 disintegrations per minute.

West Valley test, 7/24-8/2, 1995

Pertechnetate capture by Aliquat 336 on

activated carbon; flow rate $=8 \mathrm{gph}$,

WWL cartridge, 16 pleats, $100 \mathrm{mil}$ thickness

nominal four-inch cartridge

$100 * \mathrm{C} / \mathrm{Co}$, Co varied from 1100 to $1780 \mathrm{pCi}$. Average $\mathrm{Co}_{\mathrm{O}}=1379$

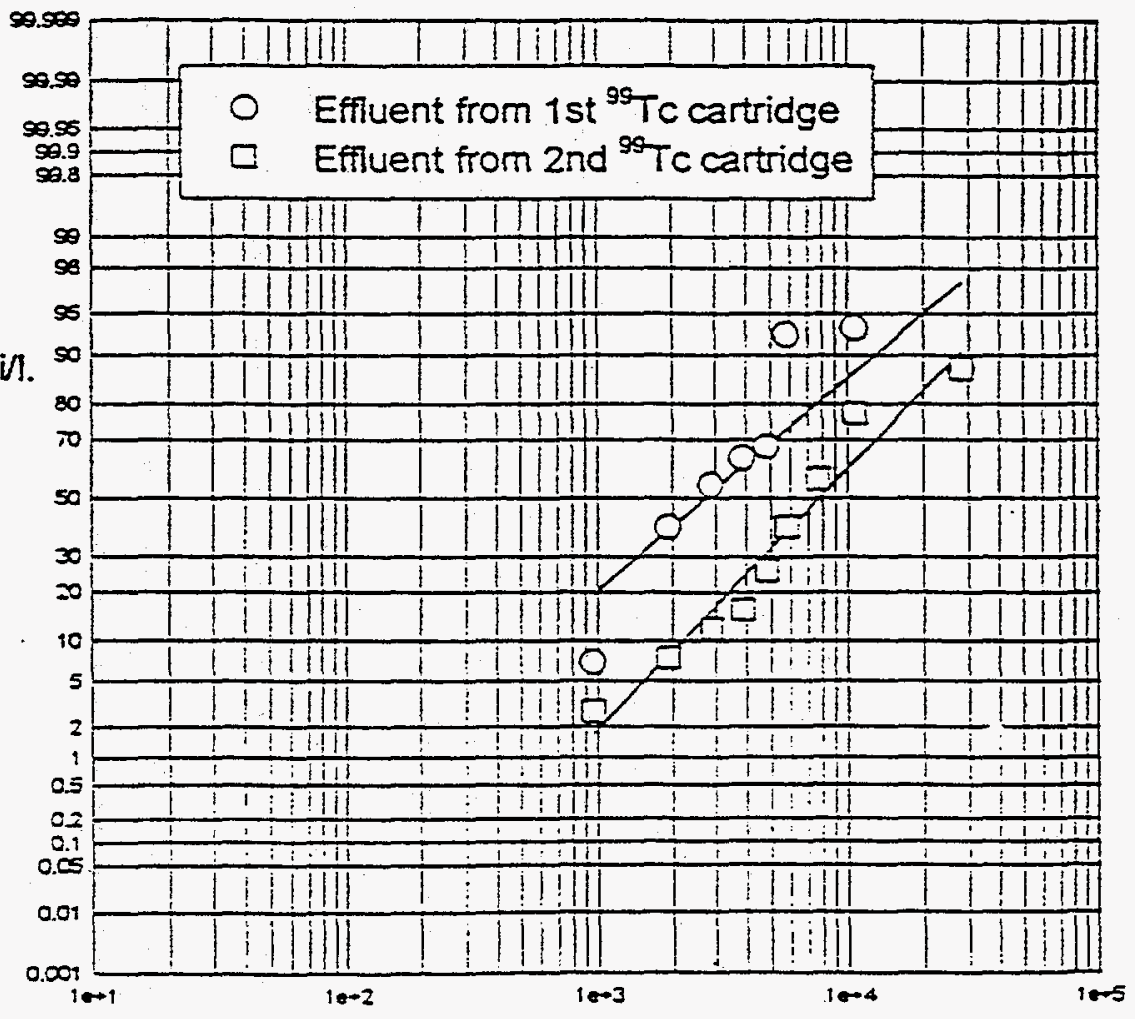

Number of column volumes, $1 \mathrm{CV}=126 \mathrm{ml}=0.033 \mathrm{gai}$

Figure 5.3. Tc Removal During the Second West Valley Demonstration 
Effect of Concentration and Competing Ions. The effects of competing ions and the actual concentration of pertechnetate were studied as possible explanations for the unexpectedly low Tc capacity that was observed at the site when compared with that predicted by laboratory trials.

Comparisons of the performance of SLP, Reillex ${ }^{\mathrm{TM}}$, (alternate anion adsorbers), and Aliquat 336/carbon as perrhenate adsorbers in the presence of competing anions showed that the competing ions are not a factor under the conditions involved here but that the concentration of the perrhenate (surrogate for pertechnetate) is a factor. With an SLP adsorber, reducing the concentration of perrhenate from 3.0 to $0.3 \mathrm{ppm}$ increased the volume to breakthrough by a factor of 3 and not 10 , which might be expected. This may explain why Tc breakthrough occurred much earlier than expected at WVNS, i.e., we cannot extrapolate performance at very low concentrations from performance at higher levels.

Alternative Resins. Alternative anion exchange resins were studied with the objective of finding a material that would have a larger capacity for pertechnetate so as to reduce the frequency of cartridge changeover. SLP, a proprietary strong anion exchange resin, was incorporated into WWL membrane and shown to have nearly ten times the capacity of Aliquat ${ }^{\mathrm{TM}} 336$ on activated carbon.

\subsubsection{West Valley III}

The primary objective of the third experiment at WVNS (January 1996) was to demonstrate the use of cartridges or other membrane holders loaded with high-capacity SLP anion exchanger to remove Tc. A secondary objective was to demonstrate the ability of membrane-loaded cartridges to remove trace amounts of $\mathrm{Cs}$ and $\mathrm{Sr}$, which remain in water that has passed through conventional ion exchange columns, using $\mathrm{K}$ cobalthexacyanoferrate (CoHex) and $\mathrm{Na}$ titanate, produced by AlliedSignal, as the adsorbers.

The equipment was the same as before except for the addition of a holder containing a 7-in.-diameter disk of SLP incorporated in WWL membrane. A slip stream was processed at $0.3 \mathrm{gpm}$, treating more than 3,200 gallons over 192 hours. The initial Tc concentration was $8.6 \mathrm{E}-7 \mathrm{Ci} / \mathrm{mL}$, and a DF of 100 was achieved at the beginning of the run that leveled off to 10 in the last several hours (Figure 5.4). Cs was not detected in the effluent of the test system at any time during the experiment: the initial Cs level was $3.8 \mathrm{E}-07 \mathrm{mCi} / \mathrm{ml}$, meaning that $4.7 \mathrm{mCi}$ of ${ }^{137} \mathrm{Cs}$ was collected by the cartridge. The analytical data indicate that $\mathrm{Sr}$ was not absorbed by the Na titanate cartridge. The reason for this is not understood because a similar experiment at NEL with a cartridge produced at the same time from the same batch of resin had been very effective (Herbst et al. 1995).

\subsubsection{Idaho Falls TAN}

Groundwater remediation efforts are in progress for injection well waters at TAN located at INEL. Efforts are primarily focused on the Technical Support Facility-05 injection well (TSF-05). The Groundwater Treatment Facility (GWTF) near the TSF-05 injection well at TAN was installed in 1994 to pump and treat the injection well water. The GWTF was designed for continuous operation at $50 \mathrm{gpm}$. However, ${ }^{137} \mathrm{Cs}$ was present in the water at higher concentrations than anticipated. The presence of ${ }^{137} \mathrm{Cs}$, combined with higher than expected concentrations of suspended particles, significantly hampered GWTF operations. 


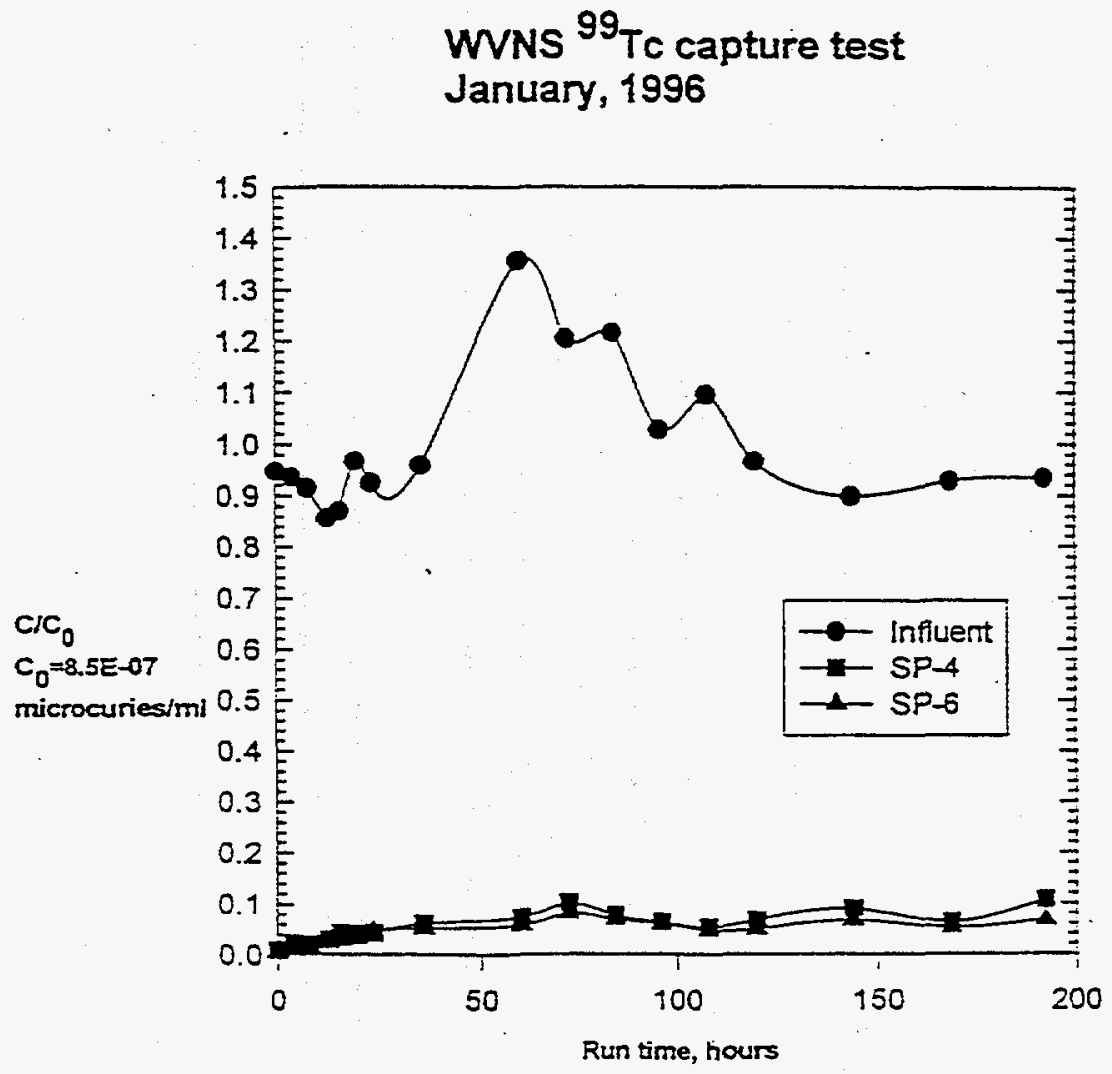

Figure 5.4. Tc Concentrations During the Third West Valley Demonstration

We were given the opportunity to demonstrate the effectiveness of a membrane cartridge system for the remediation of groundwater. Twelve hundred gallons of water that had been processed using the existing system at TAN but that still contained $33 \mathrm{pCi} / \mathrm{L}$ of ${ }^{90} \mathrm{Sr}$ and $256 \mathrm{pCi} / \mathrm{L}$ of ${ }^{137} \mathrm{Cs}$ were drummed and shipped to the Idaho Chemical Processing Plant (ICPP) where INEL personnel, under the direction of PNNL and 3M, continuously operated the system at 16 gallons per hour. Complete removal of the $\mathrm{Sr}$ and Cs was achieved, and the prefiltration system was shown to be effective. The demonstration is described in detail in Herbst et al. (1995).

The test was significant in that all other attempts at the TAN GWTF have been unsuccessful at removing radioactive $\mathrm{Cs}$ and $\mathrm{Sr}$ to acceptable levels $\left(118 \mathrm{pCi} / \mathrm{L}\right.$ for ${ }^{137} \mathrm{Cs}$ and $18 \mathrm{pCi} / \mathrm{L}$ for $\left.{ }^{90} \mathrm{Sr}\right)$. Representatives of R. M. Parsons Co. visited the test in progress and discussed the potential for additional testing and possible implementation.

The experience gained in this program, particularly as a result of the WVNS demonstrations, enabled definition of the separation skid that would be required at TAN. The components were purchased or fabricated by INEL personnel, assembled according to the specification, and performed as required on startup without any time lost for "debugging." 
The system comprised two prefilters followed by a 4-in. WWL/Na titanate cartridge to remove the Sr and a 4-in. WWL/CoHex ( $\mathrm{K}$ cobalthexacyanoferrate) cartridge to remove the $\mathrm{Cs}$. The Na titanate was obtained from AlliedSignal and the CoHex was produced at 3M. Initial breakthrough of Sr was observed at 550 gallons but $50 \%$ breakthrough did not occur until 800 gallons had been treated (Figure 5.5), indicating that for the most efficient, cost-effective system several cartridges would be used in series. Analysis showed that the process water (Table 5.1) contained significant quantities of $\mathrm{Ca}$ and other bivalent metals that were in competition with the Sr. Cs breakthrough was not observed, and the Cs levels in the effluent remained below detection limits $(9 \mathrm{pCi} / \mathrm{L})$. One prefilter was replaced after 84 hours to determine whether the flow rate could be increased. Beta activity was observed on the surface of the cartridge indicating Sr particulates in the water, possibly including fines from the ion exchange columns.

\subsubsection{Hanford N-Springs}

In January 1996, Sr was removed from water at Hanford's N Springs at $3.5 \mathrm{gpm}$, using the PADU for the first time (Figure 5.6). The unit was operated by BHI personnel under the direction of PNNL and 3M staff onsite. AlliedSignal's Na titanate was the active adsorber. The cartridges were fabricated in 3M's laboratory, and a pretreatment procedure was developed, based on advice from AlliedSignal, which increased their adsorptive capacity. Sr breakthrough was observed at 1,200 bed volumes, Sr activity was $1,090 \mathrm{pCi} / \mathrm{ml}$, the $\mathrm{Sr}$ concentration was $0.13 \mathrm{mg} / \mathrm{L}$, and the $\mathrm{Ca}: \mathrm{Sr}$ ratio was $230: 1$.

Analysis of the data confirmed that cartridges in parallel perform as individual cartridges but allow a higher flow rate to be attained ( $3.5 \mathrm{gpm}$ in this case). Figure 5.7 shows a comparison with the performance of a single cartridge.

\subsubsection{Hanford N-Basin}

The BHI staff responsible for the remediation of Hanford's $\mathrm{N}$ Basin requested that the PADU be evaluated for the removal of $\mathrm{Cs}$ and Sr. They had a need to process 1 million gallons of contaminated water by August 1996 and were interested in evaluating this technology as a back-up to their preferred method of trucking the water to the Effluent Treatment Facility for disposal.

The PADU demonstration took place in March 1996 under the supervision of PNNL and 3M personnel. The equipment and cartridges performed as predicted from previous work and the PNNL pretest using $\mathrm{N}$ Basin water. Sodium titanate and $\mathrm{CoHex}$ were used to remove $\mathrm{Sr}$ and $\mathrm{Cs}$, respectively. Sr removal was run at $2 \mathrm{gpm}$, Sr activity was $7,135 \mathrm{pCi} / \mathrm{ml}$, the $\mathrm{Sr}$ concentration was $0.39 \mathrm{mg} / \mathrm{L}$, and the $\mathrm{Ca}: \mathrm{Sr}$ ratio was $82: 1$.

Sr breakthrough was seen at 1,200 bed volumes as a result of competition from the high concentration of Ca present (Figure 5.8). The data for Sequence 2 are shown on Figure 5.9. Cs was removed at 1 gpm. No Cs (input ${ }^{137} \mathrm{Cs}=1,235 \mathrm{pCi} \mathrm{mL}{ }^{-1}$ ) breakthrough was seen with two of the three Cs cartridges used. Breakthrough was seen on the other cartridge, which is inconsistent with the long history accumulated with CoHex. Without running a repeat experiment, it is not possible to determine whether the problem is with cartridge fabrication or a mechanical defect in the system. 


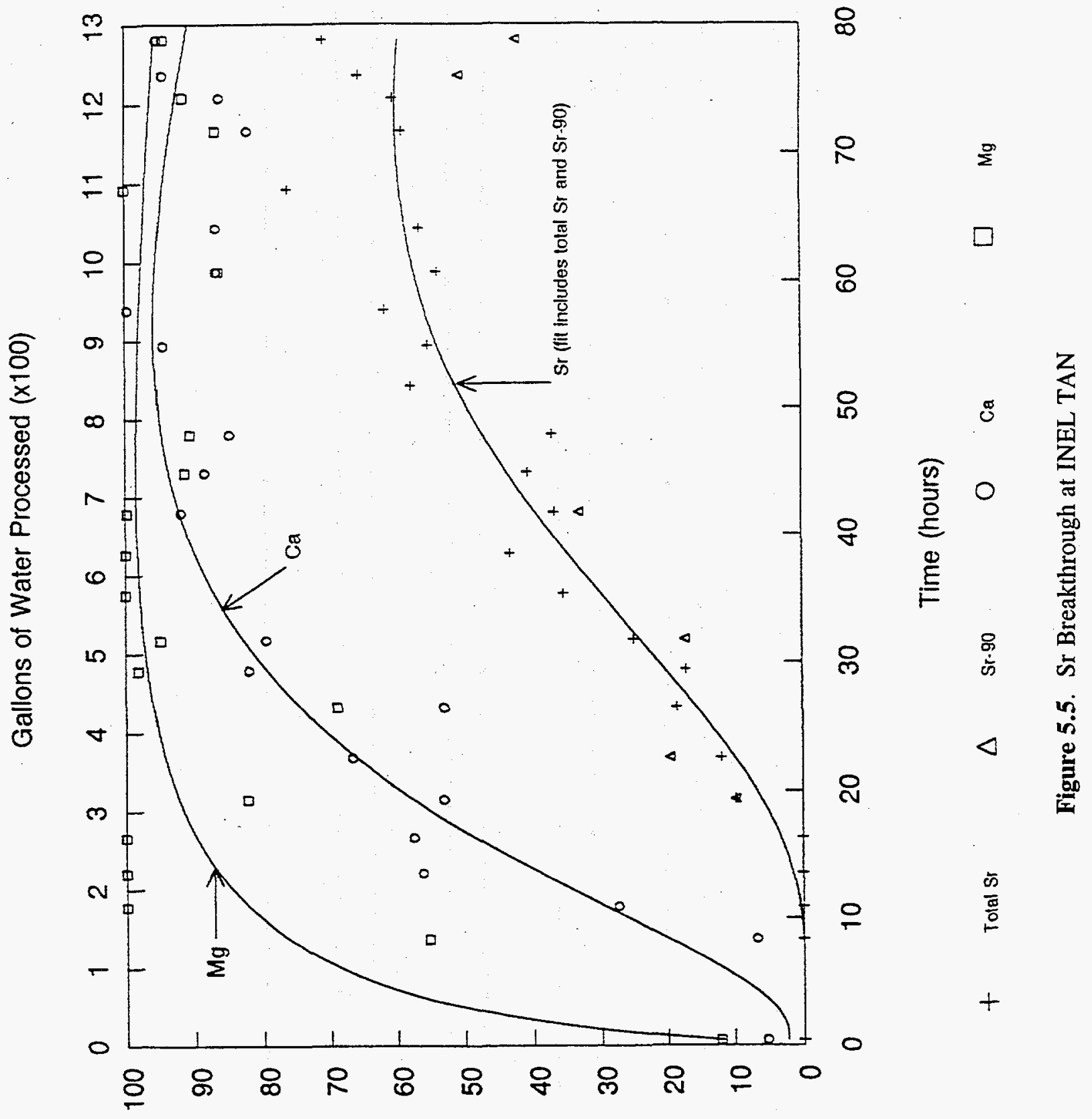

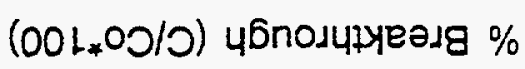


Table 5.1. Concentrations of Select Constituents in the Feed Water Used in this Study

\begin{tabular}{|c|c|}
\hline Element (Concentration Units) & Initial Concentration in Groundwater \\
\hline $\mathrm{Ca}(\mathrm{mg} / \mathrm{L})$ & 1.15 \\
\hline $\mathrm{Mg}(\mathrm{mg} / \mathrm{L})$ & 0.52 \\
\hline Total Sr $(\mathrm{mg} / \mathrm{L})$ & 0.0076 \\
\hline${ }^{90} \mathrm{Sr}(\mathrm{pCi} / \mathrm{L})$ & 33 \\
\hline${ }^{137} \mathrm{Cs}(\mathrm{pCi} / \mathrm{L})$ & 256 \\
\hline
\end{tabular}

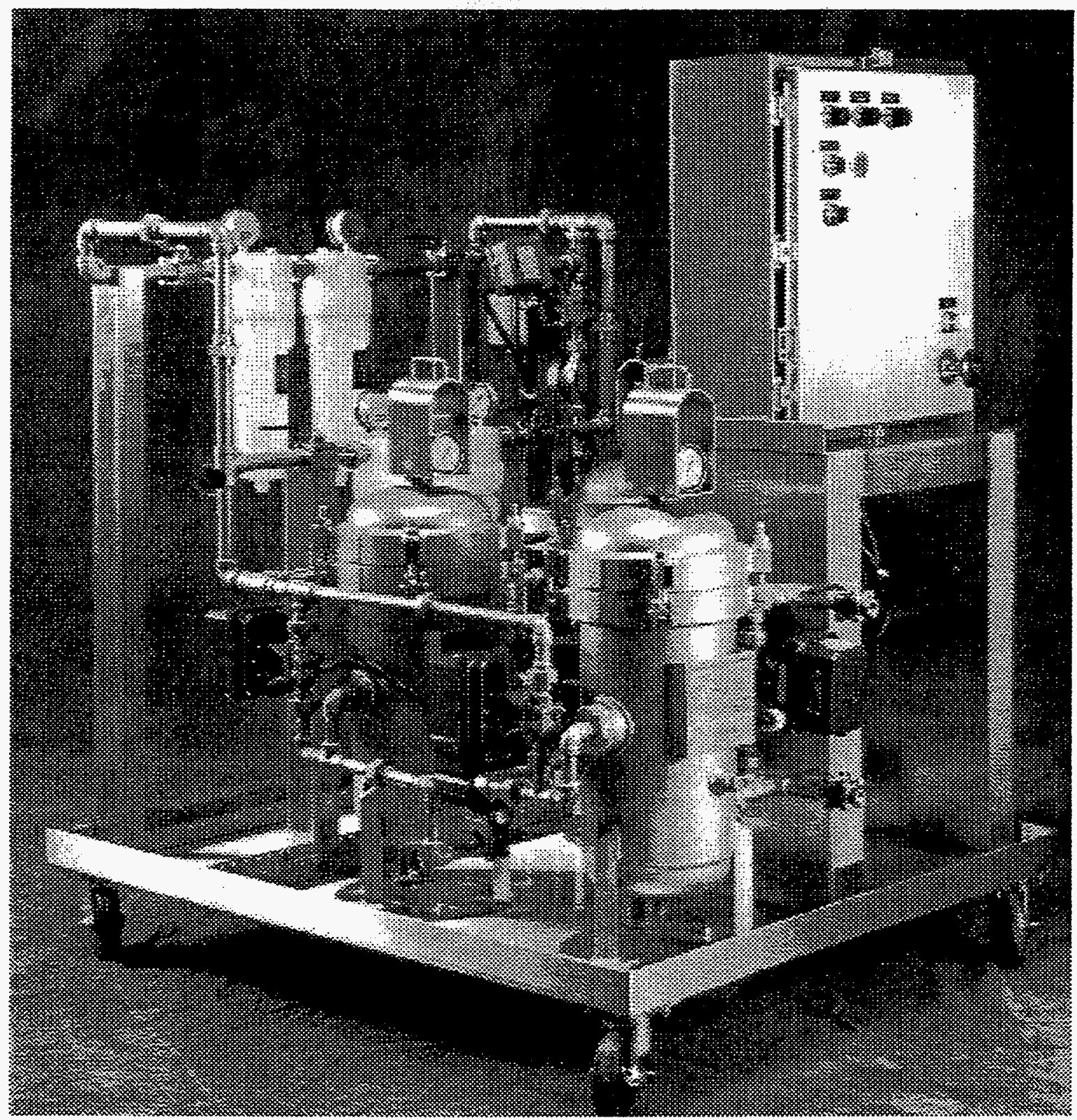

Figure 5.6. Process Adsorber Development Unit (PADU) 


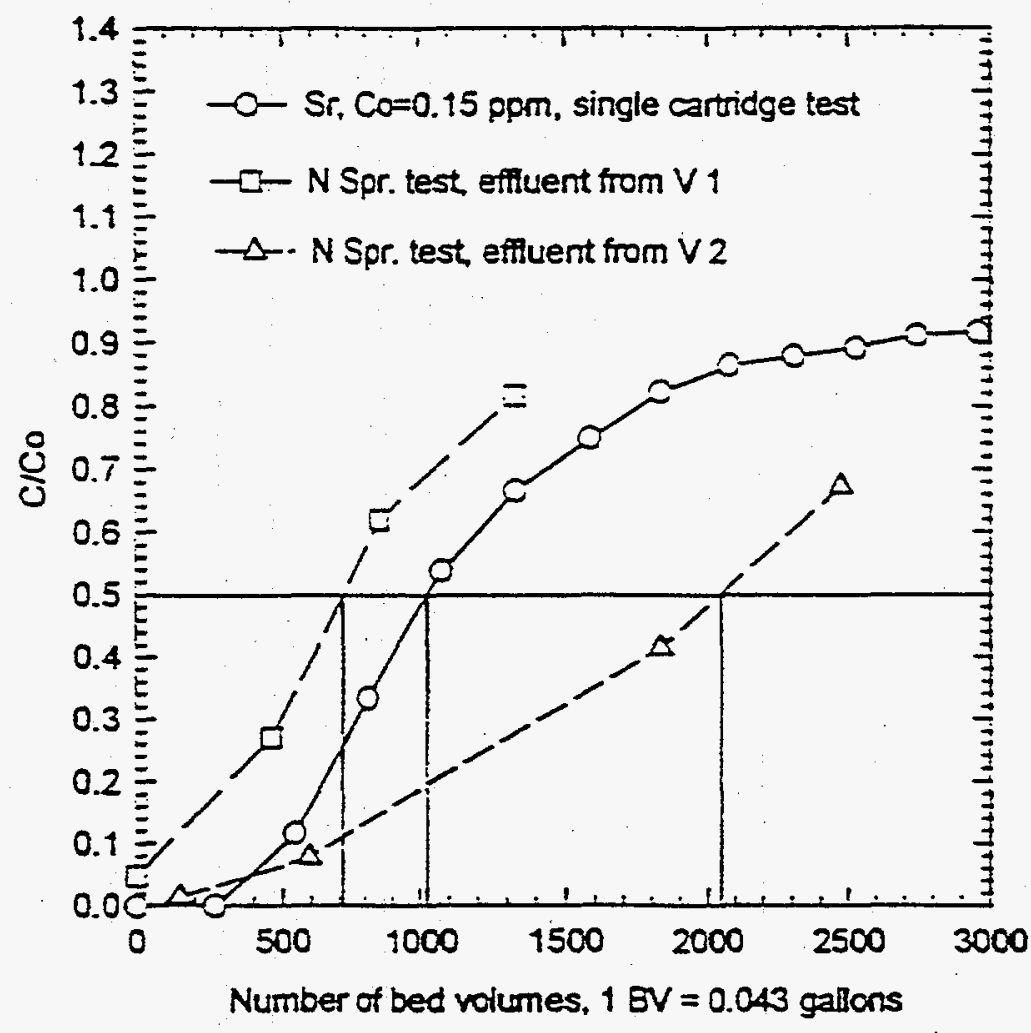

Fow rate in single artidge tat $=0.7 \mathrm{gpm}$

Fow rate in $N$ Springs test $=3-3.5 \mathrm{gpm} / 3$ cartidges in paralled

$[S T]=0.13$ ppra in N Springs water.

Figure 5.7. Performance of Cartridges in Parallel Compared with Performance of a Single Cartridge

\subsection{Materials and Equipment Development}

\subsubsection{Cs Adsorbers}

\subsubsection{SuperLig®644 Production}

IBC made progress toward the scale up of SuperLig®644, for Cs-specific separation from NCAW, $\mathrm{pH}$ 14 waste, to commercial manufacturing standards. The details are in Appendix C of IBC's report (Kafka 1995).

$3 \mathrm{M}$ provided assistance to IBC in their efforts to remove batch-to-batch variability in SuperLigß644. A multistage, multivariable process is involved, and the help was provided at one of the drying stages. $3 \mathrm{M}$ arranged for IBC to use larger scale processing equipment, and IBC's manufacturing manager ran 


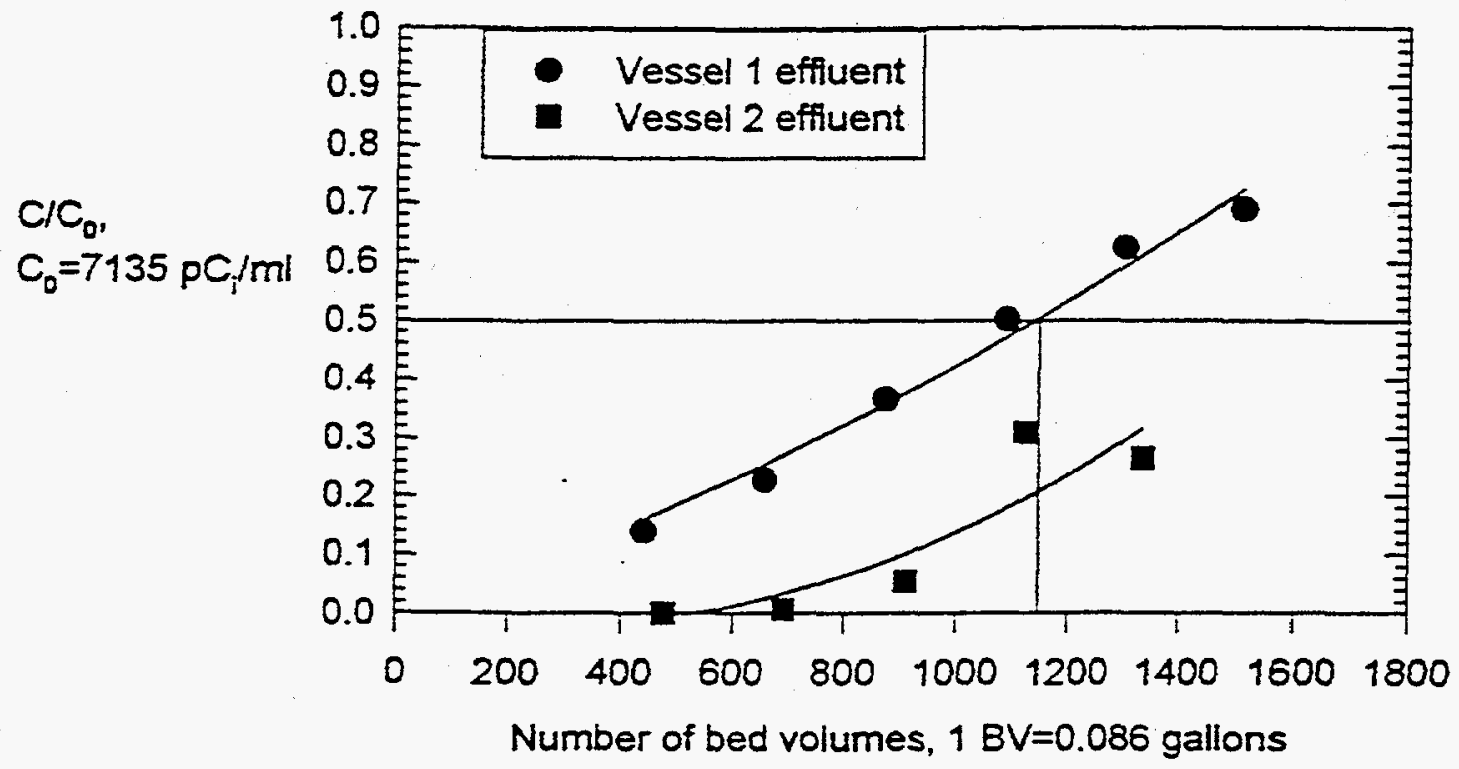

Figure 5.8. Sr Breakthrough Data at Hanford N-Basin, Sequence 1

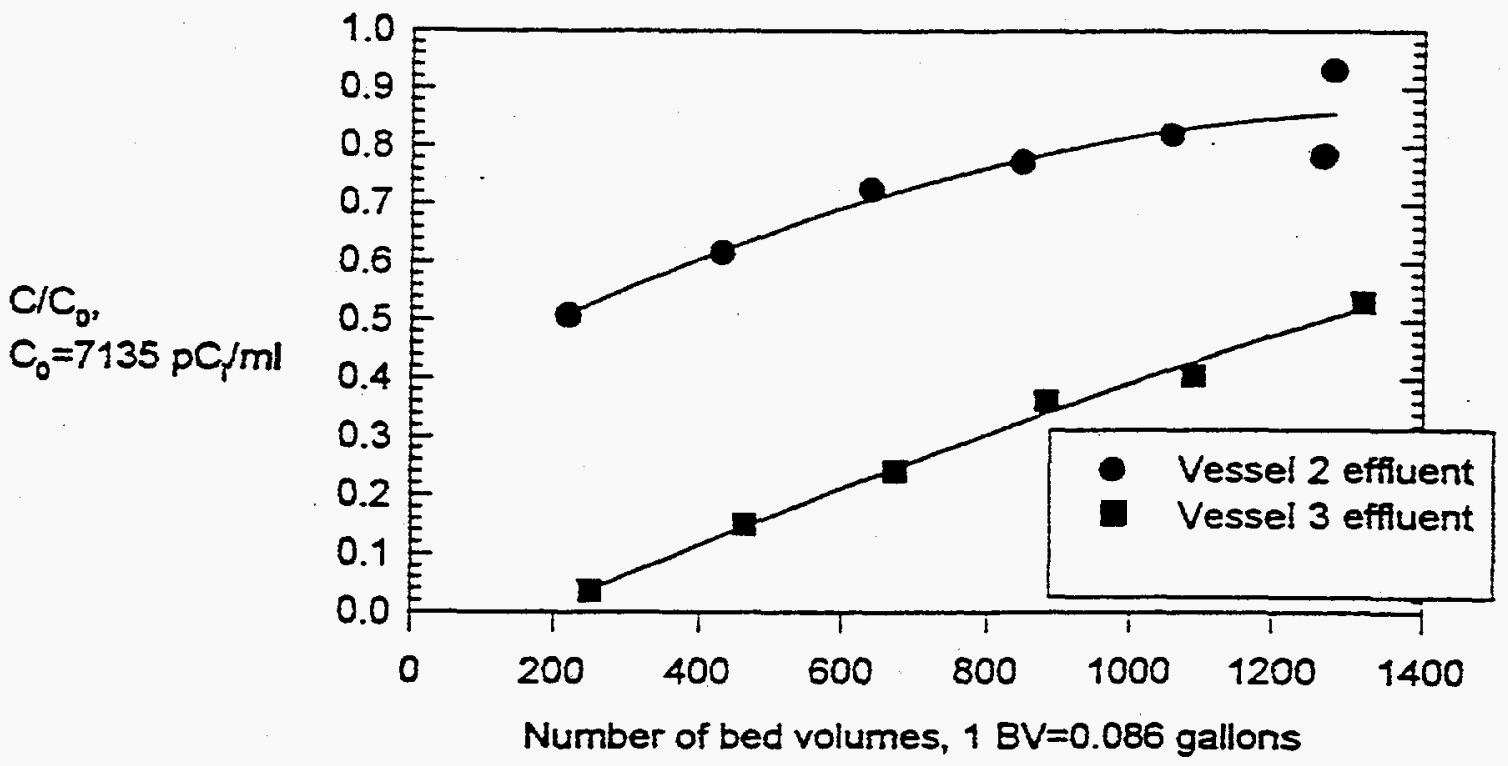

Figure 5.9. Sr Breakthrough Data at Hanford N-Basin, Sequence 2 
drying experiments at $3 \mathrm{M}$ for 2 days. Subsequently, $3 \mathrm{M}$ staff ran several additional experiments in cooperation with IBC. Two lots were produced that had similar drying curves.

\subsubsection{Potassium Cobalthexacyanoferrate (CoHex)}

CoHex, used by ORNL to remove Cs from solutions having a pH of up to 12 , similarly was found to yield outstanding results when incorporated into Empore and WWL membranes. Its use in the WVNS, TAN, and $\mathrm{N}$ - Basin demonstrations is described above. A form of CoHex that has a greater capacity than the commercially available material has been produced. Techniques have been developed for producing large batches of material that has a narrow particle size distribution. A patent application has been filed covering one part of the process. The material can be produced in the large quantities required for the production of adsorber cartridges.

\subsubsection{Strontium Adsorbers}

While a number of excellent Sr adsorbers are available, we have not been able to identify one that will exclusively remove $\mathrm{Sr}$ in the presence of a large amounts of $\mathrm{Ca}$ as is frequently found in groundwater, e.g., at INEL TAN and at Hanford. As a result, cartridges must be changed frequently because the available sites are rapidly occupied by $\mathrm{Ca}$, which leaves little capacity for $\mathrm{Sr}$. While continuing to search for a superior adsorber (new materials from TAMU and Lawrence Berkeley were evaluated), we have used Na titanate to remove $\mathrm{Sr}$ in the demonstrations conducted during the past year. A procedure for regenerating the $\mathrm{Na}$ titanate is being developed so that by following a convenient load/elute cycle, Sr may be removed from a system with fewer cartridge changes required.

\subsubsection{Tc Adsorbers}

Alternative anion exchange resins were studied with the objective of finding a material that would have a larger capacity for pertechnetate than the Aliquat ${ }^{\mathrm{TM}} 336$ used in the first two demonstrations at WVNS, to reduce the frequency of cartridge changeover.

SLP, a proprietary strong anion exchange resin, was incorporated into WWL membrane and shown to have nearly ten times the capacity of Aliquat ${ }^{\mathrm{TM}} 336$ on activated carbon.

Reillex ${ }^{\mathrm{TM}}$ NPQ polymer was also considered. On incorporation into WWL, it was shown to have high capacity but swelling was a concern. In one experiment, it was necessary to reduce flow because pressure drop across the membrane exceeded 70 psi. Fifty percent breakthrough occurred at $9,000 \mathrm{BV}$ compared with 8,500 for SLP, with a challenge of $\left[\mathrm{ReO}_{4}^{-}\right]=2 \mathrm{mg} \mathrm{L}^{-1}$ at a flow rate of $300 \mathrm{BV} /$ hour.

\subsubsection{WWL Membrane Development}

As previously reported in Bray et al. (1995), a proprietary membrane, WWL, has been developed that provides the same separation characteristics as Empore ${ }^{\mathrm{TM}}$ membranes while providing durability at high radiation levels and strongly alkaline ( $\mathrm{pH} \mathrm{14)} \mathrm{conditions.} \mathrm{A} \mathrm{patent} \mathrm{application} \mathrm{for} \mathrm{this} \mathrm{material} \mathrm{has} \mathrm{been}$ filed. 
Processing trials resulted in several major advances leading to the continuous production of CoHexloaded WWL membrane with consistent cross-web and down-web properties. Sufficient material to form 60 cartridges was produced. The product met expectations in every respect except caliper. It was difficult to produce 0.055 -in. material and a caliper of 0.083 in. was accepted for most of the run. A web monitoring and control technique has been developed. To minimize costs, all process development work, with the exception of the production run discussed above, is done using titanium dioxide as a surrogate for CoHex.

\subsubsection{Cartridge Design}

Experiments have shown that the pressure drop across a cartridge is reduced (to the order of 3 psi across a 7-in.-high CoHex cartridge at $1 \mathrm{gpm}$ ), allowing it to be used at a higher flow rate and/or with less rigorous prefiltration when a thinner version of WWL membrane is used. Total membrane volume, and therefore cartridge capacity, is maintained by forming the thinner web into a larger number of pleats.

A study of the effect of flow rate and cartridge holder design on separation performance has begun. These may be considerations as larger cartridges are designed. Flow by cartridge concepts are being evaluated as a means to minimize the need for prefiltration.

\subsubsection{Cartridge Cycling}

We demonstrated that a WWL membrane loaded with SuperLigß644 may be formed into a cartridge and used repeatedly to remove Cs from a NCAW simulant and, after elution, deliver it in a more concentrated form for conversion into glass logs. This may be done at a rate of over 70 bed volumes per hour, compared with the rate of 5-10 bed volumes when ion exchange columns are used.

Many of the performance characteristics reported are functions of the active adsorbent. In the case described here, the best available samples of SuperLig $® 644$ did not match the excellent performance of the material that was seen earlier. Elution peaks of $350 \mathrm{mg} \mathrm{L}^{-1}$, rather than $>2,000 \mathrm{mg} \mathrm{L}^{-1}$ demonstrated by the earlier material, combined with a long "tail" resulted in low volume compressions. Swelling of the particle led to reduced flow rates and probably increased the possibility of salting the membrane. The extreme expansion (swelling) and contraction of the particle caused high pressures and contributed to premature failure of the cartridge.

Ten load/elute cycles were run on a single cartridge, which performed adequately for nine of the cycles. A declining ability to load and elute was observed as the number of cycles increased. A total of 3.29 grams of Cs was loaded and eluted from the NCAW matrix over 54 hours.

This experiment should be used as a building block in the development of better materials, processing variables, and the whole Cs removal system. Active particle performance and characteristics need to be developed further to optimize the performance of the total system. Processing variables to help performance have yet to be optimized. Improved cartridge design will also help performance. 


\subsubsection{Mobile Process Adsorber Development Unit (PADU)}

A Mobile PADU (Figures 5.6, 5.10, and 5.11) was designed, fabricated, and used successfully in demonstrations at Hanford's N-Springs and N-Basin. The PADU has a 4-in. $x$-in. footprint and uses multiple cartridges in series and parallel to prefilter system water, remove radionuclides to customer specified levels, and introduce fresh cartridges to replace loaded ones without any down time. As supplied, the system is capable of running at up to $10 \mathrm{gpm}$. The system is the prototype for units with only a slightly larger footprint that are capable of running at $50 \mathrm{gpm}$. Scale-up factors are straightforward and well-understood, using an established technology and off-the-shelf equipment.

Before shipment, the PADU was tested using activated carbon loaded Empore ${ }^{\mathrm{TM}}$ cartridges to capture perhenate ion. Data showing that the unit performed as expected with $50 \%$ breakthrough at 1,000 bed volumes are presented in Figure 5.12.

\subsubsection{Remote Handling and Cartridge Disposal}

The maximum benefit can be obtained from our membrane technology if cartridges can be loaded to their full capacity with radioactive material, removed from the system, and then reduced to as small a volume as possible before final storage/disposal. Pacific Enterprizes Inc. (PEI), and probably other vendors, have the ability to design and produce such systems. PEI's system uses a remote arm and grapple to move a cartridge loaded with radioactive waste into a shielded container, which is transported to a location where the cartridge is crushed and sheared into small sections for disposal.

\subsection{Cross Program Interactions}

The versatility of $3 \mathrm{M}$ 's membrane technology enables it to be used to enhance the practical performance of active particles developed in other parts of the EM-50 Efficient Separations Program. Numerous interactions between sites continued during the year.

TAMU/AlliedSignal developed the $\mathrm{Na}$ titanate that was used in the demonstrations described above. Crystalline silicotitanate developed by Sandia/UOP was incorporated into WWL membrane.

Savannah River continued to provide support for the Environmental Sampling Program. SLP anion exchange material incorporated into WWL membrane was shown to be effective in removing complexed mercury from drummed waste at Savannah River.

\subsection{Site Visits and Meetings}

Numerous site visits were made to prepare for and participate in technology demonstrations and identify potential applications for the technology developed in this program.

Papers were presented at the ESP Annual Technical Exchange Meeting, Waste Management 1996, Pittcon, and EPRI: 1996 International Low Level Waste Conference. 


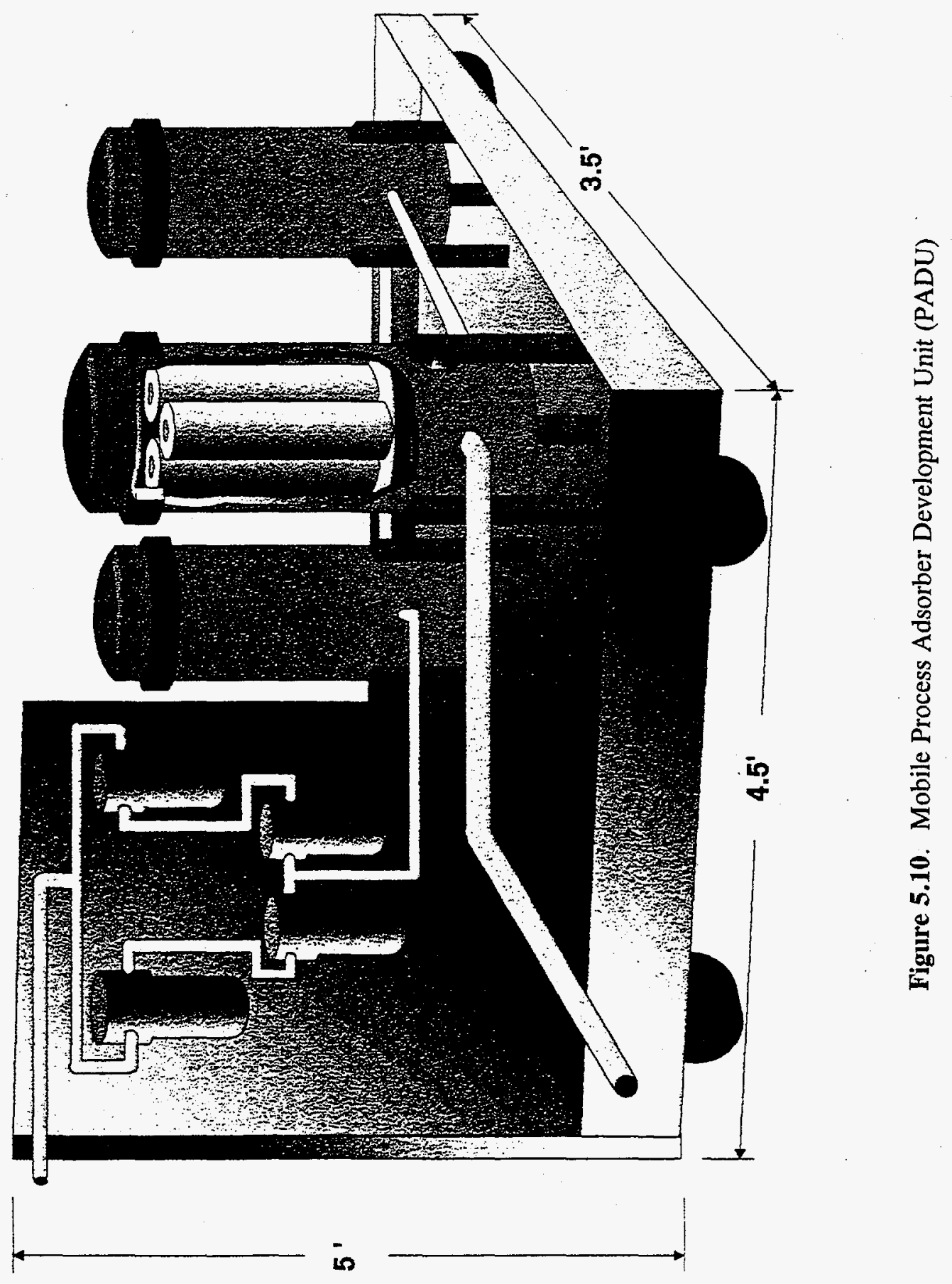




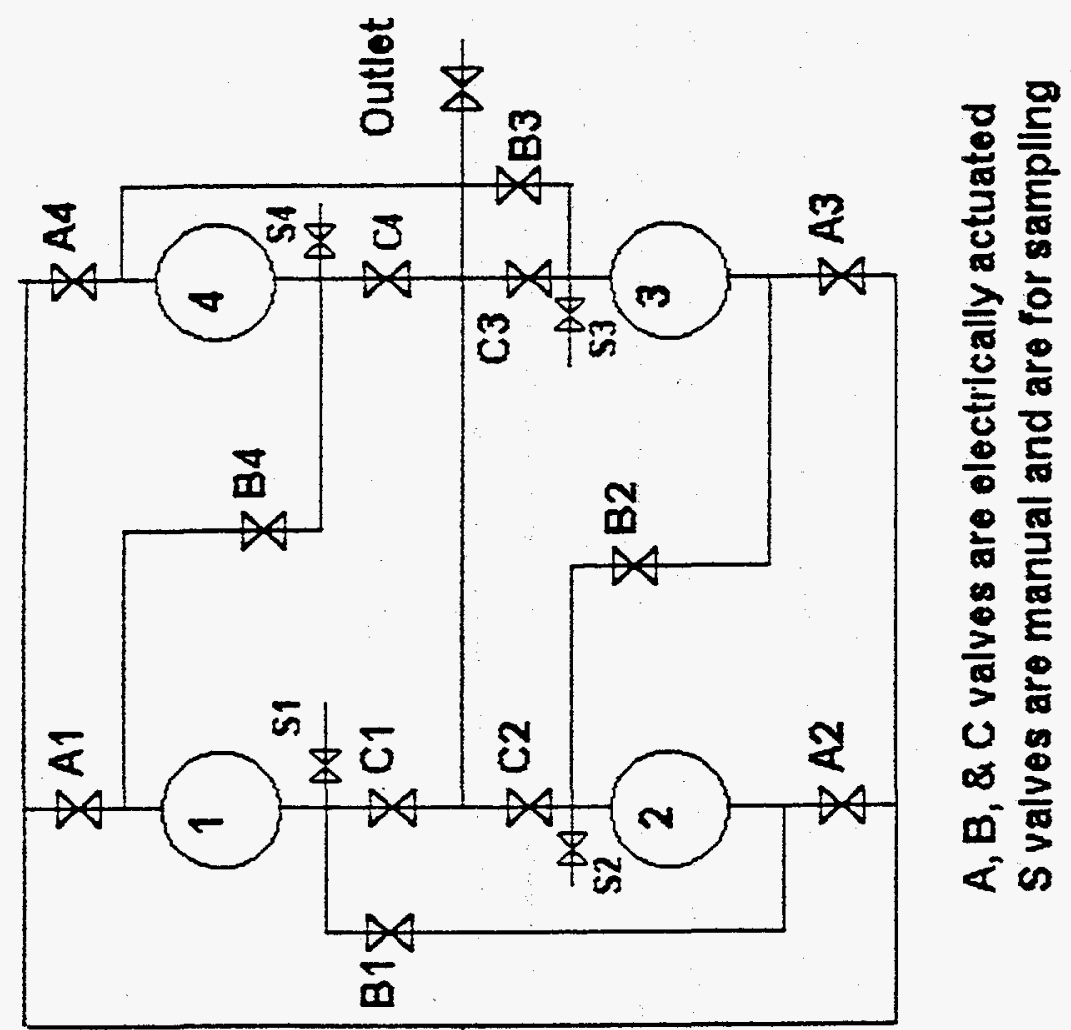

造

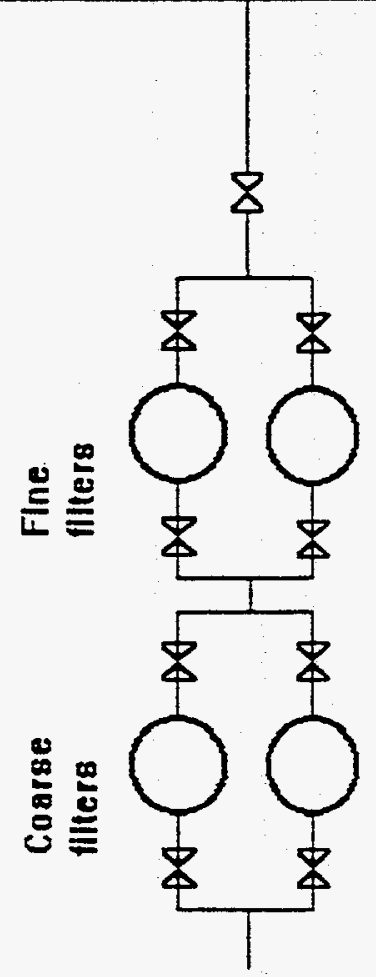

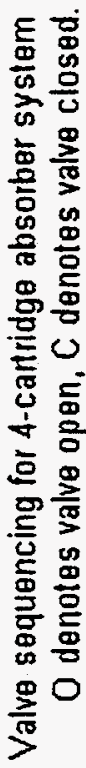

200000

Ev000000

F.

Kou000

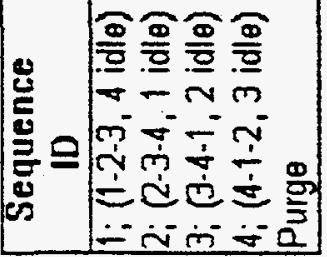




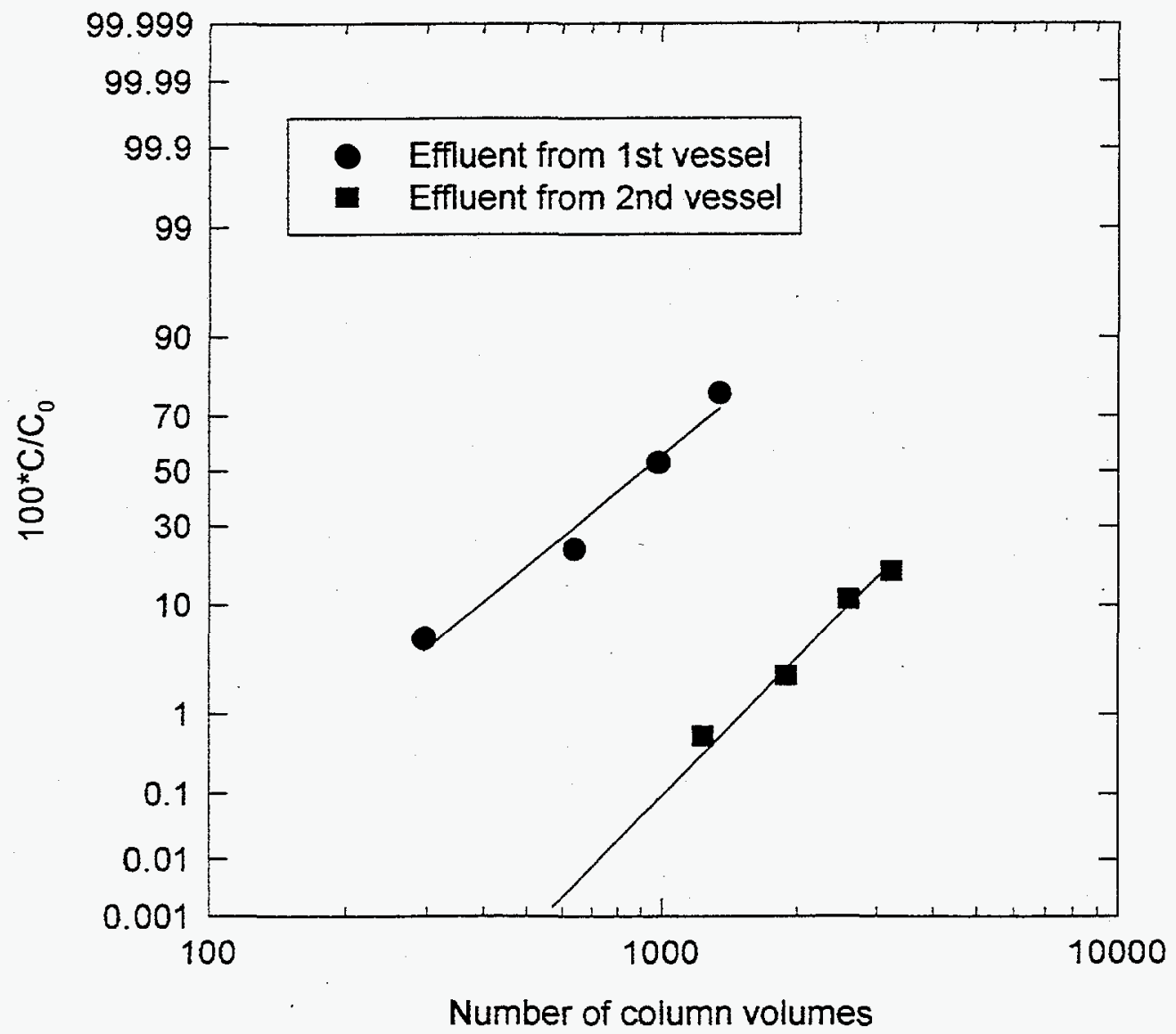

$\mathrm{C}_{0}=7.1 \mathrm{mg} / \mathrm{l}$

Three cartridges in each vessel

1 bed volume $=0.169$ gallons for vessel 1

1 bed volume $=0.182$ gallons for vessel 2

padushdn.spw

Figure 5.12. PADU Shakedown; Capture of Perrhenate Ion by Carbon/EMPORE ${ }^{\mathrm{TM}}$ 


\subsection{Future Work}

Demonstrations are planned for the INEL TAN to remove Cs directly from the waste stream rather than from previously processed water, and for the R-Basin at Savannah River to remove PCBs and Cs from stored water using the PADU.

Subject to the availability of funding, additional technology demonstrations are required in order to generate performance data required for technology transfer. Systems should be identified for appropriate shielding of modules and disposal of membranes and cartridges. 


\subsection{Novel Inorganic Ion Exchangers \\ S. A. Yates, AlliedSignal, Inc., and A. Clearfield, Texas A\&M}

AlliedSignal has a subcontract with Prof. A. Clearfield and his team at TAMU to develop and synthesize new ion exchange materials. As materials are developed, they are transferred to AlliedSignal for further testing, commercialization, and characterization. As samples are prepared by either AlliedSignal or TAMU, they are sent to PNNL for evaluation of chemical and radiation stability, tracer studies with synthetic wastes, and selected tests with actual wastes.

AlliedSignal/TAMU have prepared samples of $\mathrm{Na}$ titanate in the powder form and have discovered a binder that is radiation- and caustic-stable. Engineered-form $\mathrm{Na}$ titanates show $\mathrm{Sr}$ values equal to that of the powders. In addition, a series of Cs-specific compounds are being investigated for use in removing Cs from acidic waste streams, groundwater streams, and high-Na alkaline waste streams.

Two milestone reports were completed during the year, "Progress in Developing Sodium Nonatitanate as a Selective Strontium Sequestrant for Savannah River" by S. F. Yates, and "Cs and Strontium Ion Specific Exchangers for Nuclear Waste Effluent Remediation" by A. Clearfield, A.I. Bortun, L. N. Behrens, and E. Poojary. The following summarizes work on the development of novel ion exchangers for Cs and Sr during FY 1996.

\subsection{Exchanger Screening}

\subsubsection{Group 4B Trisilicates: A New Family of Ion Exchangers}

A new family of hydrous $\mathrm{K}$ trisilicates of $\mathrm{Ti}, \mathrm{Sn}$, and $\mathrm{Zr}$ has been prepared using a "soft chemistry" approach; namely, by synthesis from homogeneous or quasi-homogeneous reaction mixtures under mild hydrothermal conditions $\left(180-190^{\circ} \mathrm{C}\right)$. Several isomorphously substituted $\mathrm{K}$ Ti-zirconium and $\mathrm{Ce}(\mathrm{IV})-\mathrm{Zr}$ trisilicates were also synthesized by this technique.

All the synthesized compounds were characterized with the use of elemental analysis, TGA, X-ray${ }^{29}$ Si MAS NMR, IR spectroscopy and adsorption methods. It was found that the novel metal trisilicates have a channel structure, with inner cavities serving as selective adsorption sites, the diameters of which depend on the size of polyvalent metal atom. This means that by varying the chemical composition of the exchanger it is possible to regulate, within certain limits, its selectivity. The selectivity changes were measured by $\mathrm{K}_{d}$ values for alkali metal cations. Potassium titanium trisilicate, which has the smallest size of channels among the synthesized exchangers, does not uptake $\mathrm{Li}, \mathrm{Na}$, and $\mathrm{Cs}\left(\mathrm{K}_{d}<20\right)$ and exhibits "absolute" selectivity for $\mathrm{K}+$. Potassium ions could be removed from the compound only after its decomposition. Tin trisilicate, having larger size of adsorption sites, begins to adsorb $\mathrm{Na}\left(\mathrm{K}_{\mathrm{d}} 50 \mathrm{~mL} \mathrm{~g}^{-1}\right)$ and $\mathrm{Cs}\left(\mathrm{K}_{\mathrm{d}}, 300 \mathrm{~mL} \mathrm{~g}^{-1}\right)$, though it also preferably takes up $\mathrm{K}$. Further increase of the unit cell parameters, in the case of $\mathrm{Zr}$ trisilicate, enables it to adsorb selectively $\mathrm{Cs}\left(\mathrm{K}\right.$-form $\mathrm{K}_{\mathrm{d}} 1,100 \mathrm{~mL} \mathrm{~g}^{-1}$; Na-form $\mathrm{K}_{\mathrm{d}}$ 
$200,000 \mathrm{~mL} \mathrm{~g}^{-1}$ ) when the content is low ( $<5 \%$ of the IEC). Mixed Cr(IV)-Zr trisilicates with even larger dimensions of its channels are under investigation, and it is possible that a further increase in selectivity toward Cs ion will occur.

Some additional information on the selectivity of Cs adsorption by $\mathrm{Na}$ zirconium trisilicate (SZTS) as exhibiting the best performance for Cs was obtained by the potentiometric titration method using $0.05 \underline{\mathrm{M}}$ $\mathrm{CsNO}_{3} / \mathrm{CsOH}$ solutions and, in some cases, containing additionally 0.05-0.5 $\mathrm{M} \mathrm{NaNO}_{3}$ background electrolyte. The theoretical ion exchange capacity for SZTS is $4.99 \mathrm{meq}^{-1}$. For individual Cs-containing solutions, Cs uptake starts at $\mathrm{pH}<1-2\left(2.5 \mathrm{meq}^{-1}\right)$ and increases gradually to $3.5 \mathrm{meq}^{-1}$ at $\mathrm{pH} 13$. SZTS preferably adsorbs $\mathrm{Cs}$ in acid and neutral media ( $\mathrm{pH} \mathrm{2-7),} \mathrm{whereas} \mathrm{in} \mathrm{alkaline} \mathrm{media} \mathrm{its} \mathrm{affinity} \mathrm{for} \mathrm{K}$ prevails over that for Cs. The Cs potentiometric titration curve for SZTS obtained in the presence of $0.05 \underline{\mathrm{M}}$ $\mathrm{NaNO}_{3}$ electrolyte does not differ significantly from the previous one: Cs uptake is in the range of $2.55-3.15 \mathrm{meq} \mathrm{g}^{-1}$ at $\mathrm{pH}=7-12$. This is more than $60 \%$ of the theoretical IEC. Further increase of the $\mathrm{Na}$ content in the solution up to $0.5 \underline{\mathrm{M}}$ results in a certain decrease of Cs adsorption (DA=0.6-0.7 meq $\mathrm{g}^{-1}$ ), but this decrease is not proportional to the $\mathrm{Na}$ concentration increase (10 times). Cs uptake by SZTS at $\mathrm{pH}=6-10$ is about $2.0 \mathrm{meq} \mathrm{g}^{-1}(40 \%$ of the theoretical IEC), and there is a tendency for it to increase with the $\mathrm{pH}$ increase $\left(\AA=2.4 \mathrm{meq} \mathrm{g}^{-1}\right.$ or $48 \%$ of IEC at $\left.\mathrm{pH}=12\right)$. Comparative analysis of these data with those for Cs uptake by $\mathrm{Na}$ titanium silicate $\mathrm{Na}_{2} \mathrm{Ti}_{2} \mathrm{O}_{3}\left(\mathrm{SiO}_{4}\right)$ (the best known exchangers for Cs in highly alkaline media) suggests that the capacity of SZTS for Cs is much higher.

Adsorption of $\mathrm{Cs}$ and $\mathrm{Sr}$ from groundwater simulant by SZTS and $\mathrm{Na}_{2} \mathrm{Ti}_{2} \mathrm{O}_{3}\left(\mathrm{SiO}_{4}\right)$ (for comparison) was studied by batch method at V:m ratio $(1,000-12,000): 1\left(\mathrm{~mL} \mathrm{~g}^{-1}\right)$, ambient temperature, and 5-day contact. The groundwater used contained $100 \mathrm{mg} \mathrm{L}^{-1} \mathrm{Ca}, 10 \mathrm{mg} \mathrm{L}^{-1} \mathrm{Mg}, 15 \mathrm{mg} \mathrm{L}^{-1} \mathrm{Na}, 4.6-4.8 \mathrm{mg} \mathrm{L}^{-1} \mathrm{Sr}$, and $5.95 \mathrm{mg} \mathrm{L}^{-1} \mathrm{Cs}$. Analysis of the data obtained shows that the SZTS removes practically all the Cs $\left(\mathrm{K}_{\mathrm{d}} 300,000-400,000 \mathrm{~mL}^{-1}\right)$ from 12,000 volumes of groundwater without any signs of saturation. At the same time, Na titanium silicate (Sandia-type material) with a channel structure purifies efficiently removes only 3000 volumes of groundwater $\left(\mathrm{K}_{\mathrm{d}} 50,000-300,000 \mathrm{~mL} \mathrm{~g}^{-1}\right)$, after which its affinity for Cs drops drastically. Considering that ${ }^{137} \mathrm{Cs}$ concentration in contaminated groundwater is much less $\left(10^{-3}\right.$ $10^{-6} \mathrm{ppm}$ ), an even better performance of SZTS in real systems can be expected.

\subsubsection{Sodium Micas}

Micas are chemically and thermally stable layered aluminosilicates. They consist of negatively charged 2:1 layers that are compensated and bonded together by large, positively charged interlayered cations. All the known natural micas exist in the $\mathrm{K}$ form. This is connected with their crystal structure, namely, with tetrahedral $\mathrm{SiO}_{4}$ crown-ether type formations of oxygen atoms that ideally correspond to the parameters of the $\mathrm{K}$ ion. According to our calculations, such adsorption centers should fit for Cs, which indicates that natural micas could be abundant, cheap, and efficient adsorbents for radioactive Cs removal from different types of nuclear waste streams. The only problem in using the natural micas for such purpose is that the $\mathrm{K}$ ion cannot be exchanged directly for Cs because of stearic hindrance (Kmica's underlayer distance is about $10.0 \AA$, which is too small for $=C s$ to access). This problem could be remedied by the preliminary conversion of $\mathrm{K}$ mica into the $\mathrm{Na}$ form with a greater underlayer distance (12.2 A). This is normally done by the application of the "Na tetraphenylborate (STB) method", which 
allows the substitution of practically all the $\mathrm{K}$ by Na by treating mica with STB at elevated temperature for a long period of time. Unfortunately, this method cannot be used industrially because of the high cost of the STB reagent.

An alternative method for the conversion of $\mathrm{K}$ micas into their $\mathrm{Na}$ form under mild hydrothermal conditions have been developed. $\mathrm{K}_{d}$ values for $\mathrm{Cs}$ are given in Table 6.1. The data in Table 6.1 leads us to believe that $\mathrm{Na}$ mica is ideal for removal of $\mathrm{Cs}$ from groundwater where permanent immobilization is required. The data in Table 6.1 shows that using a groundwater simulant, Na-mica, and our highly crystalline $\mathrm{Na}$ zirconium silicate (SZ72) were the best of several Cs-specific sorbents tries. The $\mathrm{K}_{d}$ remains at $400,000 \mathrm{~mL} \mathrm{~g}^{-1}$ even after 12 cycles of treatment with one liter of simulant per gram for each cycle. The reason that the $\mathrm{K}_{d}$ remains constant is the uniformity of the exchange sites in mica and the very high exchange capacity and selectivity for Cs of SZ72. When about $1.25 \mathrm{meq} \mathrm{g}^{-1}$ of Cs is exchanged, the mica layers move closer together trapping the Cs permanently. This amounts to more than $13,000 \mathrm{~L} \mathrm{Kg}^{-1}$ of mica. The SZ72 in $\mathrm{Na}$ form is suitable for use when a recyclable exchanger is required. The $\mathrm{Cs}$ can be removed in strong $\mathrm{NaCl}$ solutions.

\subsubsection{Pharmacosiderites}

Pharmacosiderite is a non-aluminosilicate molecular sieve with a composition $\mathrm{KFe}_{4}(\mathrm{OH})_{4}\left(\mathrm{ASO}_{4}\right)_{3}$. It forms a framework that encloses one dimensional tunnels similar to those in the Cs selective exchanger $\mathrm{Na}_{2} \mathrm{Ti}_{2} \mathrm{O}_{3} \mathrm{SiO}_{4}$. We prepared the titanium silicate analog of pharmacosiderite, $\mathrm{K}_{3} \mathrm{HTi}_{4} \mathrm{O}_{4}\left(\mathrm{SiO}_{4}\right)_{3} \cdot 4 \mathrm{H}_{2} \mathrm{O}$. The crystal structure was solved from its powder X-ray pattern, as well as the proton and Cs forms. The compound is cubic, with cell dimension $a=7.82 \AA$. The framework has many features in common with $\mathrm{Na}_{2} \mathrm{Ti}_{2} \mathrm{O}_{3} \mathrm{SiO}_{4}$. In this compound there are two sites, one in the face centers of the framework and another within the tunnels. In the titanium pharmacosiderite, only the site in the face centers exists. $\mathrm{K}$ fits precisely into these sites with bond distances of 3.23 and $3.17 \AA$, respectively. These bond distances are somewhat long for $12-$ coordinate $\mathrm{K}(2.95 \AA)$. Therefore, $\mathrm{K}$ is easily displaced by Cs. However, $\mathrm{Cs}$ is too large to fit into the face centers and moves about $6.4 \AA$ into the tunnel. This move results in a range of bond distances 2.82-3.62 $\AA$. Again, this situation is not ideal but $\mathrm{K}_{d}$ values for Cs on the $\mathrm{K}$ pharmacosiderite are approximately $6000 \mathrm{~mL} \mathrm{~g}^{-1}$ at $\mathrm{pH}=10$ (V:m-200:1, $10 \underline{\mathrm{M} \mathrm{Cs}}$ ). In $5 \underline{\mathrm{M}}$ $\mathrm{NaNO}_{3}+1 \underline{\mathrm{M}} \mathrm{NaOH}$ the $\mathrm{K}_{\mathrm{d}}$ drops to $\sim 100 \mathrm{~mL} \mathrm{~g}^{-1}$.

Table 6.1. Distribution Coefficient Values for Cs Adsorption from Model Solutions, Containing 0.001 M Cs, on Mica Samples

\begin{tabular}{||l|c|c|c|c|c|c||}
\hline \multicolumn{1}{|c|}{ Mica } & $\mathrm{H}_{2} \mathrm{O}$ & $0.1 \mathrm{MNaNO}_{3}$ & $1 \mathrm{M} \mathrm{NaNO}_{2}$ & $5 \mathrm{M} \mathrm{NaNO}_{3}$ & $1 \mathrm{M} \mathrm{NaOH}$ & $1 \underline{\mathrm{M} \mathrm{NaNO}_{3}}$ \\
\hline Biotite-K & 15 & $<5$ & $<5$ & $<5$ & $<5$ & $<5$ \\
\hline Biotite-Na & $>400,000$ & $>100,000$ & 14,300 & 750 & - & 450 \\
\hline Phlogopite-K & 10 & $<5$ & $<5$ & $<5$ & $<5$ & $<5$ \\
\hline Phlogopite- $\mathrm{Na}$ & $>400,000$ & $>100,000$ & 6,250 & 500 & 500 & 120 \\
\hline
\end{tabular}


The $\mathrm{K}$ phase of pharmacosiderite gave a high $\mathrm{K}_{\mathrm{d}}$ for $\mathrm{Sr}$, of the order of $30,000 \mathrm{~mL} \mathrm{~g}^{-1}$ in $10^{-3} \mathrm{M}$ solution. In $5 \mathrm{M} \mathrm{NaNO}_{3}+1 \underline{\mathrm{M} \mathrm{NaOH}}$ the $\mathrm{K}_{\mathrm{d}}$ was $8200 \mathrm{~mL} \mathrm{~g}^{-1}$. Thus, this solid has a reasonable affinity for $\mathrm{Sr}$. However, it was felt that if the framework cavities of $\mathrm{K}_{3} \mathrm{HTi}_{4} \mathrm{O}_{4}\left(\mathrm{SiO}_{4}\right)_{3}$ could be enlarged so that Cs would fit neatly into the face centers to form strong bonds with the lattice oxygens the affinity might be drastically improved. We therefore prepared pharmacosiderite phases in which $10 \%, 20 \%, 30 \%$, and $50 \%$ of the silica was replaced by $\mathrm{GeO}_{2}$. The X-ray work showed that germanate species were indeed replacing silicate ions, and in the $50 \%$ sample some $\mathrm{Ge}^{4+}$ replaced $\mathrm{Ti}^{4}+$. The $\mathrm{K}_{\mathrm{d}}$ values for the $\mathrm{K} 50 \% \mathrm{Ge}$ phase are given in Table 6.2 below.

Table 6.2 shows that the $K_{d}$ values for Cs improved by ten fold, and the $\mathrm{Sr} \mathrm{K}_{\mathrm{d}}$ more than doubled. $\mathrm{X}$-ray analysis of the structure showed that the $\mathrm{Cs}$ was still slightly removed from the face center but the Cs to $\mathrm{O}$ bond distances were 3.09 to $3.14 \AA$, which were better values than for the silicate.

We next prepared a Cs Ti germanate with all of the Si replaced with Ge. As before, a certain mass of $\mathrm{CsTiGe}_{4}$ was placed in $3 \mathrm{M} \mathrm{KCl}$ in order to prepare its $\mathrm{K}$-form. We solved both structures by powder $\mathrm{X}$-ray diffraction. Once again, $\mathrm{K}_{\mathrm{d}} \mathrm{s}$ and equilibrium $\mathrm{pHs}$ were measured for $\mathrm{K}$-exchanged form of the $\mathrm{Ti}$ germanate, and these results are presented in Table 6.3.

$\mathrm{K}_{\mathrm{d}}$ values for Cs and $\mathrm{Sr}$ were measured for $\mathrm{KTiGe}_{4}$ (Table 6.4). The ground-water simulant initially contains, 6.1 ppm Sr, 7.8 ppm Cs and ppm levels of $\mathrm{Mg}, \mathrm{Ca}, \mathrm{K}$, and $\mathrm{Na}$.

Table 6.2. $\mathrm{K}_{\mathrm{d}}$ and Equilibrium $\mathrm{pH}$ Values for $\mathrm{KTiSiGe}_{0.5}$

\begin{tabular}{|c|c|c|c|c|c|c|c|}
\hline Sample & $\mathrm{Li}$ & $\mathrm{Na}$ & $\mathrm{Cs}$ & $\mathrm{Mg}$ & $\mathrm{Ca}$ & $\mathrm{Sr}$ & $\mathrm{Ba}$ \\
\hline KTiSiGe $_{0.5}$ & 124 & 282 & 32000 & 4910 & 5480 & $\gg 79,000$ & $>>22,780$ \\
& $(8.4)$ & $(8.9)$ & $(9.3)$ & $(8.1)$ & $(8.2)$ & $(7.8)$ & $(8.2)$ \\
\hline
\end{tabular}

Table 6.3. $\mathrm{K}_{\mathrm{d}}$ and Equilibrium pH Values for $\mathrm{K}$-Exchanged Form of Ti Germanate

\begin{tabular}{|c|c|c|c|c|c|c|c|}
\hline Sample & $\mathrm{Li}$ & $\mathrm{Na}$ & $\mathrm{Cs}$ & $\mathrm{Mg}$ & $\mathrm{Ca}$ & $\mathrm{Sr}$ & $\mathrm{Ba}$ \\
\hline \hline KTiSiGe $_{4}$ & 204 & 100 & 46160 & 6073 & $>6988$ & $\gg>79,000$ & $>>22,780$ \\
& $(8.5)$ & $(8.2)$ & $(8.5)$ & $(8.3)$ & $(8.3)$ & $(8.2)$ & $(8.3)$ \\
\hline
\end{tabular}

Table 6.4. Groundwater Simulant $K_{d}$

\begin{tabular}{|c|c|c|c|c|}
\hline Sample & $\mathrm{Sr}$ & $\mathrm{Cs}$ & $\begin{array}{c}\% \mathrm{Sr} \\
\text { Removed }\end{array}$ & $\begin{array}{c}\% \text { Cs } \\
\text { Removed } \\
\end{array}$ \\
\hline $\mathrm{KTiSiGe}_{4}$ & $\begin{array}{c}>>5150 \\
(7.8)\end{array}$ & $\begin{array}{c}>>2420 \\
(7.8)\end{array}$ & $99 \%$ & $96 \%$ \\
\hline
\end{tabular}


These results are highly encouraging. Certainly they are useful for groundwater remediation and will be tested for tank waste effluent in the next quarter.

\subsection{Sodium Titanate Development and Outside Testing}

Activities this year concentrated on supplying NaTi to customers within the DOE system who were interested in evaluating the material for use in groundwater or alkaline tank waste remediation. This built on last year's studies, which completed the scale-up of the production technique of this material to pilot plant quantities and included the development of a scaleable pelletization technique for the preparation of $\mathrm{Na}$ titanate pellets. Efforts this year were largely customer-guided, focusing on delivering to each customer the product they desired in the optimum physical form for their application. Figure 6.1 shows a bar chart of the trials now under way and their status.

Highlights of this year's activities included the following:

- Scaled-up pellet production to $1 \mathrm{~kg}$ batch, and improved selectivity and durability

- Developed technology for producing 1-100 $\mu \mathrm{m}$ powders for 3M, Savannah River, and British Nuclear Fuels

- Sold NaTi to $3 \mathrm{M}$ for the first time

- Los Alamos and PNNL both identified NaTi as the best available ion exchanger for $\mathrm{Sr}$

- Savannah River reported that our material exceeds current specifications

- Initiated collaborations with three ORNL groups and one INEL group.

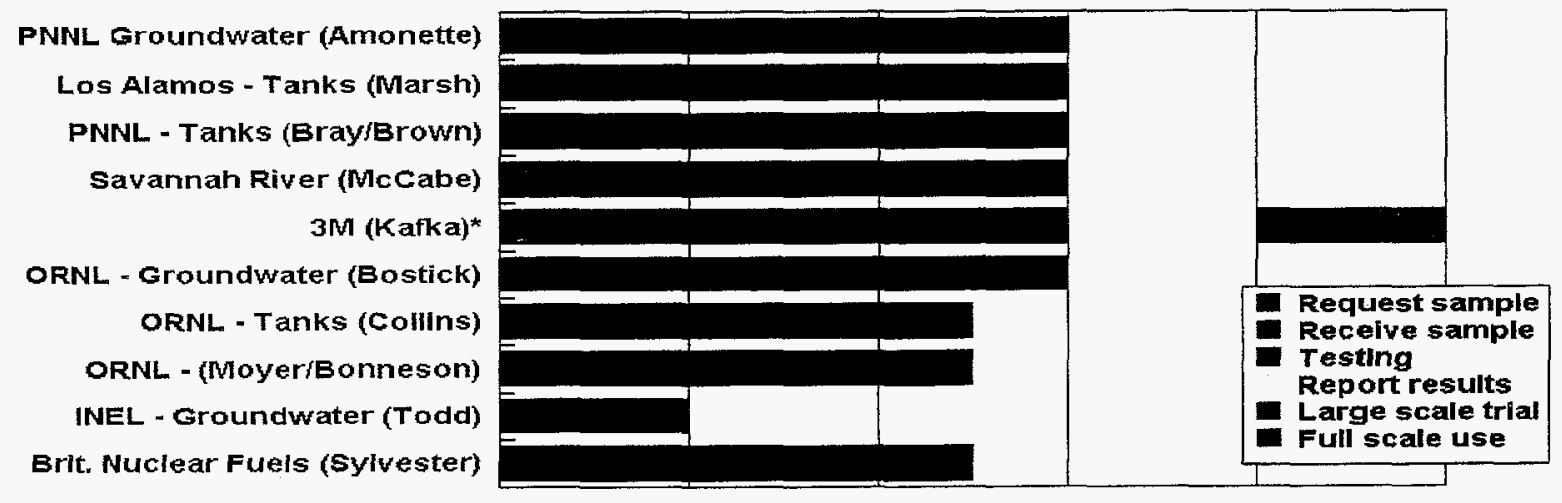

Figure 6.1. Status of NaTi Testing 
In general, we found that potential NaTi users fell into two groups. Many users requested $\mathrm{NaTi}$ in the form of fine powders and required this powder in the form of monodisperse $1-100 \mu \mathrm{m}$ dispersions. Such customers intended to use the material by contacting the fine powder with the feed by adding it to a tank and then removing it by filtration, or they intended to incorporate the material into a filter cartridge to merge these two steps. Examples of such users were Savannah River and 3M. The second group of users needed engineered-form pellets for use in conventional ion exchange columns. For them, good mass transfer into the pellets and pellet durability were the two key properties. Examples of such users were INEL, WVNS, and PNNL. Providing each customer with the correct physical form while maintaining separation effectiveness appears to be the key to getting users to try $\mathrm{NaTi}$ in their application. We discuss several key customers and their results below.

\subsubsection{Testing at Savannah River}

Continuing studies at Savannah River by Dr. Daniel McCabe have demonstrated the effectiveness of our NaTi for removal of Sr from tank waste at that site. Samples were submitted to Dr. McCabe, who tested them and provided feedback to allow subsequent samples to be further tailored to Savannah River's needs. Table 6.5 shows the improvement in decontamination factor we observed through these trials. The most recent sample met Savannah River's criteria for decontamination factor, distribution coefficient, and oxalic acid solubility. Ongoing studies are focused on filterability and TRU pick up.

\subsubsection{Testing by 3M at INEL and Other Sites}

AlliedSignal's productive relationship with 3M Company lead to demonstrations of using NaTi for Sr removal. AlliedSignal provided 3M NaTi samples that meet the particle size requirements necessary for preparing 3M's Empore membranes. 3M prepared such membranes and took them to several DOE sites including INEL, Hanford (N-Springs), WVNS, and Savannah River. Since the effectiveness of the membrane modules in removing $\mathrm{Sr}$ is obviously due to the $\mathrm{NaTi}$ active material, these demonstrations are good indicators of the performance of our material, regardless of physical form.

Table 6.5. Recent Results of NaTi Testing at Savannah River

\begin{tabular}{||c|c|c||}
\hline Sample & Decontamination Factor $(48 \mathrm{~h})$ & $\mathrm{K}_{\mathrm{d}}\left(\mathrm{mL} \mathrm{g}^{-1}\right)$ \\
\hline \hline $8212-79$ & $47 \pm 22$ & $9.2 \mathrm{E}+04$ \\
\hline $8212-89$ & $73 \pm 24$ & $1.4 \mathrm{E}+05$ \\
\hline $8212-91$ & $101 \pm 26$ & $2.0 \mathrm{E}+05$ \\
\hline $8212-123$ & $260 \pm 100$ & $5.2 \mathrm{E}+05$ \\
\hline
\end{tabular}


The performance of $\mathrm{NaTi}$ in treating Sr-contaminated groundwater has been documented in a report by the INEL team. Figure 6.2 shows the excellent selectivity of this material for Sr over other alkaline earth metals. A larger scale demonstration was run at the N-Springs area at Hanford. In this trial, the selectivity for $\mathrm{Sr}$ over $\mathrm{Ca}$ was insufficient to prevent the column from loading primarily with $\mathrm{Ca}$.

\subsection{Preparation and Testing of Pellet Form Sodium Titanate}

Users interested in using $\mathrm{NaTi}$ in conventional ion exchange columns require the material to have a sufficiently large pellet size that the pressure drop across the column is reasonable. This requirement forced us to develop a technology for the pelletization of $\mathrm{NaTi}$. We bind our NaTi with an inorganic binder that is chemically related to the NaTi material itself. This provides a material that has a distribution coefficient exceeding that of the parent $\mathrm{NaTi}$ and a capacity roughly $10 \%$ less than that of the parent material. The material shows good mass transfer kinetics, providing sharp breakthrough curves at reasonable ion exchange column feed rates, and has been shown to have good radiation stability. While the material is normally provided as cylindrical pellets, many users will prefer to crush the material to reduce its granule size to their preferred range. Table 6.6 shows some typical pellet properties.

Pellets of the type described here have been provided to Dr. D. Bostick at ORNL and Dr. Terry Todd at INEL. Dr. Bostick has published some preliminary results with both the pellets and the parent powder. She finds that $\mathrm{NaTi}$ powder has a distribution coefficient superior to the better known R-F

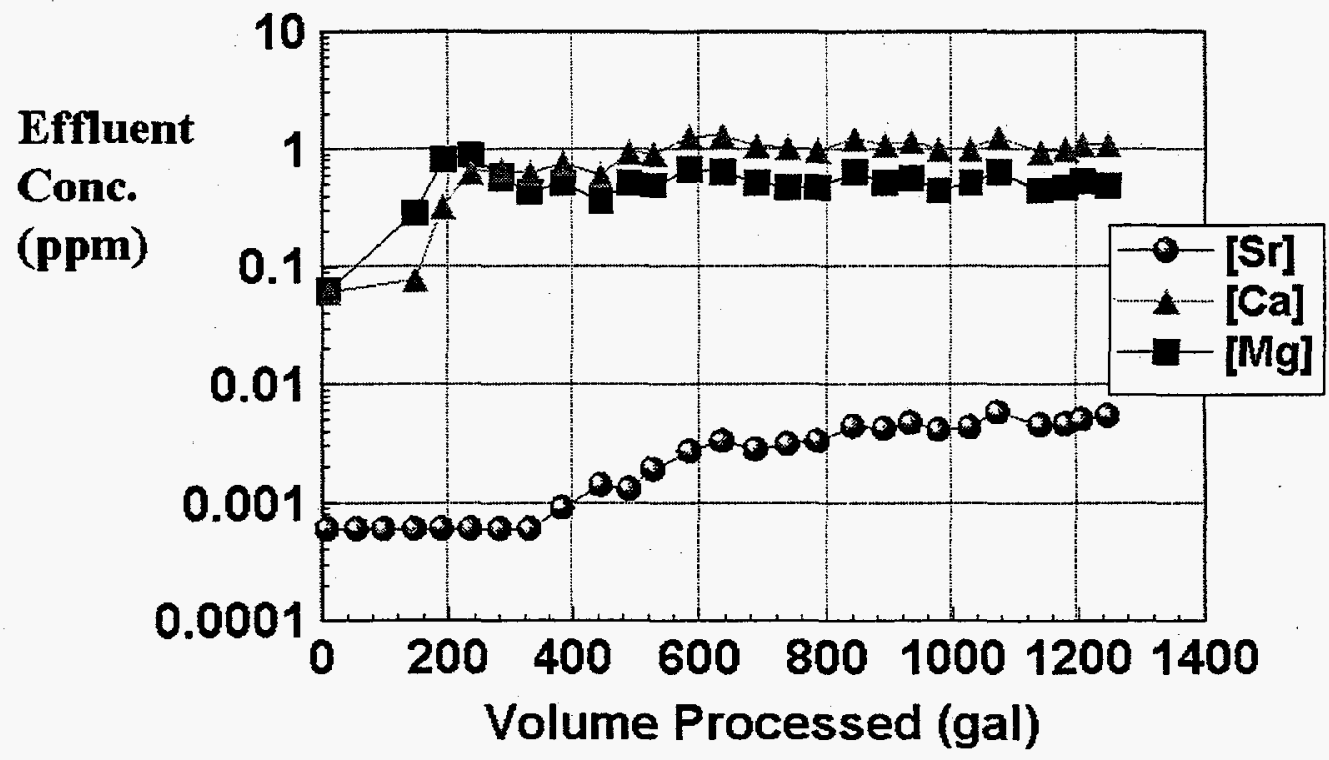

Figure 6.2. Performance of NaTi Using INEL Groundwater 
Table 6.6. NaTi Pellet Physical Properties

\begin{tabular}{|l|l||}
\hline \multicolumn{1}{|c|}{ Property } & \multicolumn{1}{c|}{ Value } \\
\hline Dimensions & $2.3(\mathrm{~d}) \times 3 \mathrm{~mm}$ \\
\hline Piece Density & $1.85-2.1 \mathrm{~g} \mathrm{~mL}^{-1}$ \\
\hline Sr $\mathrm{K}_{\mathrm{d}}$ in $5 \underline{\mathrm{M} \mathrm{Na} / 0.1 \underline{\mathrm{M}} \mathrm{OH}}$ & $21,419 \mathrm{~mL} \mathrm{~g}^{-1}$ \\
\hline Sr Capacity & $0.81 \mathrm{meq} \mathrm{g}^{-1}$ \\
\hline Radial Crush Strength & $518 \mathrm{psi}^{-1}$ \\
\hline BET Surface Area & $52.6 \mathrm{~m}^{2} \mathrm{~g}^{-1}$ \\
\hline Total Pore Volume & $0.108 \mathrm{~mL} \mathrm{~g}^{-1}$ \\
\hline
\end{tabular}

resin, but that the pellets have slightly lower $\mathrm{K}_{\mathrm{d}} \mathrm{s}$ and slower mass transfer than the powder. Dr. Bostick has also reported selectivity results for $\mathrm{Sr}$ over $\mathrm{Ca}$ which, as in the INEL results reported earlier, confirm that NaTi shows a very large selectivity for $\mathrm{Sr}$. 


\subsection{Conclusions and Recommendations}

A collaborative effort between PNNL and industry/university participants has been under way since FY 1992. In conjunction with the two contracts (AlliedSignal and 3M), PNNL continues to be involved in other areas of research directed toward the same goals. These include, as examples, interaction with industry, academia, and the national laboratories in the study and understanding of binders and alternative web systems; testing and interaction with $3 \mathrm{M}$ and AlliedSignal as they prepare new materials for testing; evaluation of other ion exchange materials being tested with simulated and actual Hanford wastes; and initial evaluation for testing engineered systems with actual wastes from Hanford, INEL, ORNL and WVNS. Several onsite demonstrations (Hanford N-Springs, Hanford N-Basin, INEL TAN, SRTC R-Basin, and WVINS) were initiated or completed during the year; the $3 \mathrm{M} / \mathrm{IBC}$ web system has been tested at ORNL using actual Melton Valley radioactive waste and at Hanford using actual 101-AW DSSF tank waste. The PADU skid unit cartridge system was constructed and demonstrated at N-Springs and N-Basin. 


\subsection{References}

10 CFR 61. 1994. U.S. Nuclear Regulatory Commission, "Disposal of Low-Level Radioactive Wastes." Code of Federal Regulations.

Alonso, A. I., A. M Urtiaga, A. Irabien, and M. I. Ortiz. 1994. "Extraction of Cr(VI) with Aliquat 336 in Hollow Fiber Contractors: Mass Transfer Analysis and Modeling." Chem. Eng. Sci. 49:901909.

Bibler, J. P., R. M. Wallace, and L. A. Bray. 1989. "Testing A New Cesium-Specific Ion Exchange Resin For Decontamination of Alkaline-High Activity Waste," In: Proceedings of the Symposium on Waste Management '90, February 25 - March 1, 1990, Tucson, Arizona.

Bibler, J. P. 1991. A Comparison of DuoliteTM CS-100 and SRS Resorcinol/Formaldehyde Ion Exchange Resins with Three High-Level Waste Simulants Before and After Irradiation.

WSRC-RP-91-1221, Westinghouse Savannah River Company, Savannah, Georgia.

Bibler, J. P. 1994. Year-End Report for UST: Cesium Extraction Testing Project DOE/DT\&E TTP No. SRI-03-20-01 (U). WSRC-RP-94-146. Westinghouse Savannah River Company, Aiken, South Carolina.

Bibler, N. E., and C. L. Crawford. 1994. An Investigation of the Radiolytic Stability of a ResorcinolFormaldehyde Ion Exchange Resin. WSRC-RP-94-148, Westinghouse Savannah River Company, Aiken, South Carolina.

Boyd, S. A., M. M. Mortland, and C. T. Chiou. 1988. "Sorption Characteristics of Organic Compounds on Hexadecyltrimethylammonium-Smectite." Soil Sci. Soc. Am. J. 52:652-657.

Bray, L. A., L. K. Holton, T. R. Meyers, G. M. Richardson, and B. M. Wise. 1984. Experimental Data Developed to Support the Selection of a Treatment Process for West Valley Alkaline Supernatant. PNL-4969, Pacific Northwest Laboratory, Richland, Washington.

Bray, L. A. 1989. Determination of Batch Sorption Ratios for Ion Exchange Materials Using Radionuclide Tracer Techniques. WTC-006-21-1, PNL Test Procedure, Pacific Northwest Laboratory, Richland, Washington.

Bray, L. A., and F. T. Hara. 1991. "Use of Titanium-Treated Zeolite for Plutonium, Strontium, and Cesium Removal from West Valley Alkaline Wastes and Sludge Wash Waters," In: First Hanford Separations Science Workshop, PNL-SA-19697S, pp. II.87-II.91, Pacific Northwest Laboratory, Richland, Washington. 
Bray, L. A., K. J. Carson, R. J. Elovich, and D. E. Kurath. 1992. Equilibrium Data for Cesium Ion Exchange of Hanford CC and NCAW Tank Waste. TWRSPP-92-020, Pacific Northwest Laboratory, Richland, Washington.

Bray, L. A., C. D. Carlson, K. J. Carson, J. R. DesChane, R. J. Elovich, and D. E. Kurath. 1993. Initial Evaluation of Two Organic Resins and their Ion Exchange Column Performance for the Recovery of Cesium from Hanford Alkaline Wastes. TWRSPP-93-055, Pacific Northwest Laboratory, Richland, Washington.

Bray, L. A., J. E. Amonette, G. N. Brown, T. M Kafka, and S. F. Yates. 1995. Efficient Separations and Processing Crosscutting Program: Develop and Test Sorbents. PNNL-10750, Pacific Northwest National Laboratory, Richland, Washington.

Brown, G. N., L. A. Bray, C. D. Carlson, K. J. Carson, J. R. DesChane, R. J. Elovich, and P. K., Tanaka. 1994. Initial Evaluation of Processes Capable of Removing Strontium from ComplexantContaining Alkaline Waste Supernate. FY 1994 Final Report. TWRSPP-94-097, Pacific Northwest Laboratory, Richland, Washington.

Brown, G. N., S. R. Adami, L. A. Bray, S. A. Bryan, C. D. Carlson, K. J. Carson, J. R. DesChane, R. J. Elovich, S. J. Forbes, J. A. Franz, J. C. Linehan, W. J. Shaw, P. K. Tanaka, and M. R.

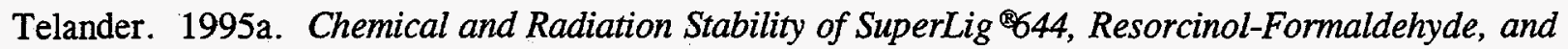
CS-100 Cesium Ion Exchange Materials. PNNL-10772, Pacific Northwest National Laboratory, Richland, Washington.

Brown, G. N., J. R. Bontha, C. D. Carlson, K. J. Carson, J. R. DesChane, R. J. Elovich, D. E. Kurath, P. K. Tanaka, D. W. Edmonson, D. L. Herting, and J. R. Smith. 1995b. Ion Exchange Removal of Cesium from Simulated and Actual Supernate from Hanford Tanks 241-SY-101 and 241-SY103. PNNL-10792, Pacific Northwest National Laboratory, Richland, Washington.

Brown, G. N., L. A. Bray, and R. J. Elovich. 1995c. Evaluation and Comparison of SuperLig ${ }^{844}$, Resorcinol-Formaldehyde and CS-100 Ion Exchange Materials for the Removal of Cesium from Simulated Alkaline Supernate. PNNL-10486, Pacific Northwest Laboratory, Richland, Washington.

Brown, G. N., L. A. Bray, C. D. Carlson, K. J. Carson, J. R. DesChane, R. J. Elovich, F. V. Hoopes, D. E. Kurath, L. L. Nenninger, and P. K. Tanaka. 1996a. Comparison of Organic and Inorganic Ion Exchangers for Removal of Cesium and Strontium from Simulated and Actual Hanford 241-AW-101 DSSF Tank Waste. PNNL-10920, Pacific Northwest National Laboratory, Richland, Washington.

Brown, G. N., K. J. Carson, J. R. DesChane, R. J. Elovich, T. M. Kafka, and L. R. White. $1996 \mathrm{~b}$. Ion Exchange Removal of Strontium from Simulated and Actual $N$-Springs Well Water at the Hanford 100-N Area. PNNL-11198, Pacific Northwest National Laboratory, Richland, Washington. 
Brown, G. N., K. J. Carson, J. R. DesChane, R. J. Elovich, and P. K. Berry. 1996c. Chemical and Radiation Stability of a Proprietary Cesium Ion Exchange Material Manufactured from WWL Membrane and SuperLig ${ }^{8644 . ~ P N N L-11328, ~ P a c i f i c ~ N o r t h w e s t ~ N a t i o n a l ~ L a b o r a t o r y, ~ R i c h l a n d, ~}$ Washington.

Brown, M. J., and D. R. Burris. 1996. "Enhanced Organic Contaminant Sorption on Soil Treated with Cationic Surfactants." Ground Water 34:734-744.

Bryan, S. A., S. R. Adami, L. A. Bray, C. D. Carlson, J. R. DesChane, R. J. Elovich, and M. R. Telander. 1993. Radiation Testing of Organic Ion Exchange Resin, CS-100. TWRSPP-93-073, Pacific Northwest Laboratory, Richland, Washington.

Buckingham, J. S. 1967. Waste Management Technical Manual. ISO-100 DEL, Hanford Atomic Products Operation, Richland, Washington.

Carlson, C. D., S. R. Adami, L. A. Bray, G. N. Brown, S. A. Bryan, J. R. DesChane, R. J. Elovich, J. A. Franz, D. E. Kurath, J. C. Linehan, W. J. Shaw, and M. R. Telander. 1995. Radiation Testing of Organic Ion Exchange Resins. PNL-10767, Pacific Northwest Laboratory, Richland, Washington.

Dinsmore, E. F., G. Smith,, L. A. Bray, G. N. Brown,, K. C. Carlson, T. M. Kafka, D. C. Seely, and L. R. White. 1996. Removal of Specific Radionuclides from Process Streams at the West Valley Demonstration Project using 3M Separation Technology. Topical Report to Efficient Separations and Processing Crosscutting Program, May 1996, St. Paul, Minnesota.

Dirkes, R. L. 1990. 1988 Hanford Riverbank Springs Characterization Report. PNNL-7500, Pacific Northwest Laboratory, Richland, Washington.

DOE/RL. 1994. Hanford Federal Facility Agreement and Consent Order, DOE/RL-89-10, Rev. 3, Amendment 4 (Milestone M-16-01E-T2), U.S. Department of Energy, Richland Operations Office, Richland, Washington.

Eager, K. M., D. L. Penwell, and B. J. Knutson. 1994. Preliminary Flowsheet: Ion Exchange Process for Separation of Cesium from Hanford Tank Waste Using Duolite CS-100 Resin.

WHC-SD-WM-TI-667 Rev. 0, Westinghouse Hanford Company, Richland, Washington.

Feng, Q., H. Kanoh, K. Ooi, M. Tani, and Y. Nakacho. 1994. "Synthesis of Hollandite-Type Manganese Dioxide with H+ Form for Lithium Rechargeable Battery." J. Electrochem. Soc. 141 L135-L136.

Galan, B., A. M. Urtiaga, A. I. Alonso, A. Irabien, and M. I. Ortiz. 1994. "Extraction of Anion with Aliquat 336: Chemical Equilibrium Modeling." Ind. Eng. Chem. Res. 33:1765-1770. 
Haggerty, G. M., and R. S. Bowman. 1994. "Sorption of Chromate and Other Inorganic Anions by Organo-Zeolite." ES\&T 28:452-458.

Hartman, M. J., and K. A. Lindsey. 1993. Hydrogeology of the 100-N Area, Hanford Site, Washington. WHC-SD-EN-EV-027, Westinghouse Hanford Company, Richland, Washington.

Herbst, R. S., K. N. Brewer, T. A. Todd, T. M. Kafka, L. R. White, and L. A. Bray. 1995. Decontamination of TAN Injection Well Water Using 3M Web Technology. INEL-95/0589, Lockheed Idaho Technologies Company, Idaho Falls, Idaho.

Hubler, T. L., J. A. Franz, W. J. Shaw, S. A. Bryan, R. T. Hallen, G. N. Brown, L. A. Bray, and J. C. Linehan. 1995. Synthesis, Structural Characterization, and Performance of Resorcinol-Formaldehyde ( $R-F)$ Ion-Exchange Resin. PNL-10744, Pacific Northwest Laboratory, Richland, Washington.

James, B. R., J. C Petura, R. J. Vitale, and G. R. Mussoline. 1995. "Hexavalent Chromium Extraction from Soils: A Comparison of Five Methods.” ES\&T 29:2377-2381.

Jones, Y. M. 1966. A Preliminary Study of Cesium Sorption from Acid Waste Solutions Utilizing Phosphate Exchangers, BNLW-270, Pacific Northwest Laboratory, Richland, Washington.

Kafka, T. M. 1995. Separation Technologies for Cesium and Strontium, Phase IIIC Technical Report (May 1 - September 30, 1995). 3M Company, St. Paul, Minnesota.

Kurath, D. E., L. A. Bray, W. A. Ross, and D. K. Ploetz. 1989. "Correlation of Laboratory Testing and Actual Operations for the West Valley Supernatant Treatment System." Presented at the Fourth International Symposium on Ceramics in Nuclear Waste Management, American Ceramic Society Annual Meeting, April 23-27, 1989. PNL-SA-16871, Pacific Northwest Laboratory, Richland, Washington.

Kurath, D. E., L. A. Bray, K. P. Brooks, G. N. Brown, S. A. Bryan, C. D. Carlson, K. J. Carson, J. R. DesChane, R. J. Elovich, and A. Y. Kim. 1994. Experimental Data and Analysis to Support the Design of an Ion Exchange Process for the Treatment of Hanford Tank Waste Supernatant Liquids, PNNL-10187, Pacific Northwest Laboratory, Richland, Washington.

Luykx, F. 1986. "Technetium Discharges into the Environment." In Technetium in the Environment, eds. G. Desmet and C. Myttenaere, pp. 21-27. Elsevier, London.

Marsh, S. F., Z. V. Svitra, and S. M. Bowen. 1994a. Distributions of 14 Elements on 63 Absorbers from Three Simulant Solutions (Acid-Dissolved Sludge, Acidified Supernate, and Alkaline Supernate) for Hanford HLW Tank 102-SY. LA-12654, Los Alamos National Laboratory, Los Alamos, New Mexico. 
Marsh, S. F., Z. V. Svitra, and S. M. Bowen. 1994b. Distributions of 15 Elements on 58 Absorbers from Simulated Hanford Double-Shell Slurry Feed (DSSF). LA-12863, Los Alamos National Laboratory, Los Alamos, New Mexico.

Marsh, S. F., Z. V. Svitra, and S. M. Bowen. 1994c. Distributions of 12 Elements on 64 Absorbers from Simulated Hanford Neutralized Current Acid Waste (NCAW). LA-12889, Los Alamos National Laboratory, Los Alamos, New Mexico.

Marsh, S. F., Z. V. Svitra, and S. M. Bowen. 1995. Effects of Aqueous-Soluble Organic Compounds on the Removal of Selected Radionuclides from High-Level Waste. LA-12863, Los Alamos National Laboratory, Los Alamos, New Mexico.

McCabe, D. J. 1995. "Sodium Titanate Preliminary Examination Results," WSRC-TR-95-TBD, Westinghouse Savannah River Company, Savannah, Georgia.

Mizelli, H., and H.-J. Bart. 1994. "Extraction of Cyanamide and Dicyandiamide from Ammoniacal Solution with Aliquat ${ }^{\circledR} 336$." Ind. Eng. Chem. Res. 33:329-335.

Penwell, D. L., K. M. Eager, and B. J. Knutson. 1994. Preliminary Flowsheet: Ion Exchange Process for Separation of Cesium from Hanford Tank Waste Using Resorcinol-Formaldehyde Resin. WHC-SD-WM-TI-638 Rev. 0, Westinghouse Hanford Company, Richland, Washington.

Polemio, M., and J. D. Rhoades. 1977. "Determining Cation Exchange Capacity: A New Procedure for Calcareous and Gypsiferous Soils." Soil Sci. Soc. Am. J. 41:524-528.

Salazar, E., M. I. Ortiz, A. M. Urtiaga, and J. A. Irabien. 1992. "Equilibrium and Kinetics of Cr(VI) Extraction with Aliquat 336." Ind. Eng. Chem. Res. 31:1516-1522.

Sposito, G. 1984. The Surface Chemistry of Soils. Oxford University Press, New York.

Wagner, J., H. Chen, B. J. Brownawell, and J. C. Westall. 1994. "Use of Cationic Surfactants to Modify Soil Surfaces to Promote Sorption and Retard Migration of Hydrophobic Organic Compounds." ES\&T 28:231-237. 


\subsection{Bibliography}

Bengtsson, G. B., A. I. Bortun, and V. V. Strelko. 1996. "Strontium Binding Properties of Inorganic Adsorbents" J. Raioanalyt. and Nuclear Chem. Art., 204, 75-82.

Bortun, L. N., A. I. Bortun, and A. Clearfield. 1996. "Sodium Micas as Cesium Ion Selective Adsorbents" Intern. Conf. Ion Exchange Developments and Applications (IEX '96) July 14-19, 1996, Cambridge, England.

Bortun, A. I, L. N. Bortun, A. Clearfield, J. R. Garcia, M. A. Villa-Garcia, E. Jaimez, and J. Rodriguez. 1996. "Synthesis and Characterization of Titanium Phosphate-Phenylphosphonate Based Adsorbents" 211 th ACS Meeting, March 24-28, 1996, New Orleans, Louisiana.

Bostick, D. 1996. "Evaluation of Improved Techniques for Removing Strontium and Cesium from Process Wastewater and Groundwater," presented at Efficient Separations and Processing Crosscutting Program Technical Exchange Meeting, January 16-19, Gaithersburg, Maryland.

Boyd, S. A., Mortland, M. M., and C. T. Chiou. 1988. "Sorption Characteristics of Organic Compounds on Hexadecyltrimethylammonium-Smectite." Soil Sci. Soc. Am. J. 52:652-657.

Bray, L. A., K. J. Carson, and R. J. Elovich. 1993. Initial Evaluation of Sandia National Laboratory Prepared Crystalline Silico-Titanates for the Recovery of Cesium. PNNL-8847, Pacific Northwest Laboratory, Richland, Washington.

Bray, L. A., J. E. Amonette, G. N. Brown, T. M. Kafka, and S. F. Yates. 1995. Efficient Separations Program (EM-50): Develop and Test Sorbents: FY95 Annual Progress Report from October 1, 1994 to June 30, 1995, PNL-10750, Pacific Northwest Laboratory, Richland, Washington.

Brown, G. N., K. J. Carson, J. R. DesChane, R. J. Elovich, T. M. Kafka, and L. R. White. 1996. Ion Exchange Removal of Strontium from Simulated and Actual N-Springs Well Water at the Hanford 100-N Area, PNNL-11198, Pacific Northwest National Laboratory, Richland, Washington.

Cahill, R., A. Clearfield, C. Andren, I. DeFilippi, R. Sedath, G. Seminara, M. Straszewski, L. Wang, and S. Yates. 1995. "Partially Crystalline Layered Sodium Titanate." Patent Application Serial 08/546,041, October 20, 1995.

Cahill, R., B. Shpeizer, B. Zhang, J. D. Wang, and A. Clearfield. 1995. "Use of Derivatized Zirconium Phosphate Materials for the Separation of Rare Earths." 209th American Chemical Society Meeting, Anaheim, California. 
Clearfield, A., A. I. Bortun, and L. N. Bortun. 1996. "Synthesis and Investigation of Ion Exchange Properties of the Sodium Titanium Silicate Na2Ti2O3(SiO4)2" Intern. Conf. Ion Exchange Developments and Applications (IEX '96) July 14-19, 1996, Cambridge, England.

Clearfield, A., A.I. Bortun, L. N. Bortun, R. A. Cahill, D. M. Poojary, and E. A. Behrens. 1995. "Ion Exchange Materials for Nuclear and Environmental Waste Remediation," Proceedings of the 1995 International Conference on Ion Exchange (ICIE '95), December 4-6, Takamatsu, Japan.

DeFilippi, I., S. F. Yates, R. Sedath, M. Straszewski, M. Andren, and R. Gaita. 1995. "Scale-Up and Testing of a Novel Ion Exchanger for Strontium," poster presented at Ninth Symposium on Separation Science and Technology for Energy Applications," October 22-26, 1995, Gatlinburg, Tennessee.

DeFilippi, I., S. F. Yates, R. Sedath, M. Straszewski, M. Andren, and R. Gaita. (In press.) "Scale-Up and Testing of a Novel Ion Exchanger for Strontium" Separation Sci. Tech.

DeFilippi, I., S. Yates, J. Shen, R. Gaita, R. Sedath, G. Seminara, M. Straszewski, and D. Anderson. 1995. "Titania Bound Sodium Titanate Ion Exchanger," Patent Application Serial 08/546,448, October 20, 1995.

Garcia, J. R., E. Jaimez, M. A. Villa-Garcia, J. Rodriguez, A. Bortun, L. Bortun, and A. Clearfield. 1996. "Titanium and Zirconium-based Inorganic-Organic Hybrid Ion Exchangers with Carboxylic and Iminodiacetic Functional Groups," 211th ACS Meeting, New Orleans, Lousiana, March 24-28, 1996.

Kafka, T. M. 1996. Membrane Based Separation Technologies for Cesium, Strontium and Technetium. Efficient Separations and Processing Crosscutting Program, Annual Technical Exchange Meeting, January 1996, Gaithersburg, Maryland.

Kafka, T. M., and C. G. Markell. 1996. Applications of Novel Chemical Absorbing Membranes for the Removal of Specific Radionuclides from Nuclear Waste. Pittcon 96, March 4-8, 1996, Chicago, Illinois.

Kafka, T. M., C. G. Markell, and L. R. White. 1996. An Overview of Recent Developments in the Use of Chemical Absorbing Membranes for Radionuclide Separations. Waste Management 96, February 25-29, 1996, Tucson, Arizona.

Kafka, T. M., C. G. Markell, and L. R. White. 1996. Recent Developments in the Use of Chemical Absorbing Membranes for Radionuclide Separations. EPRI: 1996 International Low Level Waste Conference, July 22-24, 1996, New Orleans, Louisiana.

Strelko, V. V., A. I. Bortun, and S. A. Khainatov. 1995. "Concentration of Microquantities of Cations of Heavy Metals and Radionuclides by Inorganic Ionites in Autonomous Systems for the Purification of Drinking Water," Proceedings of the 1995 International Conference on Ion Exchange (ICIE '95), December 4-6, Takamatsu, Japan. 
Thompson, M., and D. McCabe. 1996. “Advanced Separations at Savannah River Site," presented at Efficient Separations and Processing Crosscutting Program Technical Exchange Meeting, Gaithersburg, Maryland, January 16-19, 1996.

Yates, S., I. DeFilippi, M. Andren, R. Gaita, G. Seminara, J. Shen, and A. Clearfield. 1996. "Novel Ion Exchangers for Strontium and Cesium" presented at Efficient Separations and Processing Crosscutting Program Technical Exchange Meeting, January 16-19, 1996, Gaithersburg, Maryland. 


\section{Distribution}

No. of

Copies

Offsite

2 DOE/Office of Scientific and Technical Information

G. Allen

Department 6607/MS 0756

Sandia National Laboratories

P.O. Box 5800

Albuquerque, NM 87185-0756

D. H. Bandy

U.S. Department of Energy

P.O. Box 5400

Albuquerque, NM 87115

J. E. Baublitz, EM-40

DOE/Office of Environmental

Restoration

Forrestal Building

U.S. Department of Energy

1000 Independence Ave. SW

Washington, D.C. 20585

J. P. Bibler

Westinghouse Savannah River Co.

Building $773 \mathrm{~A}$

Aiken, SC 29802

2 W. W. Bixby, EM-60

DOE/Office of the Deputy Assistant

Secretary Facility

Transition and Management

U.S. Department of Energy

1000 Independence Ave. SW

Washington, D.C. 20585

N. E. Brown

6608 Loftus, NE

Albuquerque, NM 87109
No. of

Copies

R. L. Bruening

505 East 1860 South

IBC Advanced Technologies, Inc.

American Fork, UT 84603

J. Corones

Ames Laboratory

329 Wilhelm Hall

Iowa State University

Ames, IA 50011

R. Craig

HAZWRAP

P.O. Box 2003, MS 7606

Oak Ridge, TN 37831-7606

6 DOE/Office of Technology Development

Trevion II Building

12800 Middlebrook Road

Germantown, MD 20874

ATTN: G. G. Boyd

EM-50

S. T. Lien

EM-53

R. T. Parker

EM-52

P. J. Ritzcovan

EM-542

W. C. Schutte

EM-54

S. M. Wolfe

EM-532

5 DOE/Office of Waste Management

Trevion II Building

12800 Middlebrook Road

Germantown, MD 20874

ATTN: J. O. Boda

EM-32

J. A. Coleman

EM-35

S. P. Cowan

EM-30

S. L. Domotor

EM-35

H. F. Walter

EM-34 
No of

Copies

N. Egan

Program Development Division

MSE Inc.

P.O. Box 3767

Butte, MT 59702

D. Emillia

Strategic Planning Dept.

Chem-Nuclear Geotech

P.O. Box 1400

2597B-3/4 Road (81503)

Grand Junction, CO 81502-2567

B. Erdal

Los Alamos National Laboratory

MS D446

Los Alamos, NM 87545

D. J. Fennelly

UOP Corp.

307 Fellowship Road

Suite 207

Mt. Laurel, NJ 08054

2 J. J. Fiore, EM-42

DOE/Office of Environmental

Restoration

Trevion II Building

12800 Middlebrook Road

Germantown, MD 20874

C. W. Frank, EM-50

DOE/Office of Technology Development

Forrestal Building

U.S. Department of Energy

1000 Independence Ave. SW

Washington, D.C. 20585

E. Franz

Brookhaven National Laboratory

Building 830

Upton, NY 11973
No. of

Copies

K. D. Gerdes, EM-532

DOE/Office of Technology Development

19901 Germantown Road

Germantown, MD 20874

J. E. Helt

Office of Waste Management Programs 9700 South Cass Avenue

Argonne, IL 60439-4837

R. Jacobson

Desert Research Institute

P.O. Box 19040

Las Vegas, NV 89132

3 T. M. Kafka

3M Center

Bldg. 209-1W-24

St. Paul, MN 55144-1000

K. Kibbe

Martin Marietta Energy Systems

P.O. Box 2003

Bldg. K-1011, MS 7172

Highway 58

Oak Ridge, TN 37831-7172

K. Kostelnik

EG\&G Idaho, Inc., MS 3930

P.O. Box 1625

200 South Woodruff

Idaho Falls, ID 83415-3970

J. E. Lytle, EM-30

DOE/Office of Waste Operations

Forrestal Building

U.S. Department of Energy

1000 Independent Ave. SW

Washington, D.C. 20585

J. F. McGlynn

SAIC

555 Quince Orchard Road, Suite 500

Gaithersburg, MD 20878 
No. of

Copies

Frances Fadullon

SAIC

555 Quince Orchard Road, Suite 500

Gaithersburg, MD 20878

K. McWilliam

U.S. Department of Energy

Nevada Operations Office

P.O. Box 98518

Las Vegas, NV 89109

J. Moore

U.S. Department of Energy

Oak Ridge Operations Office

P.O. Box E

Oak Ridge, TN 37831

K. Nuhfer

FERMCO

P.O. Box 398704

Cincinnati, OH $45239-8704$

9 Oak Ridge National Laboratory

P.O. Box 2008

Oak Ridge, TN 37831-6223

ATTN: J. B. Berry

MS-6044

J. L. Collins

B. Z. Egan

R. D. Hunt

D. Lee

A. P. Malinauskas

C. P. McGinnis

J. F. Walker

J. S. Watson

D. Olona

U.S. Department of Energy

Albuquerque Operations Office

P.O. Box 5400

Albuquerque, NM 87115
No. of

Copies

B. Park

MSE Inc.

P.O. Box 4078

Butte, MT 59702

J. Tourikis

MSE Inc.

P.O. Box 4078

Butte, MT 59702

P. J. Pettit

P.O. Box 538704

Mailstop 81-2

Cincinnati, OH 45253-8704

R. W. Rice

MSE, Inc.

307 Quincy

El Paso, TX 79922

2 Sandia National Laboratories

P.O. Box 5800

Albuquerque, NM 87185-5800

ATTN: J. E. Miller MS-0709

J. Nelson MS-6621

G. Staats

U.S. Department of Energy

Pittsburgh Energy Technology Center

P.O. Box 10940

Pittsburgh, PA 15236-0940

J. L. Steele

Savannah River Site

SRL, 773 A, A208

Aiken, SC 29802

S. L. Stein

Battelle Seattle Research Center

4000 NE 41st Street

Seattle, WA 98105 
No. of

Copies

K. Stevenson

U.S. Department of Energy

376 Hudson Street

New York, NY 10014-3621

J. L. Swanson

1318 Cottonwood Drive

Richland, WA 99352

J. Sweeney

U.S. Department of Energy

Oak Ridge Operations Office

P.O. Box E

Oak Ridge, TN 37831

I. R. Tasker

Waste Policy Institute

Quince Diamond Executive Center

555 Quince Orchard Road

Gaithersburg, MD 20878-1437

M. C. Thompson

Savannah River Technology Center

P.O. Box 616

Aiken, SC 29802

T. A. Todd

Lockheed Idaho Technology Company

P.O. Box 1625, MS 5213

Idaho Falls, ID 83415

C. Tsang

Earth Sciences Division

Bldg. 50E

Lawrence Berkeley Laboratory

Berkeley, CA 94720

UOP Corp.

50 East Algonquin

Des Plaines, IL 60017-5016

ATTN: J. Sherman

R. Braun
No. of

Copies

S. Webster

U.S. Department of Energy

Chicago Field Office

9800 South Cass Avenue

Argonne, IL 60439-4837

T. Williams

U.S. Department of Energy

Idaho Operations Office

785 DOE Place

Idaho Falls, ID 83402

J. Wright

U.S. Department of Energy

Savannah River Operations Office

RFD \#1, Bldg. 703A, Rm. E208 North

P.O. Box A

Aiken, SC 29802

S. Yates

AlliedSignal

50 East Algonquin Road

Des Plaines, IL 60017-5016

J. Yow

Lawrence Livermore National Laboratory 7000 East Avenue

P.O. Box 808

Livermore, CA 94550

C. Zeh

Morgantown Energy Technology Center 3610 Collins Ferry Road

Morgantown, WV 26507-0880

\section{Onsite}

7 DOE Richland Operations Office

J. A. Frey

K8-50

J. P. Hanson

$\mathrm{K} 8-50$

P. E. Lamont

S7-53

C. S. Louie

S7-53 
No. of

Copies
B. M. Mauss
D. E. Trader
L. S. Walder

7 Bechtel Hanford, Incorporated
A. G. Duda
M. H. Hyman
S. A. Hobart
K. J. Koegler
S. Kretzschmar
M. J. Lauterbach
S. K. Pulsford

2 CH2M Hill Hanford, Inc.

T. E. Moody

D. J. Vaught

2 Fluor Daniel Hanford, Inc.

G. T. Berlin

D. J. Washenfelder

4 Lockheed Martin Hanford Corp.

J. N. Appel

S. A. Barker

W. B. Barton

K. A. Gasper

MACTEC

D. J. Swanberg

2 Numatec Hanford Corporation

D. L. Herting

R. A. Kirkbride

No. of

Copies

K8-50

K8-50

S7-53

H0- 18

H4-80

H4-80

H0-18

X5-54

X5-54

$\mathrm{X} 5-53$

H9-03

H9-01

H6-34

H5-27

G3-21

R2-11

R2-11

G3-21

K8-50

T6-09

H5-27
4 SGNeurisys Services Corporation

M. D. Britton

H5-49

K. M. Eager

M. J. Klem

H5-27

D. L. Penwell

H5-27

H5-27

45 Pacific Northwest National Laboratory

J. E. Amonette

K9-77

W. F. Bonner

K9-14

L. A. Bray

P7-25

K. P. Brooks

P7-43

T. M. Brouns

K9-08

G. N. Brown (10)

P7-25

S. A. Bryan

P7-25

B. C. Bunker

K2-45

K. J. Carson

P7-25

C. D. Carlson

P7-25

R. J. Elovich

P7-25

J. A. Franz

K2-44

J. M. Gephart

L. K. Holton

T. L. Hubler

W. L. Kuhn

D. E. Kurath

J. P. LaFemina

M. E. Peterson

K2-21

K9-73

P8-38

K2-21

P. $7-20$

K2-25

K2-47

R. K. Quinn

K9-69

W. G. Richmond

K9-33

L. J. Sealock

K2-10

J. T. Slankas

K9-81

S. O. Slate

P8-44

Technical Report Files (5)

PNNL Information Release

Office (7) 